\title{
Investigating Wood Welding Parameters Using a Prototype Welding Machine
}

\author{
A Thesis \\ Presented to \\ The Faculty of California Polytechnic State University, \\ San Luis Obispo
}

In Partial Fulfillment

of the Requirements for the Degree

Master of Science in Engineering, with Specialization in Materials Engineering

by

Timothy Robert Melin

December 2010 
(C) 2010

Timothy Melin

ALL RIGHTS RESERVED 


\section{COMMITTEE MEMBERSHIP}

TITLE:

AUTHOR:

DATE SUBMITTED:

Committee Chair:

Committee Member:

Committee Member:
Investigating Wood Welding Parameters Using a Prototype Welding Machine

Timothy Melin

December 2010
Dr. Charles Chadwell, Professor, Civil Engineering

Dr. Richard Savage, Professor, Materials Engineering

Dr. Dan Walsh, Professor, Materials Engineering 


\begin{abstract}
Investigating Wood Welding Parameters Using a Prototype Welding Machine Timothy Melin
\end{abstract}

Understanding how different processing variables influence wood welded bonds is vital if the technique will ever be used to create engineered lumber without using adhesives. A variation of vibration welding, wood welding uses pressure and friction to bond materials together. During welding, heat causes a softening in the wood, a naturally occurring composite material. This softening leads to fiber entanglement and a bond forms upon cooling.

The goal of this research was to investigate several processing aspects of the wood welding procedure. A prototype wood welding machine, designed and fabricated from the ground up, was used to investigate the effects of various welding parameters using birch wood. Wood welds were evaluated on the basis of bond coverage and ultimate shear strength.

Four experiments were performed: welding frequency and duration interaction, grain orientation effects, alternative welding completion metrics, and strength development over time. During the wood welding process, three distinct phenomena were repeatedly observed: smoke creation, welding residue formation, and an audible pitch change. The presence of each was recorded for every wood welded specimen and used later in additional data analysis. Investigating each of the welding phenomena was done in an attempt to better characterize when fusion was achieved at the weld interface. 
ImageTool, an image analysis software package, was used to investigate and quantify the often irregular bonds exposed after shear fracture. The results of the various welding variables were analyzed on the basis of shear strength and bond uniformity.

From the birch samples, it was shown that better bonds result from lower welding frequencies and longer welding durations. The grain orientation analysis demonstrated that welding orientation marginally affects the average shear strength of the wood weld. The data from the alternative welding metrics suggests that welding time is not a quality indicator of welding completion (bond coverage). The strength development trials confirmed previous research; wood welds obtain most of their strength in a relatively short period of time.

Douglas fir and poplar both proved to be weldable for the first time, but they were sufficiently weaker than birch. When welding was attempted with Douglas fir under similar pressures used for birch, Douglas fir samples would commonly "washboard." With reduced welding pressure, Douglas fir formed wood welds more easily.

KEYWORDS: wood welding, vibration bonding, digital area analysis, shear testing, birch, Douglas fir, engineered lumber 


\section{ACKNOWLEDGEMENTS}

First and foremost I need to thank my amazing family: my mother, Lisa, father, Gary, and brother, Troy. With unconditional support, guidance, and patience, they have always encouraged all of my endeavors, from elementary through graduate school. I would also like to thank Bethany Tucker for her persistent motivation and sympathetic listening skills.

Next, I would like to thank both the Materials and Civil Engineering departments for the knowledge and skills I have attained in my unique course study. I had a strong desire to blend topics from both of these disciplines and both departments were very accommodating.

The machine and equipment that I built for this project would not have been possible without the assistance of several people. The AERO Hanger and Mustang '60 faculties were quite generous with the use of their CAM and manual machining capabilities. Additionally, these individuals were more than willing to freely share their exceptional knowledge of both machining and mechanical design.

I would like to personally thank Sean Kaylor and Brian Donnely for their contributions to my projects. Sean, most graciously gave me my first machining lessons, while Brian was instrumental in helping me to obtain all of SEM images.

Lastly, I would like to thank my thesis panel: Dr. Chadwell, Dr. Savage, Dr. Walsh, and Mr. Gibbs. Each of you was always ready to listen to whatever problems arose with the project and lend a hand. Your knowledge and experience have given me a goal to strive for in my professional career. 


\section{TABLE OF CONTENTS}

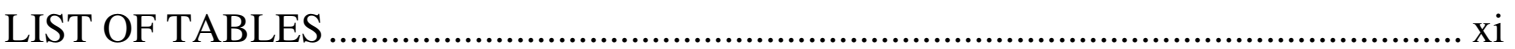

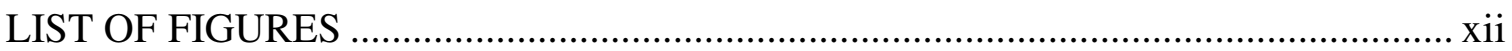

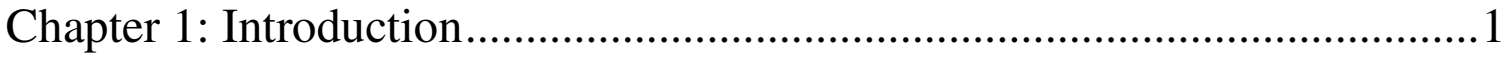

1.1 Structural Engineering Materials - Strengths and Weaknesses.........................1

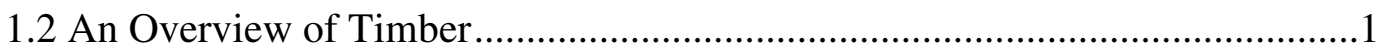

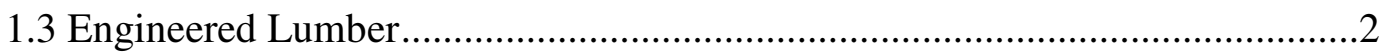

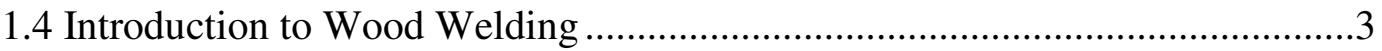

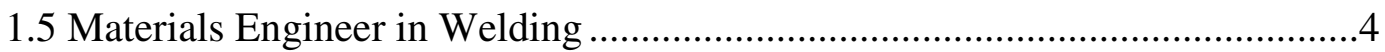

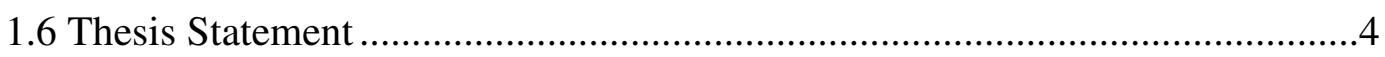

Chapter 2: Wood Welding (Literature Review) ...........................................6

2.1 Origin and Brief History of Wood Welding .......................................................6

2.2 Main Forms of Wood Welding ...................................................................

2.2.1 Planar (Surface) Wood Welding .......................................................

2.2.2 Rotational (Dowel) Wood Welding ......................................................

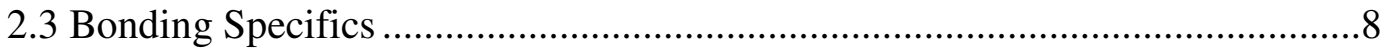

2.3.1 Fiber Entanglement, Matrix Softening, and Densification ..................8

2.3.2 Polymerization Reactions .................................................................9

2.4 Analytical and Mechanical Evaluation .........................................................10

2.4.1 Chemical and Organic Bonding Analysis.......................................10

2.4.2 Processing/Weldment Imaging .........................................................11

2.4.3 Mechanical Testing .........................................................................11

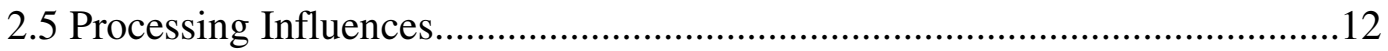

2.5.1 Pressure, Frequency, and Duration...............................................12

2.5.2 Grain Orientation ........................................................................... 14

2.5.3 Timber Species Used For Wood Welding .......................................15

Chapter 3: Testing Equipment Design \& Preliminary Investigation .............17

3.1 Prototype Welding Machine Minimum Requirements ......................................17 


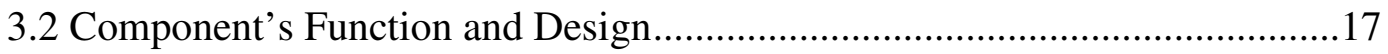

3.2.1 Welding Head .................................................................................18

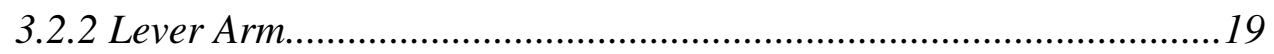

3.2.3 Motor and Gearing .....................................................................19

3.2.4 Completed Machine ..........................................................................21

3.3 Selection of Preliminary Wood Species ……………...................................22

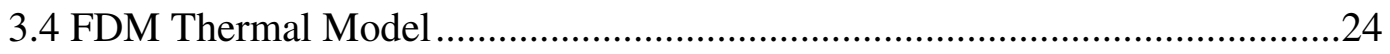

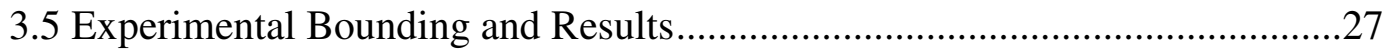

3.5.1 Processing Variables Overview ....................................................27

3.5.2 Surface Preparation.....................................................................2

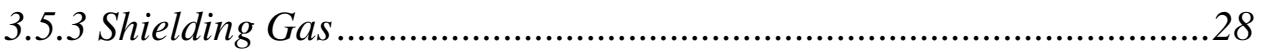

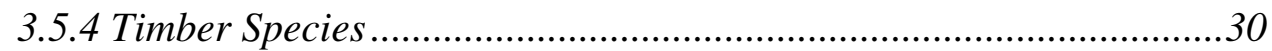

Chapter 4: Primary Investigation - Experimental Procedure .........................32

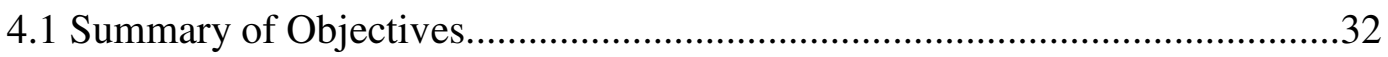

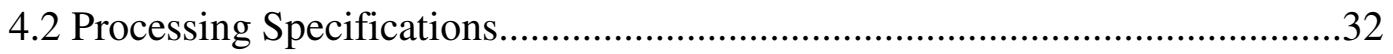

4.2.1 Shear Strength Development Over Time.............................................32

4.2.2 Welding Frequency and Duration Interactions .................................33

4.2.3 Grain Orientation ............................................................................... 34

4.2.4 Control Comparison …………………………………………….......

4.3 Sample Preparation \& Processing......................................................................38

4.4 Alternative Welding Completion Metrics...........................................................39

Chapter 5: Testing and Evaluation Procedure ..............................................41

5.1 Fixture Design and Fabrication.....................................................................

5.2 Testing \& Equipment ................................................................................

5.3 Digital Area Analysis.................................................................................

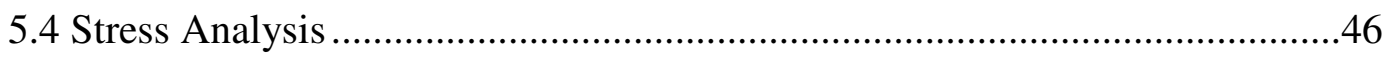

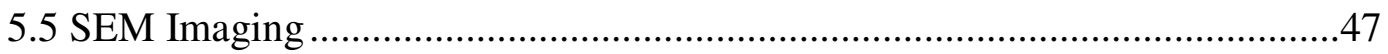

Chapter 6: Data and Results ...................................................................49

6.1 Welding Frequency and Duration Interaction...............................................49

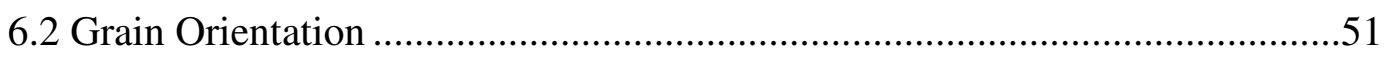

6.3 Shear Strength Development Over Time .......................................................54 
6.4 Alternative Welding Completion Metrics

6.4.1 Shear Strength.

6.4.2 Bond Uniformity. .58

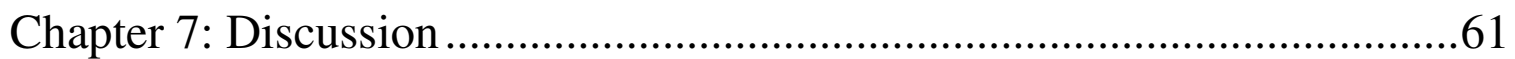

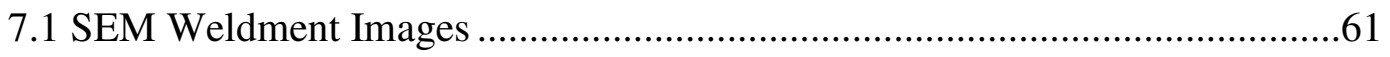

7.2 Welding Frequency and Duration Interaction.............................................70

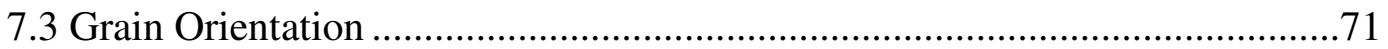

7.4 Shear Strength Development Over Time ................................................... 71

7.5 Alternative Welding Completion Metrics.................................................... 71

7.6 Image Analysis \& Bonding Percentage .......................................................73

7.7 Hypothesis for Weldability Differences Between Wood Species ..................74

Chapter 8: Conclusions \& Future Research .................................................81

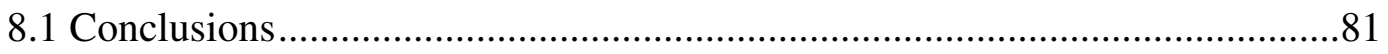

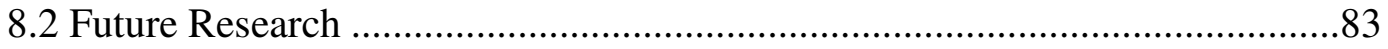

8.2.1 Project Continuation: Experimental Bounds Revisited ....................83

8.2.2 Project Continuation: Thermal Modeling and Data ......................84

8.2.3 Expanded Analysis of Material Properties ....................................85

8.2.4 Implementation of Alternative Welding Completion Metrics ...........85

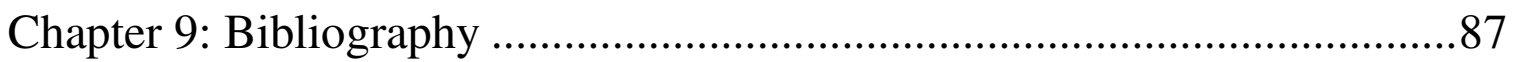

Appendix A: Tables \& Figures with SI Units ..............................................94

Appendix B: Supplementary Literature Review Subjects...........................101

B.1 Hardness Testing and Water Resistance ..................................................101

B.2 Chemical Additives, Surface Hardening, Heat Treated Samples..................101

B.3 Alternative Modes: Ultrasonic and Friction Stir .......................................103

Appendix C: Additional Design Information ............................................105

C.1 Concerns Regarding Rotational Wood Welding .......................................105

Appendix D: Motor Requirements and Calculations ...................................108

Appendix E: Wood Block Sample Creation - SOP ...................................109

Appendix F: Shop Drawings - Shear Fixture............................................113

Appendix G: ImageTool Example and SOP ….......................................120 
Appendix H: Experimental Bounding - Additional Material .....................126

H.1 Shielding Gas Side Effect - Potential Surface Hardening .............................126

H.2 Summary of Hardness Testing Methods .......................................................126

H.3 Experimental Set-up..............................................................................128

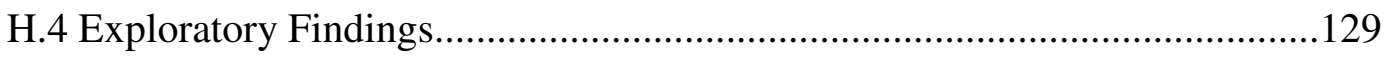

Appendix I: Machine Shop Basics ..........................................................130

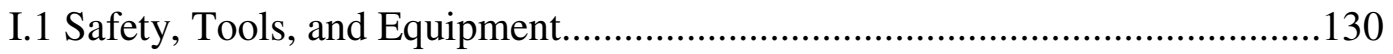

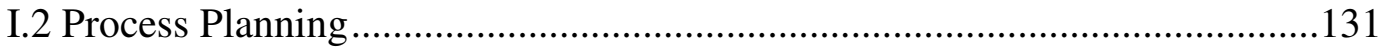

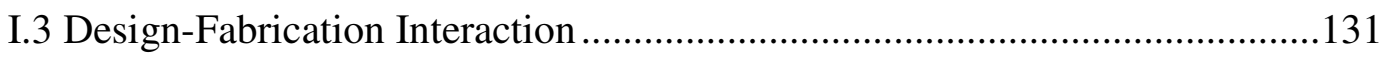

Appendix J: Sample Machining Procedure ...............................................134

Appendix K: ImageTool Sample Photographs..........................................136

Appendix L: FEA Analysis: Orthotropic Model Data ................................158

Appendix M: Load versus Displacement Charts........................................160

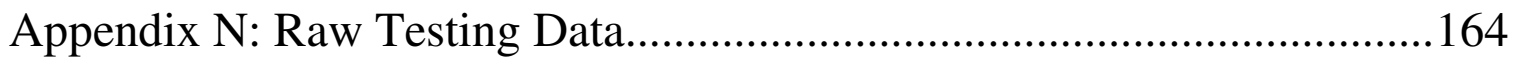

Appendix O: Testing Statistics ..............................................................168

Appendix P: Testing Statistics with SI Units ............................................172 


\section{LIST OF TABLES}

Table I Chemical Reaction Summary [7] ............................................................................. 10

Table II Various welding frequencies resulting from different crankshaft sprockets. ................. 20

Table III Finite difference model: parameters and goals............................................................ 25

Table IV Main Variable Experimental Results (Birch, 200 psi WP) ………………..................... 50

Table V Grain Orientation Shear Strength Results (Birch, 200 psi WP, 6-sec WT, 92 Hz) ........ 53

Table VI Grain Orientation Bonding Results (Birch, 200 psi WP, 6-sec WT, 92 Hz)................. 53

Table VII Shear Strength Tested at Various Curing Times ............................................................ 54

Table VIII Frequency/Duration Interaction - Welding Metrics: Shear Results (Birch, 200

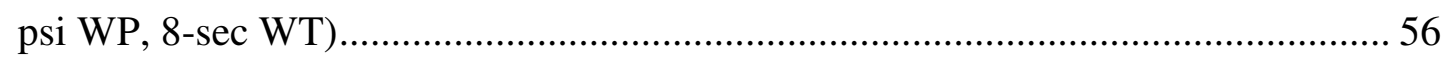

Table IX Grain Orientation - Welding Metrics: Shear Results (Birch, 200 psi WP, 6-sec

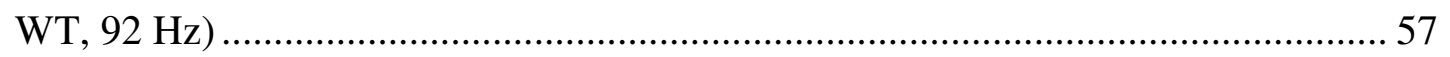

Table X Frequency/Duration Interaction - Welding Metrics: Bond Coverage (Birch, 200

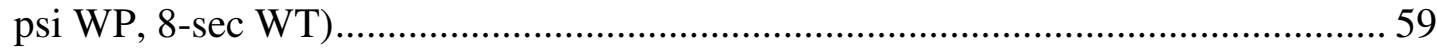

Table XI Cross-Grain Welding Metrics - Bond Coverage (Birch, 200 psi WP, 6-sec WT,

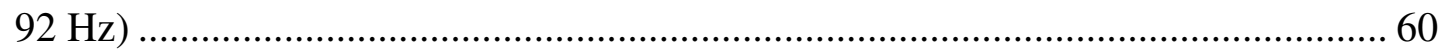




\section{LIST OF FIGURES}

Figure 1 Basic elements involved with planar vibration welding. (Left) Linear Vibration.

(Right) Orbital Vibration. ...................................................................................

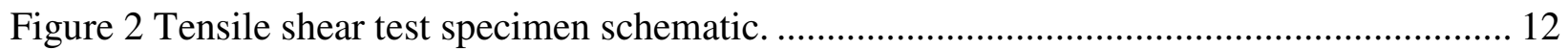

Figure 3 Schematic diagram illustrating the key components of the welding machine. ............... 18

Figure 4 (Left) Primary directions as applied to the welding head. (Right) The chief job of the welding head was to transfer both pressure and displacement to the top most wood block or veneer................................................................................... 19

Figure 5 By changing the sprocket attached to the crankshaft, different welding frequencies were possible................................................................................. 20

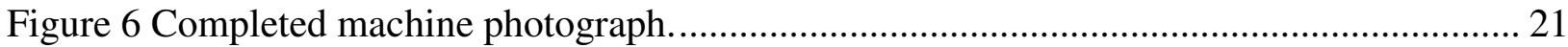

Figure 7 Density comparisons between various timber species (transverse properties). ............. 23

Figure 8 Hardness values for multiple woods (transverse properties).......................................... 23

Figure 9 Thermal distribution results of the FDM analysis. The temperature scale applies to all models, where red represents the highest temperature found in any model, and blue represents the coldest, 700 and $200 \mathrm{~K}$ respectively. The left half of Model 4 is shown as the model is symmetric about its center. Note: Each model represents a veneer with a thickness of $0.125 \mathrm{in}(3.175 \mathrm{~mm})$. 26

Figure 10 The nitrogen gas was supplied from a compressed bottle (clear tube) and directed at the external edges of the welding interface from two directions (blue, segmented hoses).

Figure 11 During multiple attempts to weld DF, the interface degraded and formed a washboard pattern. 30

Figure 12 Three primary modes of wood welding (Left, parallel welding; Center, perpendicular welding; Right, cross welding).

Figure 13 When the three possible wood welding orientations are combined with parallel and perpendicular grain testing directions, five processing possibilities emerge. 
Figure 14 (Left) Simple orientation marks would later indicate how the specimen was positioned during welding. (Right) Every specimen was positioned in the machine in this same orientation.

Figure 15 (Top Left \& Right) Images of goop excretion immediately following the welding procedure have been highlighted. (Bottom) The image shows a sample where goop had accumulated.

Figure 16 The test fixture was designed to create a pure shear load at the wood welded surface. (Sample restraining set screws not shown.).

Figure 17 Wood samples of various sizes could be tested in the fixture. 42

Figure 18 A wide variety of bonds were formed during the experiments. Several examples have been presented: (Top left) Striations - (Top right) Striations with incomplete bonding - (Bottom left) Excellent bond coverage - (Bottom right) Partial failure outside of the wood weld interface, i.e. within the base material. 44

Figure 19 Image analysis photo progression (Clockwise from top left: original color image, gray-scale version, bonded threshold image, calibrated threshold image) (Welding frequency/duration series: $72 \mathrm{~Hz}, 8 \mathrm{sec}$ WT, sample \#6) 45

Figure 20 While the best wood welding results overlap with the stronger glue, the majority of the wood welding results were significantly stronger than the second adhesive (Birch, 200 psi WP). The dashed lines indicate published shear strength reference values (parallel to grain at 12\% moisture content) for several birch species (Paper Birch: 1,210 psi (8.3 MPa) - Sweet Birch: 2,240 psi (15.4 MPa) - Yellow Birch: 1,880 psi (13.0 MPa)) [46] 50

Figure 21 While being influential, discrepancies in welding times have a more pronounced affect at low welding frequencies ( $\overline{\mathrm{x}} \pm 1 S D)($ Birch, $200 \mathrm{psi}$ WP).

Figure 22 While different welding directions produce negligible differences in shear strength, testing orientation had a noticeable influence on shear strength (Birch, 200 psi WP). 52

Figure 23 While the average ultimate shear strength of the bonds appeared to fluctuate over time, these were likely statistically insignificant $(\overline{\mathrm{x}} \pm 1 S D)$. 54 
Figure 24 When the fusion criteria (smoke generation, welding goop formation, and audible pitch change) were used to filter the sample data, little change in the average shear strength was observed $(\overline{\mathrm{x}} \pm 1 S D)$.

Figure 25 As was seen in Figure 24, when samples were discarded using the fusion

criteria for the grain orientation analysis little change in the average shear strength was observed $(\overline{\mathrm{x}} \pm 1 S D)$. 58

Figure 26 Given an equal welding time of 8 seconds, the lower and higher welding frequencies yielded a less bonded interface, regardless of completion metric $(\overline{\mathrm{x}} \pm 1 S D)$. 59

Figure 27 The comparisons of the welding metrics have been illustrated. While the amount of improvement varied, average bond values increased and variability decreased with the use of the metrics. 60

Figure 28 SEM image map of wood fiber pull-out (parallel welding). 61

Figure 29 This SEM image shows examples of both wood removal and deposition (Grain Orientation trial : 92Hz, 200 psi WP, 6-sec WT, parallel welding). (201x)............. 62

Figure 30 SEM image progression showing fiber pull-out (parallel welding)......................... 63

Figure 31 SEM image map illustrating wood deposition (parallel welding)............................6 64

Figure 32 SEM image progression showing fiber deposition (parallel welding)...................... 65

Figure 33 SEM image map highlighting exposed fibers (perpendicular welding).................... 66

Figure 34 This SEM image shows both fiber entanglement and reorientation. (Grain Orientation trial : 92Hz, 200 psi WP, 6-sec WT, perpendicular welding). $(101 x)$ 66

Figure 35 SEM image progression showing fiber reorientation and bundling (perpendicular welding). 67

Figure 36 SEM image map detailing exposed fibers (perpendicular welding). 68

Figure 37 SEM image progression showing the fiber-mesh fracture (perpendicular welding).

Figure 38 Hardness and density index for commonly used wood welding species (nongreen ellipses) (Transverse properties reported).............................................. 75

Figure 39 When Douglas fir welded, bonds formed between areas of latewood growth............ 76 
Figure 40 (Left) When looking at the end grain of this color-negative photograph, it was clear that springwood sections collapsed, while latewood rings remained unchanged (Original Photo: Figure 11). (Right) The dark horizontal lines are the raised latewood annual rings.

Figure 41 Compressive strength and density index for species commonly used in wood welding (non-green ellipses) (Transverse properties reported). 78

Figure 42 (Left) When significant loads are applied to timber perpendicular to grain, a crushing failure can occur. (Right) The individual annular rings have been clearly buckled out of plane. 


\section{Chapter 1: Introduction}

\subsection{Structural Engineering Materials - Strengths and Weaknesses}

The primary goal of structural engineering is to decide how a structural system will support itself and resist loads. Depending on the application, these loads can include: earthquakes, wind, water pressure, machinery, human occupants, etc. In civil engineering: towers, bridges, and buildings are common structures, while aircraft frames or pressure vessels are structural examples from other engineering disciplines. By knowing the intended use and approximating loading conditions, the different supporting elements are designed such that the structure, a building for example, has enough strength to be safe as dictated by governing regulatory entities [1].

The three primary materials at the disposal of a civil engineer for structural applications are: timber, steel, and reinforced concrete. While other materials are available, these three are the most prevalent and each has its advantages. Generally, for steel and reinforced concrete strength and stiffness are their most desirable qualities. However, both steel and reinforced concrete are usually heavy, susceptible to corrosion, and can require specialized tools or forming equipment. Timber on the other hand is generally light weight and does not have the same problems inherent to steel or reinforced concrete construction $[2,3]$.

\subsection{An Overview of Timber}

One of the benefits of timber is that it can be environmentally friendly, as compared to steel and reinforced concrete structural systems. Refining iron ore and producing Portland cement both generate substantial amounts of carbon dioxide $\left(\mathrm{CO}_{2}\right)$. 
However, trees absorb $\mathrm{CO}_{2}$ as they grow, and when properly managed, forests function as an excellent sustainable resource.

Lumber has many advantages, including its excellent strength to weight ratios and workability. Generally, wood is easy to work and build with and in most cases, requires only a few simple hand tools for construction. Timber is relatively inexpensive and is considered to have a significant amount of aesthetic appeal. Beams and columns made from sawn lumber do have their disadvantages, stemming mainly from the fact that it is a natural material. The prominent disadvantages of wood are it susceptibility to property variation, moisture, and defects. Property differences caused by species variation are expected, but a substantial amount of variability commonly exists between two pieces of lumber that appear to be identical. Since water is needed for trees to grow, moisture is always present in timber. With time, as the beam or column dries out, the moisture content drops and the material shrinks and may distort leading to material defects that affect both the strength and stiffness of the material. A beam that was initially cut straight, can twist, bow, or crack over the course of weeks or years [4].

To circumvent the disadvantages of timber, good pieces of lumber can be combined together to form an engineered material.

\subsection{Engineered Lumber}

Regardless of the specific engineered lumber product: Glulams, OSB, plywood, Ijoists, or laminated veneer lumber (LVL), engineered lumber is produced in a similar manner. Trees are broken down into small pieces, combined with adhesives, and pressed to their final shape. This process helps to remove the natural variability. Structural defects normally found in timber, such as knots or cracks, can be removed. These factors 
work together to create a stronger, larger, and more reproducible material than that found in nature. Another advantage of these products is that some wood typically used for these different products, aspen and poplar for example, would normally not be considered for structural applications. The process that makes engineered lumber can take timber that is generally thought of as weak and transform it into a structural member [4, 5].

One of the biggest concerns with engineered lumber is the reliance on some type of adhesive to bond the layers together. The amount and costs of these bonding agents can be significant. Regardless of the specific type of adhesive, a curing time is required for the adhesive to adequately set, usually a number of hours [6]. During which time the lumber product may need to be kept under constant pressure and/or possibly exposed to microwave radiation [7].

A potential alternative to adhesives does exist. Research has been conducted involving bonding wood without the use adhesives or mechanical fasteners. The process is called wood welding. Welded wood joints can achieve significant strength quickly, in a matter of seconds, and do not require any additional chemical additives. Wood welding can potentially allow these engineered lumber products to be made cheaper, faster, and in a more ecologically friendly way, all because adhesives would not be required.

\subsection{Introduction to Wood Welding}

Wood welding is an area of research involving bonding separate pieces of wood without the use of mechanical or adhesive binders. This technology has previously been used to join thermoplastics and metals, but has only recently been adapted to function with wood. With plastics, pressure and vibrations generate heat which causes the polymer to locally change phase into a liquid with a gel-like consistency. Timber has 
been found to exhibit a similar phase change under the proper conditions given wood's microstructure. Wood is a natural example of a fiber-matrix composite. As a result, when pressure and heat from vibrations are applied, the polymer-like material comprising the wood's microstructural matrix begins to flow. This flow allows fibers from different pieces of wood to become entangled and attached to one another. When the heat is removed and the welds are allowed to solidify, a bond is formed joining the two individual pieces of wood together [7].

\subsection{Materials Engineer in Welding}

While wood welding and metallurgic welding appear vastly different on the surface, a closer inspection reveals their commonalities. Both depend on being able to use heat and pressure to create new bonds [8]. Both are subject to the same laws of heat transfer, and both can benefit from the experiences of researchers from different fields.

By applying the four basic pillars of materials engineering, multiple outcomes can be characterized and predicted by observing how "processing, structure, and properties" can all effect "performance." To date, much of the research regarding wood welding has been performed by individuals with backgrounds in polymer chemistry and adhesives and the technique has seen limited exposure beyond those fields. It was the goal of this research to bring a different perspective to wood welding and advance the understanding of the wood welding process.

\subsection{Thesis Statement}

Currently, wood welding research has only been conducted on small-scale samples. Researchers have acknowledged this fact and stated that, "In the future it will be 
necessary to test larger specimens and to investigate technology that could produce full sized standard products [9]."

Before wood welding techniques can be applied to produce larger samples or engineered lumber, a better understanding of wood welding's processing variables and wood weld characteristics are required. The research presented herein was dedicated to investigating how wood weld strength developed over time, how processing variables influenced weld performance, and lastly, examined the validity of alternative wood welding completion metrics. To accomplish that goal, a prototype wood welding device was designed and fabricated to allow for a variety of processing variables to be evaluated and compared on the basis of bond shear strength and bond uniformity. 


\section{Chapter 2: Wood Welding (Literature Review)}

\subsection{Origin and Brief History of Wood Welding}

As is the case with many innovations, wood welding was discovered by accident and arose from an older variation of vibration bonding [7]. This previous version used two pieces of wood separated by a plastic layer that was melted with frictional heat and acted as a binding agent for the wood. Wood welding was first observed when a technician neglected to add the plastic insert [9]. The machine was run as normal, but afterwards the technician realized the mistake; however, it did not matter, the wood pieces had bonded to themselves.

While much of the literature refers to the wood only method as wood welding, other synonymous terms exist in the literature on occasion, such as "mechanicallyinduced wood flow welding" or "mechanically induced wood fusion."'[7, 10] Wood welding, in the context presented herein, refers to the vibrational bonding method in which only wood is used.

To date, research into wood welding has been limited due to the newness of this technology. This small, but growing pool of research has primarily been conducted by European scientists operating in Germany, France, and Switzerland. While the oldest reference to wood welding was a German patent filled in 1996 by Sutthoff et al. [11], other publications to follow included: Gerber, 2000 [12], Gerber, 2001 [13], Gfeller, 2003 [7]. 


\subsection{Main Forms of Wood Welding}

\subsubsection{Planar (Surface) Wood Welding}

There are two main branches of wood welding: planar [7, 9-11, 14-27] and rotational [9, 28-39]. Planer is further broken down further into linear vibrational [7, 911, 14-24] and orbital [25-27]. Both planer methods apply pressure perpendicular to the desired interface, the bonded surface plane created between the wood blocks, and displace in a direction parallel to the interface. However, these methods differ in how they achieve displacement. Linear vibration moves the material along a single axis, back and forth in a reciprocating motion (Figure 1). Orbital vibration is accomplished when the work piece is moved simultaneously in two axes, clockwise or counterclockwise, and the resulting path of motion forms an orbit (Figure 1).

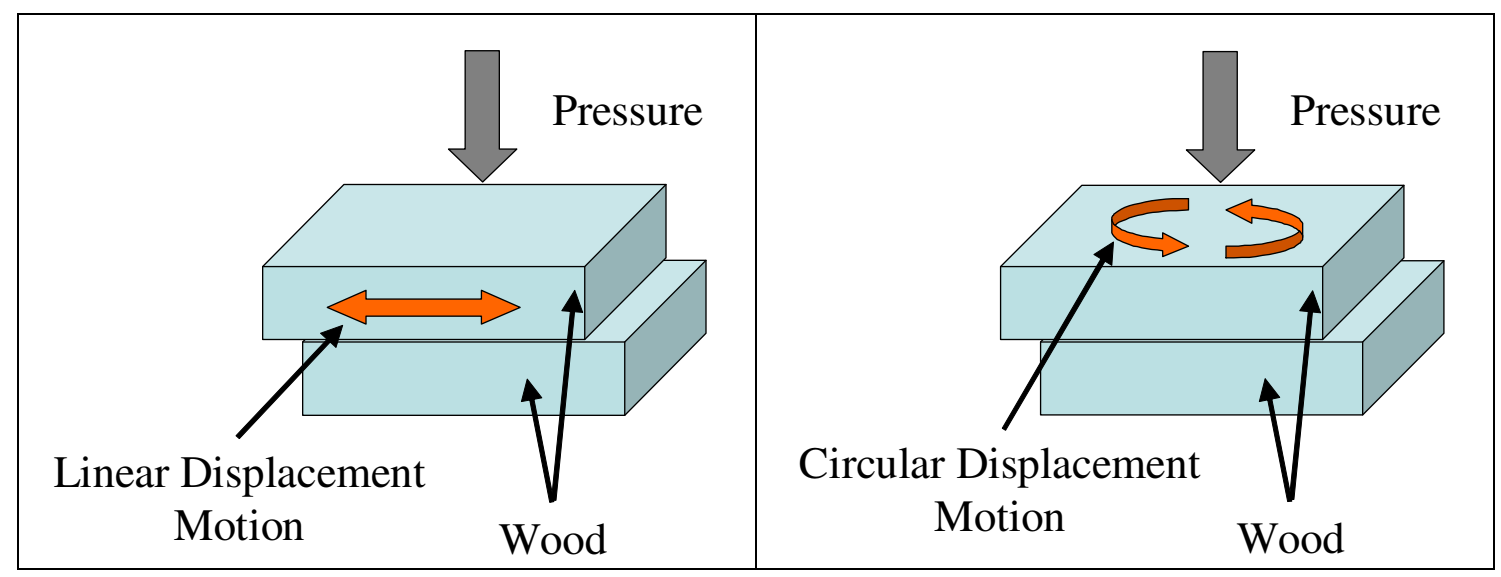

Figure 1 Basic elements involved with planar vibration welding. (Left) Linear Vibration. (Right) Orbital Vibration.

\subsubsection{Rotational (Dowel) Wood Welding}

While the two previously mentioned forms of wood welding result in a planar bond, rotational wood welding forms a cylindrical bond between a predrilled hole and a wooden dowel. The dowels are often slightly larger than the corresponding drilled holes 
and must be rotated at high speeds before being plunging into the predrilled base

material. Friction is generated between the outside of the dowels and inside of the drilled hole and a bond forms between those surfaces. Connections formed between two pieces of wood using the rotational method are often connected with multiple dowel welds.

The equipment needed for rotational welding is in many ways less complicated than that needed for planar bonding. In many instances researchers have been able to utilize high speed fixed base drill presses [28-30, 33, 35, 36, 39] and hand drills [32, 34] to generate the rotational speed required for the dowels.

\subsection{Bonding Specifics}

\subsubsection{Fiber Entanglement, Matrix Softening, and Densification}

While some cross-linking polymerization reactions, bonding occurring between individual polymer chains, have been shown to occur in wood welded bonds, the primary structural mechanism is fiber entanglement [7]. As the mechanically driven vibrations begin to generate friction and as a consequence heat, the amorphous polymer matrix that binds the wood fibers together begins to soften and flow. This amorphous polymer material is found in the connections between biological cells in the timber. The amorphous material is composed mostly of lignin, an organic polymer, and to lesser extent hemicelluloses, a matrix polysaccharide [7].

As the polymer becomes more pliable and soft, some of the long wood fibers are partially separated. These fibers combine with the melted polymer and become entwined with other long wood fibers. After solidification, it is the inter-fiber connections, facilitated by the matrix, that bonds the two pieces of timber together $[7,10,14,15]$. However, this fiber-matrix bonding is not the only type to have been observed. In some 
cases direct welding has taken place between the cell walls of the respective pieces of lumber and were fused together with nothing more than the intercellular material. This cell-cell mode of bonding has been the predominant mode found in oak welds, while a combination of fiber-matrix and cell-cell fusion have been observed in beech [17].

In addition to the mechanical entanglement that can occur, wood welding can also result in a bond layer significantly denser than the surrounding base material $[9,16,19$, $29,42]$. During the welding processes, the material closest to the welded interface is partially compressed and densified. This densification becomes less pronounced and density values gradually taper out as the distance from the weld increases. However, samples exhibiting a narrower and more homogeneous density increase typically produced wood welds with greater shear strength [16].

\subsubsection{Polymerization Reactions}

With the use of Nuclear Magnetic Resonance (NMR), researchers have identified several chemical changes that occur during the welding procedure (Table I). During the welding procedure, some cross-linking and self-condensation reactions occur between lignin and furfural, two chemical compounds commonly found in timber. However, these reactions are not the primary bonding mechanism. Researchers have stated, "These reactions are surely a contributory factor, but they are unlikely to be the main cause of the bonding results obtained in mechanically-induced wood flow welding [14]." 
Table I Chemical Reaction Summary [7]

1. Partial demethoxylation of lignin during welding

2. Minute increase in relative amounts of amorphous carbohydrates during welding

3. Autocondensation of lignin's aromatic rings

4. Furfural appearance and probable reactions: furfural self polymerization, furfural reacting with lignin aromatic nuclei, possibly both

5. Partial deacetylation of hemicelluloses through welding process, free acetic acid possibly aiding previously mentioned reactions

\subsection{Analytical and Mechanical Evaluation}

\subsubsection{Chemical and Organic Bonding Analysis}

The majority of research conducted on wood welding has been performed by individuals with polymer and adhesive expertise and have attempted to explain the mechanisms responsible for creating a wood weld. As a result, many of the techniques used to analyze the wood before, during, and after welding were designed to characterize and quantify organic compounds and polymeric bonding structures. The usage of these techniques has been valuable in the categorization of the fundamental mechanics of wood welding and are thus listed herein.

Two methods: Cross Polarization Magic Angle Carbon-13 Nuclear Magnetic Resonance (CP-MAS ${ }^{13} \mathrm{C}$ NMR) $[7,10,14,15,29]$ and Fourier Transform Infrared spectrometry (FT-IR) [27, 40, 41] have been used to obtain what specific types of polymeric bonding occurs during wood welding. Another pair of techniques, Ionexchange chromatography [11] and Gas Chromatography-Mass Spectrometry (GC/MS) $[27,38,41]$, have investigated the volatile chemicals byproducts generated during wood welding to see if those compounds were hazardous. 


\subsubsection{Processing/Weldment Imaging}

A few techniques frequently utilized to examine metallurgical welds, such as infrared thermal imaging [19, 21, 29] and Scanning Electron Microscopy (SEM) [7, 9-11, $14,15,17,20,28,30,41,42]$ have been employed for wood welding research. In regards to imaging, optical microscopy $[21,28,43]$ has been used, but SEM has been much more prevalent. While SEM images can undoubtedly yield results at higher magnification, Confocal Laser-Scanning Microscopy (CLSM) [25, 26] has produced excellent images that capture the entire wood weldment on the micro-scale. The final technique employed by researchers was x-ray microdensitometry $[16,17,19-22,28,30$, $31,35,42,43]$. By taking $x-$ ray images of thin wood samples and two known calibration samples, investigators were able to map the density in the base wood and wood-welded zone.

\subsubsection{Mechanical Testing}

The bulk of the literature suggests that researchers are typically more interested in testing for chemical/bonding information than for mechanical data. Details pertaining to the experimental procedures used in the mechanical testing of planar wood welds in the published literature have ranged from largely absent $[7,10,16,22,43]$ to satisfactory $[17,18,20,25]$. However, some papers did reference the relevant European standards, specified testing equipment manufacturers, or load rates [14, 15, 17, 18, 20, 22-26, 29].

In the majority of cases involving linear vibration welding, two pieces of timber, each with dimensions 5.9x0.8x0.6in. $(150 \times 20 \times 15 \mathrm{~mm})$ were bonded to form a joint 5.9x0.8in. (150x20mm) [7, 10, 14-18, 19, 20]. After welding, the samples were prepared for what the literature defined as a "tensile shear test." This was a test conducted on the 
specimen that began by making two cuts, one on the top layer of wood and another on the bottom. These cuts were spaced $0.98 \mathrm{in} .(25 \mathrm{~mm})$ apart and went down to the weld line. During testing, those cuts insured that the entire load was transferred through the shear bond between the pieces of wood. Each end of the sample was secured to the testing machine and was then pulled in a direction parallel to the sample. While a tensile shear test was frequently used in the literature, bond strength was often reported as "joint tensile strength." It has been assumed that the researchers are actually referring to the shear strength that occurs between the two welded wood specimens. This is consistent with the test set up and method of testing (Figure 2).

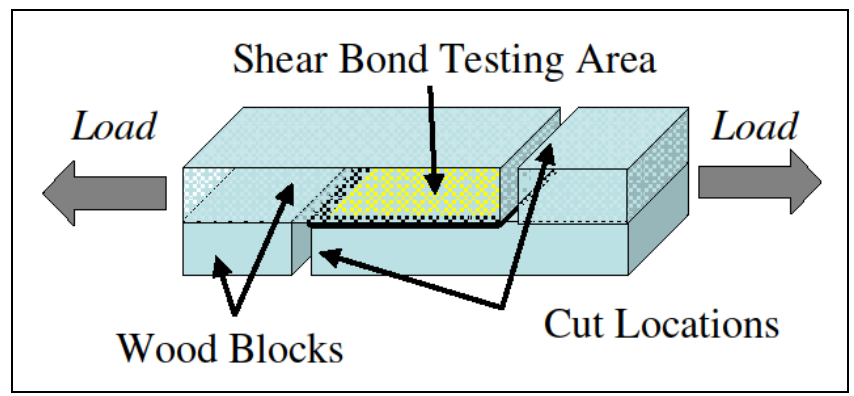

Figure 2 Tensile shear test specimen schematic.

\subsection{Processing Influences}

\subsubsection{Pressure, Frequency, and Duration}

Vibration welding needs the heat generated from friction in order to be effective. This friction is created by moving one surface past the other while the interface is subjected to pressure. To achieve these conditions, several factors must be controlled: frequency, displacement amplitude, welding pressure (WP), and welding time (WT). In the case of wood welding, pressure applied after the procedure creates significantly stronger bonds. This post processing step adds another two parameters: holding pressure 
(HP) and holding time (HT). Lastly, different timber species do not necessarily behave the same way.

Early research published on wood welding outlined the bounds and trends of the seven variables that need to be monitored. The pertinent literature has been summarized below $[7,10,14,15]$.

- Frequency: The bulk of the research presented by Gfeller et al. was conducted at $100 \mathrm{~Hz}$ with birch and spruce timber samples. It was determined that at higher frequencies, near $240 \mathrm{~Hz}$, the bond line temperature increased dramatically and major material degradation at the interface ensued, leading to low bond strengths.

- Displacement: Small displacements, 0.039in. $(1 \mathrm{~mm})$, were unable to produce a joint with any strength, while a larger amplitude displacement, 0.118in. $(3 \mathrm{~mm})$, produced testable joints.

- Welding Pressure: A positive correlation exists with joint strength in regards to pressure. As long as the surface does not experience any temperatureinduced degradation, high pressures create better bonds.

- Welding Time: Welding time shows a negative correlation to bond strength at $100 \mathrm{~Hz}$. Longer times produce weaker bonds; however, good results were obtained with welding times between 3 and 5 seconds.

- Holding Pressure: While holding pressure is important, the exact value is not critical; whether or not it was present was the important factor that led to increased strength. 
- Holding Time: While differences in holding time are small, significant strength advancements can be achieved by holding for 5 seconds verses 2 seconds. Holding times beyond 5 seconds were not investigated. The reason for the beneficial effect of the post weld hold stems from the fact that the additional pressure gives the surface extra time to continue any polymerization reactions that could be underway.

- Species: Lastly, the selection of timber species can affect the bond performance. Certain species, like beech, produce quality wood welds. Other, most notably Norway spruce, yield inferior welds.

From the first parameter study, the best strength results were obtained with: beech wood, 3 second weld time, 5 second hold time, 189 psi (1.3 MPa) weld pressure, and 290 psi (2.0 MPa) hold pressure. These conditions yielded an average strength of $1515 \pm 130$ psi (10.45 $\pm 0.9 \mathrm{MPa})[7]$.

\subsubsection{Grain Orientation}

Given the fact that timber is an orthotropic material, dominated in one axis by fiber properties and in the other two by matrix characteristics, it is of no surprise that grain orientation plays a part in the strength of wood welds. This was confirmed by experiments performed on beech, oak, maple, and elm samples [17, 24]. The three principle material directions found in timber are longitudinal, tangential, and radial. When tangential and radial wood specimens were welded with the grain structure of both pieces parallel, the strength results were relatively similar, within approximately $10 \%$ of each other [17]. A far greater strength disparity occurred when the wood samples were oriented to have their grain structure running perpendicular to each other during the 
welding procedure. These cross-grain specimens produced strengths almost half that of the parallel grained samples [17].

\subsubsection{Timber Species Used For Wood Welding}

While any species of lumber could conceivably be used for wood welding, to date only a handful have been attempted. The literature has been dominated by two main types of lumber, beech (Fagus sylvatica) [7, 10, 14-18, 20, 25, 26, 28-38, 40, 41, 43, 42] and Norway spruce (Picea abies) [7, 10-11, 14-16, 18, 25-28, 32-34, 37, 38, 41]. Oak, (Quercus robur) [16-18, 41, 43], and two species of maple, (Acer spp.) [17, 19] and (Acer campestre L.) [21] have seen modest usage while others including: birch (Betula alba) [20], poplar (Populus sp.) [20], and pine (Pinus sylvestris) [30], have been marginally investigated. In addition to solid sawn lumber, several engineered lumber products like particleboard, plywood, medium-density fiberboard (MDF), and oriented strand board (OSB) have been used in wood weld experimentation [22, 31].

While Beech and Norway spruce have dominated the bulk of wood welding research; spruce has been shown to rarely produce quality welds in planar wood welding. This inadequacy has been attributed to the structural characteristics of the wood itself at the microscopic level. During planar welding, the spruce's cell walls collapse $[7,10,14-$ $16,25,26]$. The cell-collapse issue stems from the fact that the springwood has cell walls that are much thinner than those found in latewood [25]. Welds attempted with spruce did not have great strength and produced a "very irregular interface" when compared against the "smooth" beech joints [16]. While Norway spruce has yielded poor results for planar bonding, it has been used extensively as a substrate material in rotational 
welding $[9,28,32-34,37,38]$. Only one article involving the rotational welding of Norway spruce was found that mentioned the problem of cell-collapse [28].

Oak, a hardwood, also appears to be difficult to wood weld, but for apparently different reasons. As with the spruce, the problems seem to be a result of the microstructure of the wood itself. While the exact cause(s) has not been determined, several possible mechanisms have been proposed [17]. The first involves the oak surface's microroughness. Low coefficients of friction could mean that sufficient heat cannot be generated. Another possible explanation is that the matrix material, lignin/hemicelluloses, found in oak has a higher molecular weight and as a result is unable to flow as easily. The final theory states the heat transfer is worse in denser woods and matrix flow is therefore restricted [17]. While the exact explanation of why some woods are able to vibrationally weld and others are not remains unknown. 


\section{Chapter 3: Testing Equipment Design \& Preliminary Investigation}

\subsection{Prototype Welding Machine Minimum Requirements}

Commercially available vibration welding equipment was not available for this research, so a machine capable of wood welding needed to be designed and built before any investigation into the wood welding phenomenon was attempted. Displacement amplitude, displacement frequency, and welding pressure were three of the welding variable that the machine needed to control or fluctuate. The remaining four processing variables: welding time, post weld hold pressure, post weld hold time, and wood species, were addressed by the operator. The machine needed to strong enough to support all the mechanical interactions, durable enough to provide large numbers of reproducible samples, and accommodate different wood sample types (blocks and veneers).

A linear vibration method, when applied to a narrow area, appeared to be the most mechanically and structurally feasible design option for the prototype machine. From the published literature, the machine would need to provide approximately $0.125 \mathrm{in}$. (3.18mm) of total displacement, an average frequency of $100 \mathrm{~Hz}$, and an approximate pressure of $200 \mathrm{psi}(1.38 \mathrm{MPa})$. All these requirements could be addressed with a linear vibration design.

\subsection{Component's Function and Design}

Before detailed components were created using a 3-D modeling program, SolidWorks, several design features were chosen. The necessary interface pressure was supplied by a simple lever arm. A crank shaft provided the reciprocating motion by means of a pin offset from center. The crank shaft thereby fixed the distance of linear 
displacement to an amplitude of 0.06in $(1.52 \mathrm{~mm})$. The fundamental components responsible for generating the displacement and pressure were the welding head and housing, lever arm, and motor/gearing systems (Figure 3).

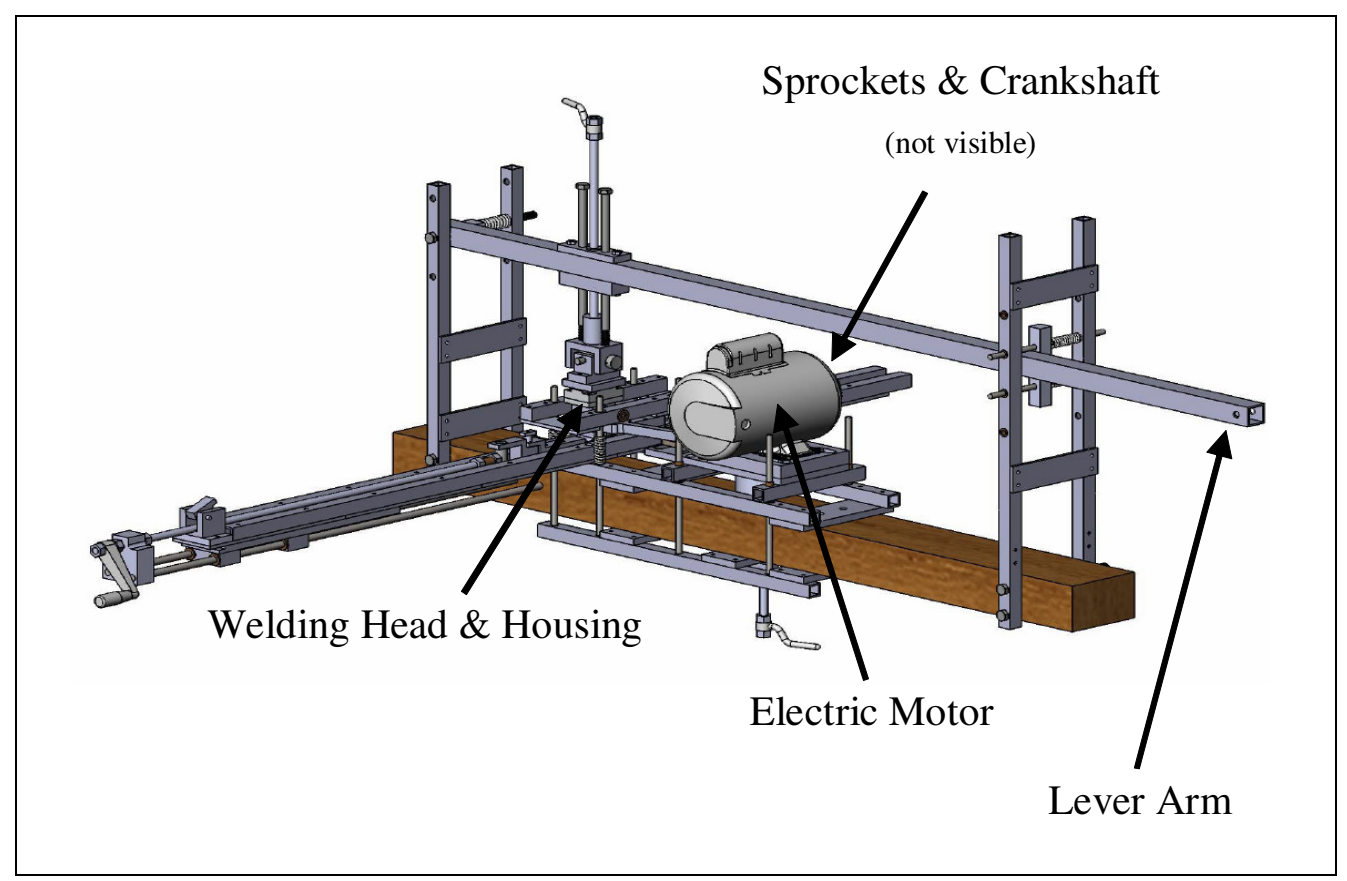

Figure 3 Schematic diagram illustrating the key components of the welding machine.

\subsubsection{Welding Head}

Linear displacement and interface pressure were addressed with the welding head.

For the welding process to be successful, a small section of wood needed to be vibrated while being simultaneously subjected to adequate pressure (Figure 4). The purpose of the welding head was to grip the top wood block and oscillate that piece of wood back and forth relative to a stationary wood block below. Additionally, the welding head transmitted a compressive force to the wood-wood interface to create adequate friction. Friction between the welding head and the load application point was addressed with a thrust bearing. 


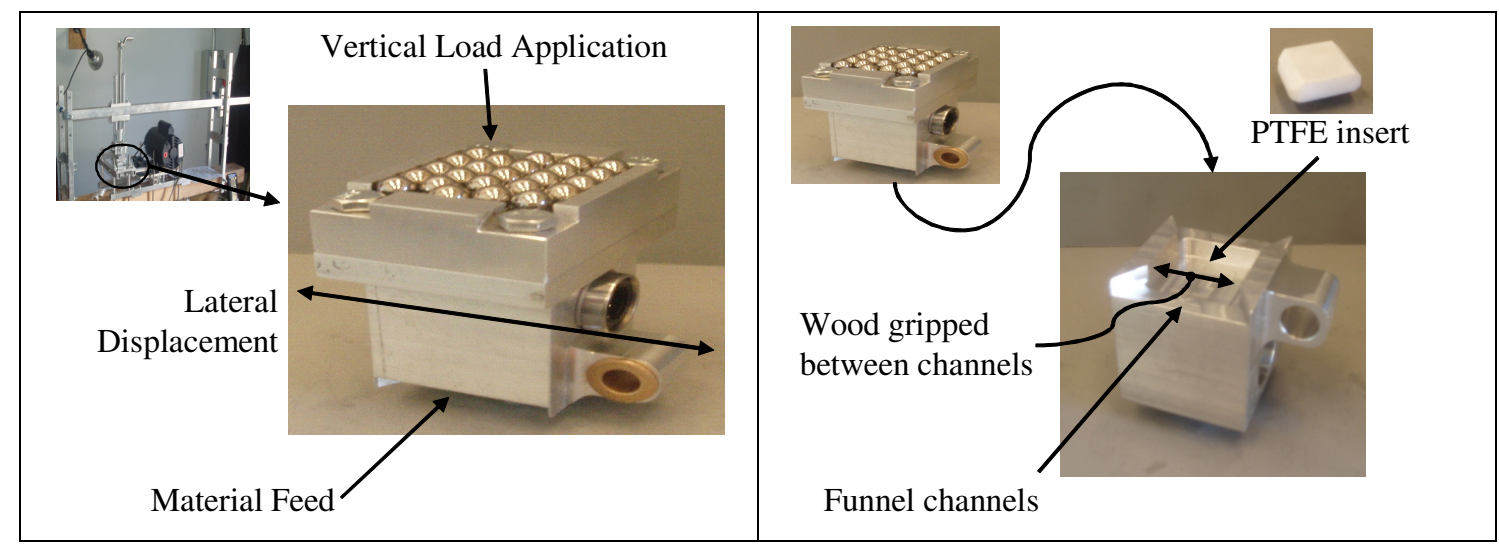

Figure 4 (Left) Primary directions as applied to the welding head. (Right) The chief job of the welding head was to transfer both pressure and displacement to the top most wood block or veneer.

\subsubsection{Lever Arm}

Given the small area of the welding head, approximately one square inch, and the welding pressures ( $200 \mathrm{psi})(\sim 1.38 \mathrm{MPa})$, a relatively small vertical load of roughly 200 pounds $(889.6 \mathrm{~N})$ was required. The lever arm amplified the applied load of approximately 45 pounds $(441.3 \mathrm{~N})$ at the end of the cantilever, and provided the calculated normal force of 200 pounds $(889.6 \mathrm{~N})$ at the weld head.

\subsubsection{Motor and Gearing}

An electric motor was selected for the prototype welding machine due to its simplicity and ability to meet the necessary design requirements. These requirements included: high torque, high rotational speed, small displacement, frequency variability, and device/accessory costs.

After choosing an electric motor, a transmission was created to achieve the requisite torque and frequency necessary to drive the reciprocating arm and in turn, the welding head (Figure 5). Details pertaining to motor selection and requirements are presented in Appendix D: Motor Requirements and Calculations. 


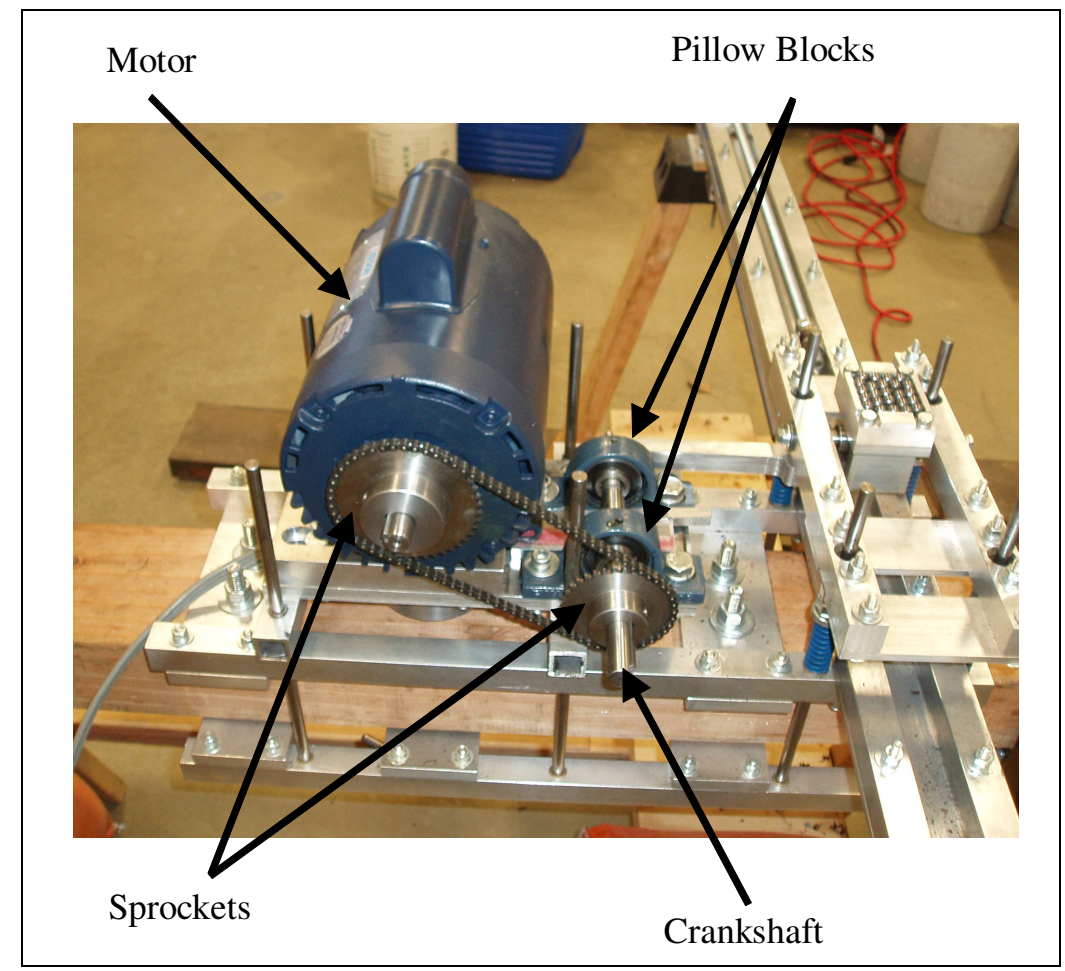

Figure 5 By changing the sprocket attached to the crankshaft, different welding frequencies were possible.

To achieve the various range of speeds needed for the experiment, the gearing ratio was manipulated between the motor and crankshaft. A fixed sprocket ( 45 teeth) was left unchanged on the motor's output while the crankshaft sprocket was changed in accordance with the desired speed. By manipulating the sprocket gearing ratio, a variety of welding frequencies were available (Table II).

Table II Various welding frequencies resulting from different crankshaft sprockets.

\begin{tabular}{|cccc|}
\hline \# Teeth & Sprocket Ratio & Speed (RPM) & Speed $(\mathrm{Hz})$ \\
21 & 2.14 & 7,393 & 123 \\
22 & 2.05 & 7,057 & 118 \\
23 & 1.96 & 6,750 & 113 \\
24 & 1.88 & 6,469 & 108 \\
25 & 1.80 & 6,210 & 104 \\
26 & 1.73 & 5,971 & 100 \\
28 & 1.61 & 5,545 & 92 \\
\hline
\end{tabular}




\subsubsection{Completed Machine}

The finished and finalized machine has been shown in Figure 6.

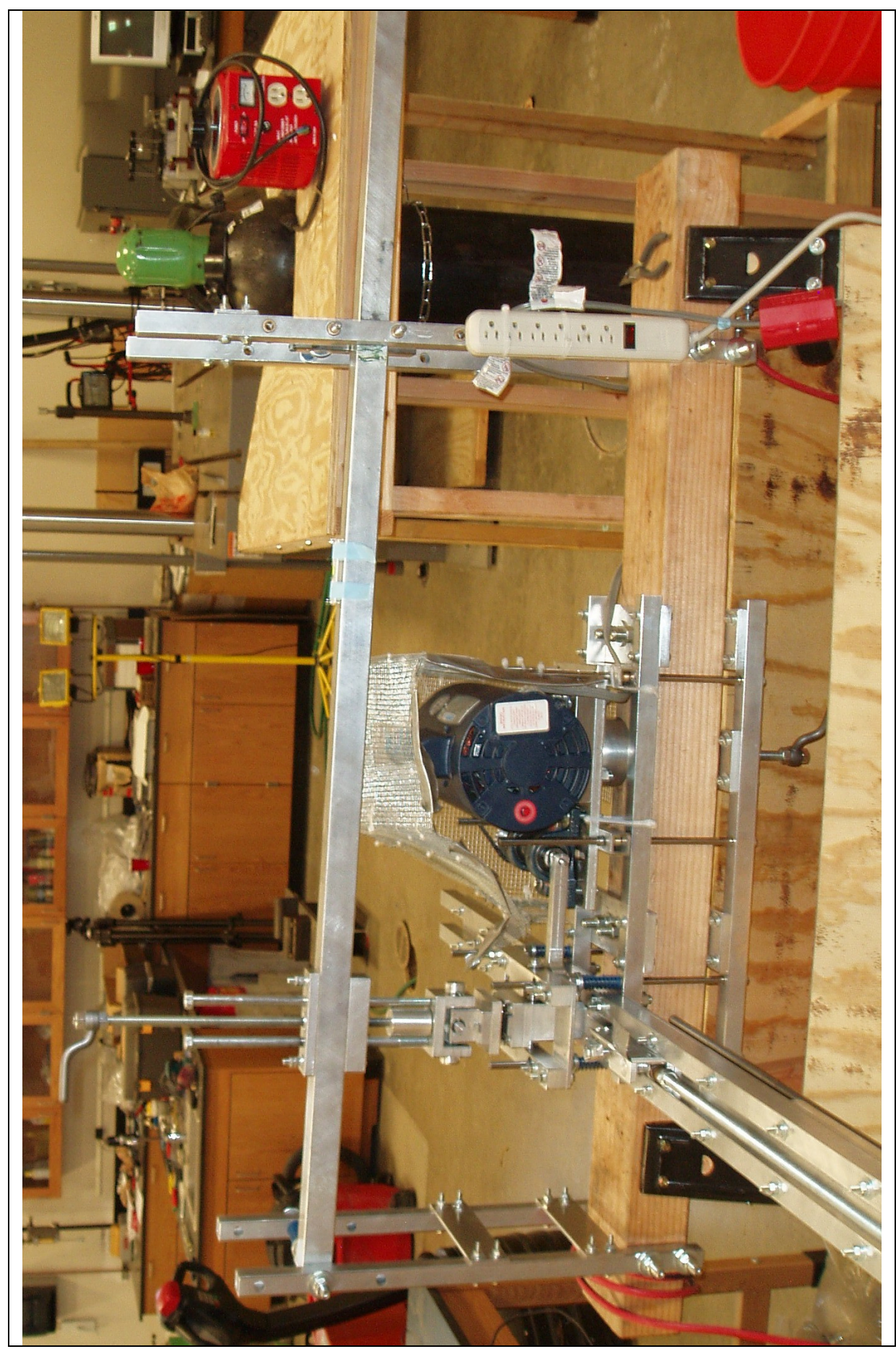

Figure 6 Completed machine photograph. 


\subsection{Selection of Preliminary Wood Species}

Several species of timber have been successfully wood welded in the literature and functioned as a point of reference in selecting the wood species to be investigated with this research. The two species most often utilized, beech and spruce, were not selected for several reasons. First, they have been the focus of substantial research. Experimenting with different species could illustrate if welding variables and joint strengths are species dependent. Second, beech wood was not readily available on a local basis. Lastly, while spruce has been successful in rotational welding, it has not performed well in planar bonding applications.

While published literature can be found using wood welding with other species, it is sparse. Published wood welding literature was found pertaining to oak, birch, maple, and poplar and were all considered as candidates for inclusion in this research. To aid in the selection process, a material property data base program, CES Selector, was utilized [44]. Researchers have noticed discrepancies in weld strength between beech (Fagus sylvatica) and oak (Quercus robur) samples and have suggested that wood density affects heat transfer rates during welding [17]. Additionally, the hardness of the wood may be influential and was also considered. By comparing the densities of the possible wood species candidates against the properties of beech and spruce, educated choices were made (Figure 7). Similar results were found in regards to the wood hardness values (Figure 8). 


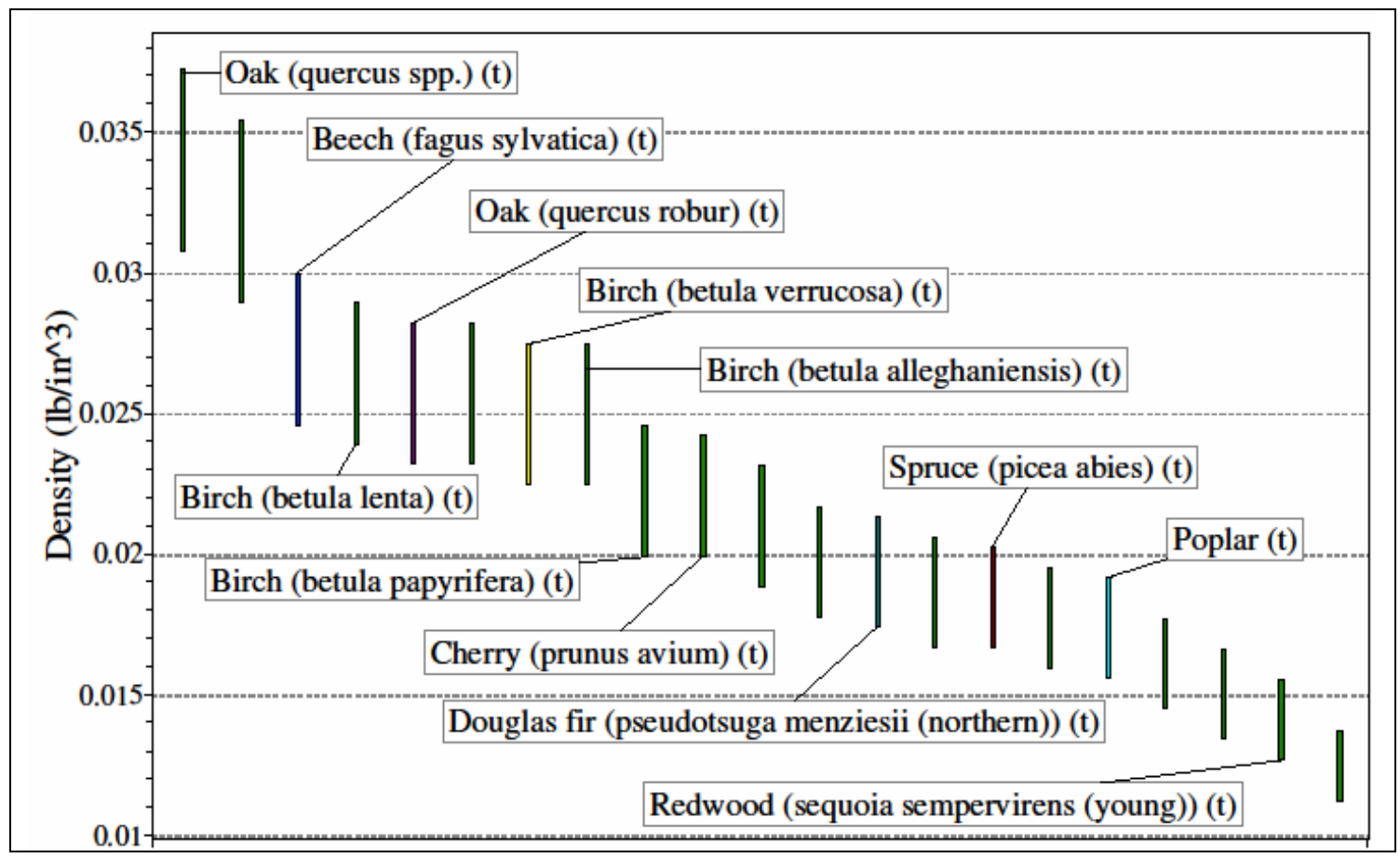

Figure 7 Density comparisons between various timber species (transverse properties).

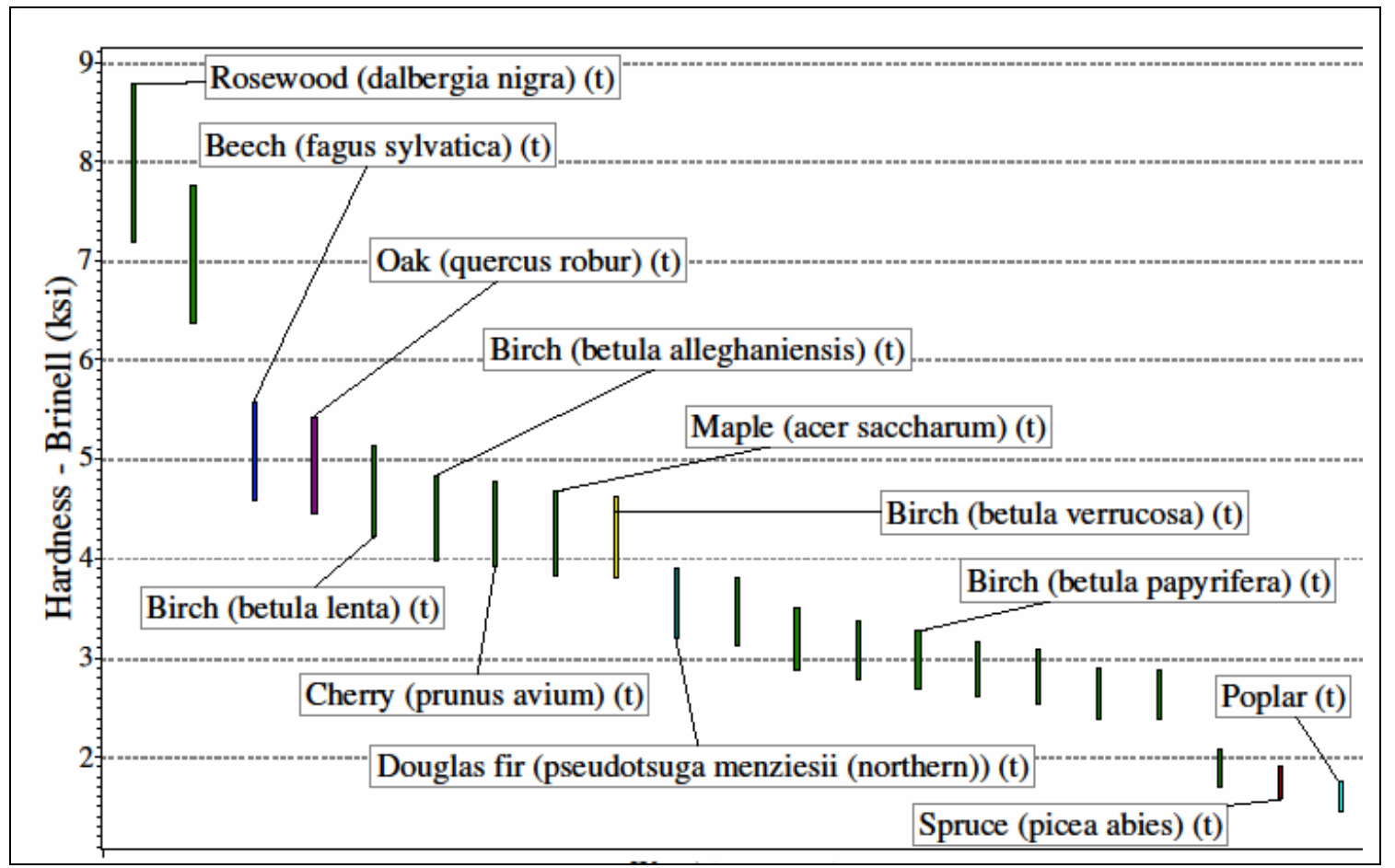

Figure 8 Hardness values for multiple woods (transverse properties). 
Douglas fir (DF) was selected for its prominence in the timber industry, being used both as sawn lumber and engineered timber products. Additionally, DF wood welding had never been attempted. Birch was selected because it had properties similar to those found in beech. Poplar was chosen since it had similar properties to spruce, and poplar is also widely employed in industry for use in engineered lumber.

\subsection{FDM Thermal Model}

During wood welding, friction is responsible for generating the heat required to soften the wood. As the dimensions of the wood cross-section gets thinner, less insulation is available to keep the weld interface hot. Hypothetically, if the wood thickness falls below an unknown critical thickness, heat generated at the interface could potentially be conducted away from the surface that was to be wood welded.

While researchers have published data pertaining to the welding surfaces, by either embedded thermocouples [25, 26] or using infrared thermography [19, 21, 29], little material has been published regarding temperature distribution or heat transfer during wood welding. In traditional welding, thermal distribution and boundary conditions are extremely important and can have profound effects on the weldment. Even though the bonding mechanisms of wood welding are different than those found in metallurgic welds, thermal effects are too important to simply ignore.

To investigate, a finite difference model was created to observe the thermal distribution in a cross-section with a height-to-width ratio approximating a thin veneer $(0.125 \times 1.25 \mathrm{in}).(3.175 \times 31.75 \mathrm{~mm})$. Timber veneers represent some of the thinnest wood cross-sections available. If a thin veneer could provide enough insulation for wood welding, wood thicker than a veneer would offer more than adequate insulation. 
Three boundary condition temperatures were used and were placed at the welding interface, sides, and base. The interface temperatures were based on measurements published in the literature $[19,25,26]$. Room temperature was normally used for the side and base boundary conditions.

The finite difference method used neglected heat transfer and assumed steady state conditions. Conduction was assumed as the primary mode of heat transfer, but convective elements could be present during the welding process. Only the sides of the veneer would be subjected to both conductive and convective elements and was the reason why they were treated as separate boundary conditions.

Four initial finite difference models were created, each with a separate purpose (Table III). Each model was created to address how changes in boundary conditions would effect the thermal distribution in the area of interest.

Table III Finite difference model: parameters and goals.

\begin{tabular}{|r|r|r|r|l|}
\hline & \multicolumn{3}{|c|}{ Temperature K } & \multicolumn{1}{c|}{ Question for model to answer. } \\
\hline Model & Interface & \multicolumn{1}{|c|}{ Sides } & \multicolumn{1}{c|}{ Base } & \multicolumn{1}{c|}{$\begin{array}{l}\text { Do higher interface temperatures affect } \\
\text { thermal distribution? }\end{array}$} \\
\hline 1 & 700 & 300 & 300 & $\begin{array}{l}\text { Would colder side boundary conditions alter } \\
\text { the thermal distribution? }\end{array}$ \\
\hline 3 & 600 & 200 & 300 & $\begin{array}{l}\text { What is the normal temperature distribution } \\
\text { under normal conditions? }\end{array}$ \\
\hline 4 & 600 & 300 & 300 & $\begin{array}{l}\text { Are normal conditions and distribution } \\
\text { affected by model size (4x larger)? }\end{array}$ \\
\hline
\end{tabular}

After the models were created, they were all compared against each other to observe any significant changes (Figure 9). Model 1 suggested that even if higher than expected welding surface temperatures were encountered, the current veneer thickness, $0.125 \mathrm{in}(3.175 \mathrm{~mm})$, would still provide sufficient insulation for the previously welded veneer. Even though the side boundary elements in Model 2 were significantly colder, 
much cooler than reasonably possible during welding, the distribution remained mostly unchanged and suggests minimal sensitivity to side temperature. Model 3 implied that under normal conditions, the veneer would provide more than adequate insulation.

Finally, Model 4 answered questions regarding model size. Model 4 was four times larger than Models 3, but the same boundary conditions utilized for both yielded comparable thermal distributions.

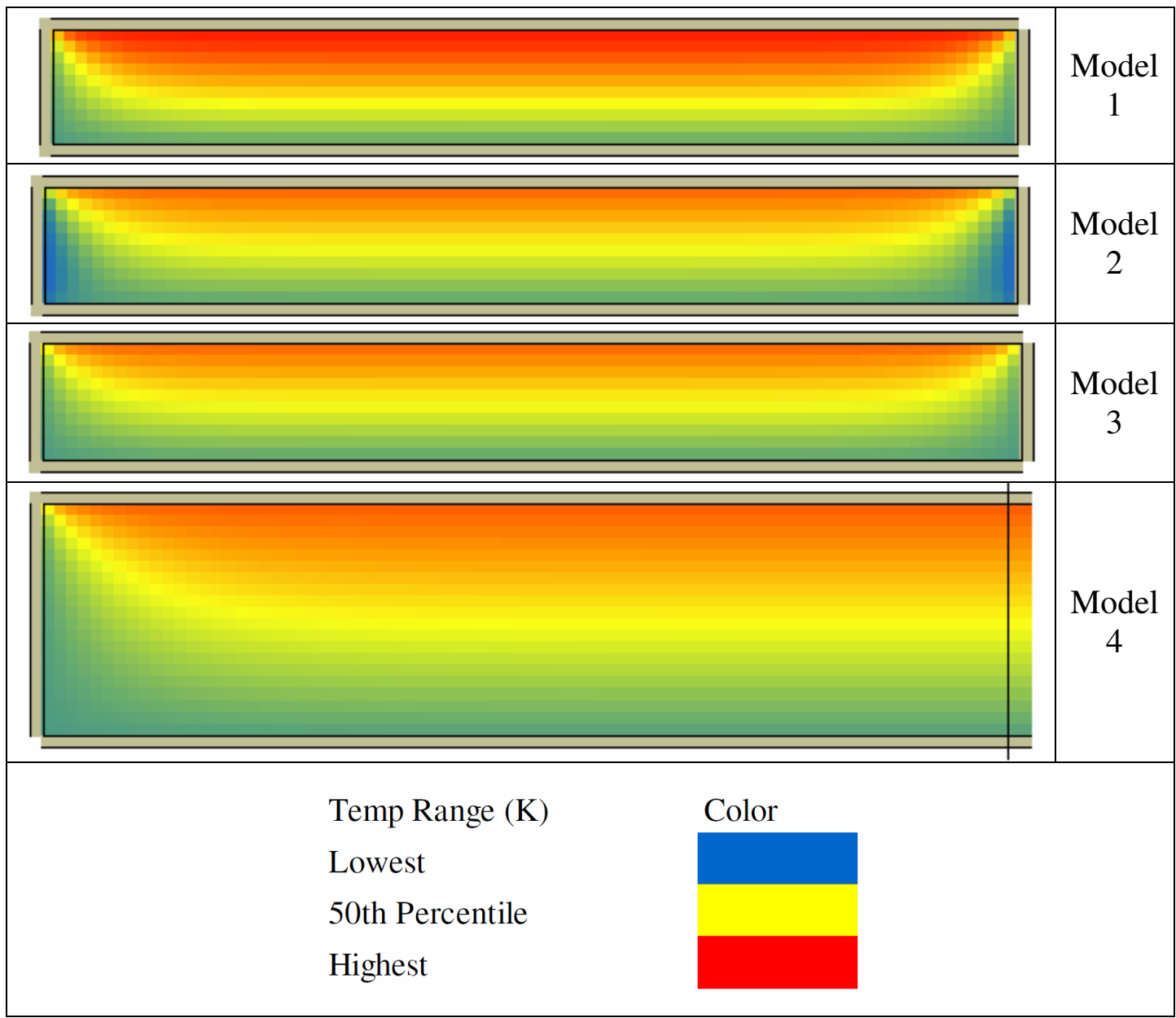

Figure 9 Thermal distribution results of the FDM analysis. The temperature scale applies to all models, where red represents the highest temperature found in any model, and blue represents the coldest, 700 and $200 \mathrm{~K}$ respectively. The left half of Model 4 is shown as the model is symmetric about its center. Note: Each model represents a veneer with a thickness of 0.125 in (3.175mm). 
Based on the FDM results it was concluded that wooden cross-sections with a thickness of $0.125 \mathrm{in} .(3.175 \mathrm{~mm})$ or greater provided acceptable thermal insulation for the welding process.

\subsection{Experimental Bounding and Results}

\subsubsection{Processing Variables Overview}

To begin the experimentation, a series of initial tests were performed in an effort to bound the variables considered and determine the mechanical limits of the prototype welding machine. Neglecting wood type, five processing variables of interest were identified: surface preparation, the use of a shielding gas, welding pressure, welding duration, and vibration frequency. Two of these variables, surface preparation and the use of a shielding gas had not been previously investigated.

Other variables such as post-weld holding time and post-weld holding pressure were held constant to minimize the scope of the experiments. Welding displacement was also held constant, due of the physical dimensions of the crankshaft, to an amplitude of 0.06in. (1.52mm). The total displacement, double the value of the amplitude (0.120in.) (3.05), was based on a common value previously published in the literature of $0.118 \mathrm{in}$. (3 $\mathrm{mm})[9,16-22]$.

\subsubsection{Surface Preparation}

For the surface preparation portion of this experiment, three different surface preparations were examined: as-cut state, roughened with 60 grit sand paper, and roughened with 80 grit sand paper. Samples were cut to dimensions with a table saw, as- 
cut, and sanded as required. Poplar was used for this experiment and each sample was welded with the same settings. Four samples of each preparation were attempted.

Each of the three surface preparations (as cut, 60 grit, and 80 grit) were examined. Generally, the "as cut" preparation produced higher shear strengths. However, the "as cut" did not achieve the high bond coverage values found in both roughened samples. Based on those observations, the "as cut" preparation was implemented on all trials after that point. The potential use of a shielding gas was investigated next.

\subsubsection{Shielding Gas}

The bonding mechanisms responsible for wood welding are completely different than that of metallurgic welding. However, since other relationships exist between these two branches of welding it is possible that a shielding agent, commonly used for metals, could be useful in wood welding as well. In the presence of oxygen, wood vibrated together will char and eventually catch fire. However, if the vibration occurred in the absence of oxygen, the wood could theoretically achieve a temperature past its kindling point.

To investigate the effect an absence of oxygen would have on the wood welding process, high purity compressed nitrogen gas was used in the experiment as a shielding gas. A flexible tubing system was created that would apply gas to both sides of the wood samples during welding (Figure 10). The goal of using the shielding agent was to displace oxygen gas around the welded sample. Birch (as per the decision from section 3.3 ) samples were welded with and without the nitrogen gas and any observed differences were noted. 


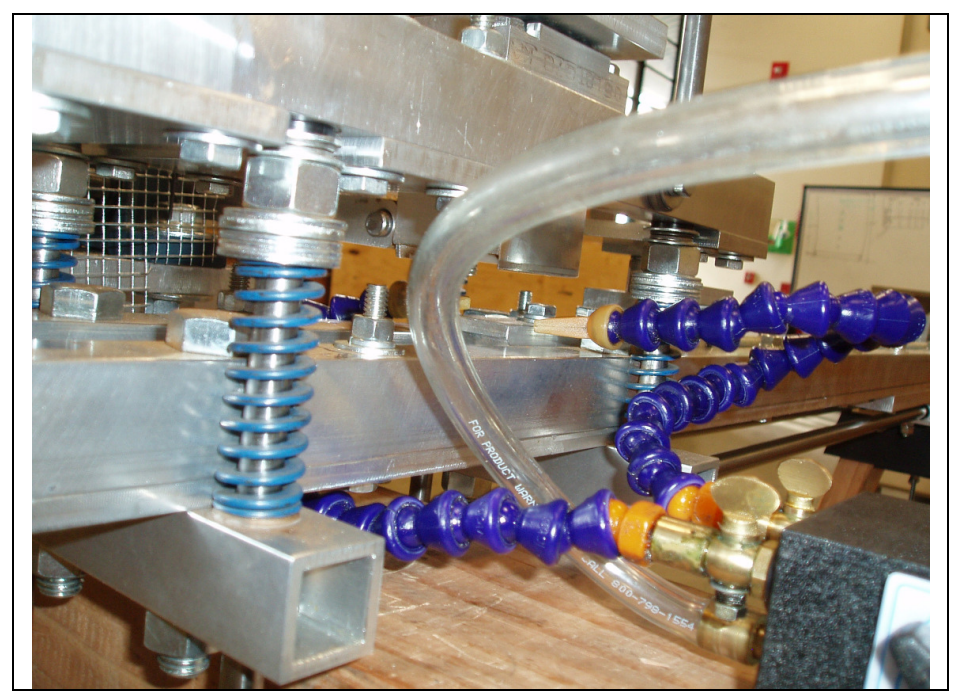

Figure 10 The nitrogen gas was supplied from a compressed bottle (clear tube) and directed at the external edges of the welding interface from two directions (blue, segmented hoses).

Using 200 psi (1.38MPa) pressure, an 8 second welding time (cold start), $92 \mathrm{~Hz}$ frequency, and a 30 second post-weld hold, the nitrogen gas was allowed to flow at both 10 and 20 psi pressure $(0.069 \& 0.138 \mathrm{MPA})$. Both pressure settings produced the same result, a successful bond. Only a few samples were created in the presence of nitrogen, and their processing seemed nearly identical to those made without the gas. Both methods, with and without gas, usually generated smoke and welding residue, and the only observed difference between using and not using a shielding gas was when the smoke generation began. Smoke creation seemed to be slightly delayed when nitrogen was used, but once started; smoke creation appeared to progress more rapidly than without the gas. While the nitrogen method did produce successful bonds, their strength was not tested because not enough pieces were made to yield any statistically significant data. Since the processing of the nitrogen samples did not yield significantly different observations when compared to samples made without nitrogen, the use of a shielding 
gas was abandoned for the remainder of the trials. The last variable to be determined, before the primary round of experimentation was attempted, focused on timber species.

\subsubsection{Timber Species}

Early trials with DF were not successful.

Instead of forming a welded bond when subjected to the pressure and vibrations, the most common outcome was a washboard like surface (Figure 11). During one welding attempt with $\mathrm{DF}$, a processing error occurred in which the welding pressure was significantly reduced on a sample and resulted in a bond. The bond albeit weak, proved that DF could be wood welded.

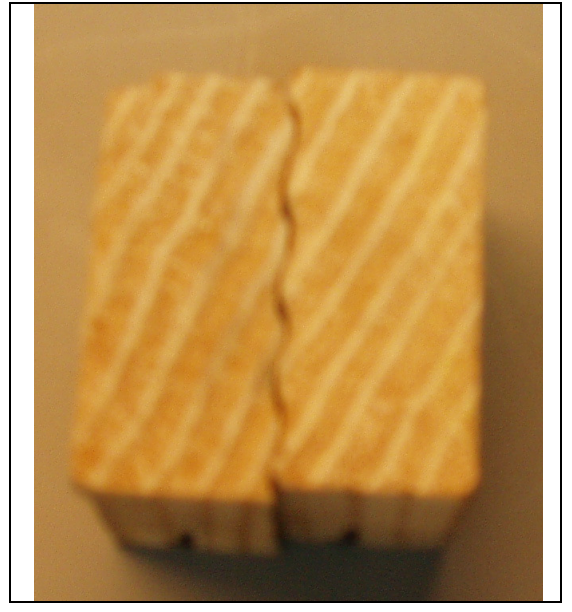

Figure 11 During multiple attempts to weld DF, the interface degraded and formed a washboard pattern.

After considering the weak bonding, DF was dropped from the remainder of the experiment. While DF had shown that it was capable of being wood welded, DF was deemed outside of the scope of this research as it did not conform to the bounds of the chosen test variables.

Of the two other wood species, birch and poplar, only birch showed significant promise and became the focus of the primary experiments. While poplar did form wood welds within the bounds of the test variables, poplar bonds had lower shear strength in comparison to the preliminary tests performed with the birch samples.

While the reason(s) for birch's success was unknown, for the given frequency, pressure, and welding duration ranges investigated in the bounding experiment, birch performed best. In depth research into how different timber species affected wood 
welding properties was beyond the scope of research for this project. For that reason, birch was selected as the sole timber species used for the primary investigation of the research presented herein. A hypothetical explanation for the weldability differences between wood species has been presented in section 7.7 . 


\section{Chapter 4: Primary Investigation - Experimental Procedure}

\subsection{Summary of Objectives}

With results from preliminary bounding experiments, details for the research parameters became evident. This research investigated three separate experiments: shear strength development, the effects of welding frequency and weld duration, and the influence of grain orientation on wood welded joints. Ultimate shear strength was used to evaluate the quality of the welds; however, it was not the sole metric used to evaluate the wood welded bonds. Bonding between wood blocks from the bounding experiment was frequently irregular; therefore, bond coverage was also recorded and evaluated.

During the weld frequency/duration and grain orientation experiments, observations pertaining to the welding process were recorded for later analysis. The presence of weld residue formation (later referred to as goop), smoke generation, and audible pitch changes were noted during the processing of each wood sample. That data was used later during the analysis to evaluate alternative methods for gauging the completion (measured in this research by bonding percentage) and quality (shear strength) of the weldments.

\subsection{Processing Specifications}

\subsubsection{Shear Strength Development Over Time}

Little research has been conducted on the topic of wood welding cure time and strength. The vast majority of researches performed mechanical evaluations of test specimens after the samples were allowed to cure for seven days, often in 
environmentally controlled conditions $\left(20^{\circ} \mathrm{C}\right.$ with a $65 \%$ relative humidity) $[7,9-11,14-$ $17,20,25,28-30]$. One particular research group conducted tests at 10, 30, 60, 300, and 900 seconds of post weld cure time. They found that the strength immediately after welding was approximately $77 \%$ of that shown at fifteen minutes (900 seconds) [25].

The research presented herein sought to evaluate cure times longer than fifteen minutes and shorter than seven days in an effort to contribute to the existing body of knowledge. Birch specimens were all welded with: 200 psi (1.38 MPa ) pressure, $92 \mathrm{~Hz}$, 2 second ramp time, 6 seconds weld, and a 30 second post-weld hold. Four samples were created for each cure time testing window: 60, 100, 750, 1200, 2040, 3000, 4500, and 6000 minutes. Shorter time spans, fifteen minutes, were not evaluated due to logistical issues. Samples were cured for their representative durations at room temperature and humidity (Approximate atmospheric conditions during the entire testing trial for San Luis Obispo, California (August 29, 2009 - September 11, 2009): Temperature: $72.3^{\circ} \mathrm{F}\left[22.3^{\circ}\right.$ C], Relative humidity: $47.0 \%)$.

\subsubsection{Welding Frequency and Duration Interactions}

To examine the change in wood weld strength as a function of processing conditions, two parameters were considered: welding frequency and weld duration. Welding frequency had been mostly unchanged throughout the literature. A range of frequencies: $80,95,110,130$, and $150 \mathrm{~Hz}$ were used by Stamm et al. to evaluate the relationship between weld frequency and the coefficient of friction at the weld interface during welding [25]. However, to date, the relationship between strength and frequency has not been addressed. A frequency of $100 \mathrm{~Hz}$ has often been used in the literature and served as an approximate median value for the main variable experiment [7, 9-11, 14-22]. 
Lower and higher frequencies were also used to evaluate the relationship between strength and weld frequency. Considering the apparatus used, the three frequencies examined were: 72,92 , and $123 \mathrm{~Hz}$.

In addition, researchers performing experiments using the $100 \mathrm{~Hz}$ frequency have reported successful bonds forming with 3-5 seconds of welding time; however, that range of welding time values may not be adequate for all welding frequencies. A faster vibration speed could require less welding time and a slower speed may need more time. This frequency-welding time interaction could influence both bond uniformity and strength.

Three welding times $(4,6$, and 8 seconds) were examined along with the three previously mentioned welding frequencies, yielding nine distinct processing variations. Each variation had a sample size of seven and was prepared under the same conditions, with the exception of the processing variables of interest. Every sample was welded, cold start, with $200 \mathrm{psi}(1.38 \mathrm{MPa})$ pressure and held under that pressure for 30 seconds after the welding time had elapsed. Birch wood blocks were used and aligned parallel to their grain orientation. Wood welding was performed perpendicular to the grain. Detailed notes including smoke and residue creation, if a bond formed, and whether or not an audible pitch change was heard, were recorded. Specimens were labeled with the appropriate information and stored at room temperature and humidity for seven days prior to mechanical shear testing (parallel with grain).

\subsubsection{Grain Orientation}

While researchers have done some investigation into the effects of grain orientation, the relative orientation of the grain was mentioned without details pertaining 
to welding direction $[17,24]$. Although the topic has not been mentioned in the published research, there are three distinct orientations in which wood welding can be performed while neglecting any end grain involvement. Wood welding can be performed with: parallel wood grain samples using a welding displacement parallel to the direction of grain, parallel wood grain samples using a welding displacement perpendicular to the grain orientation, and cross grain bonding occurring when the grain patterns of the two blocks are perpendicular to each other (Figure 12). For the cross grain scenario, the welding displacement occurs parallel to grain for one of the sample wood blocks and perpendicular to the other wood block. The grain orientation portion of this research investigated how the welding and testing directions affect shear strength.

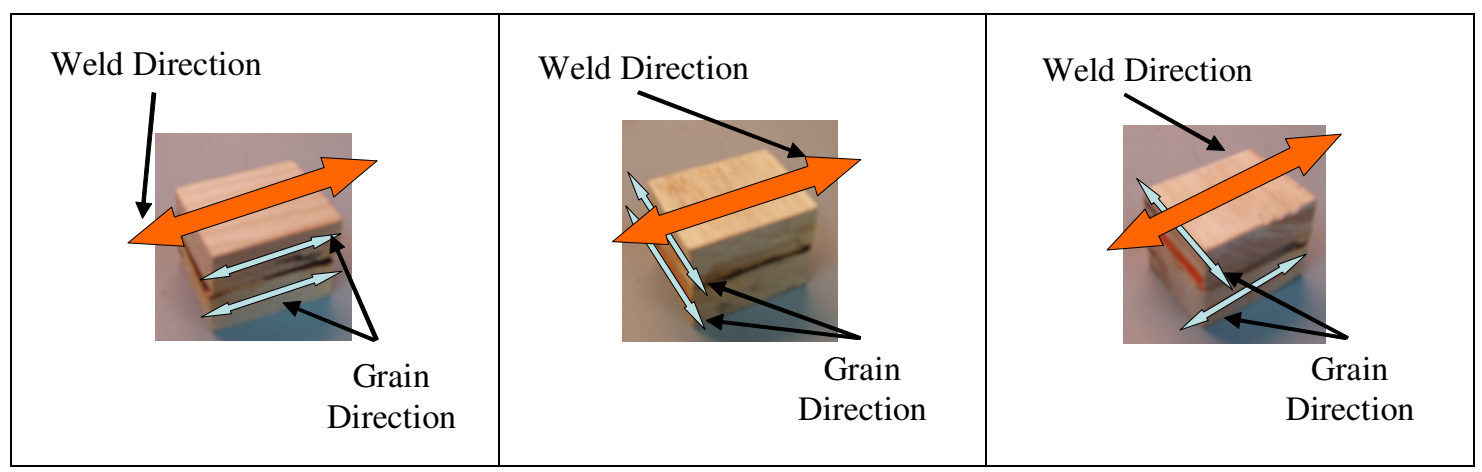

Figure 12 Three primary modes of wood welding (Left, parallel welding; Center, perpendicular welding; Right, cross welding).

Disregarding any off angle orientations, wood welded samples can be tested in two ways, either parallel to the grain structure or perpendicular to the grain. When directional testing was coupled with the three wood welding orientations mentioned earlier five distinctive weld/test possibilities emerge (Figure 13). Wood welding can be performed both parallel and perpendicular to grain. Testing can also be performed either parallel or perpendicular to the grain of the wood. The two welding orientations, each subject to the two separate testing directions, result in four of the five weld/test 
possibilities. Cross grain preparation was the fifth and final possible orientation. Parallel or perpendicular test orientations were meaningless in cross grain samples because they can only be tested in one direction with respect to the sample. Test direction in a cross grain sample would be parallel to one wood block and perpendicular to another.

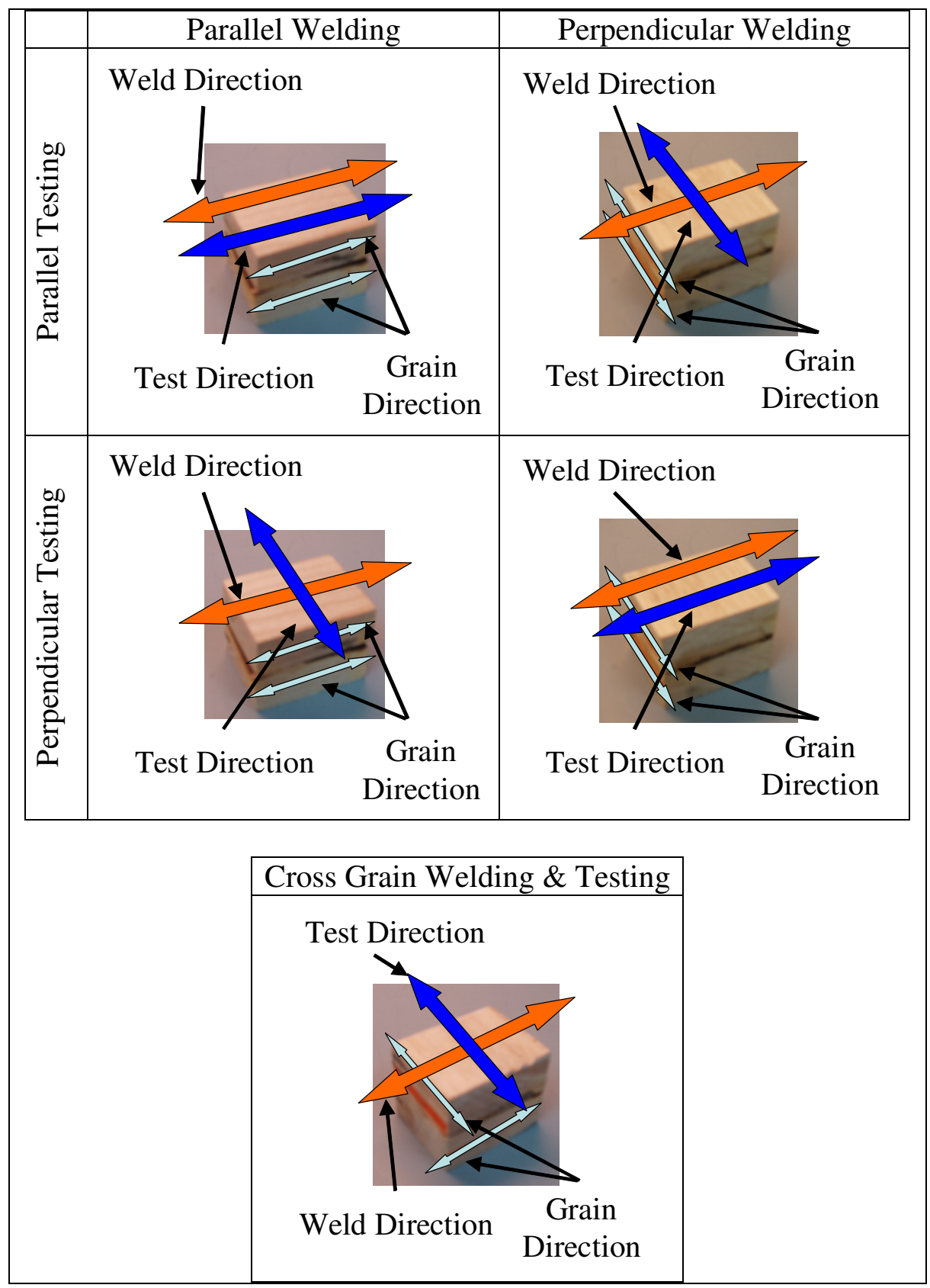

Figure 13 When the three possible wood welding orientations are combined with parallel and perpendicular grain testing directions, five processing possibilities emerge. 
The variables used for grain orientation analysis were the median values used for the frequency/duration variable experiment (section 4.2.2 ). Birch wood was welded under 200 psi (1.38 MPa) pressure at $92 \mathrm{~Hz}$ for 6 seconds (cold start) and given a 30 second post-weld hold. 40 total samples were made: 16 parallel welds, 8 cross grain, and 16 perpendicular welds. Each specimen was labeled with both a number and symbol indicating how it was made (see section 4.3 Sample Preparation \& Processing). Information was recorded regarding smoke creation, weld-reside formation, and whether or not a successful bond was formed. Notes were also taken with respect to if, and at what approximate time an audible pitch change occurred. Samples were stored at room temperature and humidity for seven days before testing. To help insure a random sample during testing for both parallel and perpendicular welds, each group was divided based on their sample number. Odd numbered samples were tested perpendicular to grain and even ones were tested parallel.

\subsubsection{Control Comparison}

While the mechanical shear values resulting from the wood welds could be listed on their own, a control group allowed the data to be seen in greater context. Since wood welding may eventually be used as a substitute for adhesive glues, adhesives seemed to be appropriate for comparison. Gorilla Glue and Elmer's Construction Glue were the glues were used for control purposes. Birch wood blocks were again used and samples were prepared as per the manufacture's instructions. Shear tests were conducted in the same manner as the wood welded samples (parallel with grain) after being allowed seven days to cure at room temperature and humidity. Image analysis was not performed and 
bonding was assumed to be perfect (100\% coverage), as the glue was uniformly applied at the wood block interface.

\subsection{Sample Preparation \& Processing}

Birch samples were welded according to a standard operating procedure. When necessary, welding frequencies were adjusted by substituting the appropriate sprocket. All the wood samples were ripped and cut to final dimensions with a table saw (Appendix E: Wood Block Sample Creation - SOP). As the single wood blocks were progressively cut from their individual strips they were all combined in a single stock pile. This was done to help randomize the samples.

The first step for each of the primary experiments was preparing all the samples ahead of time. Each welding sample consisted of two separate blocks. Before each experiment, blocks were paired off and marked for identification purposes. After the blocks were paired together, they were marked with arrows to indicate an origin point, to show whether the blocks were top (T) or bottom (B), and numbered (Figure 14). These orientation marks were mostly a precaution. If later analysis showed that welding consistently occurred preferentially on one side of the samples relative to the other, the problem could have been a mechanical issue. By knowing how the sample was positioned during welding any such issues could be addressed quickly. 


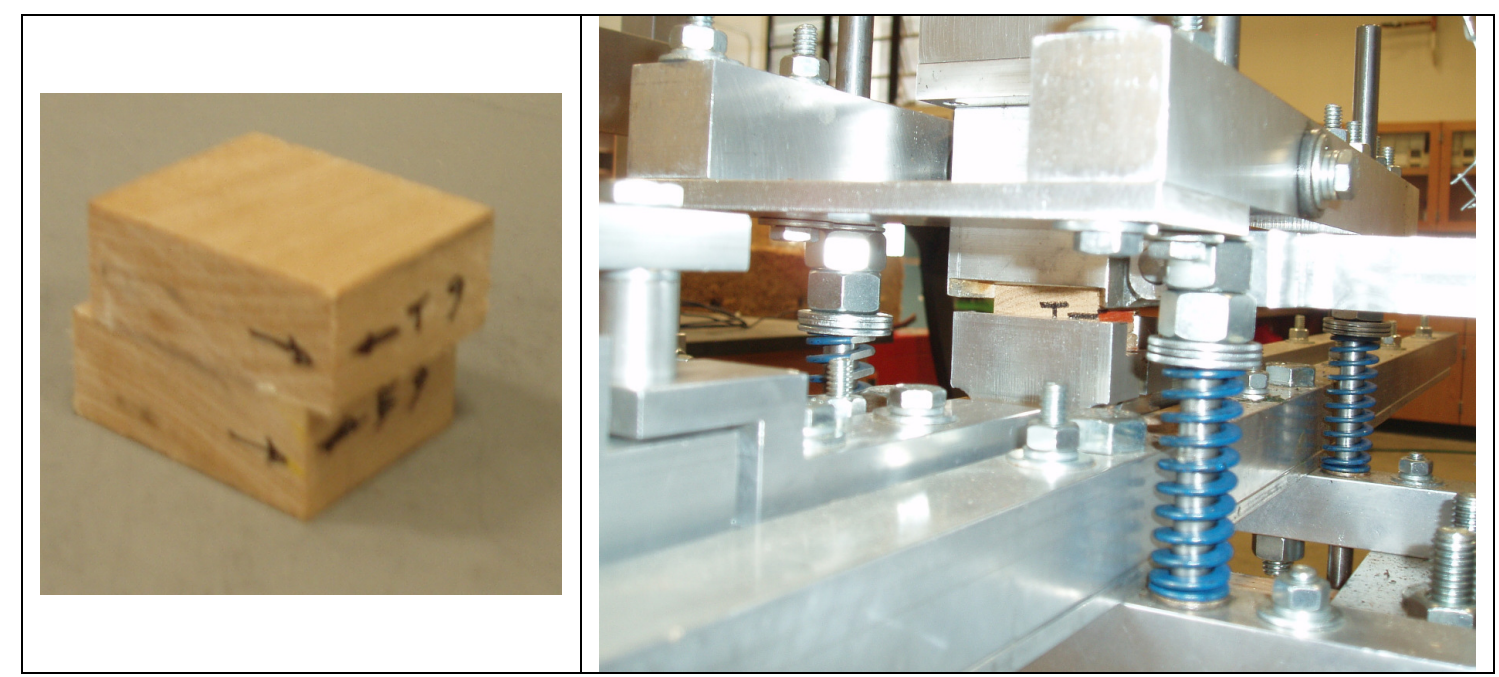

Figure 14 (Left) Simple orientation marks would later indicate how the specimen was positioned during welding. (Right) Every specimen was positioned in the machine in this same orientation.

\subsection{Alternative Welding Completion Metrics}

Throughout the literature many authors have investigated what affect welding time has on the final strength of a wood welded joint; however, such a procedure may not be the best course of action. Multiple papers have been presented where the authors have indicated that welding was performed for various amounts of time; however, in the same papers the authors indicated that vibrations were induced "until fusion is achieved" [7, $10,14,15-18,23]$. That research appeared to be using two potentially incompatible metrics for welding completion and failed to mention how "fusion" was measured. Possible explanations that sought to combine the use of both welding time and "fusion" were never discussed.

While welding time was easiest to measure, its usefulness as an indicator of fusion seemed poor. Several methods of measurement were possible but varied considerably in complexity and could be broken into one of three categories: mechanical, chemical, and perceptive. The perceptive branch of metrics relied on the user observing the welding process itself. Visual cues such as welding residue (goop) and smoke 
formation, auditory differences, and changes in smell are all potentially viable ways to gauge welding completion. While these qualitative methods rely on the discretion of the operator, they were simple, easy to qualify, and did not require any specialized equipment.

Welding residue, or goop, was occasionally excreted from the edges of the weld interface (Figure 15). What comprises this goop material is unknown. It is possible that the goop is an excess of the polymer-fiber matrix that makes wood welding possible.

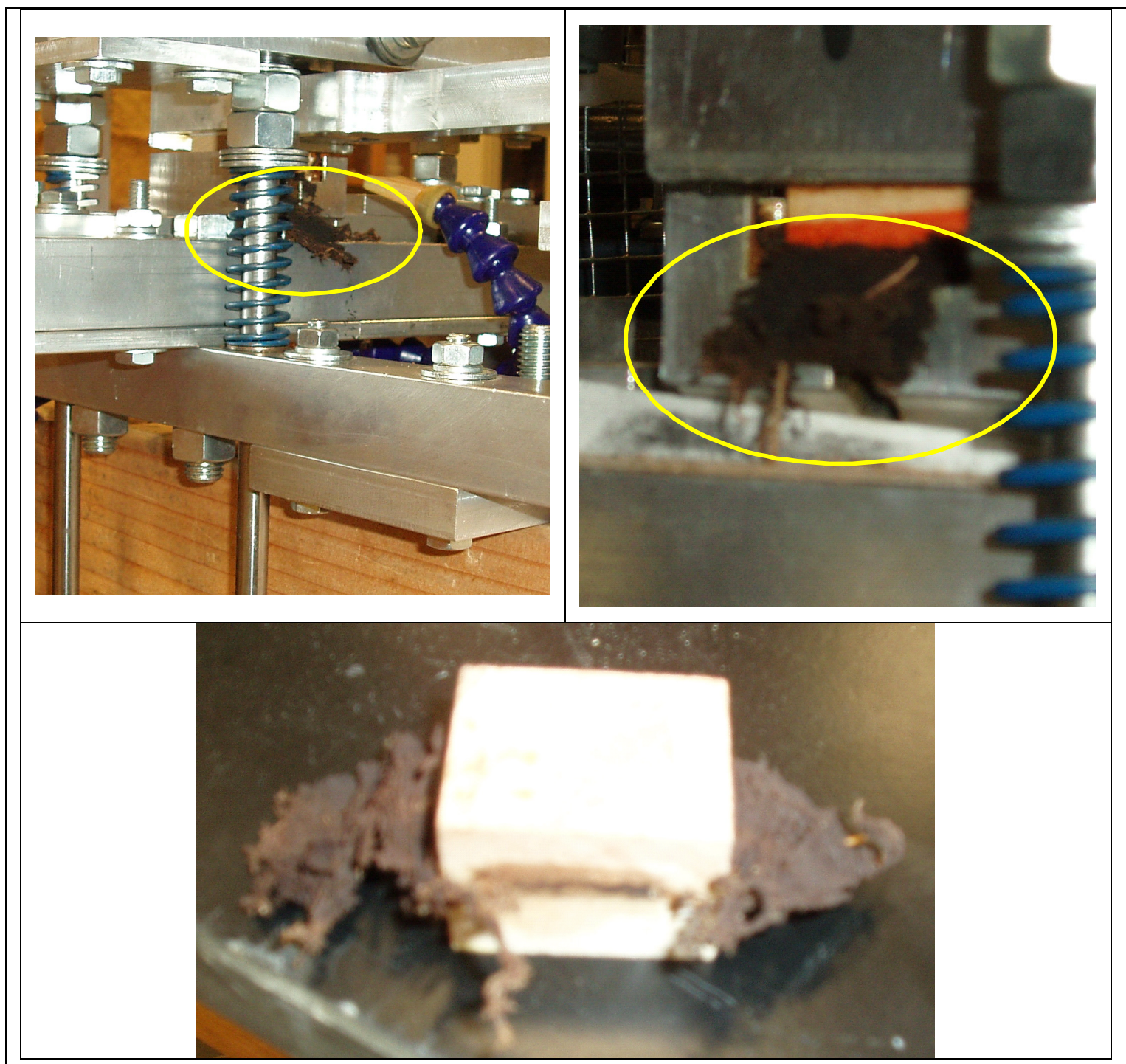

Figure 15 (Top Left \& Right) Images of goop excretion immediately following the welding procedure have been highlighted. (Bottom) The image shows a sample where goop had accumulated. 


\section{Chapter 5: Testing and Evaluation Procedure}

\subsection{Fixture Design and Fabrication}

To compare the influence of the different welding parameters, mechanical testing was required to measure the ultimate shear strength of the wood welded joints. While experimental test fixtures were commercially available, such equipment was not available at the time of testing. In order to conduct the mechanical testing, a custom shear fixture was designed and fabricated to specifications that would allow the fixture to interface with existing test equipment (Figure 16).

Each sample consisted of two blocks welded together and formed a joint whose strength was of interest. The bottom of the first block would be supported by the stationary part of the test fixture while the top portion of the second block would contact the guillotine block (Figure 17). As the guillotine pushed on the second block during a test, a shear force was transferred at the

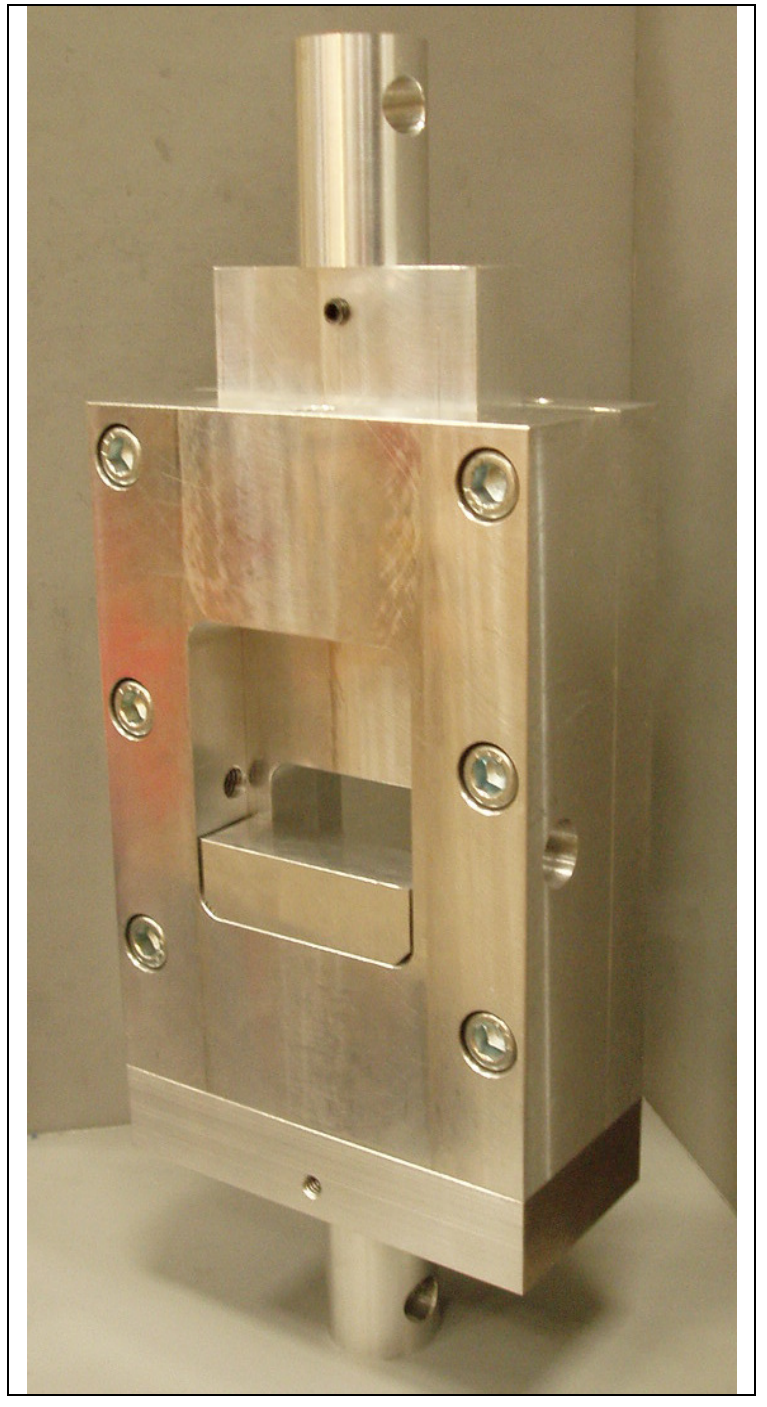

Figure 16 The test fixture was designed to create a pure shear load at the wood welded surface. (Sample restraining set screws not shown.)

interface between the two blocks. To

prevent the sample from moving during a test, three set screws were used to restrain the 
block mounted on the stationary part of the fixture. Two screws provided lateral restraint while the third was positioned vertically to prevent rotation into the guillotine during the test. The two main components were attached to a cylinder joint which would be connected to a sleeve fitting on an Instron testing device. A steel pin would pass through the sleeve and cylinder joint to prevent the fixture from moving. All of the components for the test fixture were fabricated with 6061 or 7075 aluminum. Detailed shop drawings for the test fixture have been provided in Appendix F: Shop Drawings - Shear Fixture.

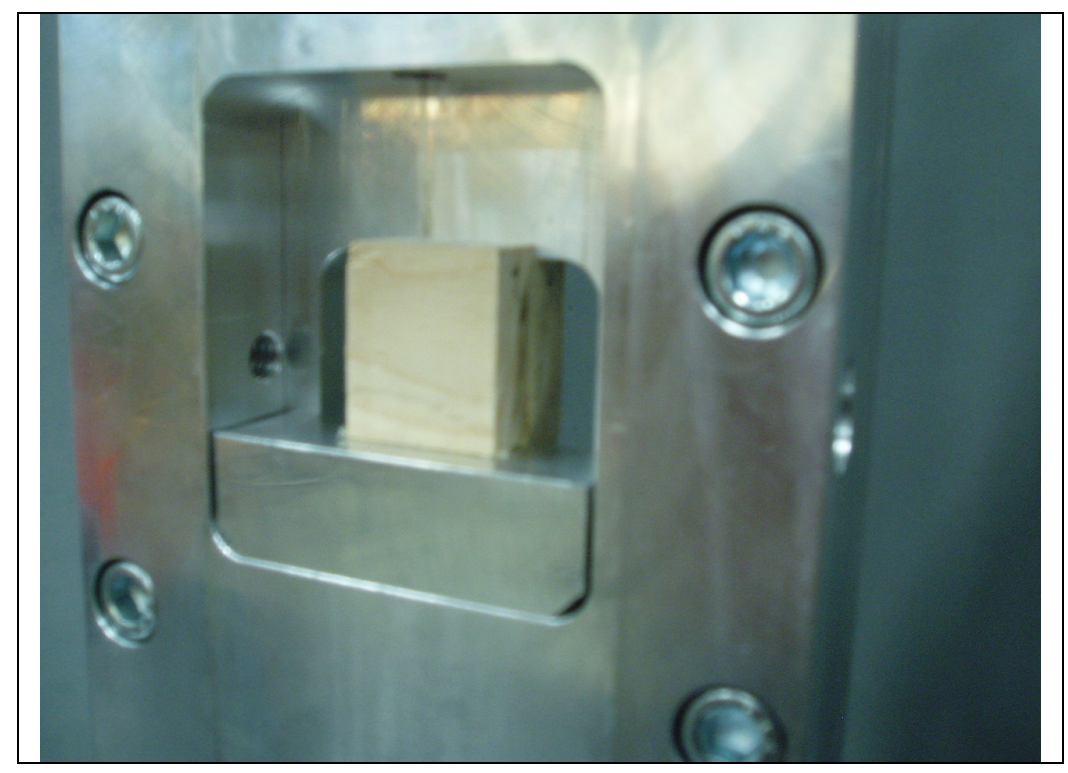

Figure 17 Wood samples of various sizes could be tested in the fixture.

\subsection{Testing \& Equipment}

All of the mechanical testing was performed on a table top Instron machine (Model: $3369,11,250$ pound (12 KN) capacity) running the Bluehill software package (version: 1.5.276). An extension rate of $0.001 \mathrm{in} / \mathrm{s}(0.0254 \mathrm{~mm} / \mathrm{s})$ was used for all cases. The value was based on the slowest rate reported in the literature, $0.0012 \mathrm{in} / \mathrm{s}(0.03$ $\mathrm{mm} / \mathrm{s}$ ) [23]. Each test was run using a compressive load sensitivity that would automatically end the test if the equipment detected a load measurement drop of $40 \%$. 
Every sample was monitored during testing and an approximate failure load was recorded manually and electronically.

\subsection{Digital Area Analysis}

To convert the force measurement into a shear stress, the contact area needed to be calculated. However, the contact area varied within the specimen set based on the uniformity of the wood weld. Upon failure of the specimen, striated patterns, alternating regions of dark bonded material and areas unaffected by the welding process, were commonly observed.

The darker bonded material identified after specimen failure was the contact area over which the shear stress was transmitted. To compute the ultimate shear stress of the wood welds an accurate method to measure the area of bonded material in each sample was required. The degree and geometry of the striations varied greatly between samples and made the prospect of manual measurements difficult, time consuming, and potentially inaccurate (Figure 18). As an alternative to physical measurement, ImageTool, an image analysis software program developed at The University of Texas Health Science Center in San Antonio, was utilized to count the number of bonded pixels in a digital image of each sample [45]. 


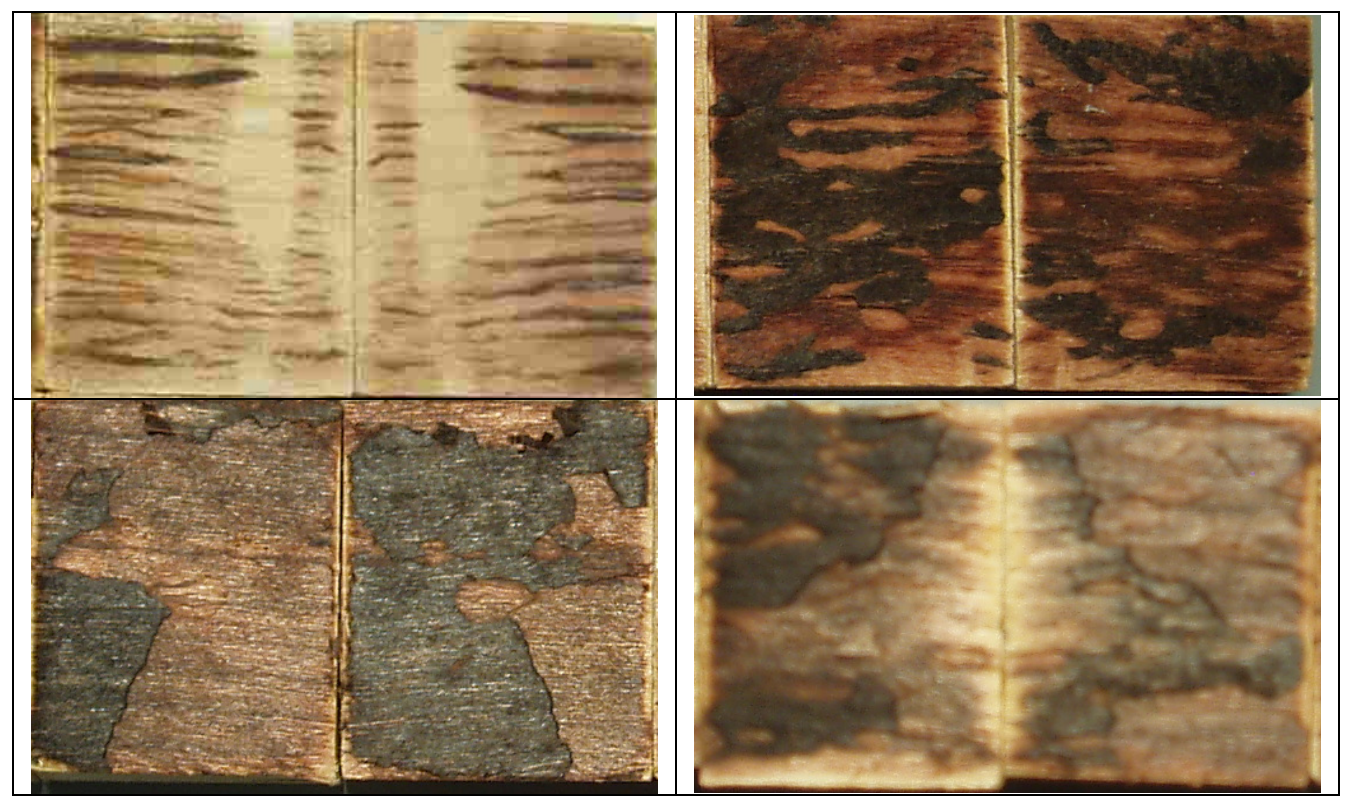

Figure 18 A wide variety of bonds were formed during the experiments. Several examples have been presented: (Top left) Striations - (Top right) Striations with incomplete bonding - (Bottom left) Excellent bond coverage - (Bottom right) Partial failure outside of the wood weld interface, i.e. within the base material.

Once all of the samples in a given series were tested to failure, the specimens were photographed using a digital camera. Both the lower and upper surfaces of the wood weld interface were photographed and used in the analysis. The top block would always appear on the left and the bottom wood block always on the right of a given image. After uploading the pictures, each specimen was cropped and saved as an individual file in preparation for the image analysis.

The first step in the four part image analysis process generated a gray-scale image of the original color photograph (Figure 19). This gray-scale image was necessary to generate the black and white image required for the pixel counting function. Before the pixels could be counted, the threshold values for the individual photographs were calculated. The threshold procedure allowed the user to dictate what gray-scale value would designate the difference between a pixel becoming white or black. Two separate 
threshold photographs were required; the first acted as a calibration reference, and the second accounted for the actual bonded area.

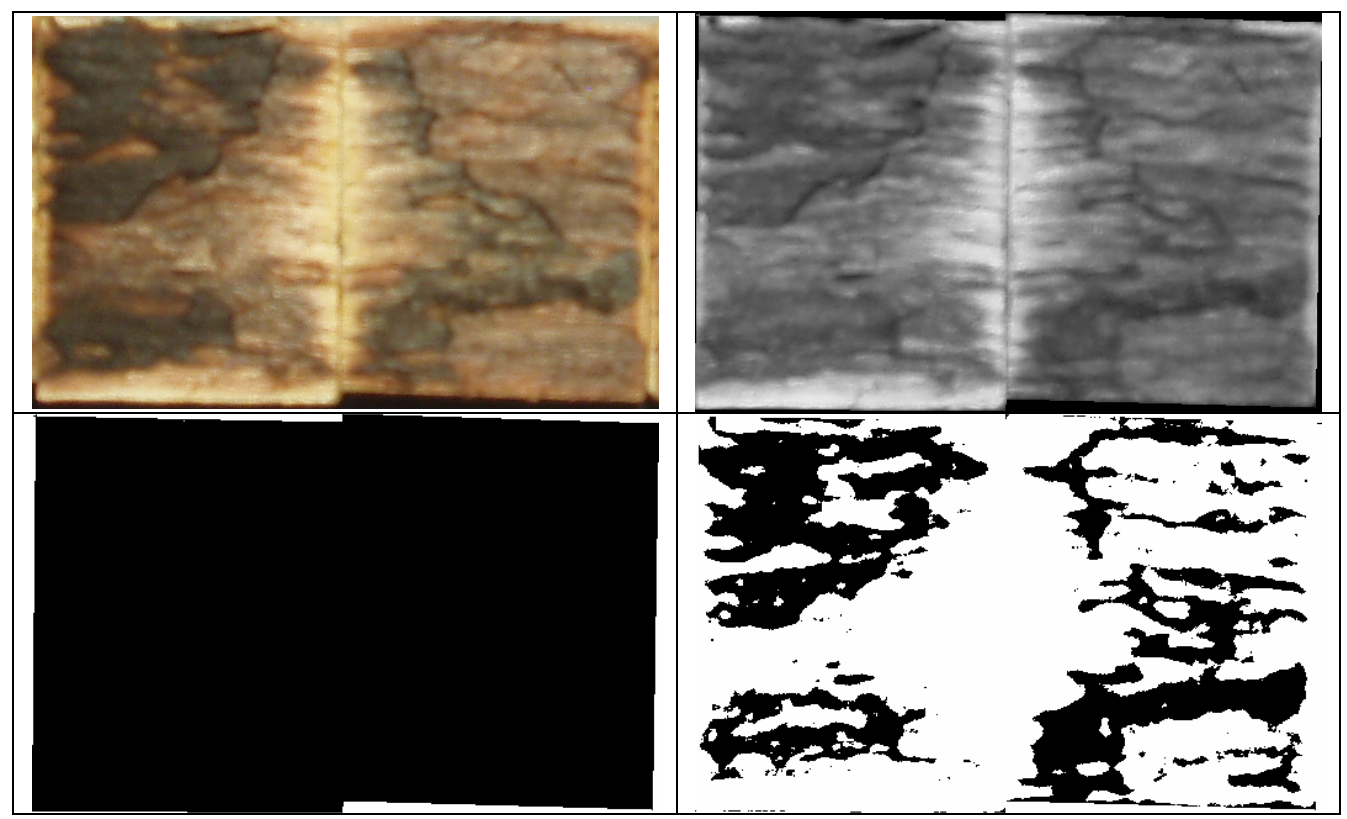

Figure 19 Image analysis photo progression (Clockwise from top left: original color image, gray-scale version, bonded threshold image, calibrated threshold image) (Welding frequency/duration series: $72 \mathrm{~Hz}, 8$ sec WT, sample \#6)

Calibration, the second step, was necessary to account for any photographs that were slightly skewed. These slanted images created artificially dark triangular areas in the gray-scale pictures. During the pixel count, these dark areas would falsely raise the number of black pixels and would not accurately represent the actual wood welded material. The black pixels from the calibration image would be used as a denominator in determining the dark pixel ratio during the pixel count.

The third step used the threshold function again, but this time the goal was to highlight the dark bonded areas of the image. For the fourth and final step, a pixel count was done on both images. The bonding percent $\left(\mathrm{B}_{\text {percentage }}\right)$ presented herein was defined as the black pixel ratio (Equation 1). 


\section{Equation 1}

$$
B_{\text {percentage }}=\frac{P_{\text {image }}}{P_{\text {calibration }}}
$$

Where $\mathrm{P}_{\text {image }}$ was the number of black pixels present in the bonding area and $\mathrm{P}_{\text {calibration }}$ was the number of black pixels determined from the calibration step. Additional information on the specifics of the image analysis procedure, were presented in Appendix G: ImageTool Example and SOP. The procedure was executed on every wood welded sample that was shear tested (approximately 100) generating roughly 400 images used in the analysis. The gray-scale and black and white images have been provided in Appendix K: ImageTool Sample Photographs.

\subsection{Stress Analysis}

The measured shear load at failure was recorded for each specimen tested. Failure was defined as bond separation corresponding to a rapid loss of load carrying capacity. In addition, specifics about each specimen were recorded including: experimental series (shear strength development, frequency/duration interaction, grain orientation, etc.), welding parameters, bonding percentage, failure load, and experimental observations (smoke generation, etc.) (Appendix N: Raw Testing Data).

The average shear stress $\left(\tau_{\mathrm{avg}}\right)$ for the experimental results contained here in was defined by Equation 2.

Equation 2

$$
\tau_{\text {avg }}=\frac{F_{\max }}{A_{\text {gross }} * B_{\text {percentage }}}
$$

Where $\mathrm{F}_{\max }$ was the ultimate shear load (lbs), $\mathrm{A}_{\text {gross }}$ was the gross contact area between the wood blocks ( $\mathrm{in}^{2}$ ), and $\mathrm{B}_{\text {percentage }}$ was the bonding percentage calculated from 
the image analysis. The mean and sample standard deviation (SD) were computed for the various samples in a given series for both shear strength and bond percentage. The coefficient of variation $(\mathrm{CV})$, defined as the ratio of the standard deviation to the mean, was also presented for the shear strength data.

Raw statistics, those inclusive of all the experimental data, and selective statistics were both calculated (Appendix O: Testing Statistics). Selective statistics were made by excluding data based on experimental observations. The goal of the selective statistics were to see if the experimental observations, whether smoke or welding residue formation or the presence of an audible pitch change, correlated with changes in bonding percentage and shear strength. Lastly, the data from the frequency/duration experiment were compared against the adhesive control samples for contextual purposes.

\subsection{SEM Imaging}

Scanning electron microscopy (SEM) images were taken of several failed wood weld interfaces. Due to the organic nature of wood, a conductive film was deposited prior to any imaging attempt. While appearing to be small in size (1.0x $1.25 \mathrm{x} 0.5 \mathrm{in})$ $(25.4 \times 31.8 \times 12.7 \mathrm{~mm})$ the wood blocks were quite large in comparison to normal SEM samples. After being mounted on standard SEM stubs and connected with conductive copper tape, the wood was placed in a sputter coater to deposit a thin conductive film of gold over the fracture surface. The large size and organic nature of the sample required approximately two hours of vacuum pumping to compensate for the wood's out-gassing. Once the machine reached the required pressure, the sputter coater could begin its short, less than a minute, coating process. 
The SEM images were all generated in a low vacuum, approximately 0.08 Torr, with relatively low voltage, roughly $5 \mathrm{KeV}$, with a working distance close to $5.2 \mathrm{~mm}$. A large field detector was utilized for the entire SEM analysis. 


\section{Chapter 6: Data and Results}

\subsection{Welding Frequency and Duration Interaction}

Of the nine welding conditions evaluated (three frequency and three duration settings), four of the conditions produced average shear results of around 1500 psi (10.3 MPa) (Figure 20). These four welding conditions ( $72 \mathrm{~Hz}$ at $8 \mathrm{~s}$ and the entire $123 \mathrm{~Hz}$ trial) yielded outcomes comparable to the construction adhesive control. When considering the overlap of the data, this finding suggests that the strength differences between the best performing wood welded samples and the control adhesive (assuming the adhesives achieved $100 \%$ bonding) are not statistically significant (Table IV). Table IV presents the four pieces of data regarding shear strength (percentage of control, mean, standard deviation, and coefficient of variation) and two pertaining to bonding (mean and standard deviation values). The percentage control value expressed the mean shear strength values as a percentage of the best performing adhesive (construction glue). The percentage control values were presented to put the data in a larger context.

In addition to comparing the best wood welding results to the controls, several processing trends can be seen. As the welding frequency was increased, average shear strength was less impacted by welding duration. However, shear strength variability appeared to be dependant upon both welding duration and frequency. The $72 \mathrm{~Hz}$ series showed that the coefficient of variation $(\mathrm{CV})$ decreased as welding time increased while the $123 \mathrm{~Hz}$ series exhibited an increase of CV with longer weld times. 


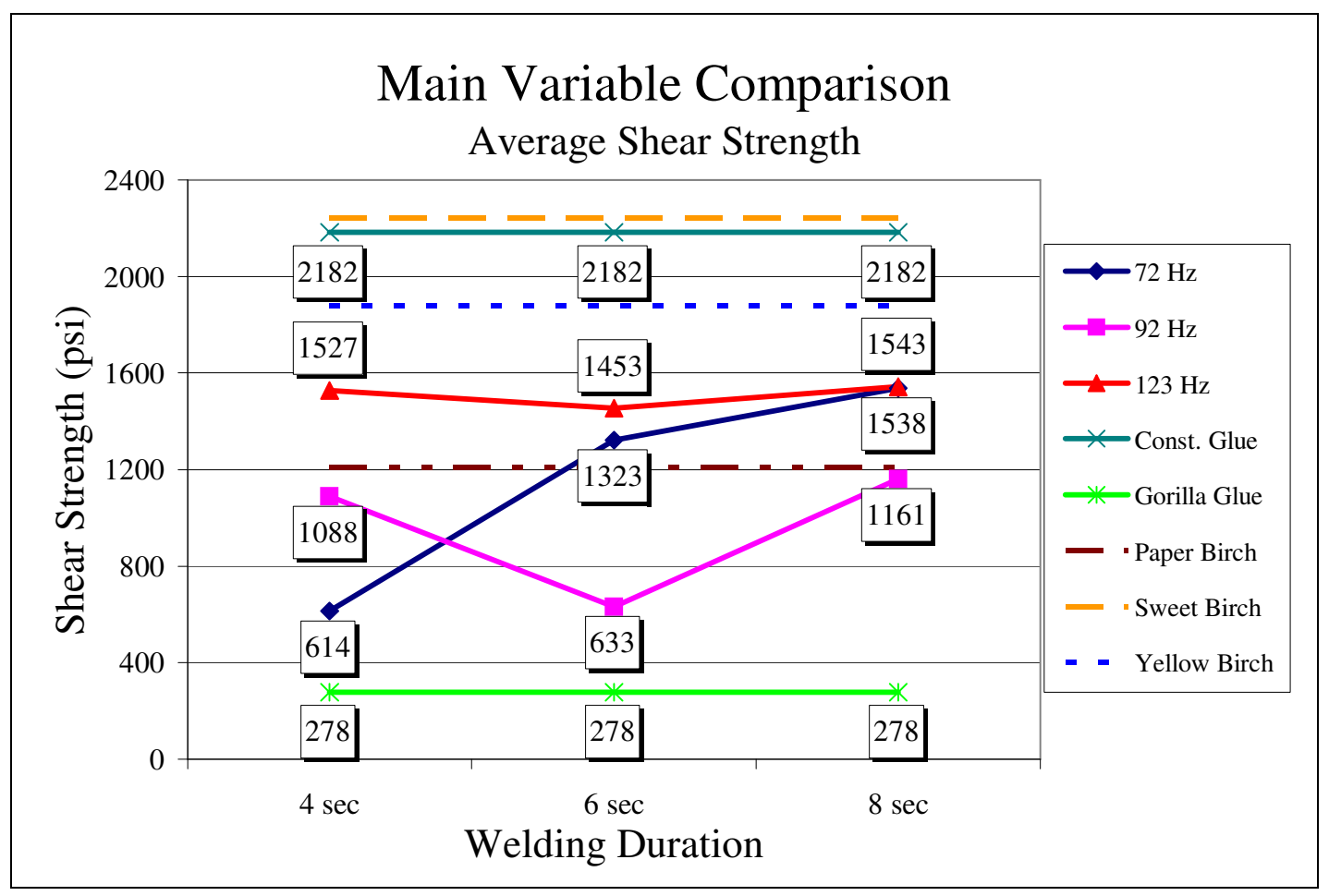

Figure 20 While the best wood welding results overlap with the stronger glue, the majority of the wood welding results were significantly stronger than the second adhesive (Birch, 200 psi WP). The dashed lines indicate published shear strength reference values (parallel to grain at 12\% moisture content) for several birch species (Paper Birch: 1,210 psi (8.3 MPa) - Sweet Birch: 2,240 psi (15.4 MPa) - Yellow Birch: 1,880 psi (13.0 MPa)) [46].

Table IV Main Variable Experimental Results (Birch, 200 psi WP)

\begin{tabular}{|c|c|c|c|c|c|c|c|}
\hline \multirow{2}{*}{$\begin{array}{l}\text { Freq. } \\
(\mathrm{Hz})\end{array}$} & \multirow{2}{*}{$\begin{array}{l}\text { WT } \\
(\mathrm{sec})\end{array}$} & \multicolumn{4}{|c|}{ Shear Strength (psi) } & \multicolumn{2}{|c|}{ Bonding } \\
\hline & & $\%$ Control & Mean & SD & $\mathrm{CV}$ & Mean & SD \\
\hline 72 & 4 & $28 \%$ & 614 & 517 & $84 \%$ & $15 \%$ & $11 \%$ \\
\hline 72 & 6 & $61 \%$ & 1323 & 725 & $55 \%$ & $49 \%$ & $11 \%$ \\
\hline 72 & 8 & $70 \%$ & 1538 & 373 & $24 \%$ & $70 \%$ & $12 \%$ \\
\hline 92 & 4 & $50 \%$ & 1088 & 588 & $54 \%$ & $59 \%$ & $25 \%$ \\
\hline 92 & 6 & $29 \%$ & 633 & 439 & $69 \%$ & $56 \%$ & $15 \%$ \\
\hline 92 & 8 & $53 \%$ & 1161 & 425 & $37 \%$ & $95 \%$ & $7 \%$ \\
\hline 123 & 4 & $70 \%$ & 1527 & 258 & $17 \%$ & $62 \%$ & $20 \%$ \\
\hline 123 & 6 & $67 \%$ & 1453 & 539 & $37 \%$ & $77 \%$ & $31 \%$ \\
\hline 123 & 8 & $71 \%$ & 1543 & 936 & $61 \%$ & $67 \%$ & $36 \%$ \\
\hline Constr & n Glue & $100 \%$ & 2182 & 556 & $25 \%$ & N.A. & N.A. \\
\hline Gor & Slue & $13 \%$ & 278 & 193 & $69 \%$ & N.A. & N.A. \\
\hline
\end{tabular}


While shear strength has been discussed and was undoubtedly important, that information did not completely describe the character of the bonded interface. Bond uniformity was the other measure of success. For the lowest welding frequency, welding time showed a strong positive correlation with bond coverage; however, this trend seemed negligible for higher frequencies (Figure 21).

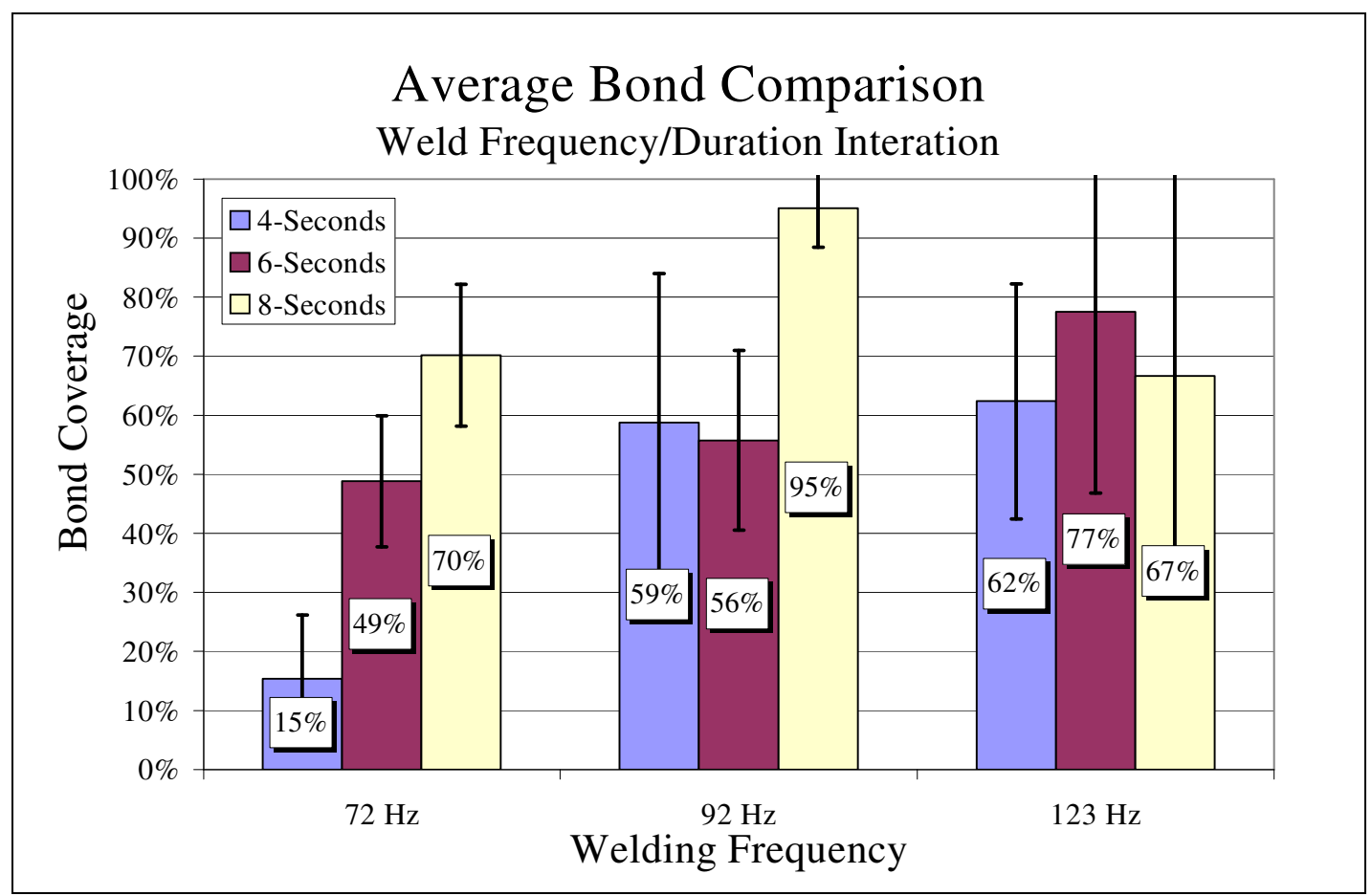

Figure 21 While being influential, discrepancies in welding times have a more pronounced affect at low welding frequencies $(\overline{\mathrm{x}} \pm 1 S D)$ (Birch, $200 \mathrm{psi}$ WP).

\subsection{Grain Orientation}

The grain orientation experiment considered how shear strength was affected by changes in welding orientation and testing direction. Welding orientation appears to have little effect on average shear strength while testing orientation played a significant role (Figure 22, Table V). Testing orientation significantly influenced mean shear strength. Regardless of welding orientation, specimens that had the test load applied parallel to the sample's grain structure yielded strengths several times larger than the results found in 
the perpendicular to grain tests. The cross-grain average shear values fell between the parallel and perpendicular tested values. Parallel shear strength was higher than perpendicular strength, thus confirming previously published literature results [17]. Welding orientation, which had not been previously investigated in the published literature, had a negligible influence on the mean shear strength values.

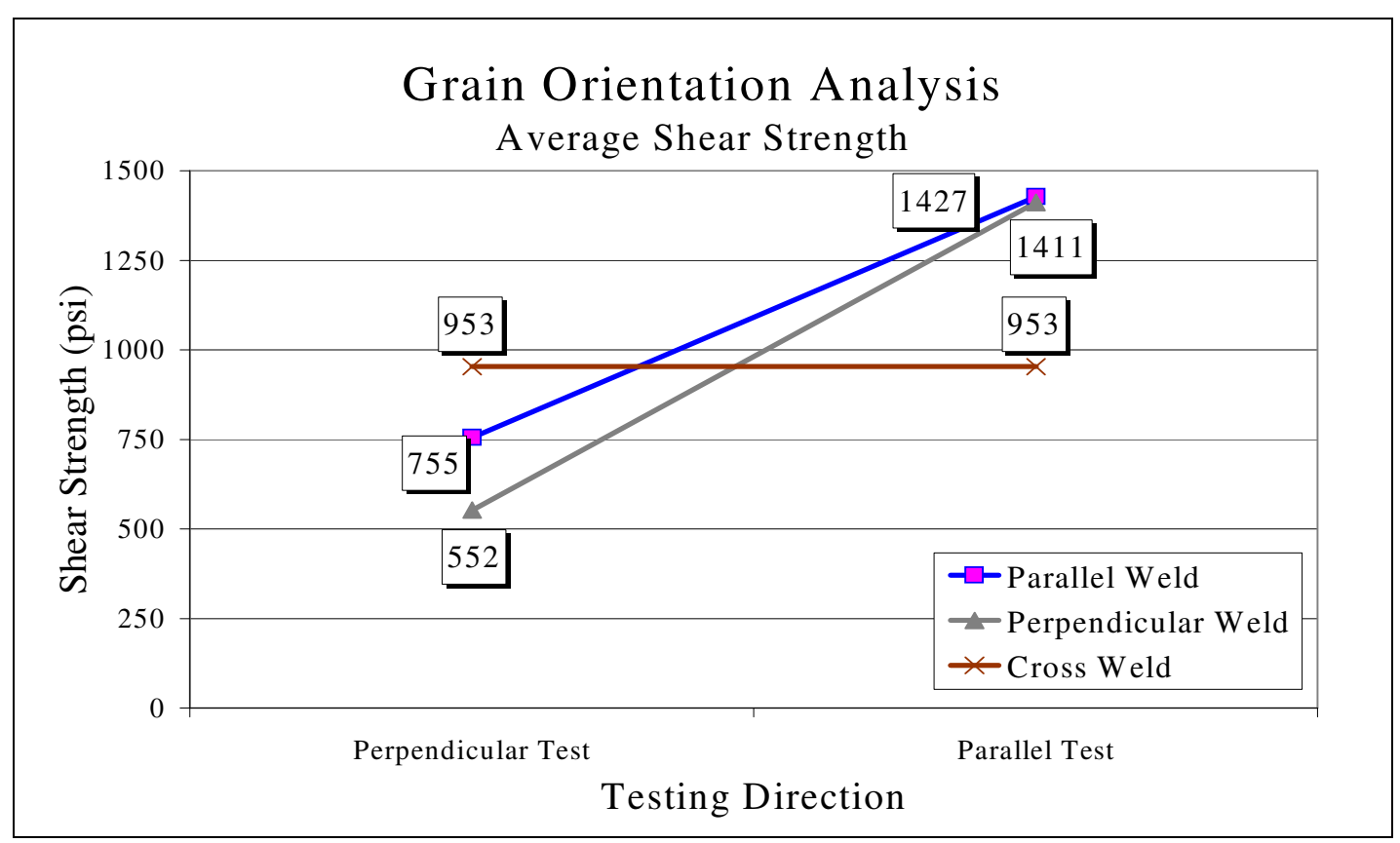

Figure 22 While different welding directions produce negligible differences in shear strength, testing orientation had a noticeable influence on shear strength (Birch, 200 psi WP).

Welding orientation and testing orientation not only affect the average shear strength, but shear variability was well (Table V). Shear variability, reported as both the standard deviation and coefficient of variation, was consistently lower when testing was performed perpendicular to grain, as opposed to parallel.

Trends in shear variability caused by welding direction were inconclusive. One welding direction did not consistently produce the lowest shear strength variability. 
Table V Grain Orientation Shear Strength Results (Birch, 200 psi WP, 6-sec WT, 92 Hz)

\begin{tabular}{|c|c|c|c|c|}
\hline & \multicolumn{2}{|c|}{ Shear Test Orientation (psi) } \\
\hline & & & Parallel & Perpendicular \\
\hline \multirow{9}{*}{ Weld Orientation } & & Mean & 1427 & 755 \\
\hline & Parallel & SD & 526 & 333 \\
\hline & & $\mathrm{CV}$ & {$[37 \%]$} & [44\%] \\
\hline & & Mean & 1411 & 552 \\
\hline & Perpendicular & SD & 818 & 203 \\
\hline & & $\mathrm{CV}$ & [58\%] & [37\%] \\
\hline & & Mean & \multirow{3}{*}{\multicolumn{2}{|c|}{$\begin{array}{c}953 \\
346 \\
{[36 \%]}\end{array}$}} \\
\hline & Cross Grain & $\mathrm{SD}$ & & \\
\hline & & $\mathrm{CV}$ & & \\
\hline
\end{tabular}

In consideration of bond uniformity, the cross-grain experiment generally produced better bonding results than those found during the welding frequency/duration experiment, Table IV. The data reported in Table VI represent a total sample size of 40: 16 specimens were welded parallel to grain, 16 were welded perpendicular to grain, and 8 were welded using the cross grain technique.

Table VI Grain Orientation Bonding Results (Birch, 200 psi WP, 6-sec WT, 92 Hz)

\begin{tabular}{|c|c|c|}
\hline \multirow{2}{*}{ Weld Orientation } & \multicolumn{2}{|c|}{ Bonding Percentage } \\
\cline { 2 - 3 } & Mean & Std. Dev. \\
\hline Parallel & $94 \%$ & $19 \%$ \\
\hline Perpendicular & $73 \%$ & $20 \%$ \\
\hline Cross Grain & $96 \%$ & $7 \%$ \\
\hline
\end{tabular}

While the cross-grain and parallel welded results have a similar bonding percentage, the cross-grain standard deviation was substantially lower than the specimens made with parallel welding. Of the three welding orientations, the data suggests that the cross-grain samples produced both the highest bond coverage and lowest variability. 


\subsection{Shear Strength Development Over Time}

While the strength development experiment had a small sample size, the data suggests that the strength of the wood welds did not significantly change within the cure periods of 60 and 6000 minutes (Table VII) (Figure 23).

Table VII Shear Strength Tested at Various Curing Times

\begin{tabular}{|r|r|r|r|r|r|}
\hline \multicolumn{3}{|c|}{ Cure Time } & \multicolumn{3}{c|}{ Shear Strength (psi) } \\
\hline Minutes & Log (Min.) & \multicolumn{1}{c|}{ Days } & Mean & Std. Dev. & \multicolumn{1}{c|}{ CV } \\
\hline 60 & 1.78 & 0.04 & 1623 & 611 & $38 \%$ \\
\hline 100 & 2.00 & 0.07 & 1102 & 523 & $47 \%$ \\
\hline 750 & 2.88 & 0.52 & 1374 & 245 & $18 \%$ \\
\hline 1200 & 3.08 & 0.83 & 1278 & 174 & $14 \%$ \\
\hline 2040 & 3.31 & 1.42 & 1120 & 868 & $78 \%$ \\
\hline 3000 & 3.48 & 2.08 & 1392 & 591 & $42 \%$ \\
\hline 4500 & 3.65 & 3.13 & 594 & 454 & $76 \%$ \\
\hline 6000 & 3.78 & 4.17 & 979 & 83 & $9 \%$ \\
\hline
\end{tabular}

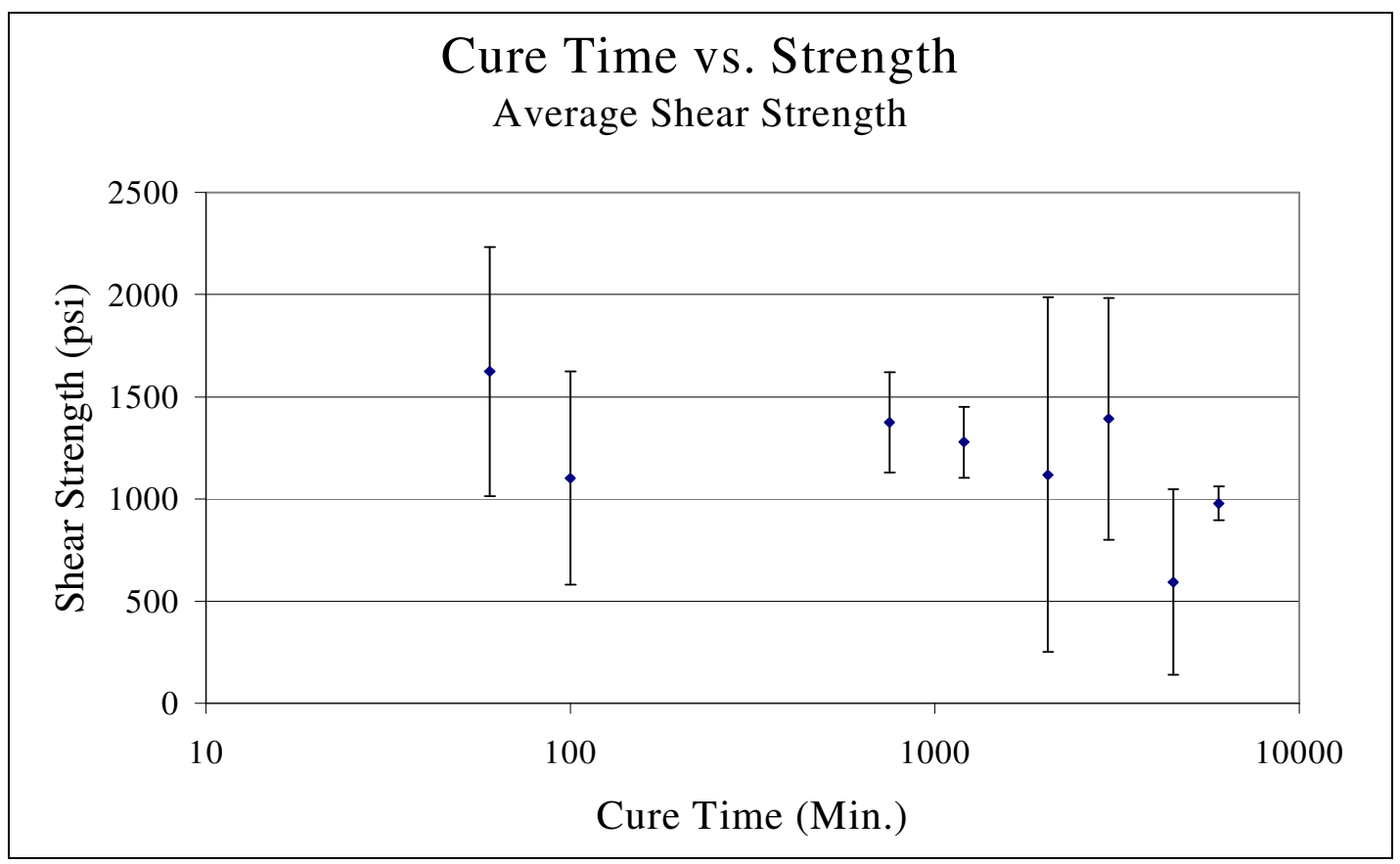

Figure 23 While the average ultimate shear strength of the bonds appeared to fluctuate over time, these were likely statistically insignificant $(\overline{\mathbf{x}} \pm 1 S D)$. 


\subsection{Alternative Welding Completion Metrics}

Three observations were recorded for two groups of experiments, the weld frequency/duration experiment and the grain orientation study. The results from using the three observations: presence of welding residue (goop), smoke creation, and the presence of an audible pitch change, were compared against the welding duration. With the collected data the potential usage of the three measurements as a measure of weld completion was addressed.

Note: If a given sample generated smoke during its processing, it was included in the "smoke" category. If it did not, that data point was intentionally omitted. Each of the three categories was considered independently. The influence of the welding metrics on mean shear strength, along with shear strength standard deviation and CV values, was reported first. The affects of welding metrics on the average bonding percentage and bonding standard deviation were addressed secondly.

\subsubsection{Shear Strength}

With regards to shear strength, the weld frequency/duration suite of experiments was compared across the different welding frequencies for a single welding time, 8 seconds (Figure 24, Table VIII). The data exclusion process used to generate the statistics for the welding metrics often excluded entire sub-sets of data or removed enough data points so a standard deviation could not be obtained. The 8 second category was the only welding duration time period that did not exclude any of the frequencies. Based on the data, the alternative welding criteria yielded comparable accuracy, mean, and only slightly better precision, standard variation, when compared to the standard welding-time. Only the results from $123 \mathrm{~Hz}$ showed a markedly lower CV. Lastly, it 
should be noted that the published average $\mathrm{CV}$ for the parallel grain shear testing of wood (bulk material) is $14 \%$ as reported by the U.S. Dept. of Agriculture, Forest Service [46].

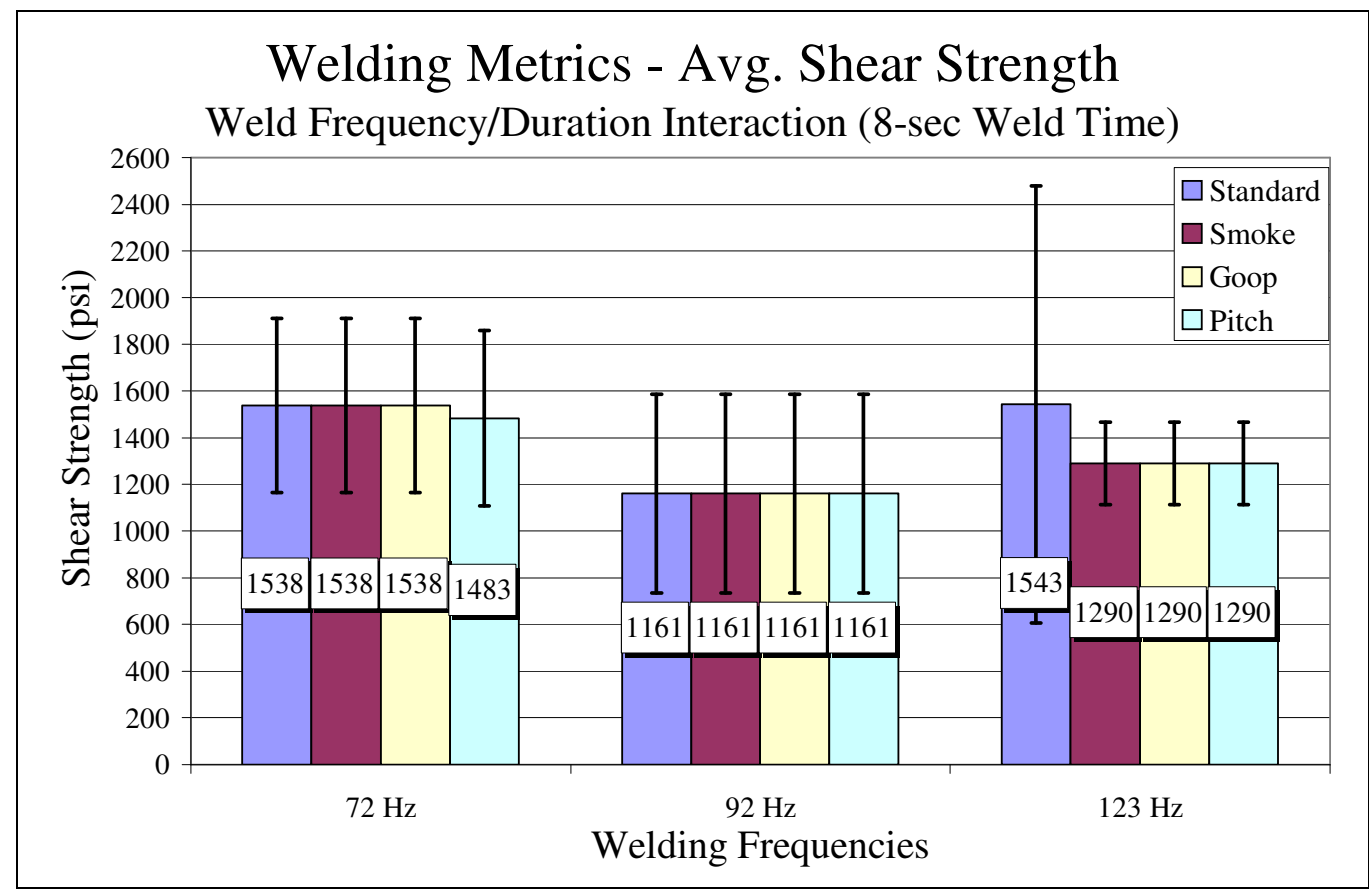

Figure 24 When the fusion criteria (smoke generation, welding goop formation, and audible pitch change) were used to filter the sample data, little change in the average shear strength was observed $(\overline{\mathrm{x}} \pm 1 S D)$.

Table VIII Frequency/Duration Interaction - Welding Metrics: Shear Results (Birch, 200 psi WP, 8sec WT)

\begin{tabular}{|c|c|r|r|r|r|}
\hline $\begin{array}{c}\text { Frequency } \\
(\mathrm{Hz})\end{array}$ & Statistics & Standard & Smoke & Goop & \multicolumn{1}{c|}{$\begin{array}{c}\text { Pitch } \\
\text { Change }\end{array}$} \\
\hline \multirow{3}{*}{72} & Mean & 1538 & 1538 & 1538 & 1483 \\
& SD & 373 & 373 & 373 & 376 \\
& CV & $24 \%$ & $24 \%$ & $24 \%$ & $25 \%$ \\
\hline \multirow{3}{*}{92} & Mean & 1161 & 1161 & 1161 & 1161 \\
& SD & 425 & 425 & 425 & 425 \\
& CV & $37 \%$ & $37 \%$ & $37 \%$ & $37 \%$ \\
\hline \multirow{3}{*}{123} & Mean & 1543 & 1290 & 1290 & 1290 \\
& SD & 936 & 177 & 177 & 177 \\
& CV & $61 \%$ & $14 \%$ & $14 \%$ & $14 \%$ \\
\hline
\end{tabular}

Note: Mean and SD Units - psi

When the data exclusion procedure was applied to the grain orientation analysis, the mean shear strength did not change significantly, but the standard deviation did 
(Table IX, Figure 25). Without considering the welding observations, the analysis mentioned in section 6.2 showed that testing orientation had a far greater impact on the average shear strength than did welding orientation. After the cross-grain data was manipulated using the welding criterion it became apparent that both welding and testing direction marginally influenced the shear strength's standard deviation. The results from the welding observations, regarding the grain orientation experiment, showed that the welding completion measures yielded similar average shear strengths, and comparable or slightly better standard deviations when compared to the welding-time constraint.

Table IX Grain Orientation - Welding Metrics: Shear Results (Birch, 200 psi WP, 6-sec WT, 92 Hz)

\begin{tabular}{|c|c|c|c|c|c|c|}
\hline Weld Direction & $\begin{array}{c}\text { Shear } \\
\text { Direction }\end{array}$ & Statistics & Standard & Smoke & Goop & $\begin{array}{c}\text { Pitch } \\
\text { Change }\end{array}$ \\
\hline \multirow{3}{*}{ Parallel } & \multirow{3}{*}{ Perpendicular } & Mean & 755 & 764 & 755 & 754 \\
\hline & & SD & 333 & 358 & 333 & 391 \\
\hline & & $\mathrm{CV}$ & [44\%] & {$[47 \%]$} & [44\%] & [52\%] \\
\hline \multirow{3}{*}{ Parallel } & \multirow{3}{*}{ Parallel } & Mean & 1427 & 1264 & 1264 & 1264 \\
\hline & & $\mathrm{SD}$ & 526 & 272 & 272 & 272 \\
\hline & & $\mathrm{CV}$ & [37\%] & {$[22 \%]$} & [22\%] & [22\%] \\
\hline \multirow{3}{*}{ Perpendicular } & \multirow{3}{*}{ Parallel } & Mean & 1411 & 1622 & 1684 & 1639 \\
\hline & & SD & 818 & 655 & 713 & 815 \\
\hline & & $\mathrm{CV}$ & [58\%] & [40\%] & [42\%] & {$[50 \%]$} \\
\hline \multirow{3}{*}{ Perpendicular } & \multirow{3}{*}{ Perpendicular } & Mean & 552 & 662 & 605 & 585 \\
\hline & & SD & 203 & 144 & 75 & 78 \\
\hline & & $\mathrm{CV}$ & [37\%] & {$[22 \%]$} & {$[12 \%]$} & {$[13 \%]$} \\
\hline \multirow{3}{*}{ Cross } & \multirow{3}{*}{ Cross } & Mean & 953 & 934 & 934 & 945 \\
\hline & & $\mathrm{SD}$ & 346 & 368 & 368 & 402 \\
\hline & & $\mathrm{CV}$ & {$[36 \%]$} & {$[39 \%]$} & {$[39 \%]$} & [43\%] \\
\hline
\end{tabular}

Note: Mean and SD Units - psi 


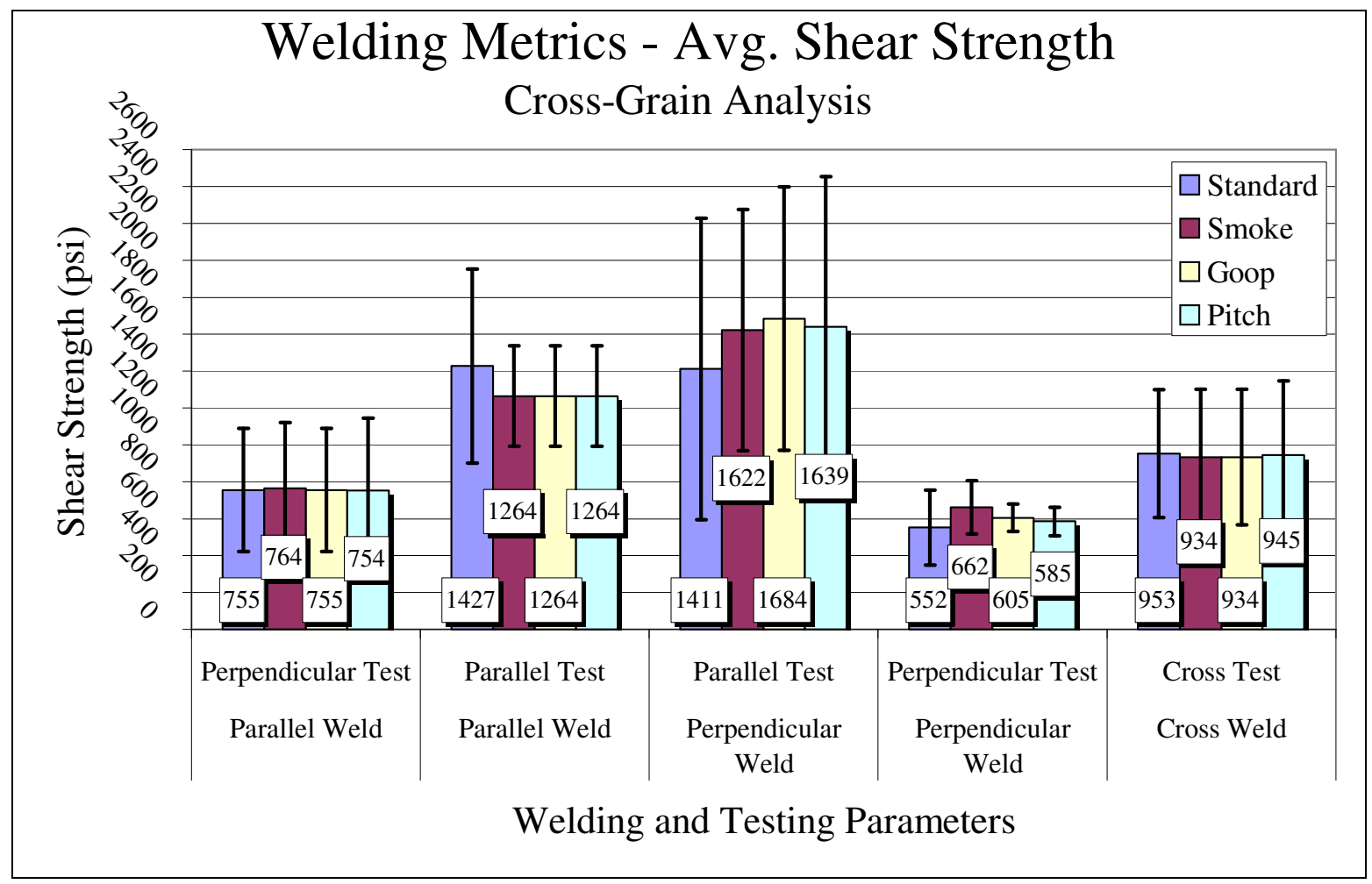

Figure 25 As was seen in Figure 24, when samples were discarded using the fusion criteria for the grain orientation analysis little change in the average shear strength was observed $(\overline{\mathbf{x}} \pm 1 S D)$.

\subsubsection{Bond Uniformity}

Until now the use of the proposed welding completion metrics have only been applied to potentially improving shear strength. For the frequency/duration trial, when the various frequencies were compared for the 8 second WT in regard to bond uniformity, the data showed that the different metrics were both as accurate and precise as the stand alone welding time for the 72 and $92 \mathrm{~Hz}$ frequencies (Table X, Figure 26). With the $123 \mathrm{~Hz}$ frequency, the metrics yielded significantly lower variation. 
Table X Frequency/Duration Interaction - Welding Metrics: Bond Coverage (Birch, 200 psi WP, 8-sec WT)

\begin{tabular}{|l|r|r|r|r|r|r|r|r|}
\hline \multirow{2}{*}{ Series } & \multicolumn{2}{|c|}{ Standard } & \multicolumn{2}{c|}{ Smoke } & \multicolumn{2}{c|}{ Goop } & \multicolumn{2}{c|}{ Pitch Change } \\
\cline { 2 - 9 } & Mean & \multicolumn{1}{|c|}{ S.D. } & \multicolumn{1}{c|}{ Mean } & \multicolumn{1}{c|}{ S.D. } & Mean & \multicolumn{1}{c|}{ S.D. } & Mean & \multicolumn{1}{c|}{ S.D. } \\
\hline $72 \mathrm{~Hz}$ & $70 \%$ & $12 \%$ & $70 \%$ & $12 \%$ & $70 \%$ & $12 \%$ & $70 \%$ & $13 \%$ \\
\hline $92 \mathrm{~Hz}$ & $95 \%$ & $7 \%$ & $95 \%$ & $7 \%$ & $95 \%$ & $7 \%$ & $95 \%$ & $7 \%$ \\
\hline $123 \mathrm{~Hz}$ & $67 \%$ & $36 \%$ & $89 \%$ & $14 \%$ & $89 \%$ & $14 \%$ & $89 \%$ & $14 \%$ \\
\hline
\end{tabular}

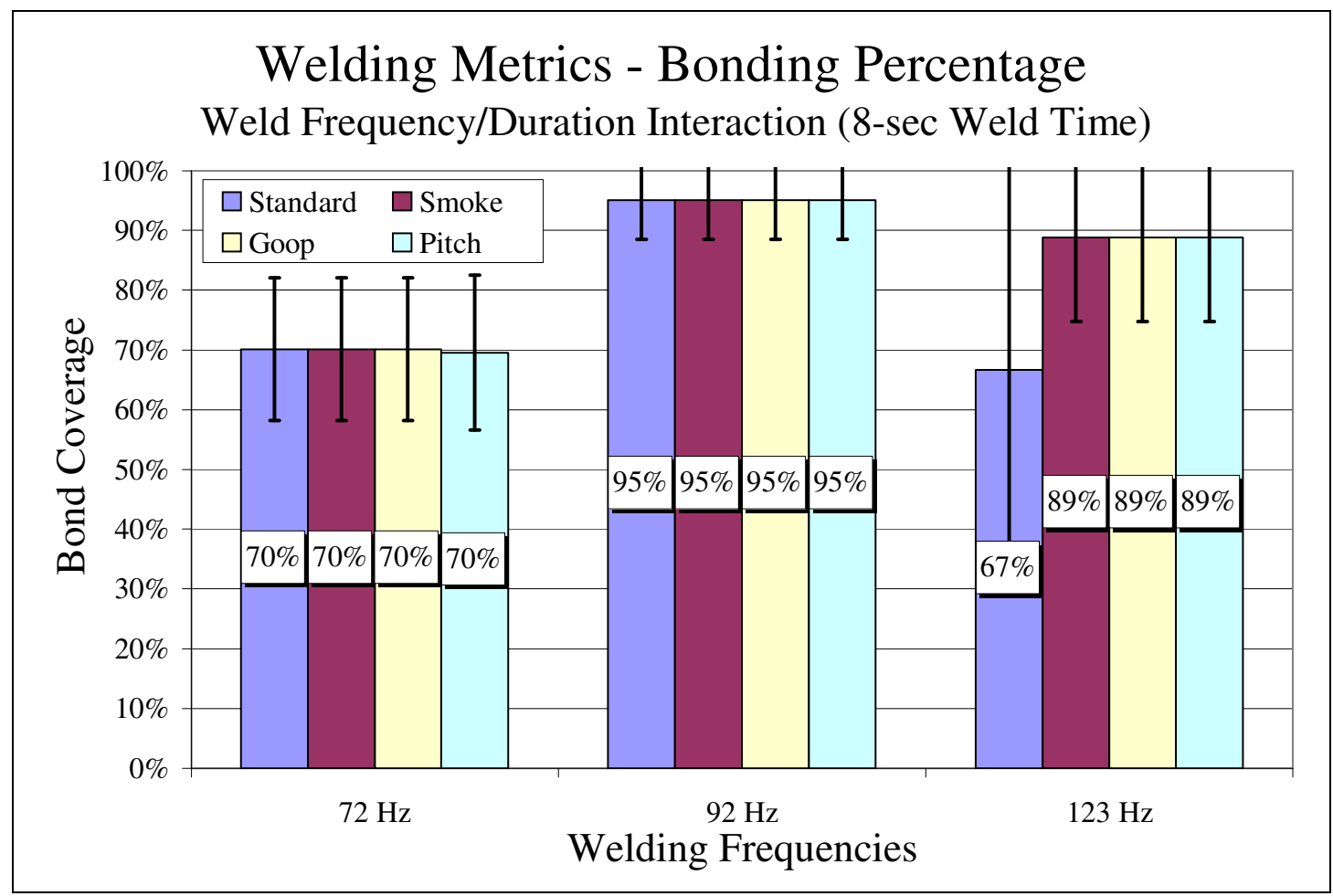

Figure 26 Given an equal welding time of 8 seconds, the lower and higher welding frequencies yielded a less bonded interface, regardless of completion metric $(\overline{\mathbf{x}} \pm 1 S D)$.

While the different metrics were only slightly better at indicating bond

completion than the standard welding time measurement for the frequency/duration trial, the differences were more significant in the grain orientation experiment. In every case, data correlated to smoke creation, goop formation, or audible pitch changes had higher average bonding percentages (Table VI, Figure 27). Not only does this data indicate that the metrics can produce better bonding results than the welding time method, they also 
seem to have a higher degree of precision. Each of the three methods functioned comparatively well in the parallel and cross welding trials, but pitch change produced a higher accuracy, mean value, in the perpendicular welded category.

Table XI Cross-Grain Welding Metrics - Bond Coverage (Birch, 200 psi WP, 6-sec WT, 92 Hz)

\begin{tabular}{|c|r|r|r|r|r|r|r|r|}
\hline \multirow{2}{*}{$\begin{array}{c}\text { Weld } \\
\text { Orientation }\end{array}$} & \multicolumn{2}{|c|}{ Standard } & \multicolumn{2}{c|}{ Smoke } & \multicolumn{2}{c|}{ Goop } & \multicolumn{2}{c|}{ Pitch Change } \\
\cline { 2 - 9 } & Mean & S.D. & Mean & S.D. & Mean & S.D. & Mean & S.D. \\
\hline Parallel & $94 \%$ & $18 \%$ & $99 \%$ & $3 \%$ & $99 \%$ & $3 \%$ & $99 \%$ & $3 \%$ \\
\hline Perpendicular & $73 \%$ & $20 \%$ & $80 \%$ & $19 \%$ & $82 \%$ & $20 \%$ & $92 \%$ & $8 \%$ \\
\hline Cross & $96 \%$ & $7 \%$ & $99 \%$ & $2 \%$ & $99 \%$ & $2 \%$ & $98 \%$ & $2 \%$ \\
\hline
\end{tabular}

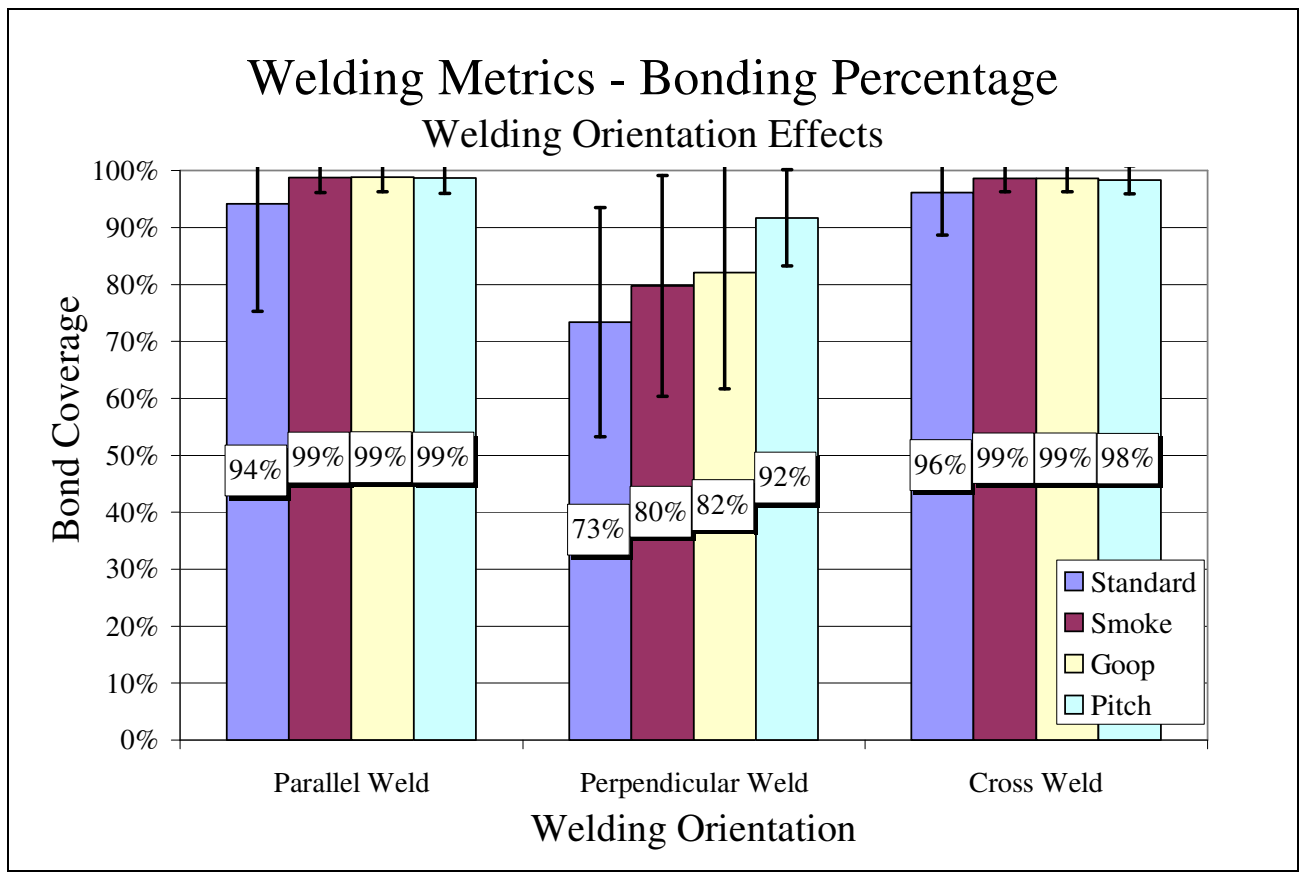

Figure 27 The comparisons of the welding metrics have been illustrated. While the amount of improvement varied, average bond values increased and variability decreased with the use of the metrics. 


\section{Chapter 7: Discussion}

\subsection{SEM Weldment Images}

Scanning electron microscopy has been performed in previous research pertaining to wood welding, but only higher magnification images were published. Often times those high power images show individual wood fibers, but fail to put those micrographs in a greater context. For the SEM analysis, both parallel and perpendicular welded samples were examined. To help illustrate where higher magnification images were taken, image maps were made to show the progression from lower magnifications to higher ones (Figure 28, Figure 31, Figure 33, Figure 36 ).

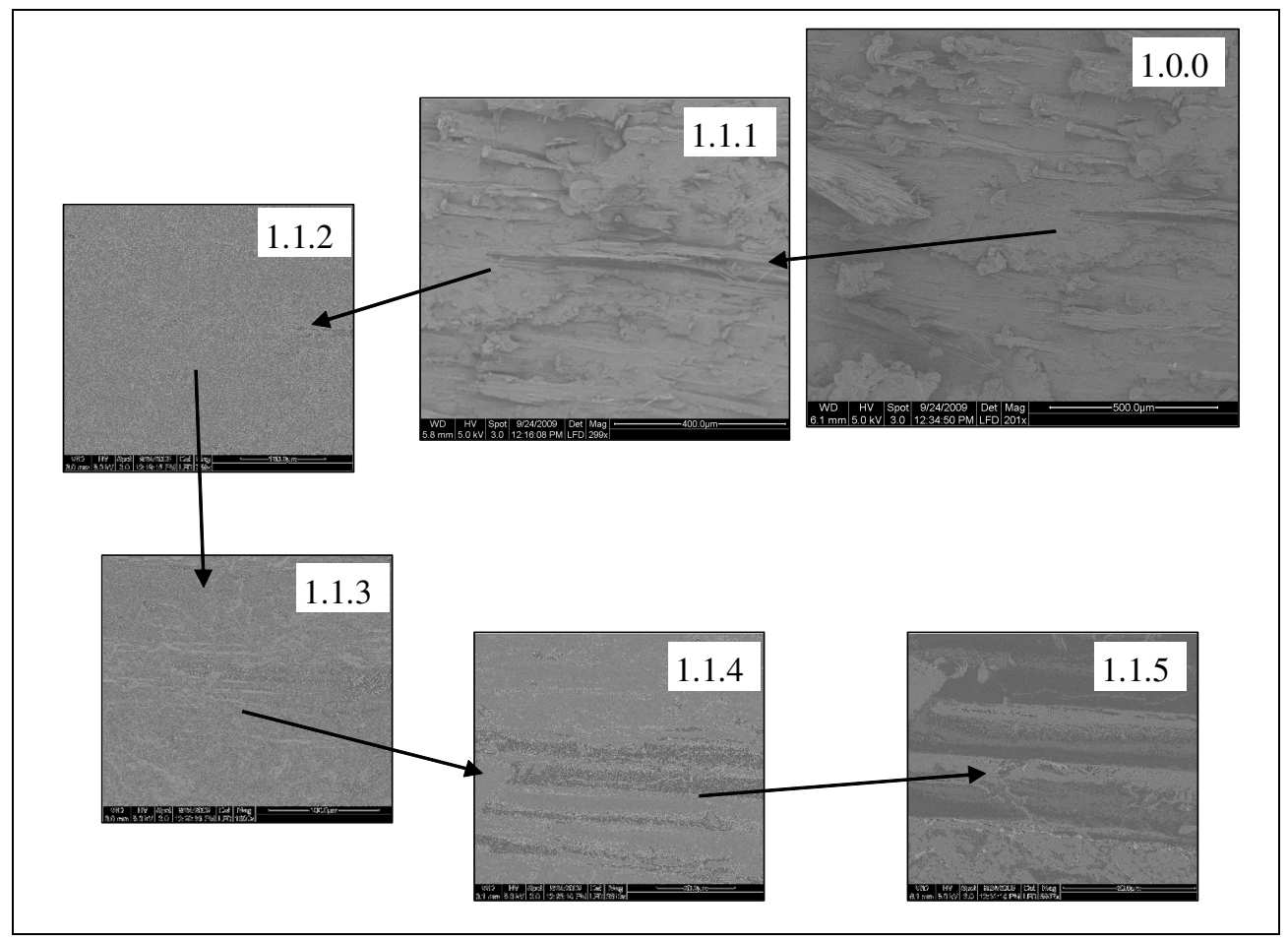

Figure 28 SEM image map of wood fiber pull-out (parallel welding).

The first welding orientation examined was the parallel welded sample, and it exhibited two interesting and distinctive features: an area of fiber removal and a region of 
fiber deposition (Figure 29). Since wood welding produces a bonded interface, when the samples are sheared apart it stands to reason that regions of one wood block would break away from their base material. This phenomenon would be analogous to a failure in the heat affected zone in metallurgical welds. Images 1.1.1-1.1.5 in Figure 30 show the boundary where it seems that a bundle of fibers were removed.

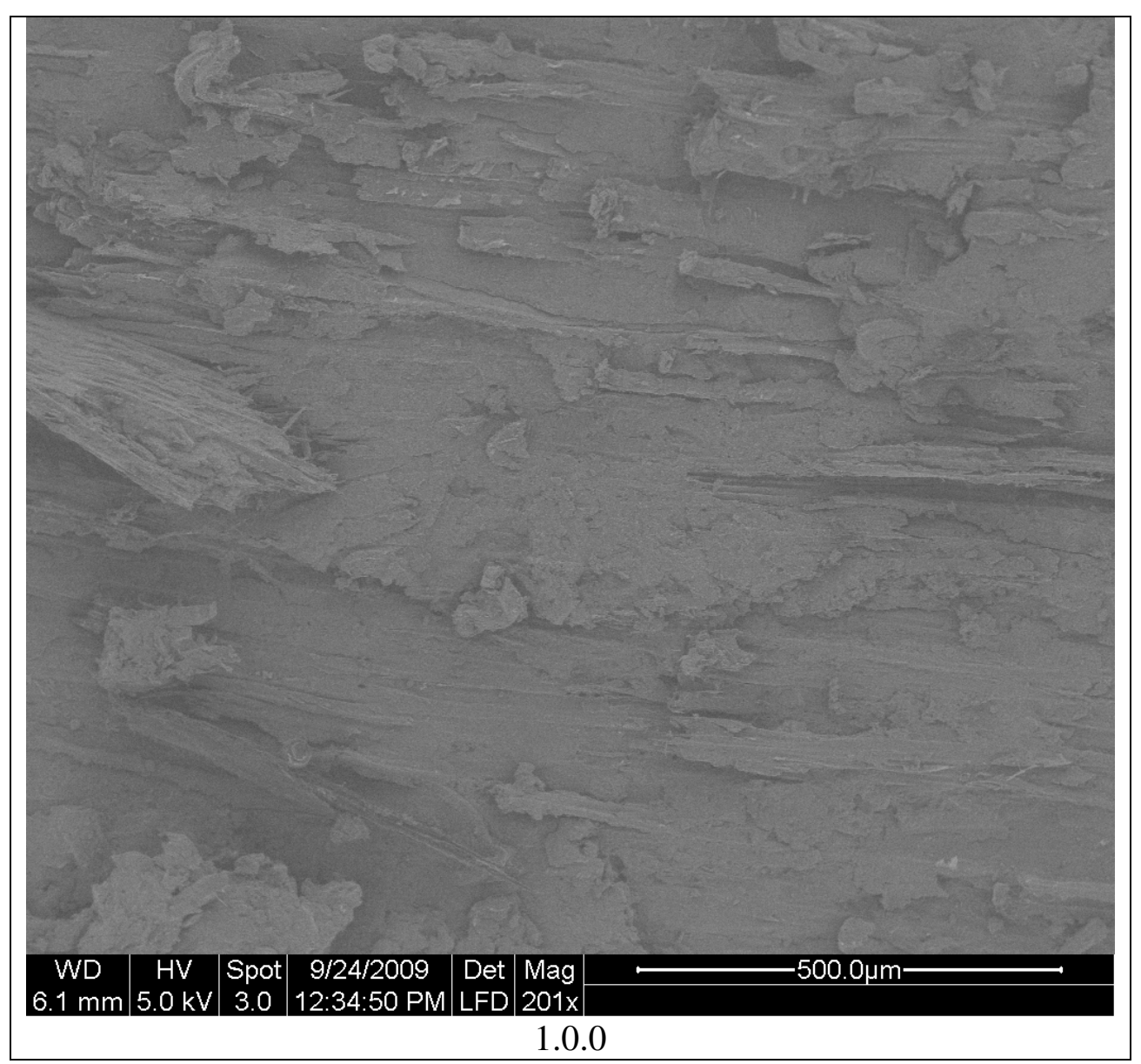

Figure 29 This SEM image shows examples of both wood removal and deposition (Grain Orientation trial : 92Hz, 200 psi WP, 6-sec WT, parallel welding). (201x) 


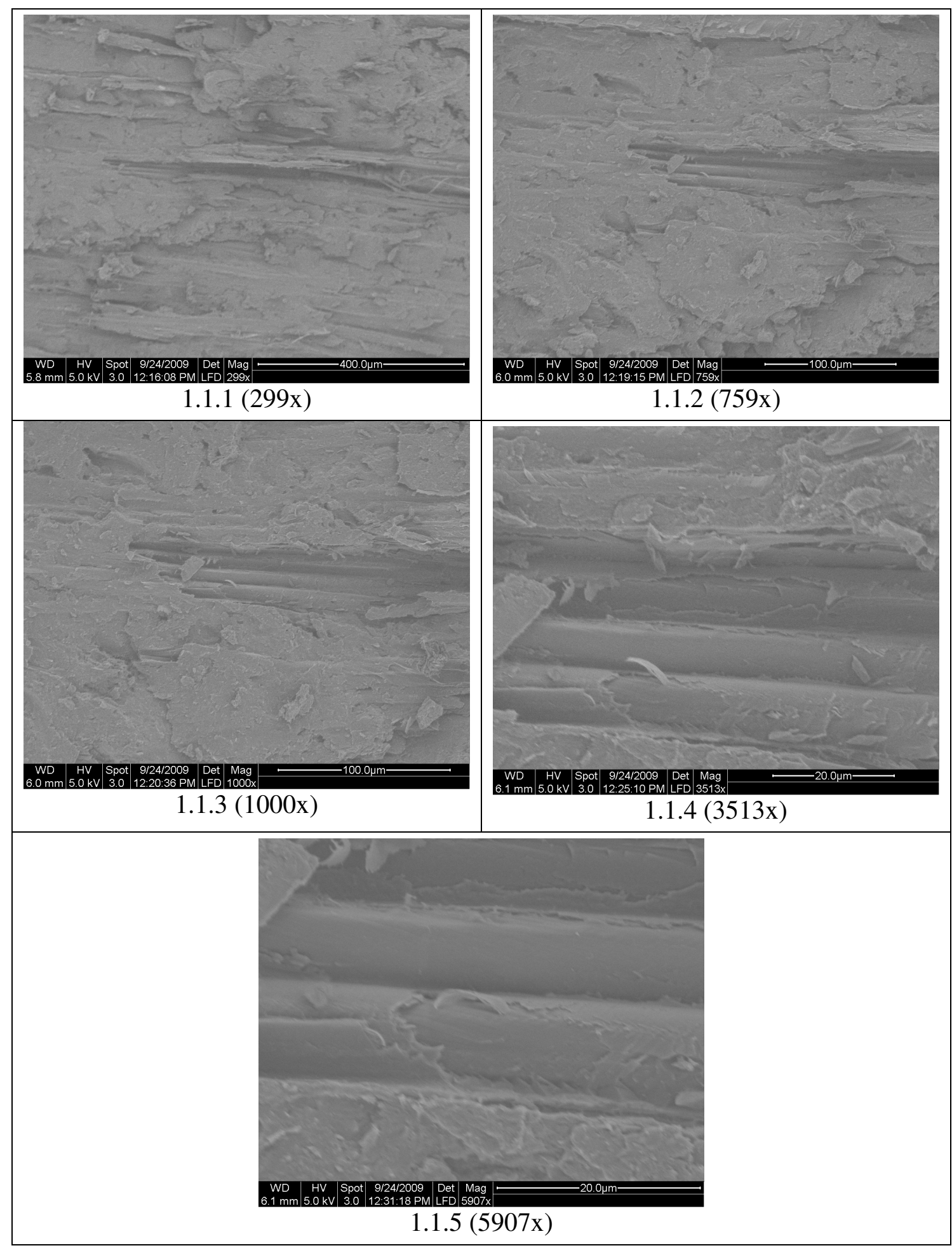

Figure 30 SEM image progression showing fiber pull-out (parallel welding).

It should be noted that while relatively mild settings were used to obtain these images, due to the organic nature of the samples and the SEM itself the imaging process 
did affect the sample. Images 1.1.4 and 1.1.5 of Figure 30 show a small cowlick like projection that changed appearance at higher magnification. When the SEM was focused on that small region, it appears that a localized charge buildup occurred and caused the projection to curl over onto itself.

The same parent image (Figure 29) also showed a region of fiber deposition. Based on the appearance of the surrounding area, the large chunk of material likely originated from the other half of the wood welded sample (Figure 32, images 1.2.1 and 1.2.2). Further magnification revealed the fact that the structure was composed of many smaller fibers and an amorphous substance found on top of some of the fibers (Figure 32, images 1.2.3 and 1.2.4). This material could be the actual welded polymer-like material thought to make wood welding possible. However, further analysis is required to confirm this suspicion.

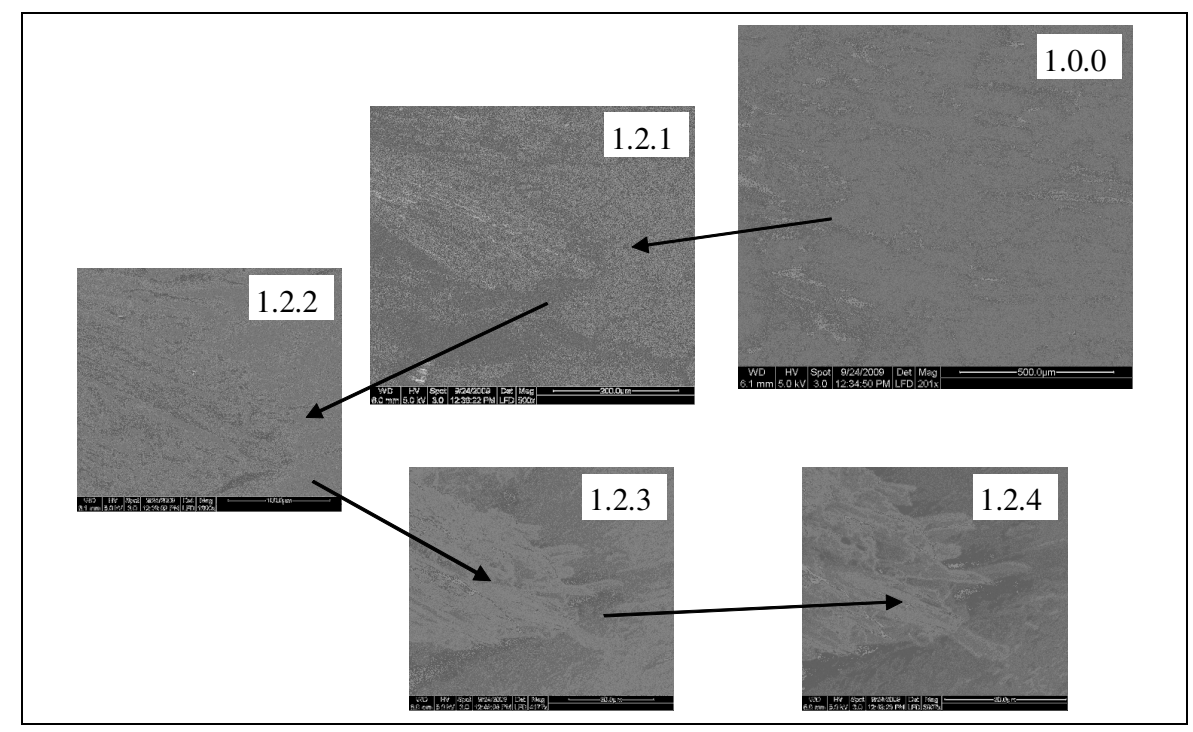

Figure 31 SEM image map illustrating wood deposition (parallel welding). 


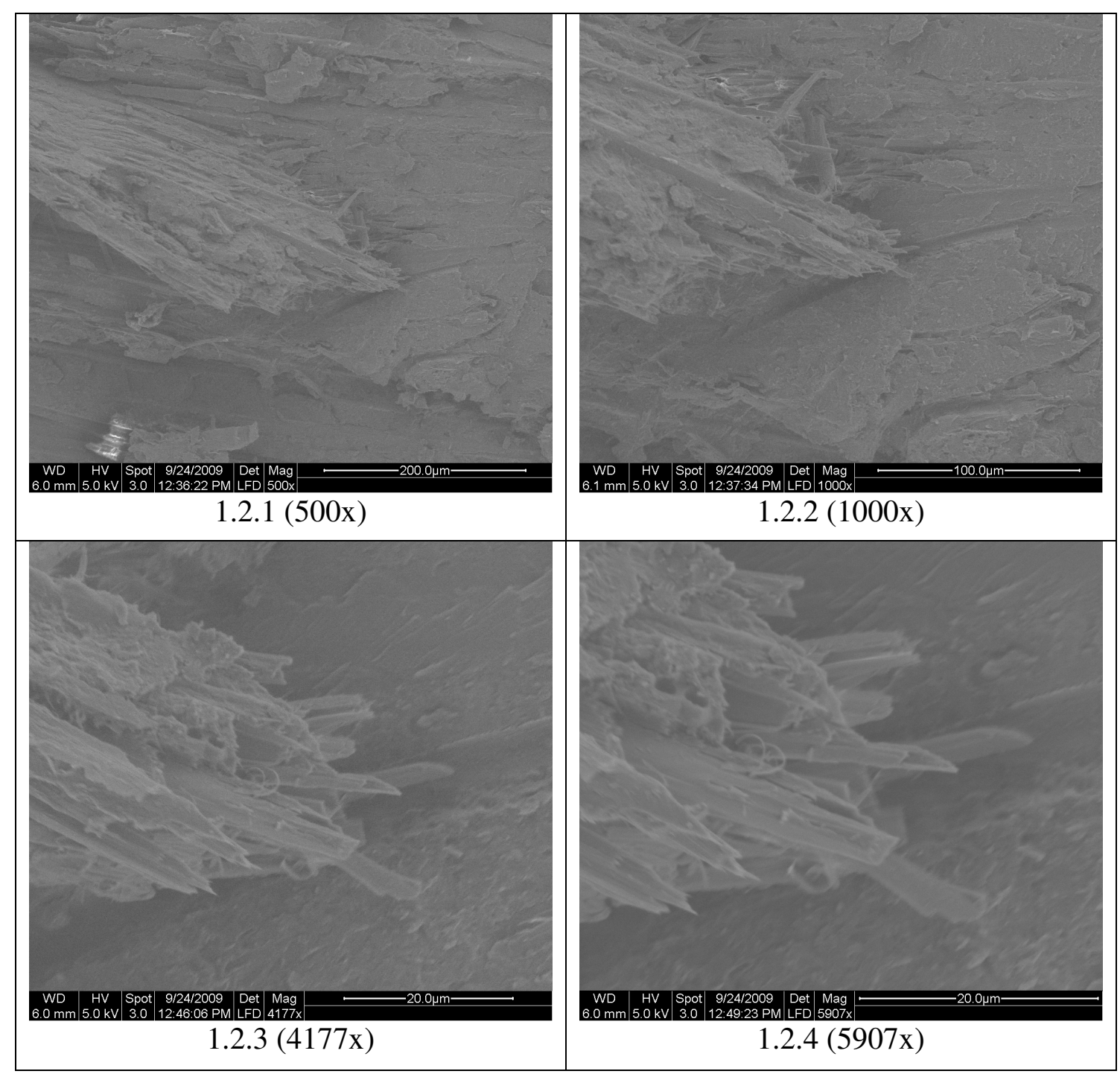

Figure 32 SEM image progression showing fiber deposition (parallel welding).

The parent image from the perpendicular welding orientation showed examples of fiber exposure and a potential fiber-mesh fracture (Figure 34). While the grain orientation in the images in Figure 34 \& Figure 35 are vertical, welding occurred in the horizontal direction. Images 2.1.1 and 2.1.2 (Figure 35) showed that the small fiber elements, those composing the larger one, were reoriented during the welding process from vertical to horizontal. Images 2.1.3 and 2.1.4 of Figure 35 illustrated that the larger fiber element appeared to have several smaller fibers missing, most likely fractured off or peeled away. 


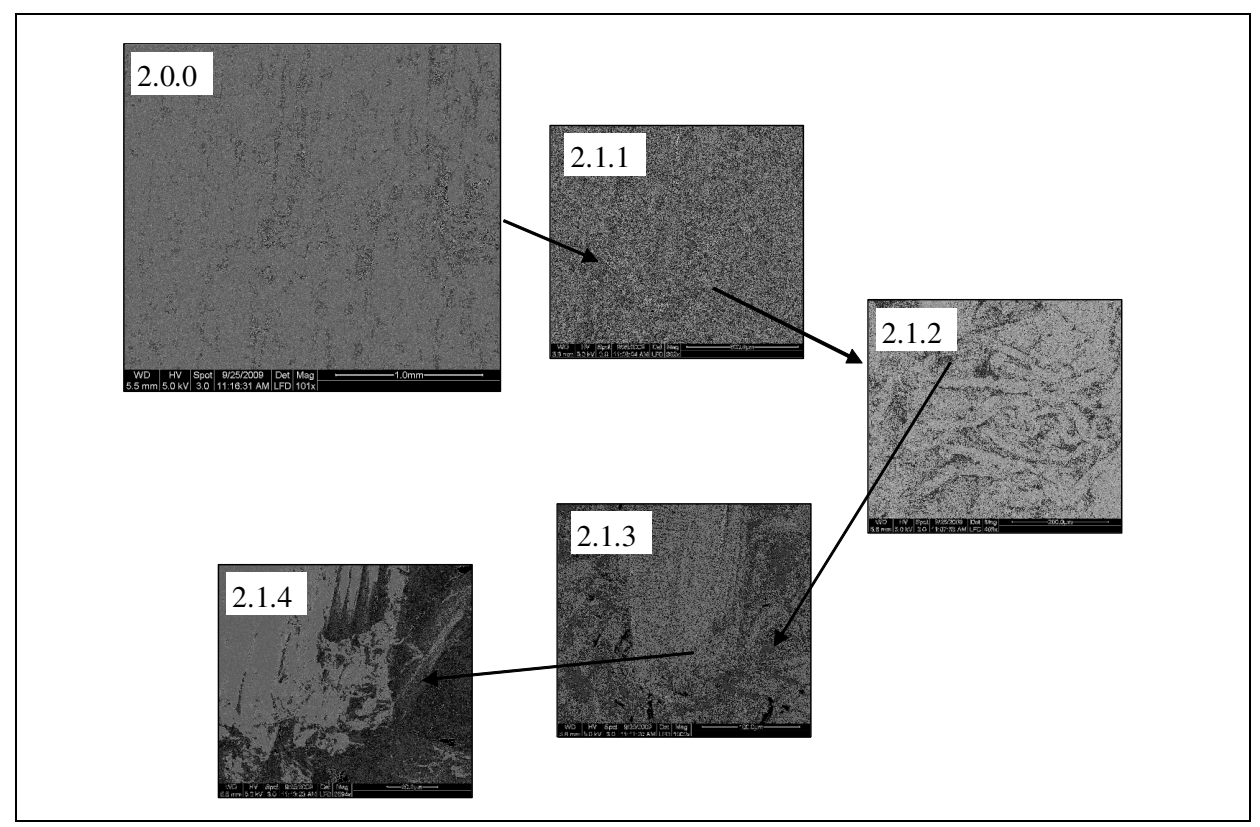

Figure 33 SEM image map highlighting exposed fibers (perpendicular welding).

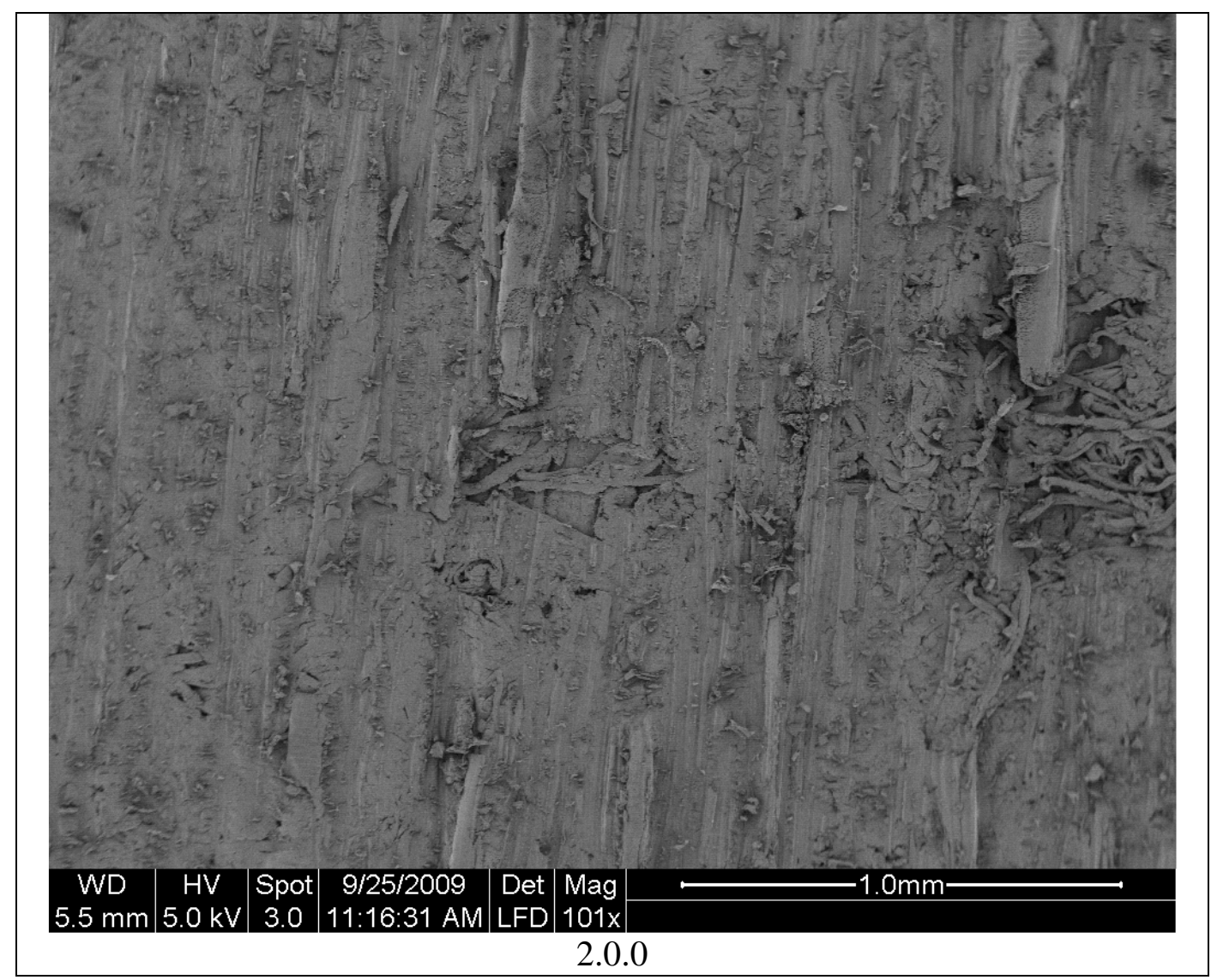

Figure 34 This SEM image shows both fiber entanglement and reorientation. (Grain Orientation trial : 92Hz, 200 psi WP, 6-sec WT, perpendicular welding). (101x) 


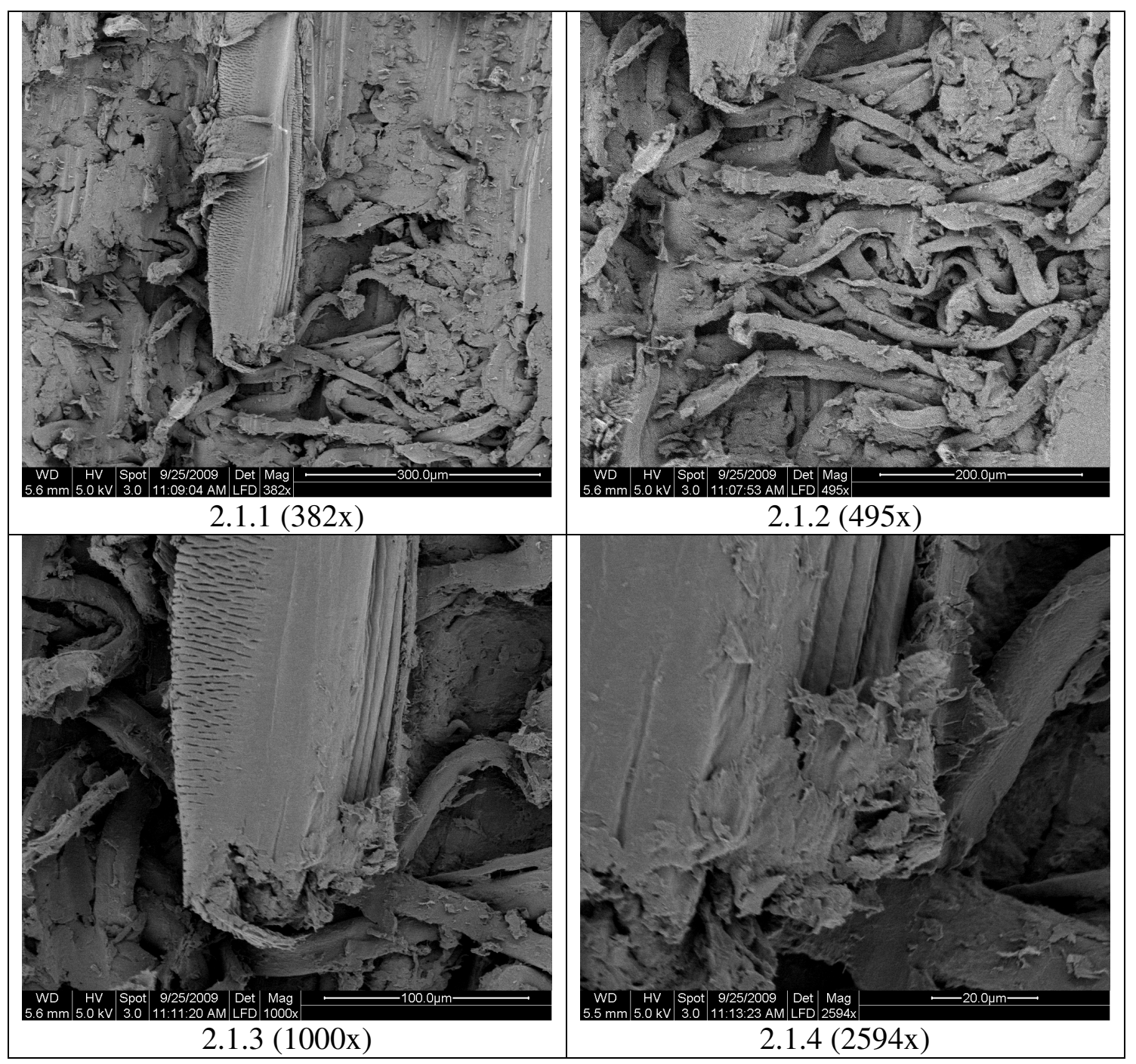

Figure 35 SEM image progression showing fiber reorientation and bundling (perpendicular welding).

The last feature found in the perpendicular welded sample, parent image shown in Figure 34, displayed a unique structure. While attempting to image a thin wood filament, a fiber-mesh material was found (Figure 37). Significantly larger fibers have been observed in other images, but this image potentially showed a fibrous fracture (Figure 37 image 2.2.5). Whether or not this fiber-mesh material played a structural role in the actual wood weld was debatable given its small size in relation to the larger fibers. Additionally, the structure could be a byproduct of the welding orientation. Given the small size, further examination is required before any definitive conclusions can be made. 


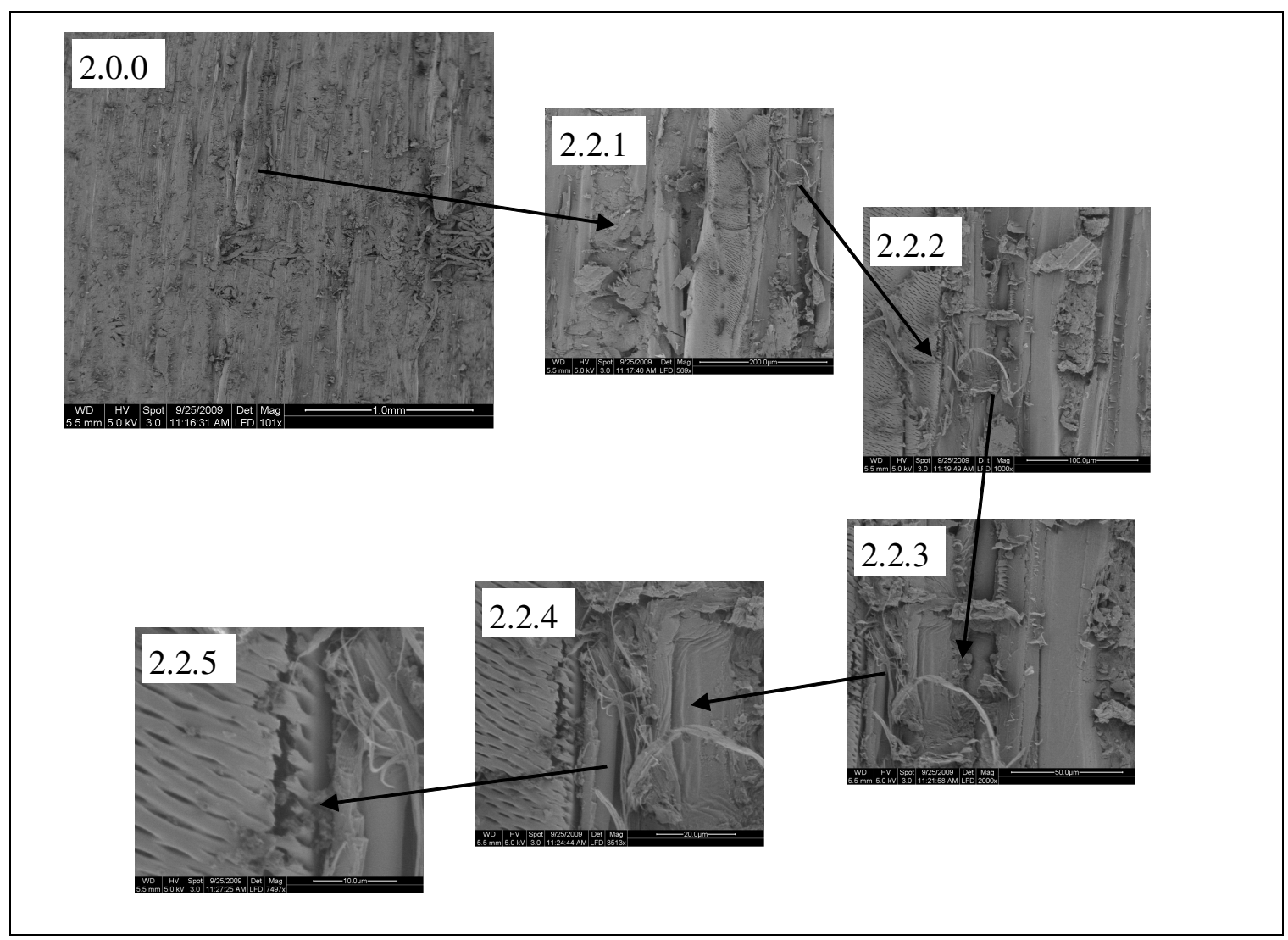

Figure 36 SEM image map detailing exposed fibers (perpendicular welding).

Each of the different SEM image analyses produced several interesting facts but were generated from just two samples. The primary reason for the small SEM sample size was sample preparation. In order for these organic specimens to create a quality image in the SEM, specimens first needed to be sputter coated with a thin gold film. Future specimens could be cut down to smaller sizes, but regardless of the method, the fractured bond surface must be preserved and kept as clean as possible. Simply sawing the samples with a band saw would be acceptable provided that saw dust not contaminate the bond surface. 


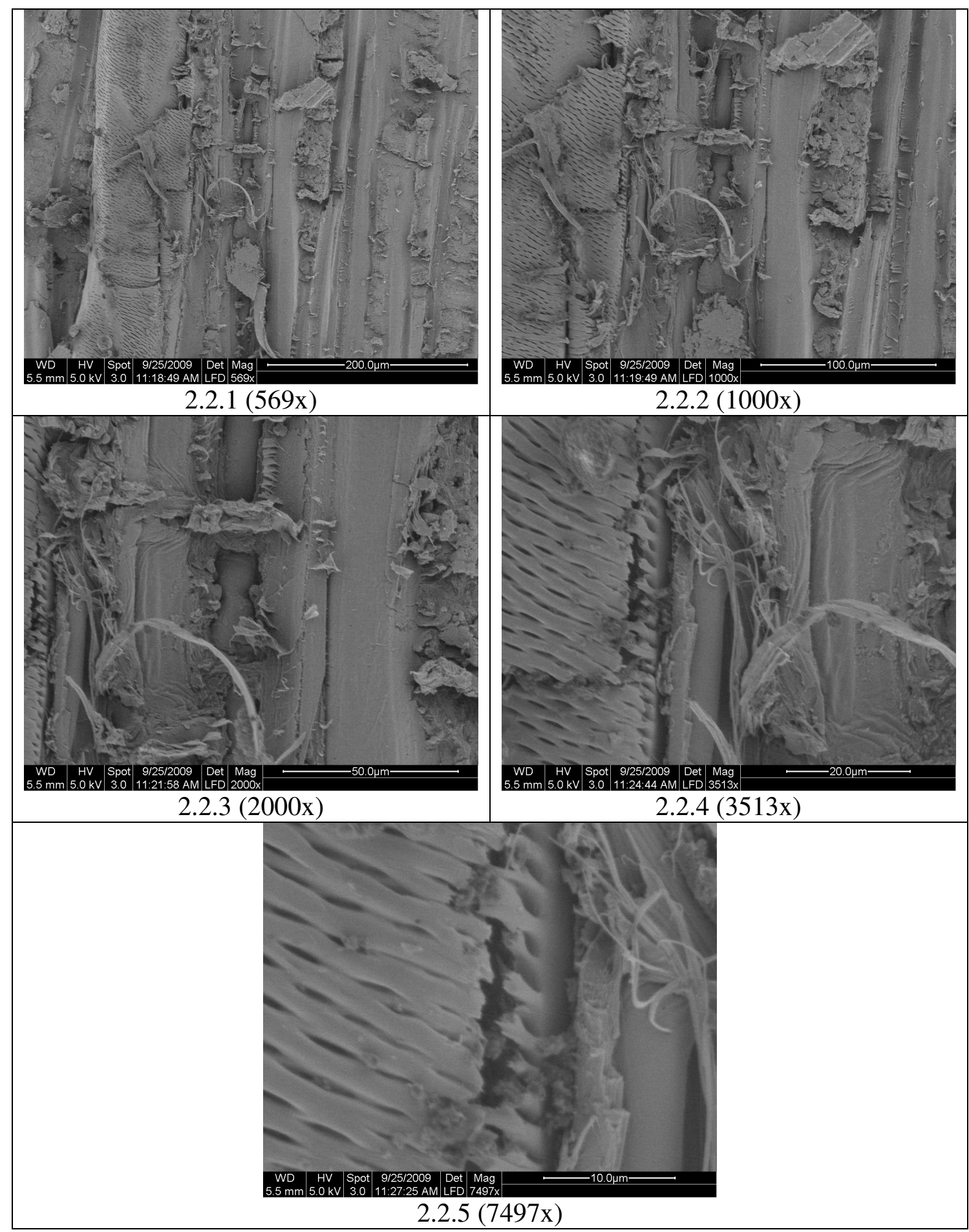

Figure 37 SEM image progression showing the fiber-mesh fracture (perpendicular welding). 


\subsection{Welding Frequency and Duration Interaction}

The best possible wood weld is achieved with both high strength and high bond coverage. However, high values for these traits are not enough; the processing should be repeatable and thusly require as low of a variation as possible. Neglecting other influences, two independent processing variables, welding frequency and duration, must be controlled in order to influence the four dependant bonding characteristics: average shear strength and variability as well as bonding percentage and variability. With the data collected from the birch samples, several conclusions can be made with regards to which processing settings produce the best bonded joint.

Based on the data, there does seem to be an optimal paring between welding frequency and duration. While both the 72 and $92 \mathrm{~Hz}$ trials produced their best results at 8 seconds, the $92 \mathrm{~Hz}$ trials produced much better bond coverage results, $95 \%$ versus the $70 \%$ found with the $72 \mathrm{~Hz}$. That suggests that a welding time longer than 8 seconds would be required at the $72 \mathrm{~Hz}$ frequency to achieve a higher degree of bonding.

Based on the trends in the data, it seemed that wood welds produced with a $72 \mathrm{~Hz}$ welding frequency with an excess of 8 seconds of welding time would produce the ideal bond in regards to strength, bond completion, and consistency. From the data, as welding time increased for the $72 \mathrm{~Hz}$ trial, average shear strength increased and variability decreased. A similar trend occurred with bond uniformity; longer weld times led to higher and more consistent bonds. While these trends may not hold for all species of wood, for birch it appears that lower welding frequencies and longer welding times produce the highest quality welded joint. 


\subsection{Grain Orientation}

By combining all the results from the grain orientation study it was shown that welding and test orientation influence the same four bond parameters mentioned earlier: average shear strength, shear variability, bond converge, and bond variability. It was not surprising to see that shear strength was heavily dependent upon testing orientation; this was to be expected given the nature of timber. As with the main variables, there appears to be both a welding and testing direction that yields the best bond with respect to shear strength and variability.

Parallel welded samples tested parallel to the grain seem to produce the best overall results. These parallel welded-parallel tested specimens were on average, strong and generally well bonded. The cross-grain trials yielded a higher and more uniform bond, but at a lower shear strength.

\subsection{Shear Strength Development Over Time}

The overlap of data from the variable cure times suggests that previous researchers' assumptions were correct, wood welds achieve the majority of their strength rather quickly after welding process has stopped [25]. Given this fact, future wood welding research could be conducted using curing times shorter than the seven days commonly presented in the literature without any appreciable differences in shear strength.

\subsection{Alternative Welding Completion Metrics}

While both the welding frequency/duration and grain orientation experiments focused on shear strength and processing interactions, they also provided data used in an 
effort to clarify a confusing matter in the literature regarding welding duration. The concern was whether or not welding duration was an appropriate and reliable indicator of quality (shear strength) and welding completion (bonding percentage).

While the metrics did generate higher strengths and lower standard deviations in certain cases, all three metrics generally yielded data comparable with the welding time criteria. This finding suggests that the alternative welding metrics were essentially equivalent indicators of strength, comparable to the welding time results.

Of the three methods investigated: smoke generation, goop formation, and audible pitch change, each seemed to generally produce as good, if not better results than the simple weld time procedure in regards to bond completion. As mentioned in section 6.4.1, the welding metric analysis for the frequency/duration experiment could only be performed for the 8-second weld time group and suggests that conditions necessary to generate the three observations were not significantly present at lower frequencies or durations. From Table IV and Figure 21 it can be shown that for the $72 \& 92 \mathrm{~Hz}$ welding frequencies, bond coverage was noticeably lower for welding times of 4 and 6 seconds. These were important observations that illustrate the fact that while some wood samples can be welded to a complete degree (high bonding percentage) in a given welding time period, many did not completely bond. If welding time were a reliable indicator of bonding percentage, the average values regardless of welding time should be similar. The data does not support that theory. While higher bonding percentages were achieved with a weld time of 8 seconds for each frequency, the 4 and 6 second results were typically lower than the 8 second results. This information indicates that welding time is a poor indicator of welding completion (bond percentage). 
In certain samples, a complete and quality bond had formed in the allotted welding time. Conversely, in many instances the bond that formed yielded inferior results; nevertheless, the same welding time and conditions had previously produced a desirable resulted. This mixture of both well bonded and incompletely bonded samples indicate that welding time is not the best indicator of welding completion. Each of the investigated welding metrics could account for wood variability, if the source of the bonding discrepancies. These metrics could accomplish this task, by not relying on a given welding time, but instead measuring the progress of the welding itself.

\subsection{Image Analysis \& Bonding Percentage}

Ideally, the perfect wood weld sample from an analytical standpoint would have a failed surface where one block was completely dark with the other being noticeably lighter in color. This perfect sample, where the welded material remained on one surface and completely pulled away from the other, would create a 50\% black pixel ratio for the entire sample. This model case rarely occurred. Welding material was often removed and deposited from both surfaces at the interface in multiple locations. In addition, failures occasionally occurred beyond the region of the weld and resulted in fracture of the base material.

By looking at both the top and bottom of a failed surface at the same time, the total amount of bonded material was calculated at once. Even if the sample was not ideal, simultaneously analyzing the top and bottom images should yield a 50\% black pixel ratio. Doubling that ratio would generate the bonding percentage, with an ideal case of $100 \%$. 
While the dark pixel ratios provided a reasonable estimate of the bond percentage, the image analysis process was based on an important assumption. The pixel counting process used to obtain that ratio was dependent on the color differences between the bonded and un-bonded regions at the failed interface. When fractured, the different regions of a failed wood weld are visually distinguishable with the naked eye. The dark material was where bonding occurred and the lighter material where bonding did not occur. However, during image analysis the program was not always able to make this distinction. In certain cases the color difference between bonded and un-bonded regions was not enough for the program to distinguish. This issue could not be corrected with the software and artificially increased the bonding area. The problem resulted in pixel ratios higher than $50 \%$. If these values were doubled to find the bonding percentage, the value would be higher than $100 \%$. On the few occasions when this occurred, the bond coverage was simply assumed to be perfect and was recorded as $100 \%$.

\subsection{Hypothesis for Weldability Differences Between Wood Species}

As mentioned in the preliminary bounding research (section 3.5.4), Douglas fir did occasionally weld. By chance it was discovered that lower welding pressures significantly increased the likelihood that a bond would form. However, the reason why birch welded with higher welding pressures was not clear.

When the possible timber species for this research were chosen, the decision was based on species that had hardness and density values similar to the wood species used in the literature (Figure $7 \&$ Figure 8). After the preliminary experiment was finished, these two properties were reexamined and combined to make a material index graph for easier comparison (Figure 38). It should be noted that the specific species of birch and Douglas 
fir used in this research was not known. The most likely species were chosen from the database so a comparison could be made. Birch appeared to have a similar range of values when compared with beech, the most prevalent species utilized in the published literature. While wood hardness had not previously been proposed as an influential property regarding wood welding, the potential use of density had been suggested in the literature [17].

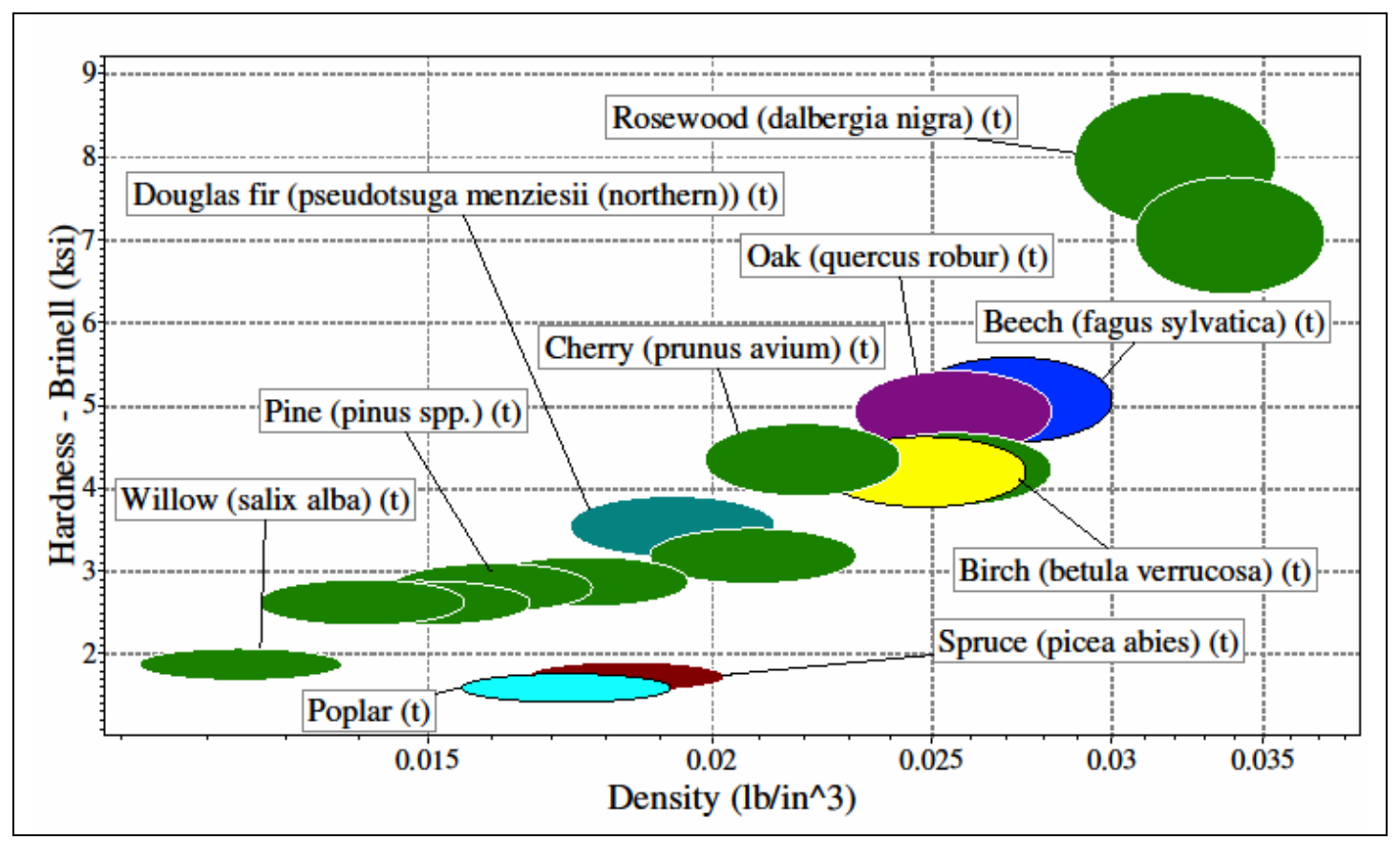

Figure 38 Hardness and density index for commonly used wood welding species (non-green ellipses) (Transverse properties reported).

When considering other prominent factors, the compressive strength of the wood appeared to be an influential property with respect to weldability and seemed to validate an experimental observation. Although DF did prove to be somewhat weldable (Figure 39), early attempts most often created a "washboard" surface at the interface (Figure 40). 
A color-negative photograph shows that spring and latewood rings do not behave in the same manner during welding. The annual rings that form each year as a tree grows are the result of differences found in the microstructure of the individual wood cells. Springwood, also called earlywood, grows

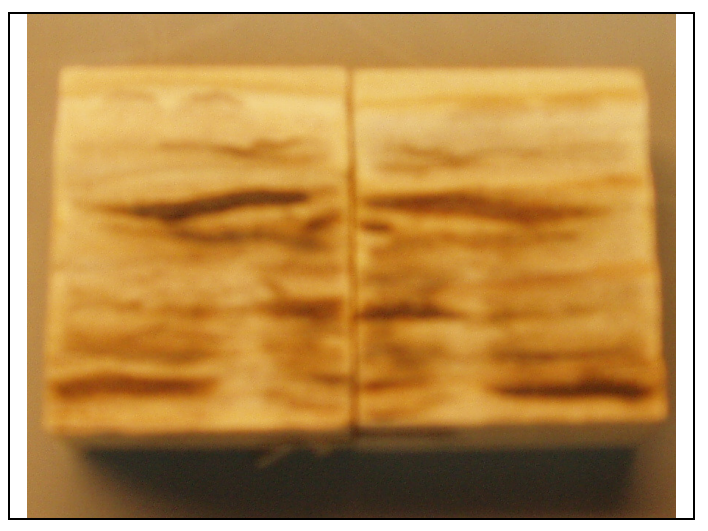

Figure 39 When Douglas fir welded, bonds formed between areas of latewood growth.

early in the season and results in large cell with thin cell walls. Latewood cells are on the other hand are characterized as being small and have thicker cell walls. These structural differences cause the latewood to have a higher density and as a result, latewood is stronger than springwood [4]. During the attempted welding of DF, the springwood sections of one wood block yielded to corresponding regions of latewood on the other wood block.

Researchers have noted a similar phenomenon during experimentation with spruce noting that "the latewood parts of one sample have compressed the earlywood parts of the other sample [16]." To compare the compressive strengths of the different species in question, another material interaction chart was created (Figure 41). 


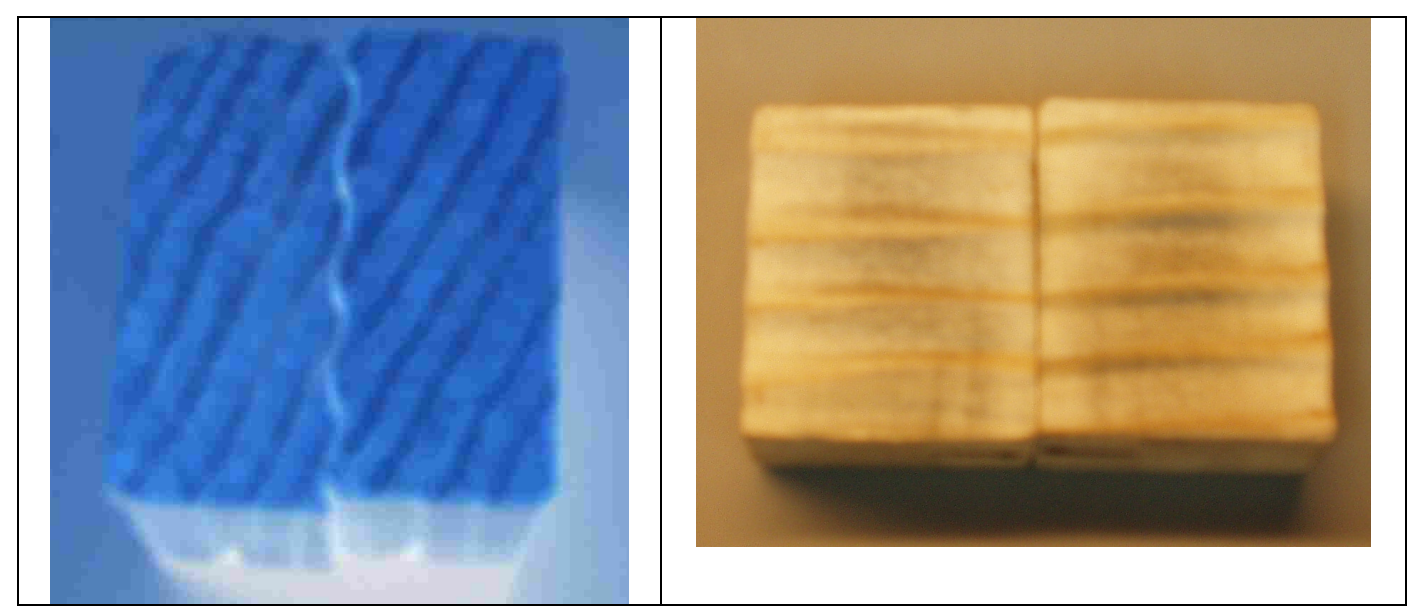

Figure 40 (Left) When looking at the end grain of this color-negative photograph, it was clear that springwood sections collapsed, while latewood rings remained unchanged (Original Photo: Figure 11). (Right) The dark horizontal lines are the raised latewood annual rings.

From the published research, under the same planar welding conditions, beech has been reported to perform better than spruce. Figure 41 shows that beech has almost twice the compressive strength (perpendicular to grain) as spruce. For this research, when birch and Douglas fir were welded under identical conditions, Douglas fir rarely formed a bond, while birch bonded consistently. Only when the welding pressure was reduced did the DF samples start to produce improved results. As with the beech-spruce interaction, the chart showed that a difference in compressive strength again exists. When poplar was compared in this research, its strength was even lower than that of Douglas fir. During the earliest preliminary experiments, poplar was shown to produce bond less frequently, if at all, and was the reason poplar was abandoned. With the beech-spruce interactions reported in the literature [16] and the birch-DF-poplar observations found in this research, there appears to be a correlation between ideal welding pressure and compressive strength (perpendicular to grain). 


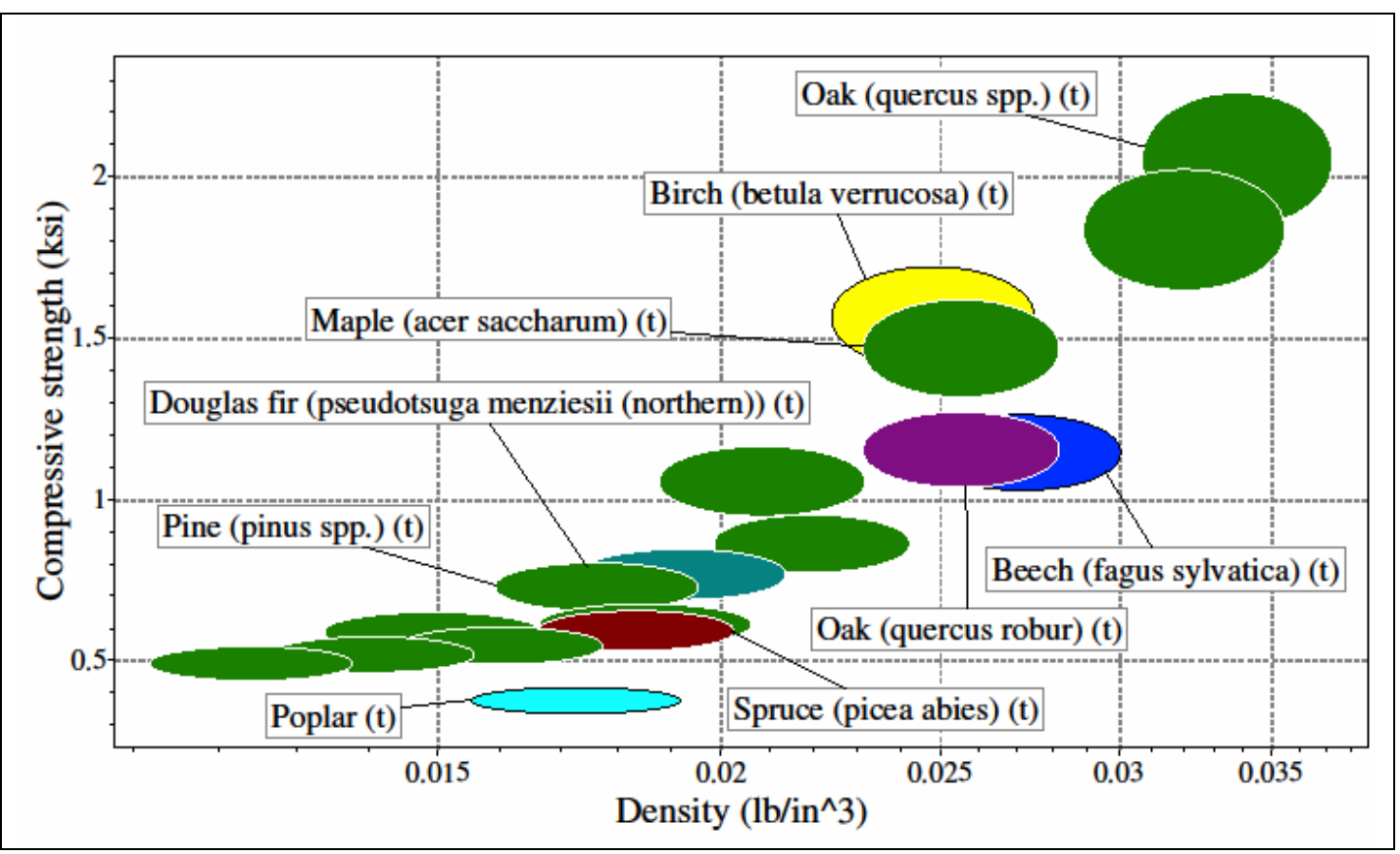

Figure 41 Compressive strength and density index for species commonly used in wood welding (non-green ellipses) (Transverse properties reported).

In timber, when significant pressures are applied perpendicular to grain, crushing can occur (Figure 42). Under normal circumstances, the $200 \mathrm{psi}$ (1.38 MPa) of welding pressure applied to the wood interface would not result in crushing in DF; however, welding conditions are not normal circumstances. Given the small sample size and the conditions generated during welding, bulk material properties should be applied with a certain amount of discretion. For the welded samples, the size and spacing of the annular rings are relatively large with respect to the individual wood sample blocks.

During wood welding, friction generates heat that helps to loosen the polymer-like material found in the wood. It is possible that this heat softens the springwood enough to cause partial localized collapse. As mentioned in section 2.5.3, spruce wood performed poorly in planar bonding and researchers have stated, "A similar irregular interface is always observed in spruce after any mechanical action, such as, for example, vacuumpressure impregnation with wood preservatives, due to the phenomenon of wood cells 
collapse which is characteristic of this wood species [16]." Given the similarities in properties between spruce and Douglas fir, a similar cellular collapse may be possible.

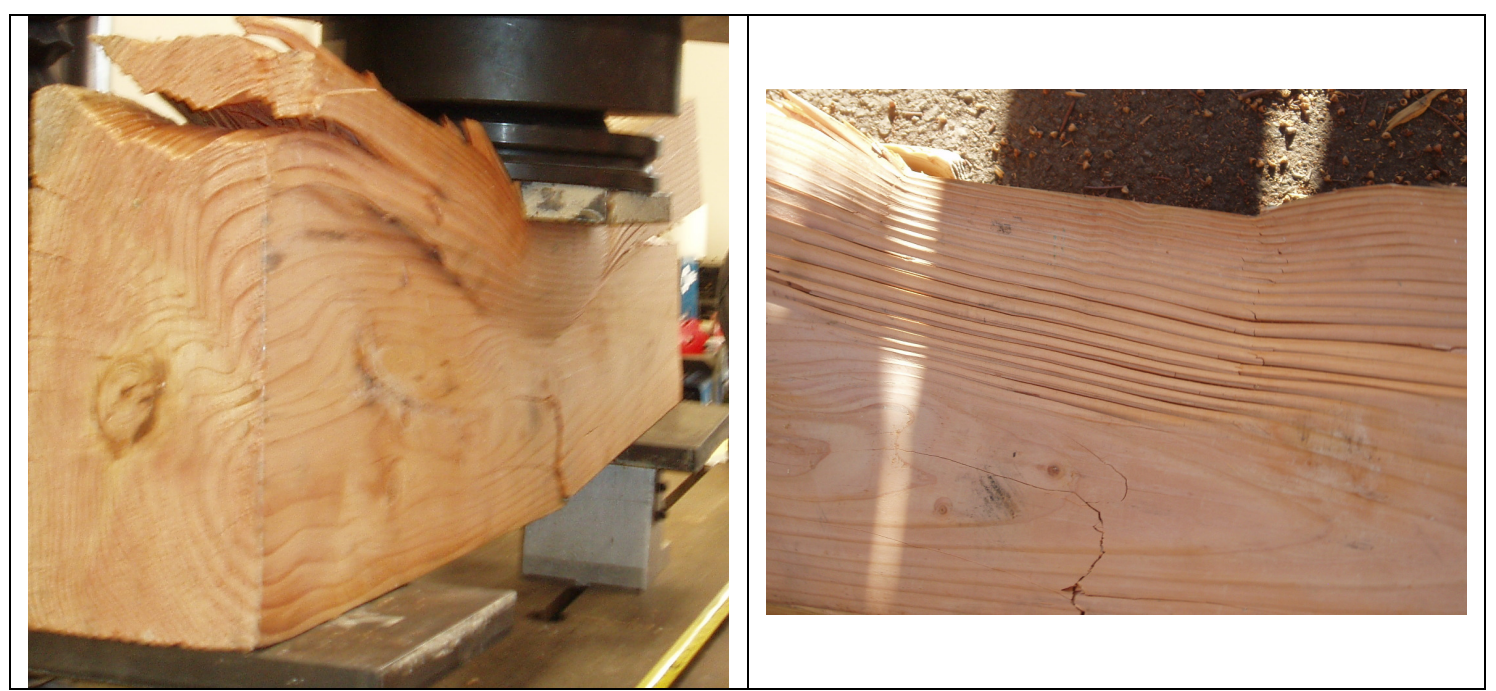

Figure 42 (Left) When significant loads are applied to timber perpendicular to grain, a crushing failure can occur. (Right) The individual annular rings have been clearly buckled out of plane.

From the birch and DF welding observations, when given their appropriate conditions, both species were weldable. In regards to birch, similar bond strengths were achieved using a variety of frequencies and welding times. As weld time decreased, bond quality also decreased; possibly indicating that insufficient heat was created by the friction welding process and agrees with the literature, "a certain amount of energy is needed to convert the surfaces to reach an acceptable weld [25]." Heat is essential for the bonding process because it softens the polymer-like material found in the timber. Once the matrix softened, the wood fibers loosen and lead to "the formation of a fibre entanglement network in the matrix of molten material which then solidifies [7]."

Although essential to create the wood weld bond, the locally generated heat may also have unfavorable side effects, such as those shown in many of the DF samples. In metallurgical welding, when molten metal cools two competing reactions occur. As the liquid begins to solidify, grains can begin to crystallize in two possibilities ways, through 
either nucleation or growth [8]. While the process is dynamic, at any given moment the liquid can form numerous small grains or fewer large grains. Depending on temperature and other factors, as the molten weld pool cools, the subordinate reaction can begin to dominate and visa versa.

The same temperature driven softening that allows wood welding to be possible may contribute to the wash-boarding, where annular rings of springwood are locally crushed, observed in Douglas fir. When the pressure was reduced during the processing of the DF samples, the "washboard" effect ceased and a wood weld formed. It is possible that depending upon the specific processing variables, the temperature induced softening can lead to either a wood weld being formed or result in localized springwood crushing. 


\section{Chapter 8: Conclusions \& Future Research}

\subsection{Conclusions}

The focus of this research was to investigate the relationship between the independent variables used to create wood welded joints and the performance of the welded bonds themselves. A prototype welding machine, designed and fabricated from the ground up, accomplished this goal and proved to be an excellent research and development tool.

Different combinations of frequency and weld duration can produce similar average shear strength results, but consistency issues can arise. Welding at lower frequencies for longer periods of time seemed to produce the best average values and lowest variation in regards to both shear strength and bond uniformity.

Examinations of grain orientation, in reference to both welding and testing direction, showed that shear strength was highly dependent on test orientation, confirming previous research. The grain orientation study also showed for the first time that welding direction had little influence on shear strength.

The analysis into how wood welds develop strength confirmed earlier research stating that the bonds develop the majority of their strength within minutes of finishing the welding process.

When both the welding frequency/duration and grain orientation experiments were conducted, the presence of three separate welding metrics was noted. Each of the three: smoke creation, weld goop formation, and audible pitch change, appeared to yield strength results comparable to the standard method of using welding time. Additionally, 
the use of welding time as an indicator of bond completions was shown to be poor. The same three indicators were generally as good if not better at indicating welding completion (bond percentage) as compared to the standard elapsed welding time method.

SEM analysis of the fractured bond surfaces revealed the presence of several noteworthy structures. The parallel welded sample showed regions where fibrous material was both ripped from the base material and where it was deposited. On the perpendicular welded samples, regions of fiber entanglement and reorientation were visible, as was evidence of a possible fiber fracture. The use of mapping images was found to be useful when attempting to place the numerous SEM image findings into a greater context.

Although birch was the primary species of timber utilized for this research, Douglas fir was shown for the first time to be capable of wood welding. While wood welds did form using Douglas fir at lower welding pressures, at higher pressures the interface between the Douglas fir blocks did not weld and commonly formed a washboard interface. When the mechanical properties of the birch and Douglas fir were compared, their compressive strength values (perpendicular to grain) were noticeably different. A correlation between compressive strength and optimum welding pressure likely exists and is species dependent.

In time, wood welding could become a valuable and environmentally friendly alternative to using traditional adhesive glues. This research has illustrated some of the possibilities and results that are capable, but there still exist a great number of unanswered questions that can only be addressed with further experimentation and investigation. 


\subsection{Future Research}

In metallurgical welding, small elemental changes in the composition of the alloy to be welded can greatly influence weldability. Minute changes in carbon or sulfur content in steel can affect the surface chemistry of the molten weld pool. While the mechanism involved in metallic welding and wood welding are different, changes and variability in basic material properties would seem to be influential in wood welding as well. What these properties are and how they influence the welding process are areas of study that must be investigated to better understand the fundamentals of wood welding.

\subsubsection{Project Continuation: Experimental Bounds Revisited}

This project investigated several areas of wood welding that had not been explored. Surface preparation and the use of a shielding gas were topics researched to inconclusive ends in the early research, due to time constraints, but could be revisited in greater scope and depth. With the existing prototype wood welding machine, the experiments reported in the exploratory research portion of this document could be performed to completion without any machine modifications. The effects of surface preparation, shield gas, and pressure fluctuations could all be observed on birch as well as a number of timber species. DF and poplar have shown an ability to be welded, but a significant optimization trial would be needed to obtain the best possible results with regard to shear strength and bond completion. Additionally, DF, poplar, and other potential species could be investigated to see if an ideal weld pressure/wood compressive strength relationship exists. 


\subsubsection{Project Continuation: Thermal Modeling and Data}

As a larger pool of data became available, more accurate and complete thermal model could be generated. While only a small portion of this research looked at heat distribution, it is important. A simple FDM model was used to help determine rough temperature extremes for this experiment, but if understanding and modeling of wood welding is to progress, more information is needed. The various properties previously listed (density, springwood/latewood differences, etc.) likely impact the final strength of bond, but the extent of influence is unknown. Knowledge of temperature distribution and heat fluxes would also be valuable in attempting to create a more accurate digital model and to further the understanding of the wood welding process itself.

For this project, the affect of changing welding duration and frequency was evaluated as changes in bond coverage and strength of the wood welds. Repeating these experiments, while monitoring the welding process with thermal imaging or thermal measurements, would provide valuable data about the conditions present during wood welding. The influence of each variable in the welding process: frequency, displacement length, weld duration, normal force, surface roughness, etc., should be investigated with reference to interface temperature and thermal properties.

Duplicating processing variables and conditions can be difficult between researchers using different equipment. Knowledge of either the interface temperature or energy input required for wood welding could largely normalize the process. Strength and bonding data could be correlated with measurable processing conditions instead of a myriad of welding parameters and variables. 


\subsubsection{Expanded Analysis of Material Properties}

Density differences between spring and latewood, size and spacing of annual rings, surface roughness, and the chemical makeup of the timber itself are all potential sources of variability for the wood welding process. These properties can vary within wood samples from the same species, let alone different species. Not only are the properties of wood variable, they are also likely to change during the welding process as temperature fluctuates and heat is generated and dissipated. During traditional welding, the base material can experience multiple phase changes. However, given its organic nature, portions of the wood may also undergo chemical changes during welding. A design of experiment characterizing several important properties of timber would likely be able to discriminate what material attributes of the wood are most influential in the welding process.

\subsubsection{Implementation of Alternative Welding Completion Metrics}

During the course of the experiment many samples emitted an audible pitch change during the welding procedure. Interfacing some type of auditory sensor with the machine would likely improve the wood welding process. If the sensor and machine could be computer controlled to some extent, the benefits could be substantial.

While each of the three welding observations could potentially be refined for future research, audible pitch change stands out among the possibilities. Smoke creation and goop formation were good qualitative measures, but pitch change could be quantitative and measurable. By using a microphone or similar device, the auditory frequency heard or felt during the welding process could be monitored and recorded by computer. After the welding pitch had been characterized and studied, it could be used in 
the welding process itself. During welding, once the frequency was measured by the computer and interfaced with the welding machine, the computer could automatically shut the machine off or turn it off after a predetermined time period. 


\section{Chapter 9: Bibliography}

1. Hibbeler, R.C. Structural Analysis. 6th ed. Upper Saddle River, New Jersey: Pearson Prentice Hall, 2006.

2. McCormac, Jack C., James K Nelson Jr. Structural Steel Design: LRFD Method. 3rd ed. Upper Saddle River, NJ: Pearson Education, 2003.

3. MacGregor, James G., James K. Wight. Reinforced Concrete Mechanics and Design. 4th ed. Upper Saddle River, New Jersey, 2005.

4. Breyer, Donald., Kenneth J. Fridley, David G. Pollock Jr., Kelly E. Corbeen. Design of Wood Structures - ASD. 5th ed. New York: McGraw-Hill, 2003.

5. Adams, David K. The Structural Engineer's Professional Training Manual. New York: McGraw-Hill, 2008.

6. Leban, Jean-Michel. "Wood welding- an award-winning dicovery." Scandinavian Journal of Forest Research 20.3 (May, 2005): 285-286.

7. Gfeller, B., M. Zanetti, M. Properzi, A. Pizzi, F. Pichelin, M. Lehmann, L. Delmotte. "Wood bonding by vibrational welding." Journal of Adhesion Science and Technology 17.11 (2003): 1573-1589.

8. Messler, Robert W. Jr. Principles of Welding: Processes, Physics, Chemistry, and Metallurgy. Berlin: Wiley-VCH, 2004. 
9. Leban, J.M., A. Pizzi, M. Properzi, F. Pichelin, P. Gelhaye, C. Rose. "Wood welding: A challenging alternative to conventional wood gluing." Scandinavian Journal of Forest Research 20 (2005): 534-538.

10. Gfeller, B., M. Properzi, M. Zanetti, A. Pizzi, F. Pichelin, M. Lehmann, L. Delmotte. "Wood Bonding by Mechanically-Induced in Situ Welding of Polymeric Structural Wood Constituents." Journal of Applied Polymer Science 92 (2004): 243-215.

11. Stamm, B., E. Windeisen, J. Natterer, G. Wegener. "Thermal behaviour of polysaccharides in wood during friction welding." Holz als Roh- und Werkstoff 63 (2005): 388-389.

12. Gerber, C., and B. Gfeller. "Wood Welding Technologies (WWT)." World Confrence on Timber Engineering (WCTE), 2000. Whistler, Canada: 1-5.

13. Gerber, C., and B. Gfeller. "Wood Welding Technologies." Advanced Engineered Wood Composites (AEWC), 2001. Bethel, USA: 1-9.

14. Gfeller, B., A. Pizzi, M. Zanetti, M. Properzi, F. Pichelin, M. Lehmann, L. Delmotte. "Solid wood joints by in situ welding of structural wood constituents." Holzforschung 58 (Jan. 2004): 45-52.

15. Gfeller, B., M. Lehmann, M. Properzi, F. Pichelin, M. Zanetti, A. Pizzi, L. Delmotte. "Interior wood joints by mechanical fusion welding of wood surfaces." Forest Products Journal 54.7 (2004): 74-79.

16. Leban, J.M., A. Pizzi, S. Wieland, M. Zanetti, M. Properzi, F. Pichelin. "X-ray microdensitometry analysis of vibration-welded wood." Journal of Adhesion Science and Technology 18.6 (2004): 673-685. 
17. Properzi, M., J.M. Leban, A. Pizzi, S. Weiland. Pichelin, F., Lehmann, M. "Influence of grain direction in vibrational wood welding." Holzforschung 59 (2005): 2327.

18. Weiland, S., S. Bozhang, A. Pizzi, M. Properzi, M. Stampanoni, R. Abela, X. Lu, F. Pichelin. "Vibration welding of wood: X-ray tomography, additives, radical concentration.” Forest Products Journal 55.1 (Jan. 2005): 84-87.

19. Ganne-Chedeville, C., J.M. Leban, M. Properzi, F. Pichelin, A. Pizzi.

"Temperature and density distribution in mechanical vibration wood welding." Wood Science and Technology 40 (2006): 72-76.

20. Boonstra, M., A. Pizzi, C. Ganne-Chedeville, M. Properzi, J.M. Leban, F. Pichelin. "Vibration welding of heat-treated wood." Journal of Adhesion Science and Technology 20.4 (2006): 359-369.

21. Ganne-Chedeville, C., M. Properzi, J.-M. Leban, F. Pichelin. "Parameters of wood welding: A study with infrared thermography." Holzforschung 60 (2006): 434-438.

22. Ganne-Chedeville, C., M. Properzi, A. Pizzi, J.-M. Leban, F. Pichelin. "Edge and face linear vibration welding of wood panels.” Holz Roh Werkst 65 (2007): 83-85.

23. Omrani, P., H.R. Mansouri, A. Pizzi. "Linear welding of grooved wood surfaces." European Journal of Wood and Wood Products 67.4 (Nov. 2009): 479-481. 
24. Omrani, P., H.R. Mansouri, A. Pizzi, E. Masson. "Influence of grain direction and pre-heating on linear wood welding." European Journal of Wood and Wood Products 68.1 (Feb. 2010): 113-114.

25. Stamm, B., J. Natterer, P. Navi. "Joining wood by friction welding." Hols als Roh- und Werkstoff 63 (2005): 313-320.

26. Stamm, B., J. Natterer, P. Navi. "Joining of wood layers by friction welding." Journal of Adhesion Science and Technology 19.13-14 (2005): 1129-1139.

27. Stamm, B., E. Windeisen, J. Natterer, G. Wegener. "Chemical investigations on the thermal behaviour of wood during friction welding." Wood Science and Technology 40 (2006): 615-627.

28. Pizzi, A., J.M. Leban, F. Kanazawa, M. Properzi, F. Pichelin. "Wood dowel bonding by high-speed rotation welding." Journal of Adhesion Science and Technology 18.16 (2004): 1263-1278.

29. Kanazawa, F., A. Pizzi, M. Properzi, L. Delmontte, F. Pichelin. "Parameters influencing wood-dowel welding by high-speed rotation." Journal of Adhesion Science and Technology 19.12 (2005): 1025-1038.

30. Ganne-Chedeville, C., A. Pizzi, A. Thomas, J.M. Leban, J.F. Bocquet, A. Despres, H. Mansouri. "Parameter interactions in two-block welding and the wood nail concept in wood dowel welding." Journal of Adhesion Science and Technology 19.13-14 (2005): 1157-1174. 
31. Resch, L., A. Depres, A. Pizzi, J.F. Bocquet, J.-M. Leban. "Welding-through doweling of wood panels." Holz als Roh- und Werkstoff 64 (2006): 423-425.

32. Bocquet, J.-F., A. Pizzi, L. Resch. "Full-scale (industrial) wood floors using welded-through dowels." Journal of Adhesion Science and Technology 20.15 (2006): 1727-1739.

33. Bocquet, J.-F., A. Pizzi, A. Despres, H.R. Mansouri, et al. "Wood joints and laminated wood beams assembled by mechanically-welded wood dowels." Journal of Adhesion Science and Technology 21.3-4 (2007): 301-317.

34. Bocquet, J.-F., A. Pizzi, L. Resch. "Full-scale industrial wood floor assembly and structures by welded-through dowels." Holz Roh Werkst 65 (2007): 149-155.

35. Omrani, P., J.-F. Bocquet, A. Pizzi, J.-M. Leban, H. Mansouri. "Zig-zag rotational dowel welding for exterior wood joints." Journal of Adhesion Science and Technology 20.10 (2007): 923-933.

36. Omrani, P., H.R. Mansouri, A. Pizzi. "Weather exposure durability of welded dowel joints." Holz Roh Werkst 66 (2008): 161-162.

37. Leban, J.-M., H.R. Mansouri, P. Omrani, A. Pizzi. "Dependence of dowel welding on rotation rate." Holz Roh Werkst 66 (2008): 241-242.

38. Omrani, P., E. Masson, A. Pizzi, H.R. Mansouri. "Emission of gases and degradation volatiles from polymeric wood constituents in friction welding of wood dowels." Polymer Degradation and Stability 93 (2008): 794-799. 
39. Renaud, A. "Minimalist $\mathrm{Z}$ chair assembly by rotational dowel welding." Holz als Roh- und Werkstoff 67 (2009): 111-112.

40. Delmotte, L., C. Ganne-Chedeville, J.M. Leban, A. Pizzi, F. Pichelin. "CP-MAS 13C NMR and FT-IR investigation of the degradation reactions of polymer constituents in wood welding." Polymer Degradation and Stability 93 (2008): 406-412.

41. Windeisen, E., and G. Wegener. "Behavior of lignin during thermal treatments of wood." Industrial Crops and Products 27 (2008): 157-162.

42. Pizzi, A., J.-M. Leban, M. Zanetti, F. Pichelin, S. Wieland, M. Properzi. "Surface finishes by mechanically induced wood surface fusion." Holz als Roh- und Werkstoff 63 (2005): 251-255.

43. Tondi, G., S. Andrews, A. Pizzi, J.-M. Leban. "Comparative potential of alternative wood welding systems, ultrasonic and microfriction stir welding." Journal of Adhesion Science and Technology 21.16 (2007): 1633-1643.

44. CES Selector Version 5.1.0. CD-ROM. Cambridge: Granta Design Limited. 2009.

45. UTHSCSA ImageTool. Computer software. Ver. 3.00. Download. San Antonio, Tx: The University of Texas Health Science Center in San Antonio. 2002 $<$ http://ddsdx.uthscsa.edu/dig/itdesc.html>.

46. Green, David., J. Winandy, D. Kretschmann. "Chapter 4 - Mechanical Properties of Wood." Forest Products Laboratory. Wood Handbook - Wood as an Engineering Material. Madison: U.S. Department of Agriculture, Forest Service, 1999, Tables: 4-1, 42, 4-3a, 4-3b, 4-6. 
47. "Friction-stir weld." CES Selector Version 5.1.0. CD-ROM. Cambridge: Granta Design Limited. 2009.

48. American Forest \& Paper Association, Inc. National Design Specifications (NDS) for Wood Construction with Commentary and Supplement: Design Values for Wood Construction 2005 Edition. Washington, DC: AF\&PA American Wood Council, 2005. 


\section{Appendix A: Tables \& Figures with SI Units}

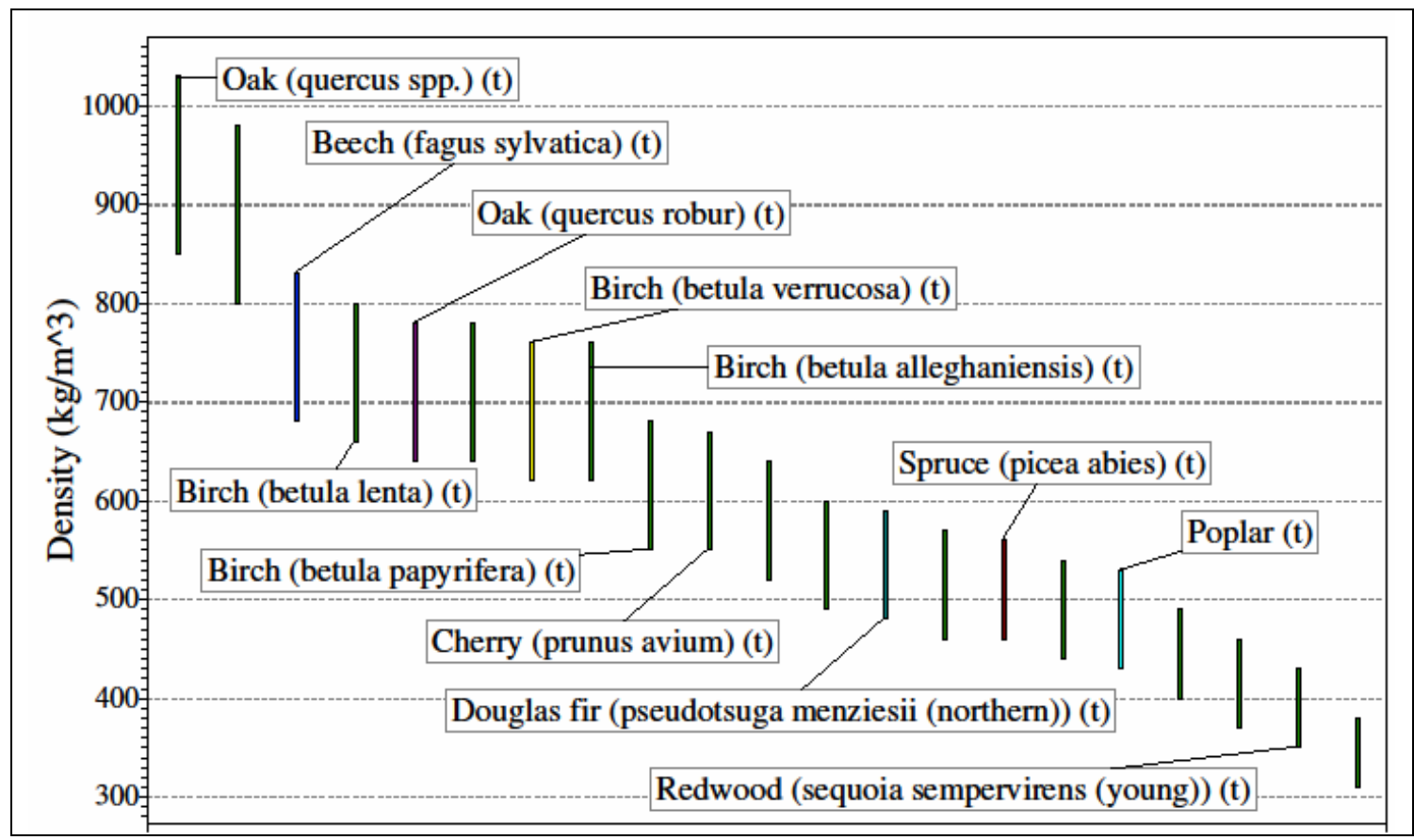

Figure 7.1 Density comparisons between various timber species (transverse properties).

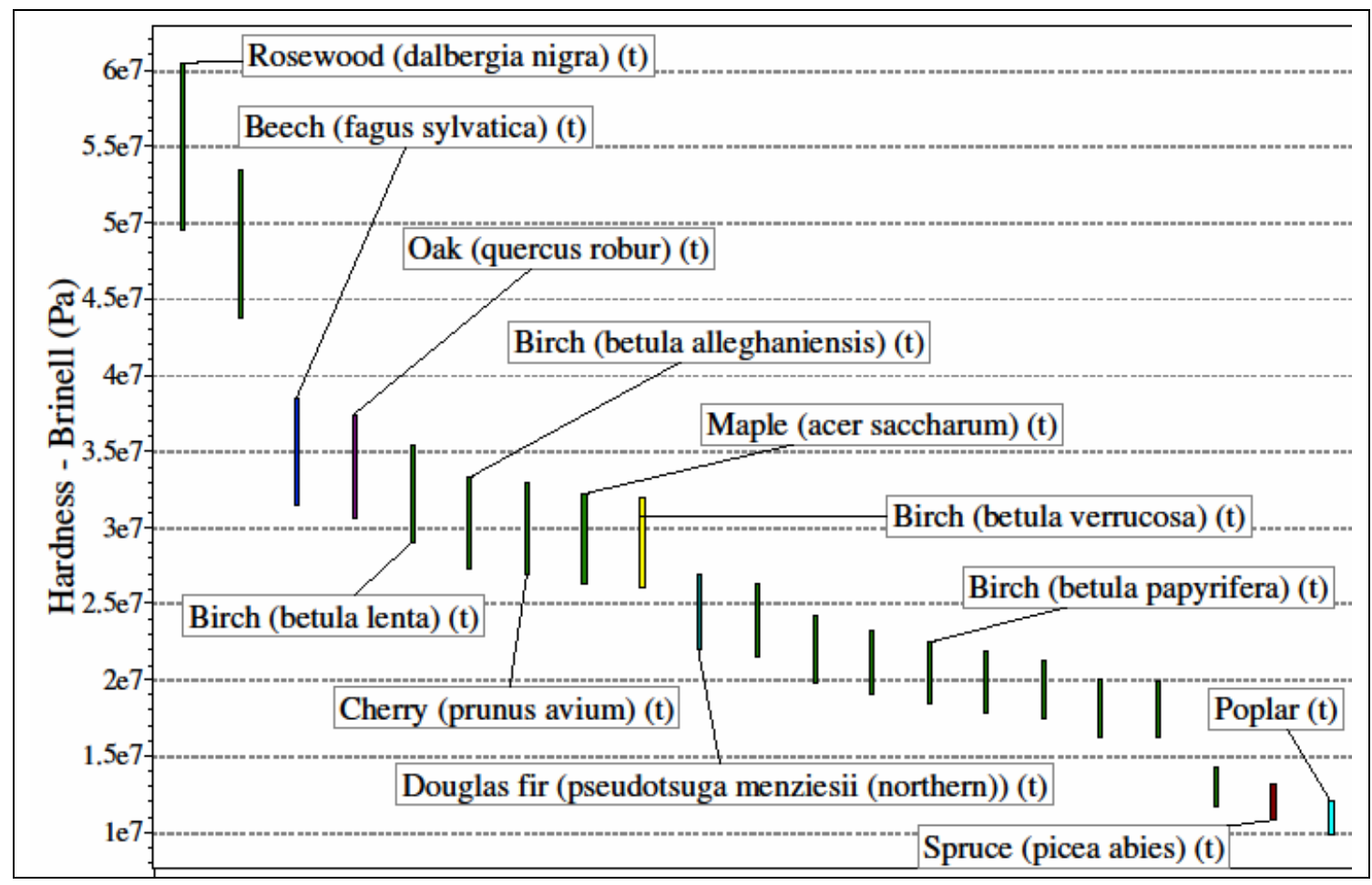

Figure 8.1 Hardness values for multiple woods (transverse properties). 


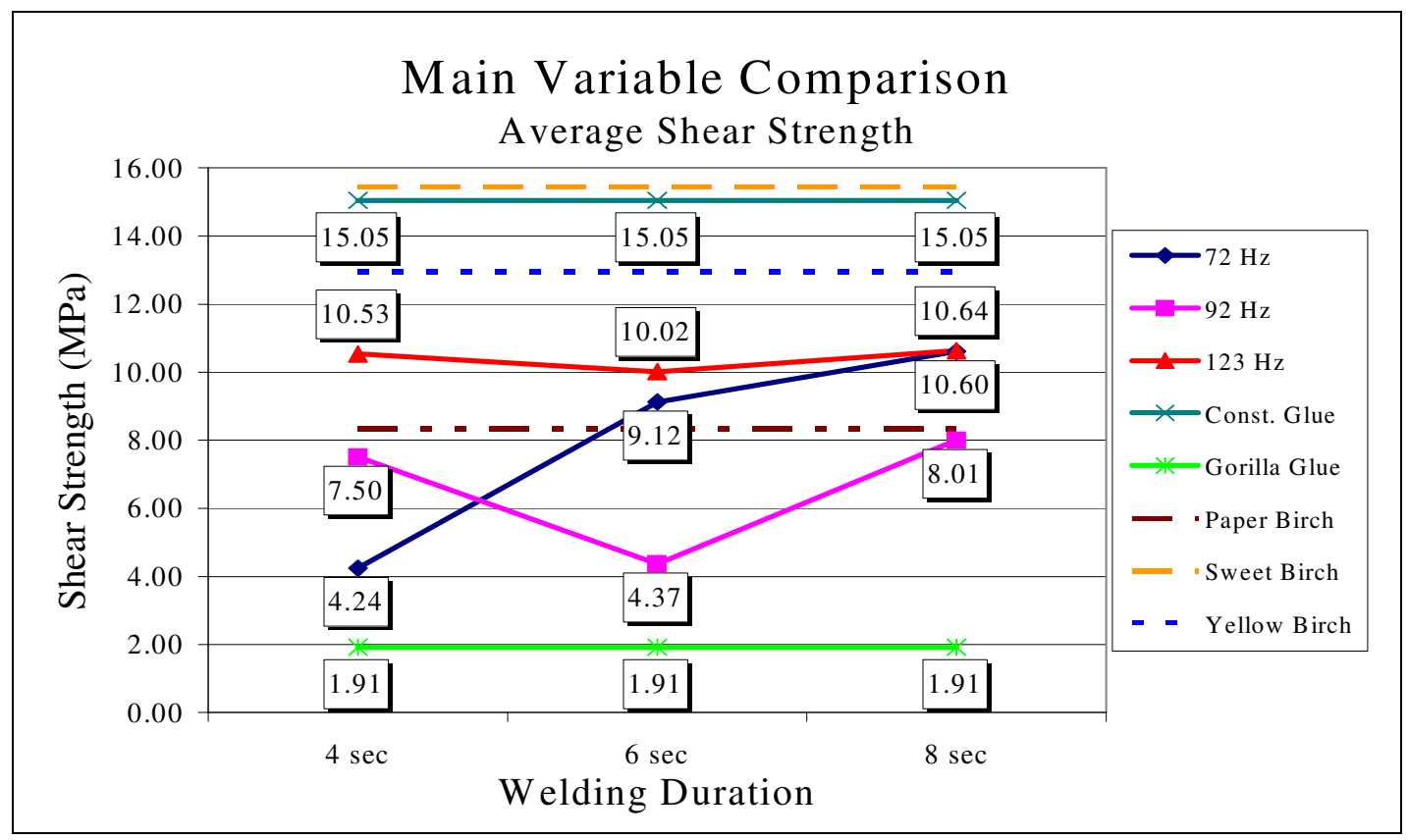

Figure 20.1 While the best wood welding results overlap with the stronger glue, the majority of the wood welding results were significantly stronger than the second adhesive (Birch, 200 psi WP). The dashed lines indicate published shear strength reference values (parallel to grain at $12 \%$ moisture content) for several birch species (Paper Birch: 1,210 psi (8.3 MPa) - Sweet Birch: 2,240 psi (15.4 MPa) - Yellow Birch: 1,880 psi (13.0 MPa)) [46].

Table IV.I Main Variable Experimental Results (Birch, 200 psi WP)

\begin{tabular}{|c|c|c|c|c|c|c|c|}
\hline \multirow{2}{*}{$\begin{array}{c}\text { Series } \\
(\mathrm{Hz})\end{array}$} & \multirow{2}{*}{$\begin{array}{l}\text { Sub-set } \\
(\mathrm{sec})\end{array}$} & \multicolumn{4}{|c|}{ Shear Strength $(\mathrm{MPa})$} & \multicolumn{2}{|c|}{ Bonding } \\
\hline & & $\%$ Control & Mean & SD & $\mathrm{COV}$ & Mean & SD \\
\hline 72 & 4 & $28 \%$ & 4.24 & 3.57 & $84 \%$ & $15 \%$ & $11 \%$ \\
\hline 72 & 6 & $61 \%$ & 9.12 & 5.00 & $55 \%$ & $49 \%$ & $11 \%$ \\
\hline 72 & 8 & $70 \%$ & 10.60 & 2.57 & $24 \%$ & $70 \%$ & $12 \%$ \\
\hline 92 & 4 & $50 \%$ & 7.50 & 4.05 & $54 \%$ & $59 \%$ & $25 \%$ \\
\hline 92 & 6 & $29 \%$ & 4.37 & 3.02 & $69 \%$ & $56 \%$ & $15 \%$ \\
\hline 92 & 8 & $53 \%$ & 8.01 & 2.93 & $37 \%$ & $95 \%$ & $7 \%$ \\
\hline 123 & 4 & $70 \%$ & 10.53 & 1.78 & $17 \%$ & $62 \%$ & $20 \%$ \\
\hline 123 & 6 & $67 \%$ & 10.02 & 3.72 & $37 \%$ & $77 \%$ & $31 \%$ \\
\hline 123 & 8 & $71 \%$ & 10.64 & 6.45 & $61 \%$ & $67 \%$ & $36 \%$ \\
\hline \multicolumn{2}{|c|}{ Construction Glue } & $100 \%$ & 15.05 & 3.83 & $25 \%$ & N.A. & N.A. \\
\hline \multicolumn{2}{|c|}{ Gorilla Glue } & $13 \%$ & 1.91 & 1.33 & $69 \%$ & N.A. & N.A. \\
\hline
\end{tabular}




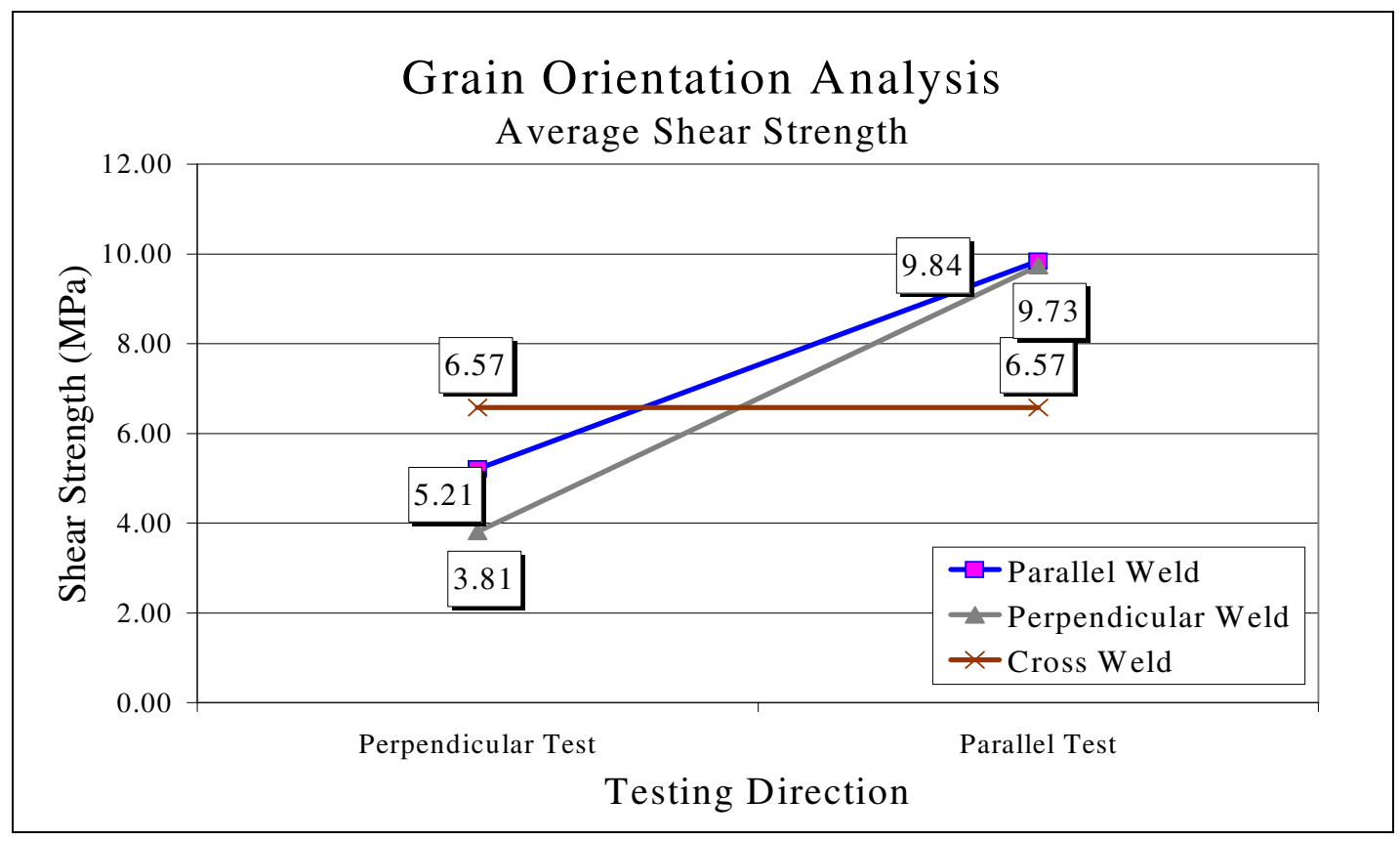

Figure 22.1 While different welding directions produce negligible differences in shear strength, testing orientation had a noticeable influence on shear strength (Birch, 200 psi WP).

Table V.I Grain Orientation Shear Strength Results (Birch, 200 psi WP, 6-sec WT, 92 Hz)

\begin{tabular}{|c|c|c|c|c|}
\hline & \multicolumn{2}{|c|}{ Shear Test Orientation (MPa) } \\
\hline & & & Parallel & Perpendicular \\
\hline \multirow{3}{*}{ Weld Orientation } & Parallel & $\begin{array}{c}\text { Mean } \\
\text { SD } \\
\text { CV }\end{array}$ & $\begin{array}{c}9.84 \\
3.63 \\
{[37 \%]}\end{array}$ & $\begin{array}{c}5.21 \\
2.29 \\
{[44 \%]}\end{array}$ \\
\hline & Perpendicular & $\begin{array}{c}\text { Mean } \\
\mathrm{SD} \\
\mathrm{CV} \\
\end{array}$ & $\begin{array}{c}9.73 \\
5.64 \\
{[58 \%]} \\
\end{array}$ & $\begin{array}{c}3.81 \\
1.40 \\
{[37 \%]} \\
\end{array}$ \\
\hline & Cross Grain & $\begin{array}{c}\text { Mean } \\
\text { SD } \\
\text { CV }\end{array}$ & \multicolumn{2}{|c|}{$\begin{array}{c}6.57 \\
2.38 \\
{[36 \%]}\end{array}$} \\
\hline
\end{tabular}


Table VII.I Shear Strength Tested at Various Curing Times

\begin{tabular}{|r|r|r|r|r|r|}
\hline \multicolumn{3}{|c|}{ Cure Time } & \multicolumn{3}{c|}{ Shear Strength (MPa) } \\
\hline Minutes & $\begin{array}{c}\text { Log } \\
\text { (Min.) }\end{array}$ & \multicolumn{1}{c|}{ Days } & Mean & Std. Dev. & CV \\
\hline 60 & 1.78 & 0.04 & 11.19 & 4.21 & $38 \%$ \\
\hline 100 & 2.00 & 0.07 & 7.60 & 3.60 & $47 \%$ \\
\hline 750 & 2.88 & 0.52 & 9.47 & 1.69 & $18 \%$ \\
\hline 1200 & 3.08 & 0.83 & 8.81 & 1.20 & $14 \%$ \\
\hline 2040 & 3.31 & 1.42 & 7.72 & 5.99 & $78 \%$ \\
\hline 3000 & 3.48 & 2.08 & 9.60 & 4.08 & $42 \%$ \\
\hline 4500 & 3.65 & 3.13 & 4.10 & 3.13 & $76 \%$ \\
\hline 6000 & 3.78 & 4.17 & 6.75 & 0.58 & $9 \%$ \\
\hline
\end{tabular}

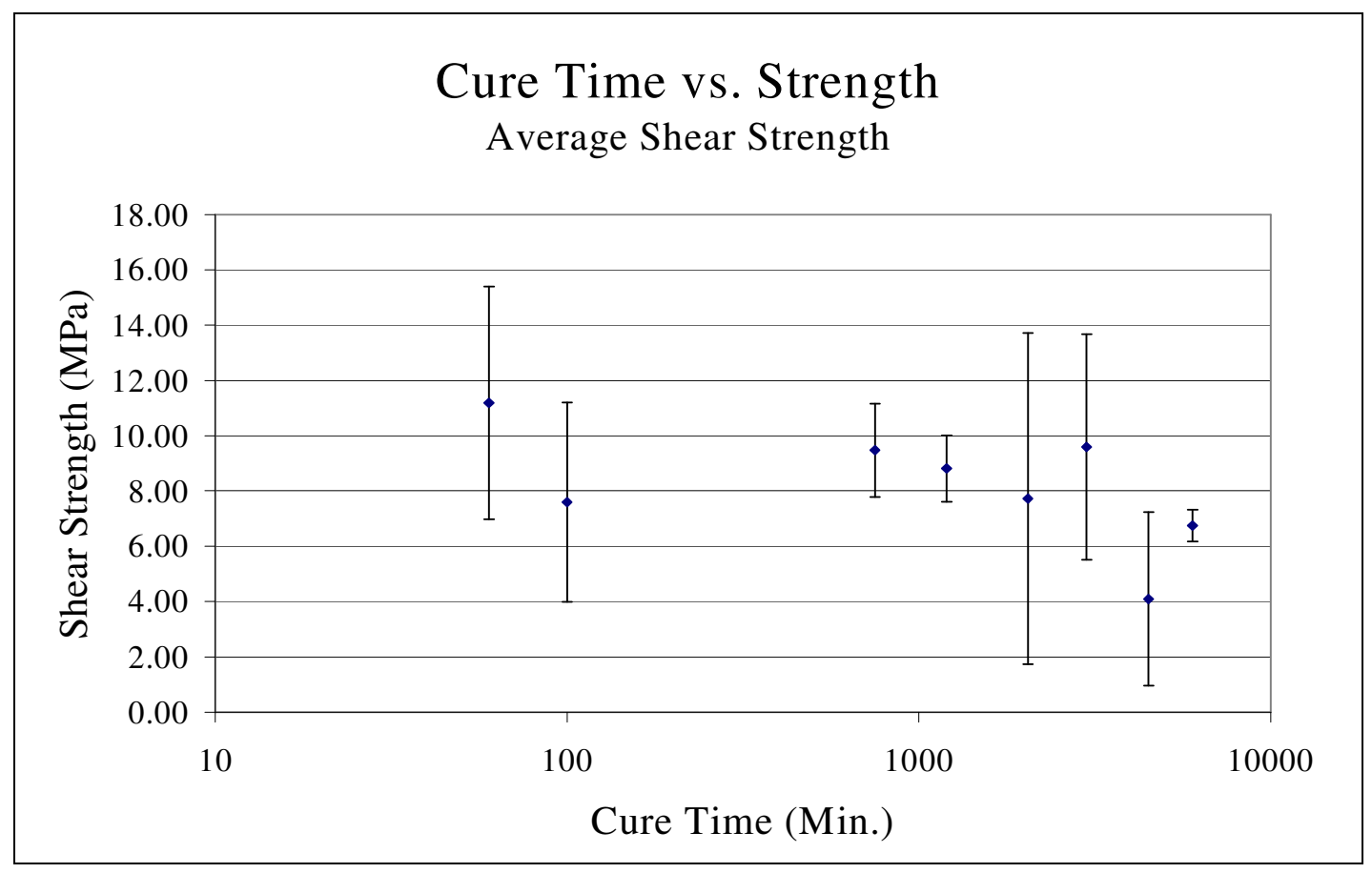

Figure 23.1 While the average ultimate shear strength of the bonds appeared to fluctuate over time, these were likely statistically insignificant $(\overline{\mathrm{x}} \pm 1 S D)$. 


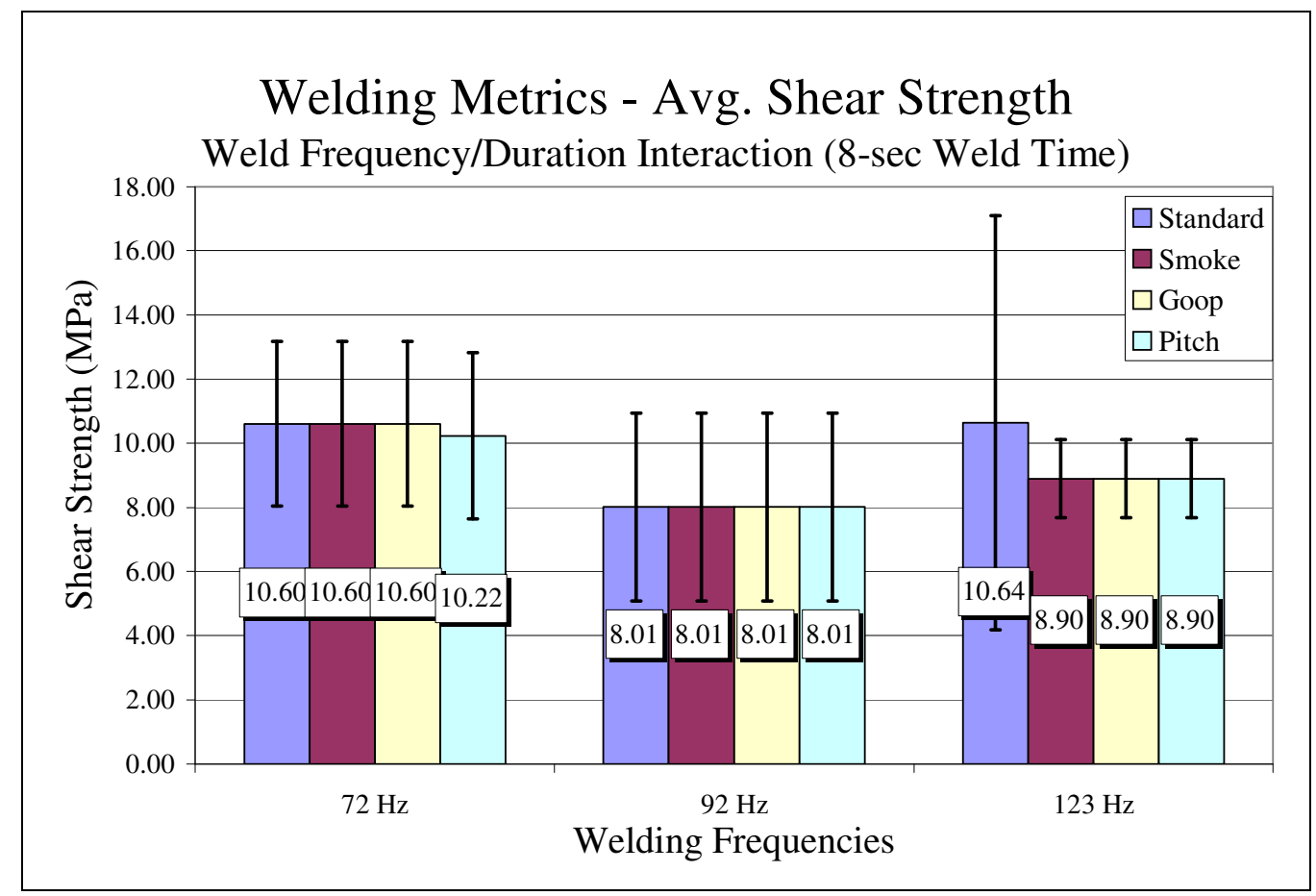

Figure 24.1 When the fusion criteria (smoke generation, welding goop formation, and audible pitch change) were used to filter the sample data, little change in the average shear strength was observed $(\overline{\mathbf{x}} \pm 1 S D)$.

Table VIII.I Frequency/Duration Interaction - Welding Metrics: Shear Results (Birch, 200 psi WP, 8-sec WT)

\begin{tabular}{|c|c|r|r|r|r|}
\hline $\begin{array}{c}\text { Frequency } \\
(\mathrm{Hz})\end{array}$ & Statistics & Standard & Smoke & Goop & \multicolumn{1}{c|}{$\begin{array}{c}\text { Pitch } \\
\text { Change }\end{array}$} \\
\hline \multirow{3}{*}{72} & Mean & 10.60 & 10.60 & 10.60 & 10.22 \\
& SD & 2.57 & 2.57 & 2.57 & 2.59 \\
& CV & $24 \%$ & $24 \%$ & $24 \%$ & $25 \%$ \\
\hline \multirow{3}{*}{92} & Mean & 8.01 & 8.01 & 8.01 & 8.01 \\
& SD & 2.93 & 2.93 & 2.93 & 2.93 \\
& CV & $37 \%$ & $37 \%$ & $37 \%$ & $37 \%$ \\
\hline \multirow{3}{*}{123} & Mean & 10.64 & 8.90 & 8.90 & 8.90 \\
& SD & 6.45 & 1.22 & 1.22 & 1.22 \\
& CV & $61 \%$ & $14 \%$ & $14 \%$ & $14 \%$ \\
\hline
\end{tabular}

Note: Mean and SD Unit: MPa 
Table IX.I Grain Orientation - Welding Metrics: Shear Results (Birch, 200 psi WP, 6-sec WT, 92 Hz)

\begin{tabular}{|c|c|c|c|c|c|c|}
\hline Weld Direction & $\begin{array}{c}\text { Shear } \\
\text { Direction }\end{array}$ & Statistics & Standard & Smoke & Goop & $\begin{array}{c}\text { Pitch } \\
\text { Change }\end{array}$ \\
\hline \multirow{3}{*}{ Parallel } & \multirow{3}{*}{ Perpendicular } & Mean & 5.21 & 5.27 & 5.21 & 5.20 \\
\hline & & SD & 2.29 & 2.47 & 2.29 & 2.70 \\
\hline & & $\mathrm{CV}$ & [44\%] & {$[47 \%]$} & [44\%] & [52\%] \\
\hline \multirow{3}{*}{ Parallel } & \multirow{3}{*}{ Parallel } & Mean & 9.84 & 8.71 & 8.71 & 8.71 \\
\hline & & $\mathrm{SD}$ & 3.63 & 1.87 & 1.87 & 1.87 \\
\hline & & $\mathrm{CV}$ & [37\%] & [22\%] & [22\%] & [22\%] \\
\hline \multirow{3}{*}{ Perpendicular } & \multirow{3}{*}{ Parallel } & Mean & 9.73 & 11.19 & 11.61 & 11.30 \\
\hline & & SD & 5.64 & 4.52 & 4.91 & 5.62 \\
\hline & & $\mathrm{CV}$ & [58\%] & [40\%] & [42\%] & [50\%] \\
\hline \multirow{3}{*}{ Perpendicular } & \multirow{3}{*}{ Perpendicular } & Mean & 3.81 & 4.57 & 4.17 & 4.04 \\
\hline & & $\mathrm{SD}$ & 1.40 & 0.99 & 0.52 & 0.54 \\
\hline & & $\mathrm{CV}$ & [37\%] & [22\%] & [12\%] & [13\%] \\
\hline \multirow{3}{*}{ Cross } & \multirow{3}{*}{ Cross } & Mean & 6.57 & 6.44 & 6.44 & 6.52 \\
\hline & & SD & 2.38 & 2.54 & 2.54 & 2.77 \\
\hline & & $\mathrm{CV}$ & [36\%] & [39\%] & [39\%] & [43\%] \\
\hline
\end{tabular}

Note: Mean and SD Units - MPa

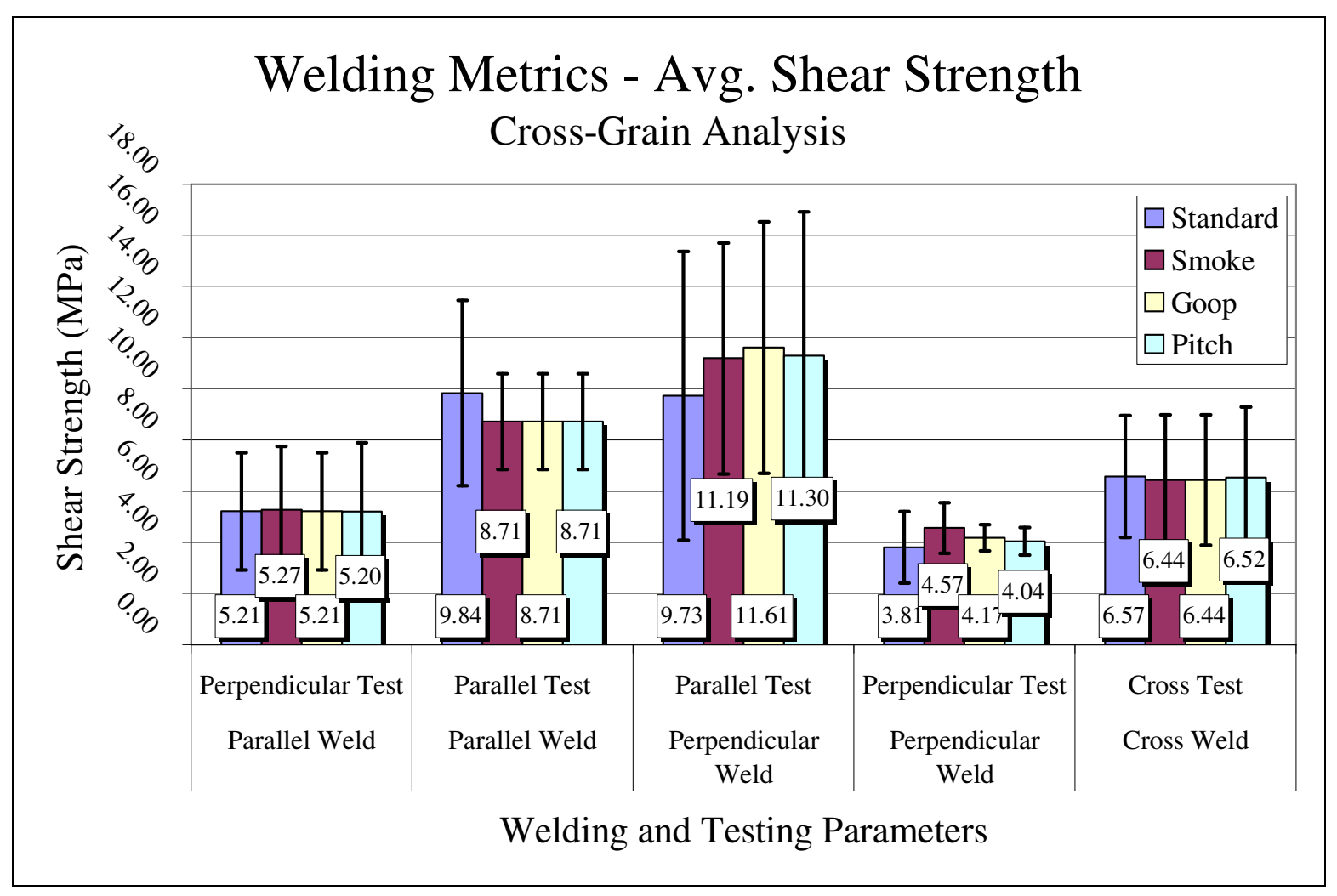

Figure 25.1 As was seen in Figure 24, when samples were discarded using the fusion criteria for the grain orientation analysis little change in the average shear strength was observed $(\overline{\mathbf{x}} \pm 1 S D)$. 


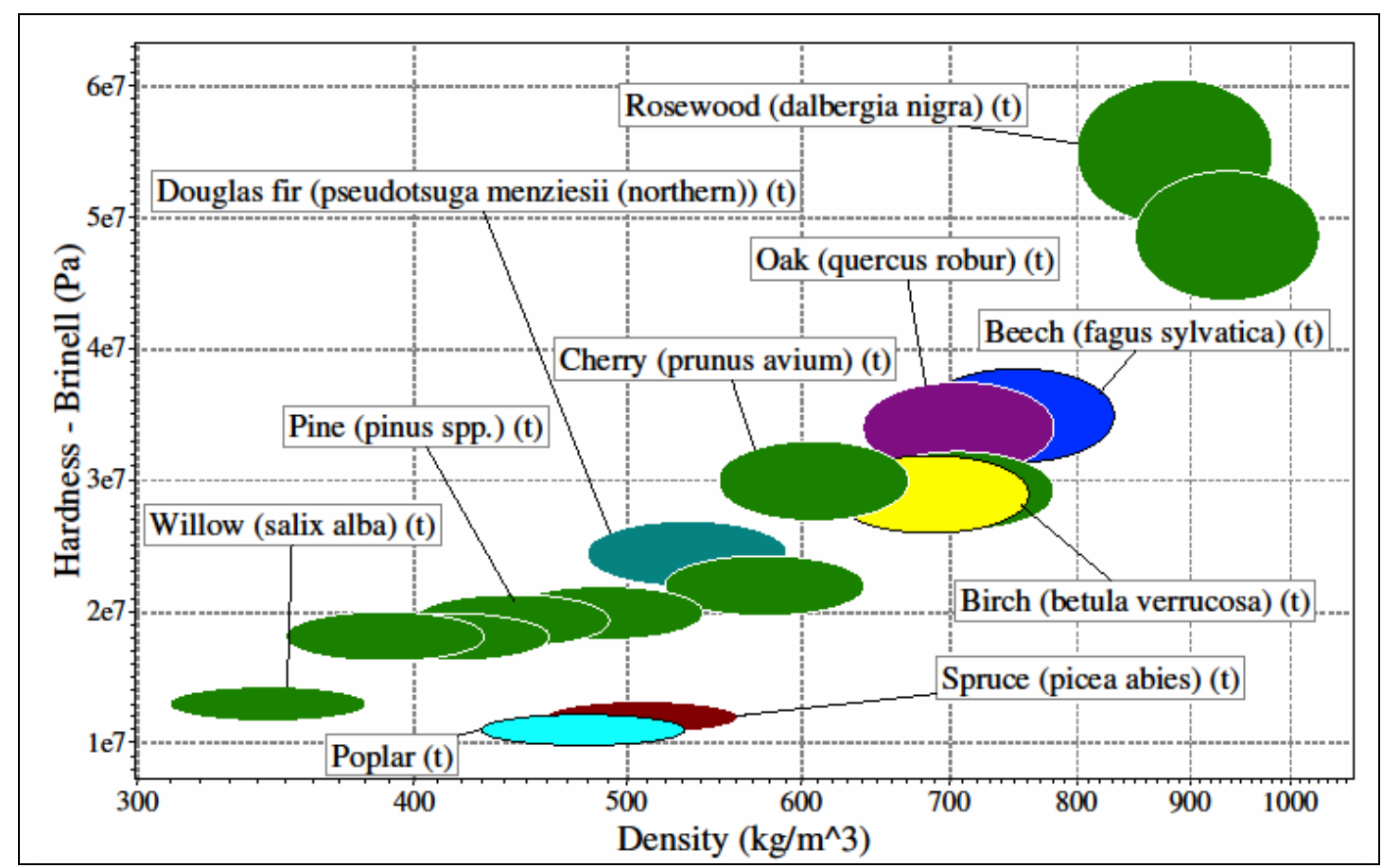

Figure 38.1 Hardness and density index for commonly used wood welding species (non-green ellipses) (Transverse properties reported).

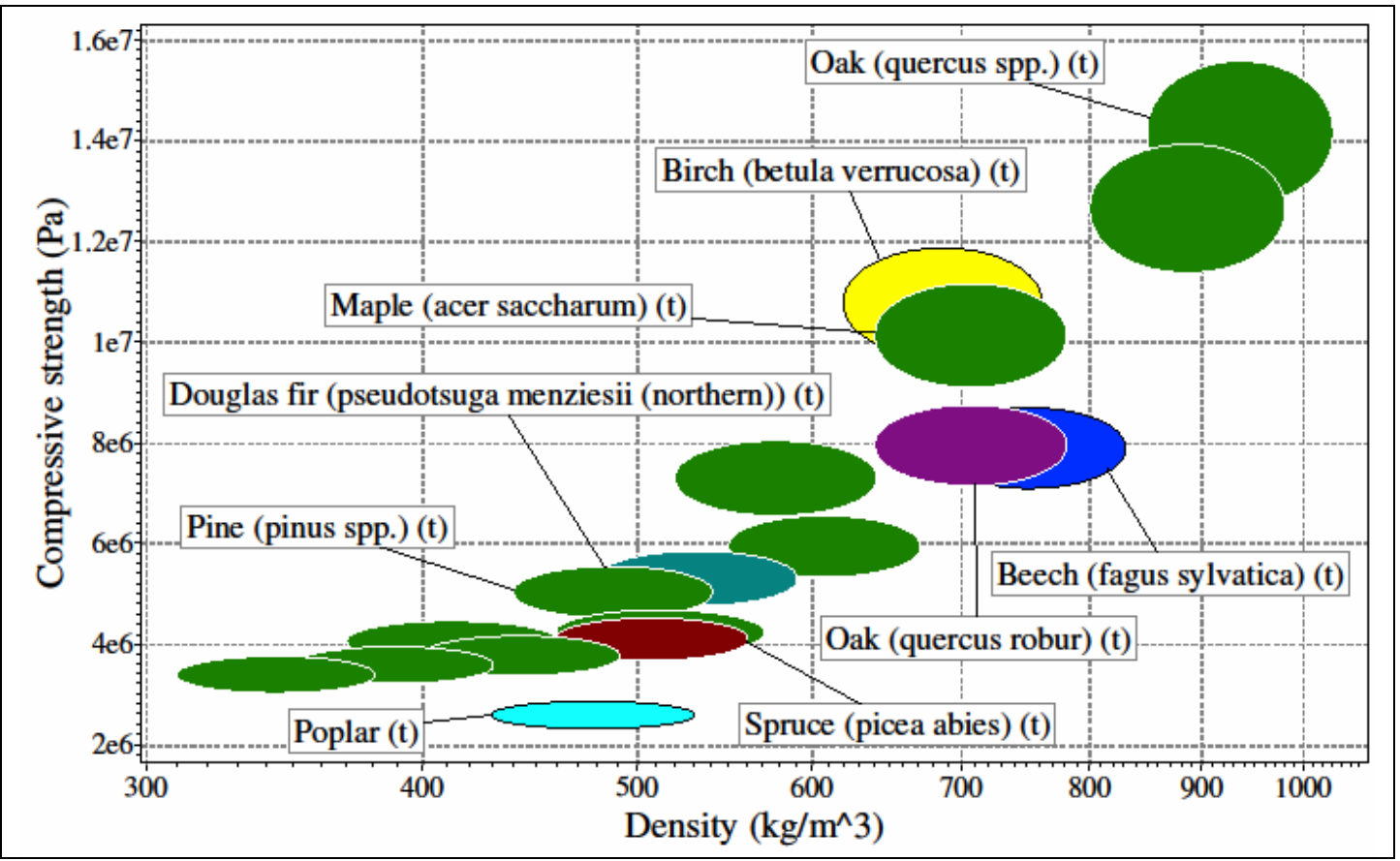

Figure 41.1 Compressive strength and density index for species commonly used in wood welding (non-green ellipses) (Transverse properties reported). 


\section{Appendix B: Supplementary Literature Review Subjects}

\section{B.1 Hardness Testing and Water Resistance}

While the primary use of wood welding is to produce joints, it has also been used as a method to surface harden timber and improve its water resistance [42]. Brinell hardness testing uses a hardened spherical steel indenter and applies a load to the surface in question. By measuring the diameter of the indentation on the surface and knowing the ball diameter and load, a hardness value can be calculated. For their experiment, a 0.39" $(10 \mathrm{~mm})$ diameter ball and a 112.4lb $(500 \mathrm{~N})$ load were used on beech wood. As for water resistance, the wettability of the surface is determined by measuring the angle of contact. A hydrophilic liquid would form a molecular thin film and result in a $0^{\circ}$ contact angle, and a perfect hydrophobic liquid would ball up and form perfect spherical droplets and have a contact angle of $180^{\circ}$.

\section{B.2 Chemical Additives, Surface Hardening, Heat Treated Samples}

In an effort to improve or assist the wood welding process, several attempts have been made to place chemical additives between the wood surfaces prior to processing. The first was plain water. A water spray was tested to observe what effects a higher moisture content had on the flow of lignin. Initial experiments found that the $12 \%$ equilibrium moisture content found normally in the wood was sufficient; additionally, thermal measurements taken at the bond line indicated a temperature of $170^{\circ} \mathrm{C}$ of higher $[7,10,14,15]$. This elevated bond line temperature suggests that any additional surface water would likely be turned to steam. 
The original studies mentioned that the wood welded joints could only be rated for interior-grade applications due to weather durability and strength, but other additives could help. Experiments were performed with a water solution of a polyflavonoid tannin (pine tannin extract), sunflower oil, furfural, and a polybutylene adipate water solution with the goal of improving bond strength and durability [18]. Sunflower oil performed the worst and acted as a type of lubricant that detrimentally affected the bond. The water in the polybutylene adipate solution almost instantly vaporized, and the salt residue left behind undermined the bonding process. While the pine tannin and furfural solutions yielded results comparable to the control sample, only the furfural improved durability. A single additive alone could not improve the bond, but a mixture of pine tannin and furfural likely would. However, such a combination is an acknowledged thermosetting adhesive and such use would mask the bonding characteristics of the wood welding process [18]. This investigation was only an initial test and further experimentation and optimization could produce better results.

While sunflower oil was shown to severely affect the ability for a bond to be created, its use may have alternative applications like wood surface finishing. When wood welding techniques are performed in concert with polymerizing unsaturated oils, such as sunflower oil, the resulting wood obtains a significant increase in surface hardness and water repellency [42]. Often times such values were more than double that of an untreated sample. Brinell hardness measurements have shown that under the proper conditions, beech wood samples can achieve hardness values comparable to samples prepared with a layer of polyurethane finish. Such hardening is the result of two separate 
mechanisms, the first being the polymerization of the oil and the second being the surface densification created by the vibration process [42].

In addition to the use of chemical additives to improve bond performance, preprocessing heat treatments have been explored. While pre-heating is used for metallurgic welding often times to minimize thermal gradients, heat treating in lumber is often done to increase durability and mitigate dimensional changes due to changing moisture content. With this fact in mind, researchers have attempted to wood weld heat treated wood [20]. Using a three step process adapted from commercially available Plato wood, beech, birch, and poplar samples were first subjected to hydrothermolysis (a lowtemperature $\left(165^{\circ} \mathrm{C}\right)$ heat treatment done in a steam atmosphere), dried in conventional manner $\left(50-60^{\circ} \mathrm{C}\right)$, and lastly heated to $170-180^{\circ} \mathrm{C}$. Although a total time was not reported, the final treatment was said to take four hours. While welding did occur, the heat treated samples were not as strong or ductile as the untreated samples and required greater welding pressure and holding times. Post weld SEM analysis showed that only minor amounts of matrix material was found at the bond line leading to little or no wood cell entanglement. These two observations led the researchers to conclude that the heattreatment most likely substantially cross-linked the lignin/hemicelluloses and increased its glass transition temperature $\left(\mathrm{T}_{\mathrm{g}}\right)$, thus decreasing its flow characteristics and making the bonding substantially more difficult [20].

\section{B.3 Alternative Modes: Ultrasonic and Friction Stir}

Planar and rotational wood welding have dominated the field of research, but there are other potentially viable friction welding procedures that exist. Ultrasonic welding is similar to planar vibration, but is characterized by significantly higher 
frequencies. Ultrasonic welding performs well with thin pieces of material and can often build components that cannot be done by other means, most often because of the size or complexity of the work piece.

Friction stir welding (FSW) was developed by The Welding Institute in the United Kingdom and is mostly used with some metals and plastics. After two separate pieces of material are placed together to form a butt joint, a spinning cylindrical or conical tipped tool is rotated up to speed, on the order of thousands of RPMs. The tip of the spinning probe contacts the butt joint and generates friction. This friction softens, but does not melt the material nearest the joint. By "stirring" together the softened material of the separate pieces, a joint is created upon solidification [47].

Both of these techniques were attempted with wood, but had poor results [43]. Only thin, 0.079 " $(2 \mathrm{~mm})$, sections would work with ultrasonic methods. Thicker sections either did not bond or were exceedingly fragile. Additionally, existing equipment can only process small circular areas $0.47-0.78 \mathrm{inch}^{2}\left(3-5 \mathrm{~cm}^{2}\right)$ [43]. Further experimentation could improve ultrasonic results, but researchers have found in general that ultrasonic wood welds "are not likely to be suitable for structural application [43]." The FSW attempt did not fair any better. Strengths were low, but with optimization and retooling existing probes, FSW of wood still remains a possibility. 


\section{Appendix C: Additional Design Information}

\section{C.1 Concerns Regarding Rotational Wood Welding}

To date, the majority of the wood welding research focused on the rotational methodology. In many regards, it is a simpler processing method where the primary variables are rotational speed, plunge force, dowel diameter, and hole diameter. While rotational methods may be applied for future applications, it is unlikely they will be employed in the creation of structural members. The main issue arises from the fact that wooden dowels would likely be used to bond various layers together. Regardless, researchers have tested dowel wood welded joints and have constructed pseudocomposite beams. Additionally, is the possibility that researchers may have poorly characterized the actual mechanics at work in the dowel bonds themselves.

Stress transfer is one of the chief reasons that the dowel welded members have been deemed pseudo-composite. In this instance, composite does not refer to one of the basic material classes, but rather to a bulk scale member. In composite members, multiple individual elements are attached to each other to form a larger or stronger member. A glue laminated beam (Glulam) is an excellent example of a composite member where an adhesive is applied between the various wood surfaces. Glues are usually the best option for attachment in composite members due to stress transfer. To achieve a true composite member using mechanical fasteners, (i.e. nails, screws, or wooden dowels) the number of fasteners required to properly transfer stress between layers is staggering. Even if a manufacturer was willing to use such a method, they would run into another issue if using timber. Since wood has anisotropic properties, 
certain material directions are stronger than others. When excessive amounts of fasteners are used in the same piece of wood, each connection acts as a small wedge. Each connector, a nail for example, generates a small, localized, and beneficial stress field. This small stress is what holds the nail in the wood; however, when too many nails are driven into a single piece of timber, the stress fields can connect with one another and will form a crack that can run the length of the board. Lastly, using wooden dowels as mechanical fasteners seems problematic. Wood performs great in bending but not as well in direct shear applications. Shear transfer is of principle concern when dealing with composite members, and the use of wooden dowels would seem to only compound the issues previously mentioned.

Even if the issues previously mentioned were addressed and solved, there still remains one profound concern regarding rotational wood welding. In the majority of the articles, slightly larger dowels are inserted into slightly smaller holes. Researchers have said that the intentional mismatch results in a stronger welded bond, but this assumption is suspect. Dowels have been used for centuries as a way to bond together timber. They work on a principle called an interference fit which forces a slightly larger peg into a slightly smaller hole. With metallic components, an interference fit can be achieved with a mismatch of only a few thousandths of an inch. Since timber is much softer and forgiving, the mismatch can be substantially larger. It is this intentional over-sizing of the dowel that makes a good joint in traditional timber construction, but any discussion of the matter is surprisingly absent in the literature regarding rotational wood welding. While welded dowel connections have been shown to exhibit strength, researchers have yet to consider or mention the possibility that the strength could substantially be due to 
the dowel action and only partially due to the wood welding. Wood welding works because of a temperature driven softening of the wood. This softening likely allows the dowels to be temporarily squeezed into their given substrates. When the rotation stops, the heat source is removed and the softening ends. Research into planar welding using Norway spruce helps to illustrate this point. As mentioned previously, planar welding results using spruce were poor, but that fact has not prevented spruce from being used extensively as a substrate material in rotational welding. Either spruce performs better in rotational welding, or something else is at work. Spruce most likely is not welding to the dowel but only providing a compressive stress to hold the dowel in place. 


\section{Appendix D: Motor Requirements and Calculations}

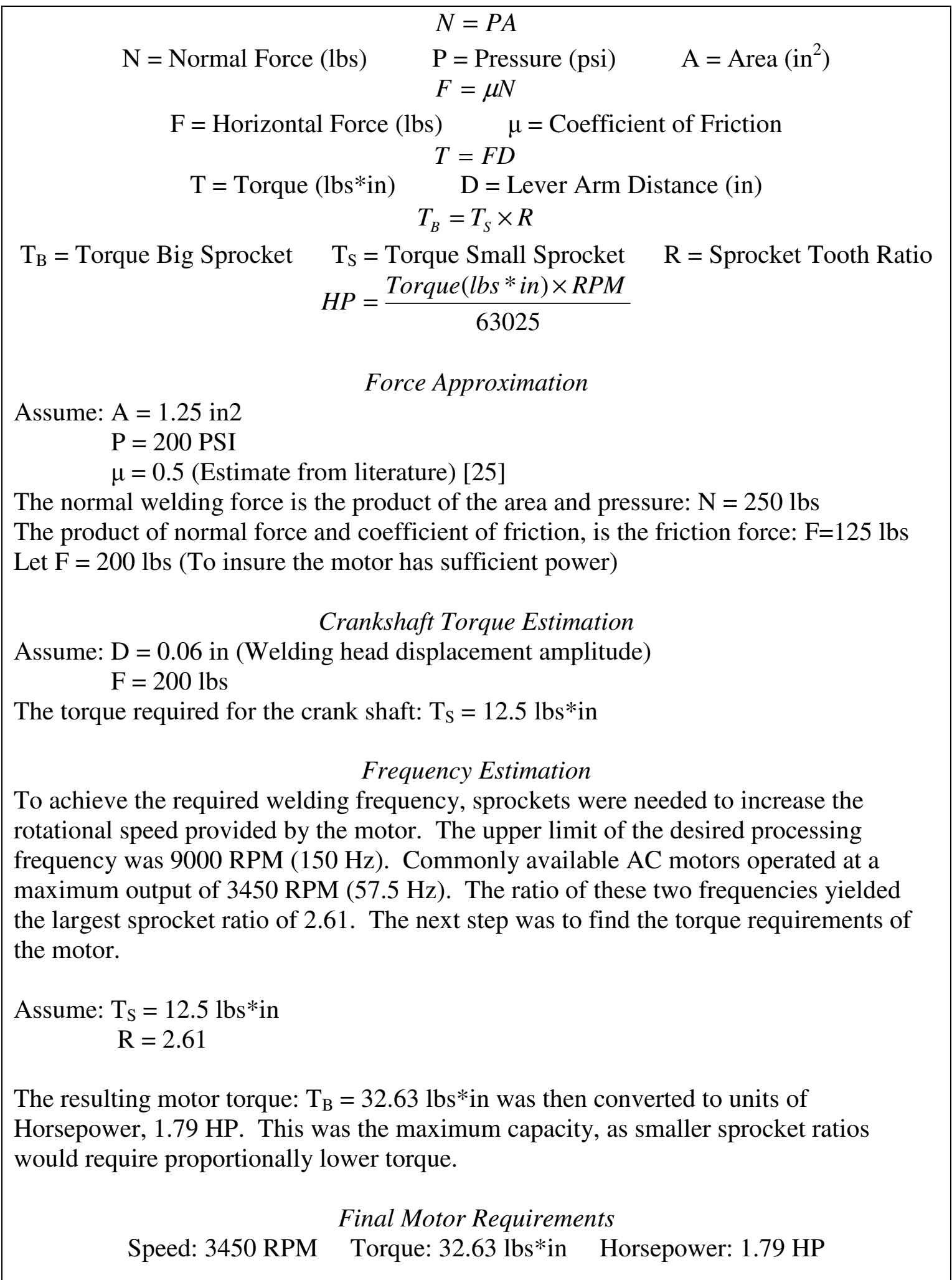




\section{Appendix E: Wood Block Sample Creation - SOP}

\section{READ AND COMPREHEND ALL INSTRUCTIONS PRIOR TO OPERATION.}

Purpose: To rip and cut larger timber boards down to the proper size needed for wood welding samples.

1. Material Selection and Preparation

a. Board Selection

i. When estimating the size of the board required to create enough samples for a given experiments, be sure to account for the saw's blade loss, processing errors, misaligned grain, etc. It is better to overestimate and have extra blocks than to underestimate and be forced to go through the block processing again.

ii. Choose boards as close as possible to the samples' final dimension. Thickness is usually a good choice as its dimensional tolerance is not incredibly important.

iii. Select boards with minimum distortion: bowing, cupping, knots, straight grain, etc.

b. Required Tools
i. Calipers
ii. Tape Measure
iii. Push Sticks
iv. Pencil
v. Colored Markers
vi. Sanding Block
vii. Table Saw
viii. "Dummy" welding head
ix. Eye goggles and face shield
X. Wood plainer (not necessary, but makes process easier)
xi. Shop Vacuum (optional) 


\section{c. General Notes}

i. Use goggles at all times when the cutting machines are running.

ii. Use push sticks when feeding the boards through the table saw.

iii. Do not set the saw blade height excessively high. The blade should only be between $1 / 8$ " to $1 / 4$ " higher than the height of the wooden board being ripped or cut.

iv. "Ripping" refers to a longitudinal cut, parallel with the grain. "Cutting" is perpendicular to grain.

v. The planing process makes a significant amount of saw dust. It is useful to run a shop vacuum connected directly to the table saw's dust collection port.

\section{Ripping and Cutting}

a. Table Saw Inspection

i. With the saw off and unplugged, inspect the different components of the saw including, but not limited to the blade, fence, cut-off guide, and electrical cord.

ii. Adjust the saw's bevel angle to $90^{\circ}$.

iii. Connect the shop vacuum's hose to the table saw's dust port.

b. Rough Cut

i. Cut the board to a convenient working length: 24 ", 30", 36", etc. with the table saw and the sliding cut-off guide.

ii. Position the fence on the table saw and verify the blade to fence distance by ripping a refuse piece of lumber and measuring the freshly ripped board with the calipers.

iii. Plan to rip the board (longitudinal cut) as to maximize the number of strips with desirable grain orientation.

iv. Rip a new side on each large board to create a clean and flat edge that later measurements can be made from (remove as little material as needed).

v. Rip the boards to a rough dimension, no less than $1 / 8$ " over the final width dimension. 


\section{c. Board Width Planing}

i. *The dimensional tolerance of this portion is very important. Over sized samples can be sanded down to achieve the necessary thickness, under sized samples will be discarded.

ii. With the help of the cut-off guide, square both ends of each wood strip.

iii. Plane the individual board to the correct width, removing approximately $1 / 16$ " each pass with the table saw, or plainer if available.

iv. Prior to the final pass, verify the width with the calipers to insure that after the final pass the strip will not be below the required final dimension.

v. Use the dummy welding head as a gauge for the strip width. Lightly sand the strip until the welding head can barely move along the strip.

d. Board Thickness

i. Rip the wood strips to within $1 / 8$ " of final thickness.

ii. Plane the strips, removing approximately $1 / 16$ " each pass until the final thickness is achieved (Dimensional tolerance is not as critical for the thickness). Again, use the table saw or plainer.

iii. Select the appropriate color coded marker for the given species of wood just dimensioned.

iv. Run the marker the full length along a narrow side of the strip (Marking one strip is easier than marking dozens of small blocks). 


\section{e. Individual Single Blocks}

i. *This is the final processing step with the table saw and requires the face shield.

ii. Adjust the table's fence to produce the final dimension on the sample, the length. This dimension should be as close as possible to the desired value.

iii. Make sure that the cut-off guide is exactly perpendicular to the saw blade.

iv. Hold the strip against the cut-off guide and butt one end of the strip against the fence.

v. Get a thin push stick ready for use.

vi. While holding the strip against the cut-off guide in one hand, use the other hand to hold the push stick. The push stick should support the end of the wood strip and be centered between the fence and saw blade. Turn the saw on and gently push the strip forward into the saw blade, thereby cutting off one small block of wood. (*Caution: This process can cause the newly cut small block to contact the spinning saw blade and make it go flying). Use the push stick to make sure that the small block slides clear of the blade and off the table saw.

vii. Repeat this process until each wood strip can no longer be braced against the cut-off guide. Depending on the make and model of the particular table saw, the short unusable section of the wood strip should be approximately 4-6" long. 


\section{Appendix F: Shop Drawings - Shear Fixture}

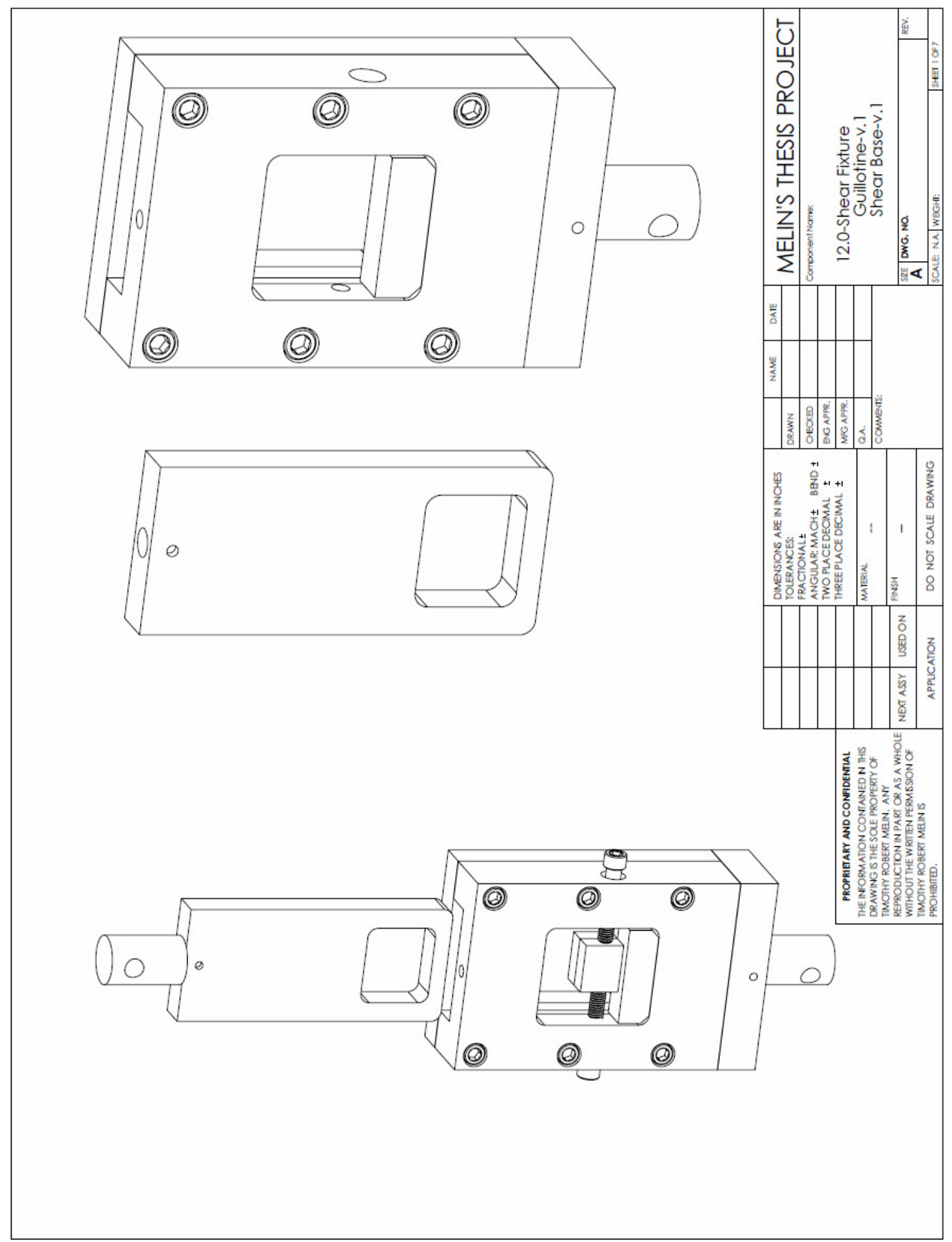




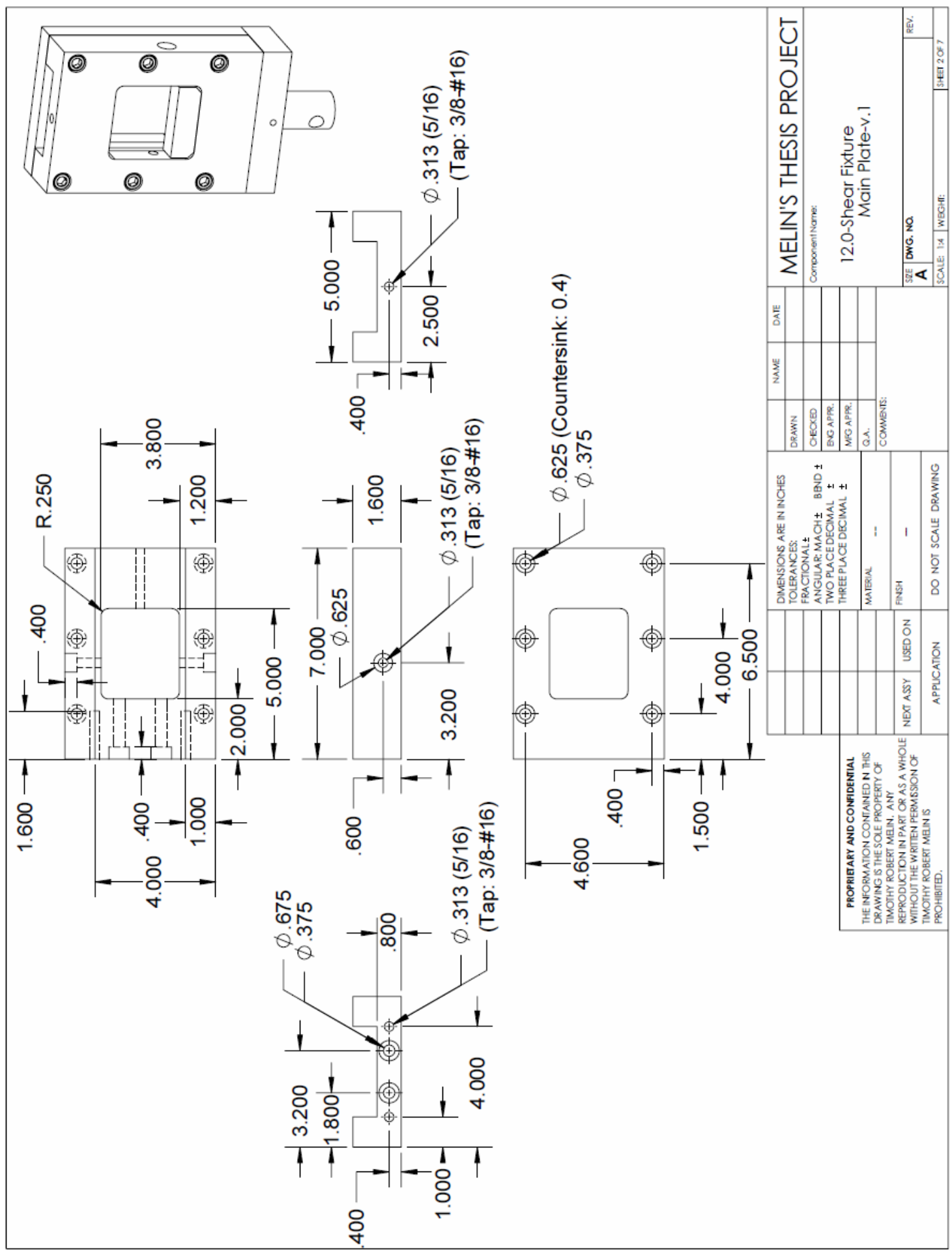




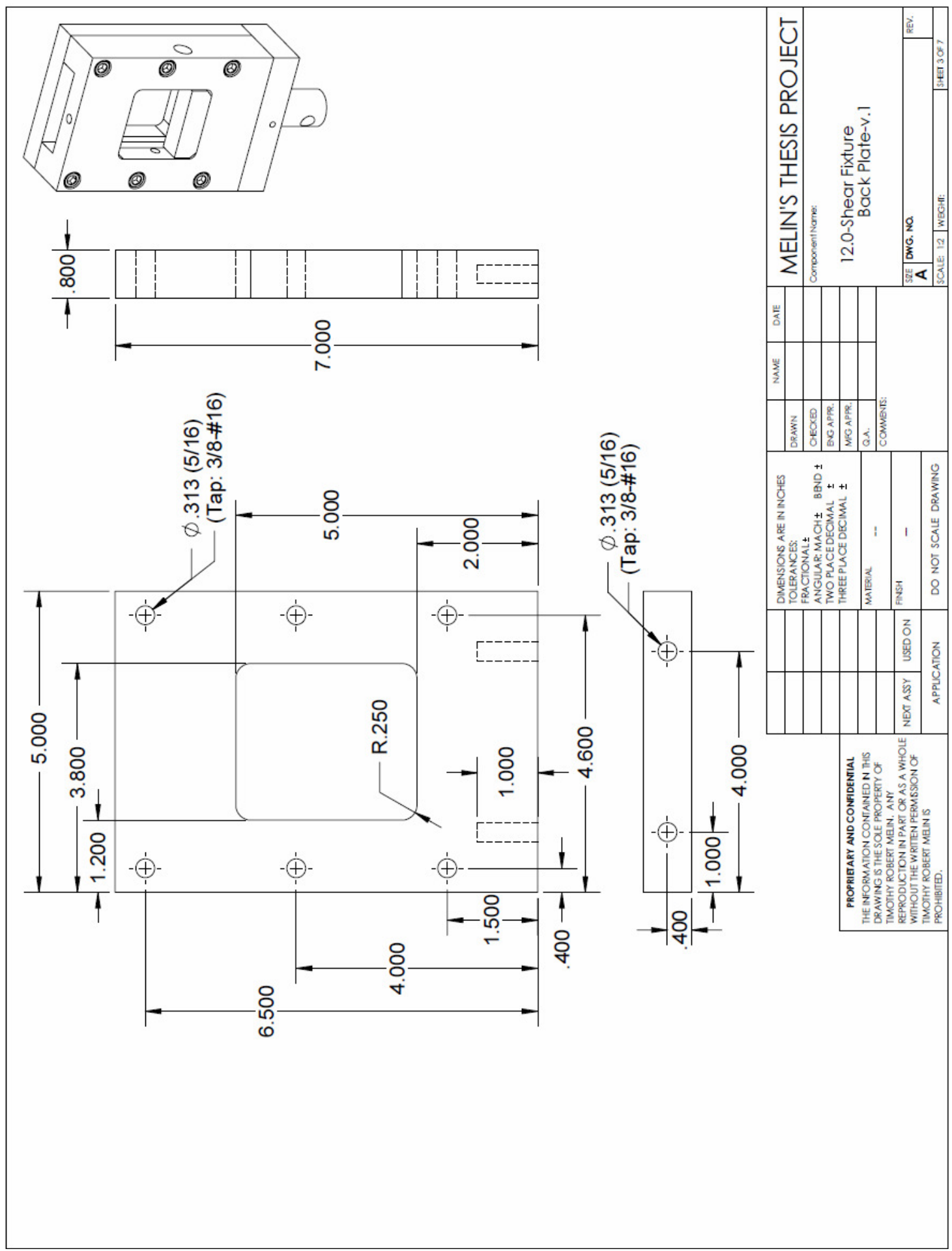




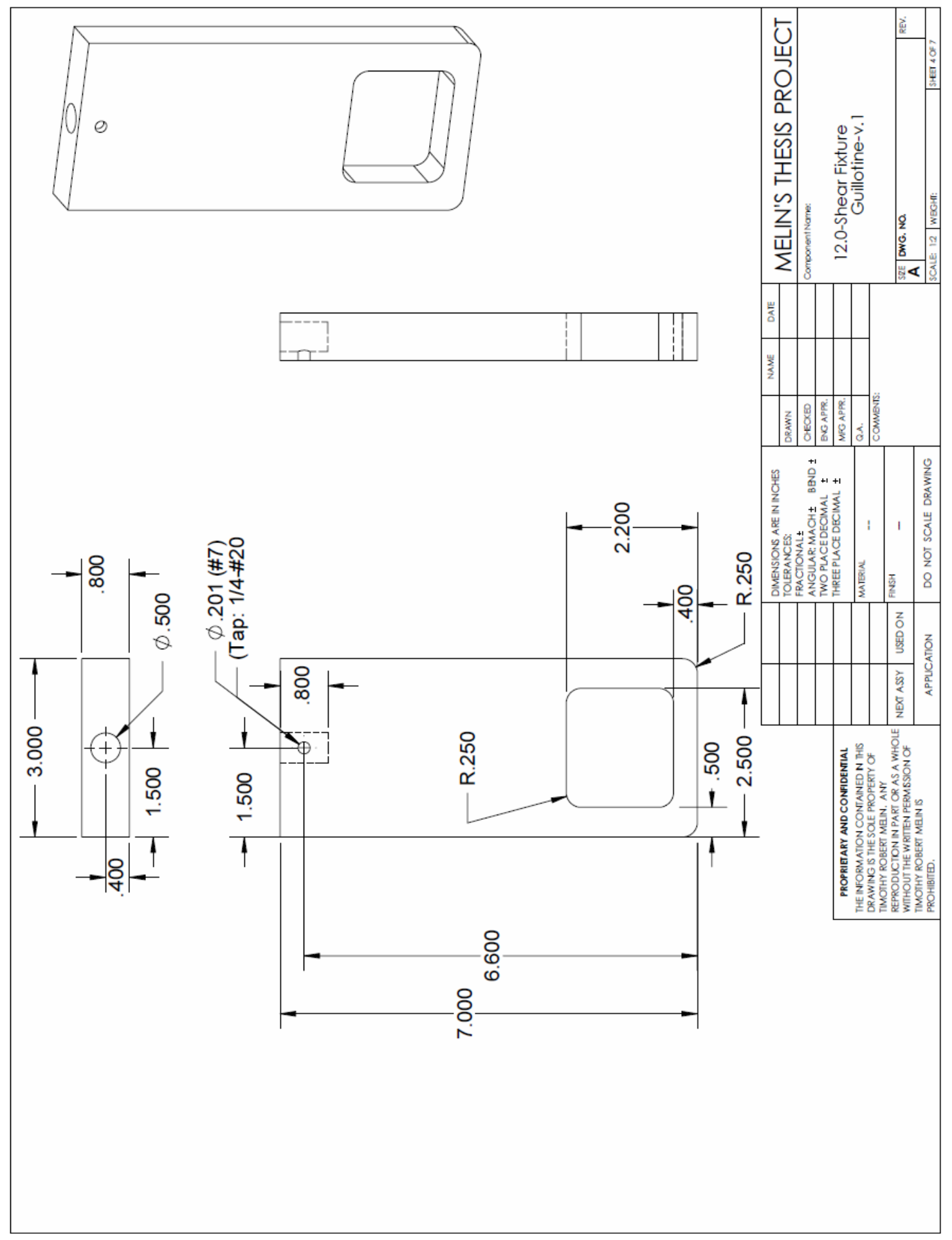



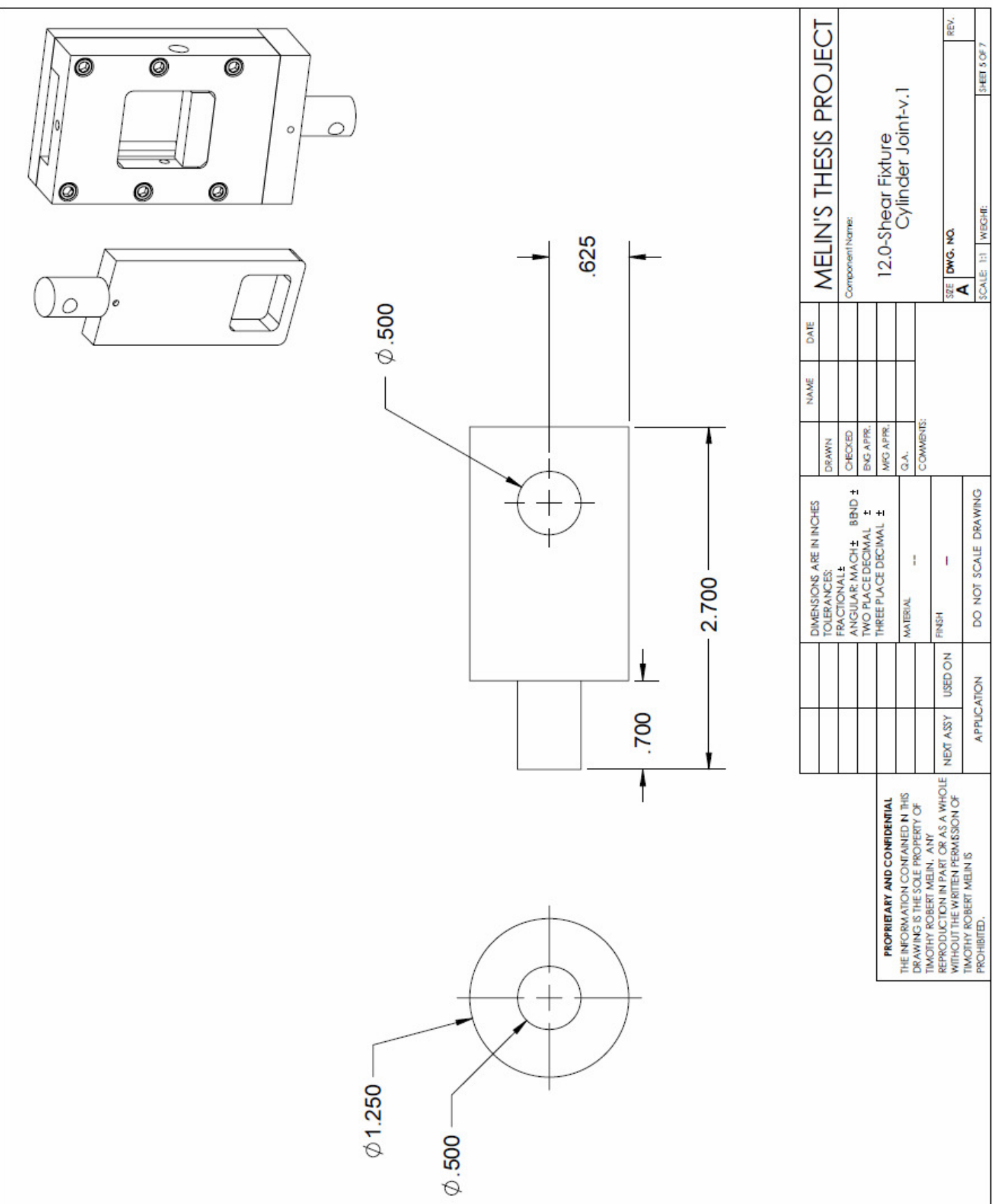


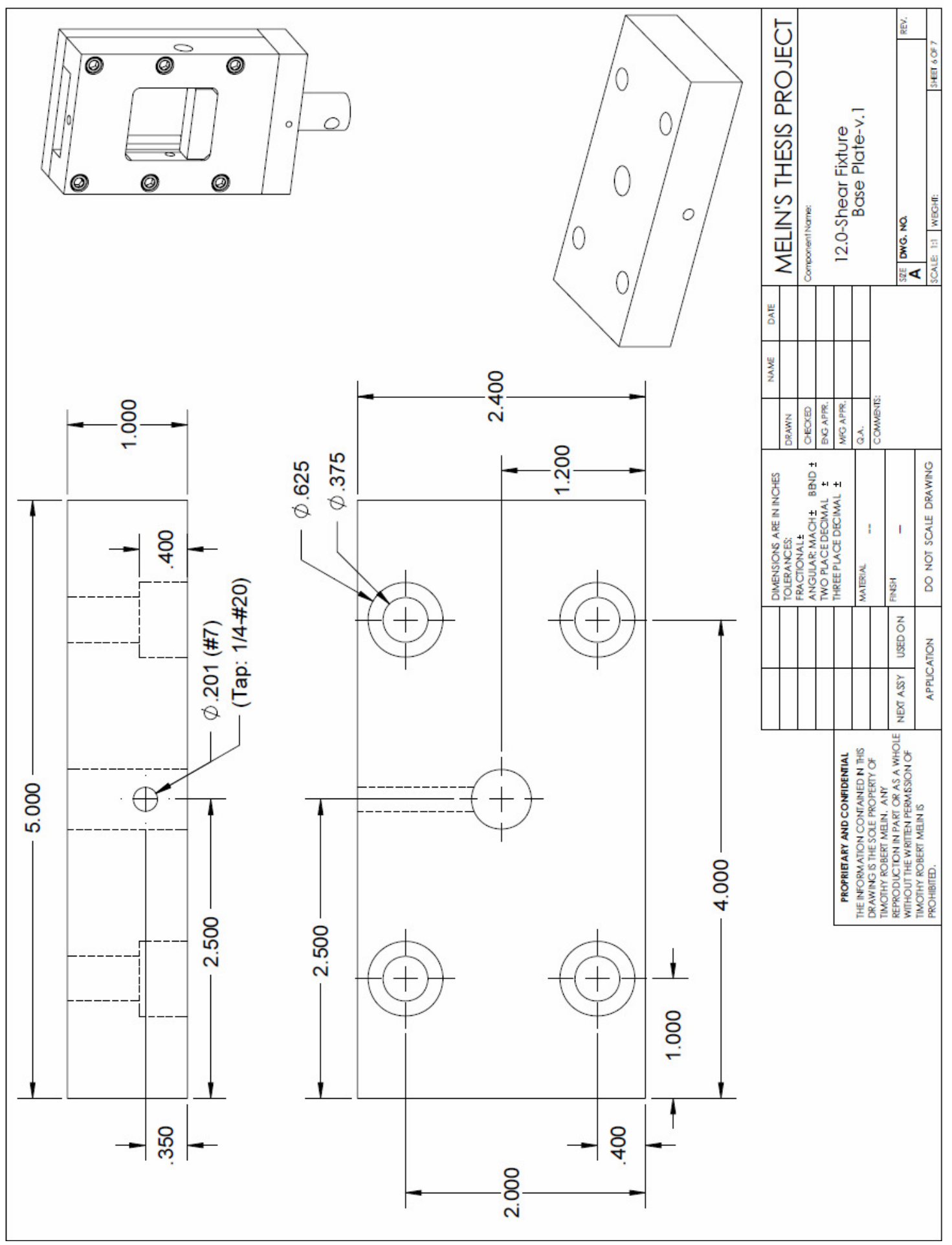



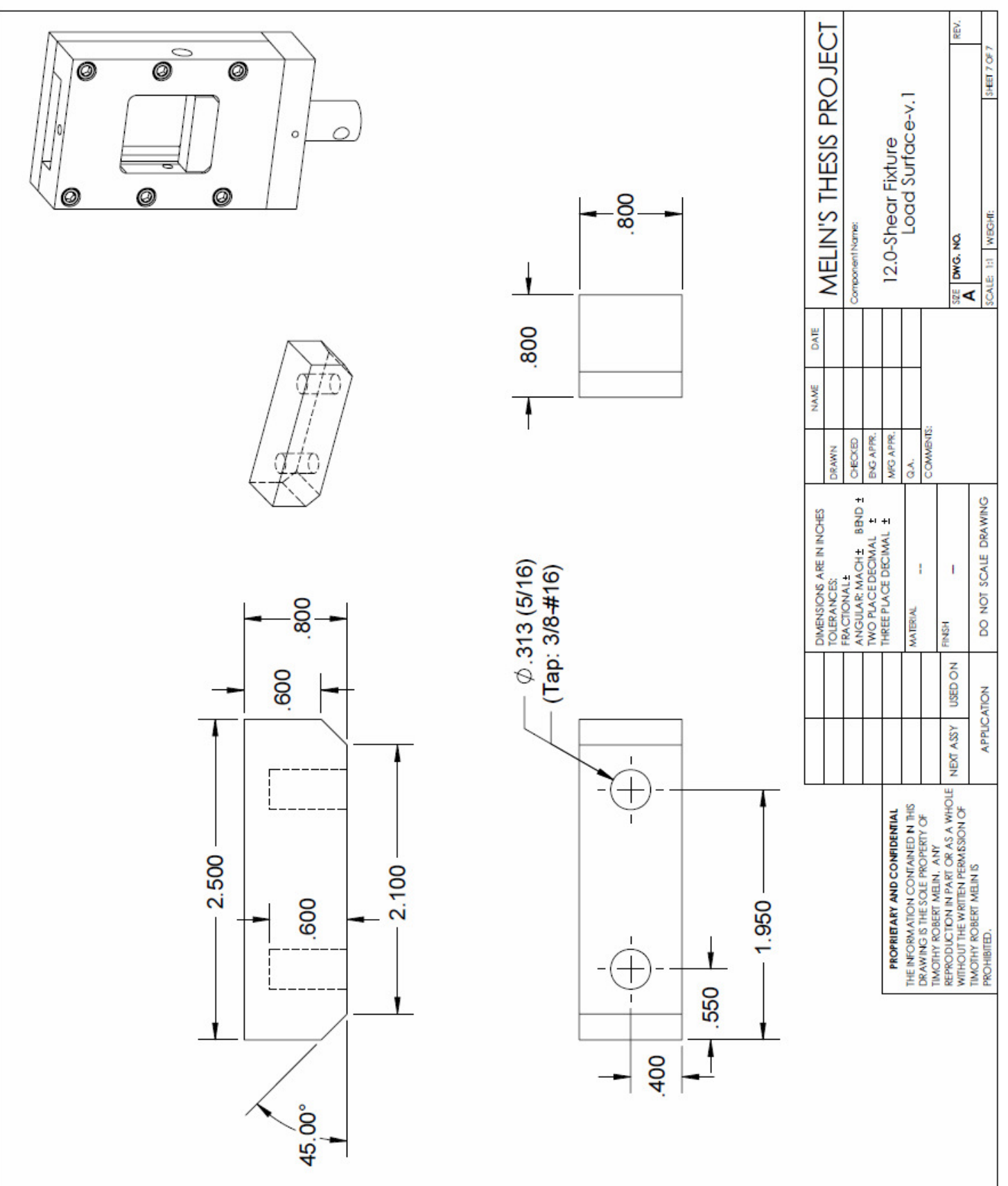


\section{Appendix G: ImageTool Example and SOP}

Purpose: To instruct and educate the user about the ImageTool software program and general procedures used to digitally measure the bonding areas.

\section{Sample Images and Preparation}

1. Arrange all the samples from a given series and make a label for them.

2. Prepare any lights and camera equipment. Make sure that shadows and other unwanted attributes will not be present in the photograph.

3. Take several digital photographs to insure that one image has sufficient quality.

4. Upload the images to a computer.

5. Download and install the ImageTool software package from The University of Texas Health Science Center in San Antonio:

$<$ http://ddsdx.uthscsa.edu/dig/itdesc.html>

\section{Image Analysis}

1. Open the program, ImageTool

2. Choose an image

a. Under "File", select "Open Image" and select the desired photo.

3. Select the area for analysis

a. Use the "Area" button in the program.

b. Draw a polygon around the desired area for a given sample. Double click to close the polygon.

c. To draw a rectangle: hold "Alt" on the keyboard, and choose the area. 


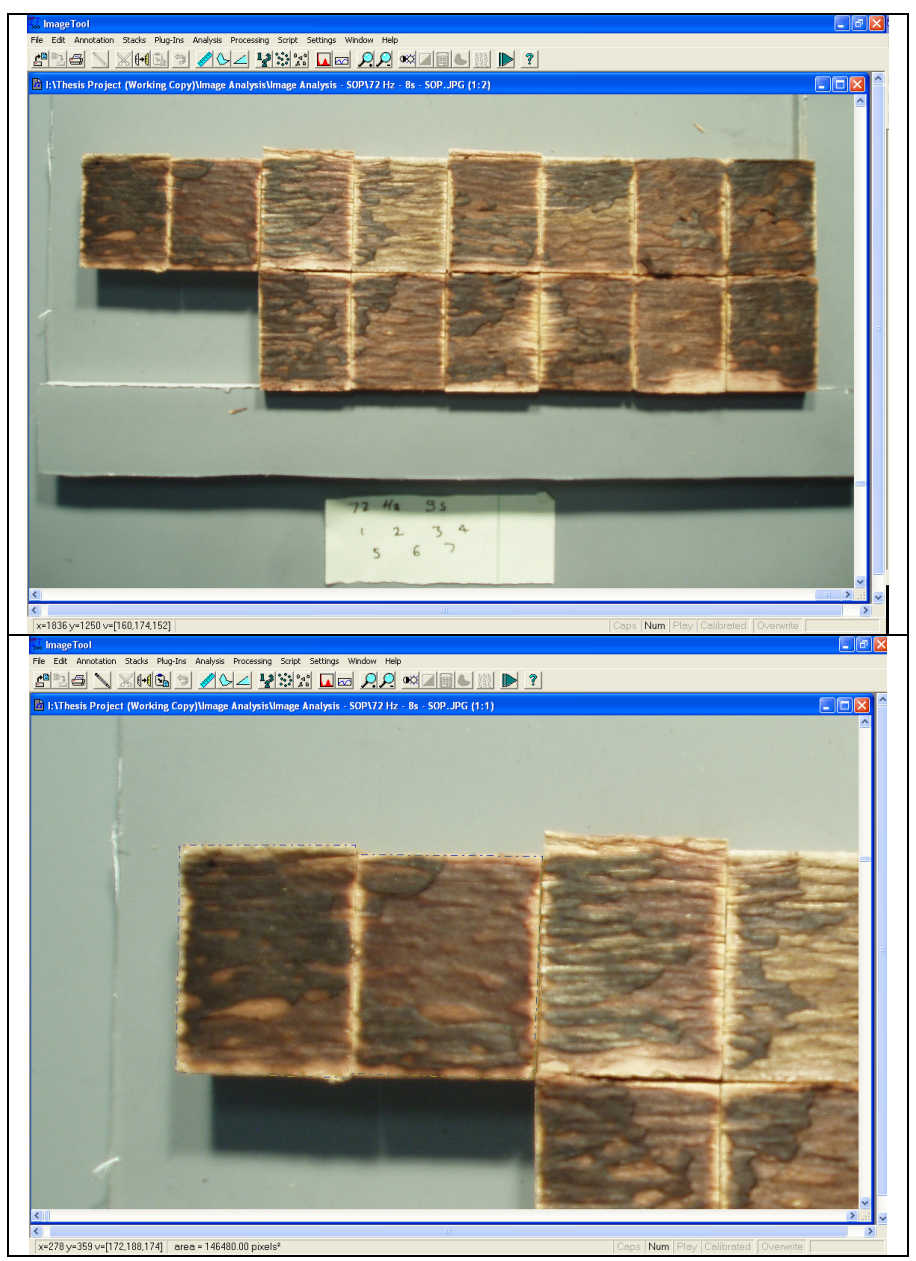

4. Creating individual sample images

a. Click the "Copy Image" button.

b. Under "Stacks", click the "New" button.

c. Hit the "Paste" icon on the screen to transfer the image.

d. If the image was slightly skewed and black outlines appear do not worry. These issues will be fixed later during the threshold process.

e. Save the individual sample images with a descriptive name; “( $72 \mathrm{~Hz}-8 \mathrm{~s})-$ Spec 1-Samp 1.stk" for example. The suffix "stk" will be automatically added. 


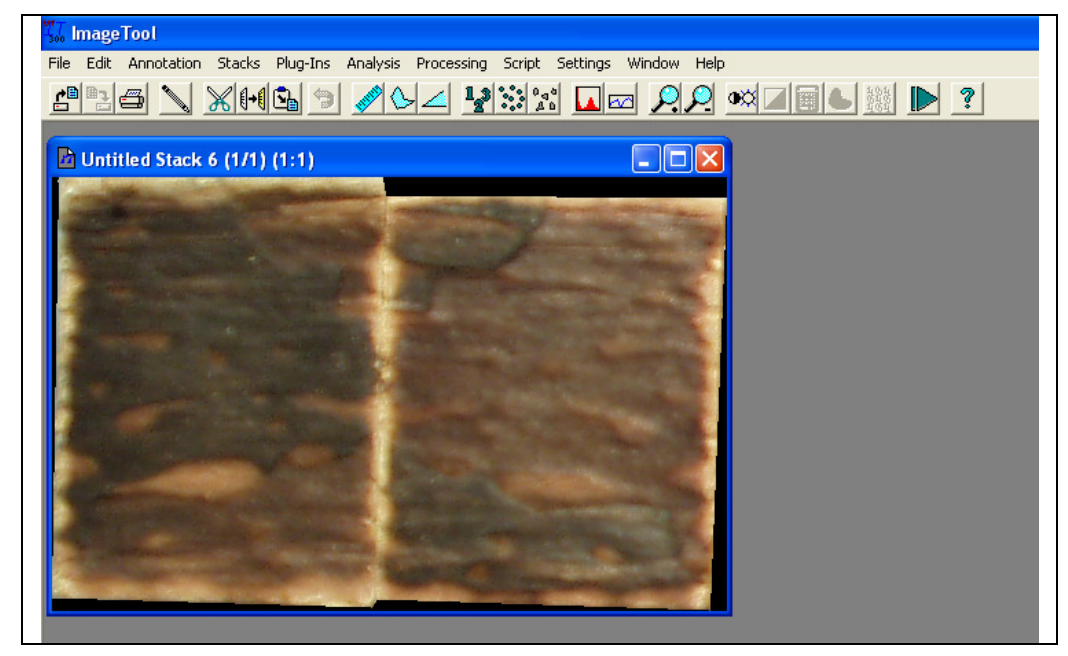

5. Image Processing and Threshold Adjustment

a. Under the "Processing" tab, select "Color-to-Grayscale". A new grayscale image of the sample will have been created.

b. Save the new gray scale image. Again, be sure to use a descriptive name; “(72 Hz-8s) - Spec 1 - Samp1-gray.tif”

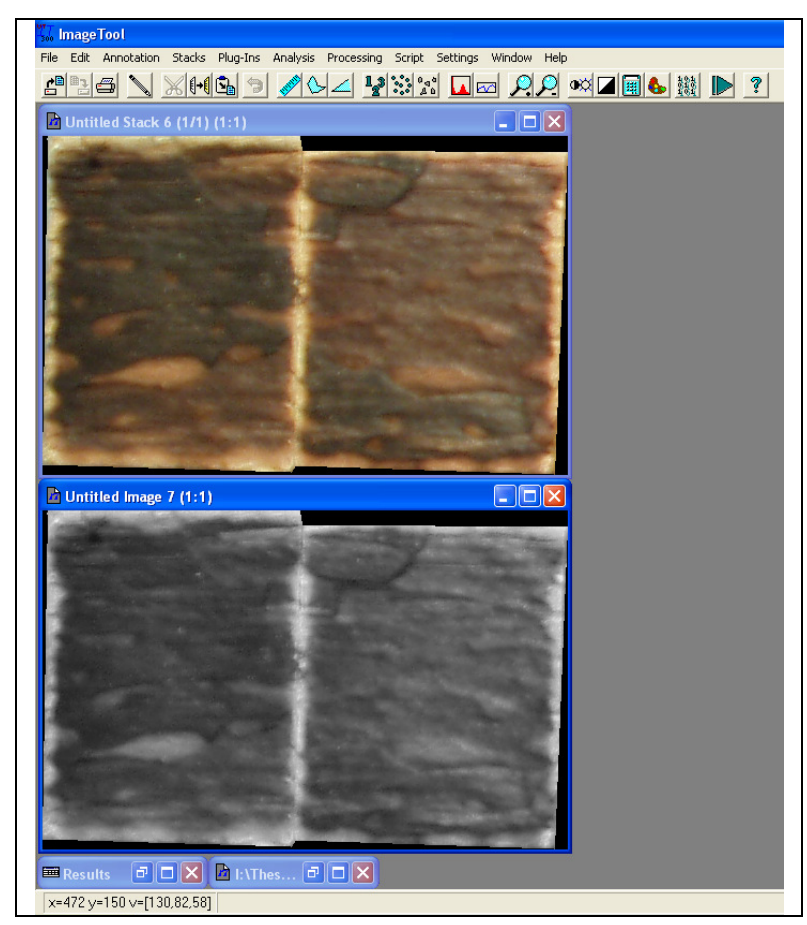

c. The threshold values will need to be adjusted twice and will create two new images that will be used for the pixel counting procedure. The 
threshold function is needed to create an image made only of black and white pixels.

d. (Calibration) Select the grayscale image of interest and click the "Manual" icon in the program. A new red image will appear on screen along with a box containing a histogram.

i. Position the red-image next to the original color image (to be used as a reference).

ii. Move the left slider below the histogram; the default value should be set at 0 . Move the slider until the outline silhouette of the sample is visible.

iii. Click "OK”.

iv. A new image will be created composed of only black and white pixels. This image will serve as a calibration image for calculating the pixel ratio and will be used as the denominator.

v. Save the new calibration image. “(72 Hz-8s) - Spec 1 - Samp1calib.tif”

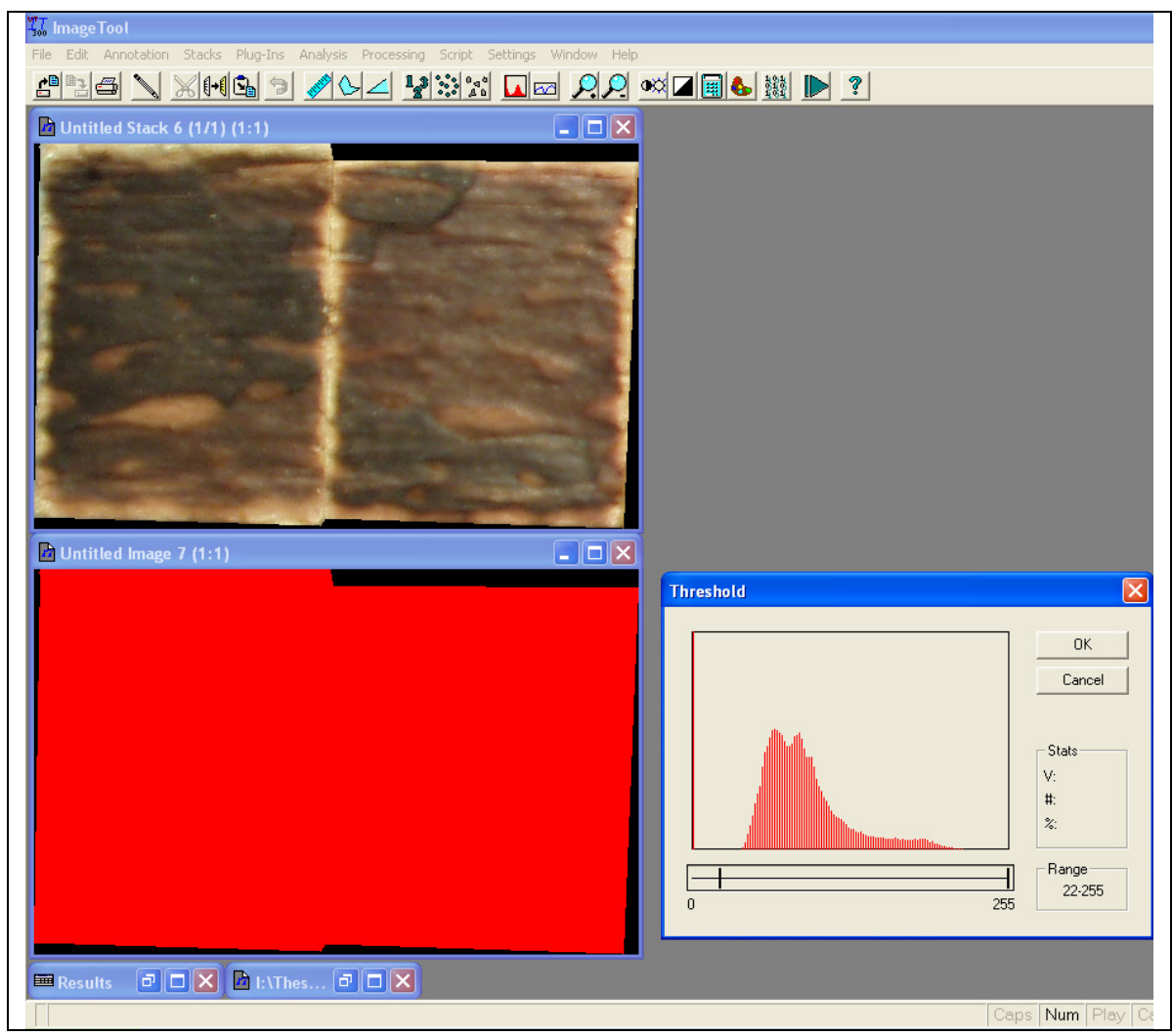


e. (Bonding) Select the grayscale image of interest again and click the "Manual" icon in the program. A new red image will appear on screen along with a box containing a histogram.

i. Position the red-image next to the original color image (to be used as a reference).

ii. Move the sliders below the histogram; the default values should be set at 0 and 255. Adjust the left and right slider to choose what features will be selected.

iii. Move the left slider until just before the main image elements (wood welded bond material) appears. The left slider should be positioned almost directly below the left tail of the histogram.

iv. Move the right slider until only the dark "weld material" is highlighted red.

v. Compare to the original color image for reference.

vi. Click "OK"

vii. A new image will be created composed only of black and white pixels. When the pixel ratio is calculated, the values from this image will be placed in the numerator.

viii. Save the new bonding image. "(72 Hz-8s) - Spec 1 - Samp1bw.tif" 


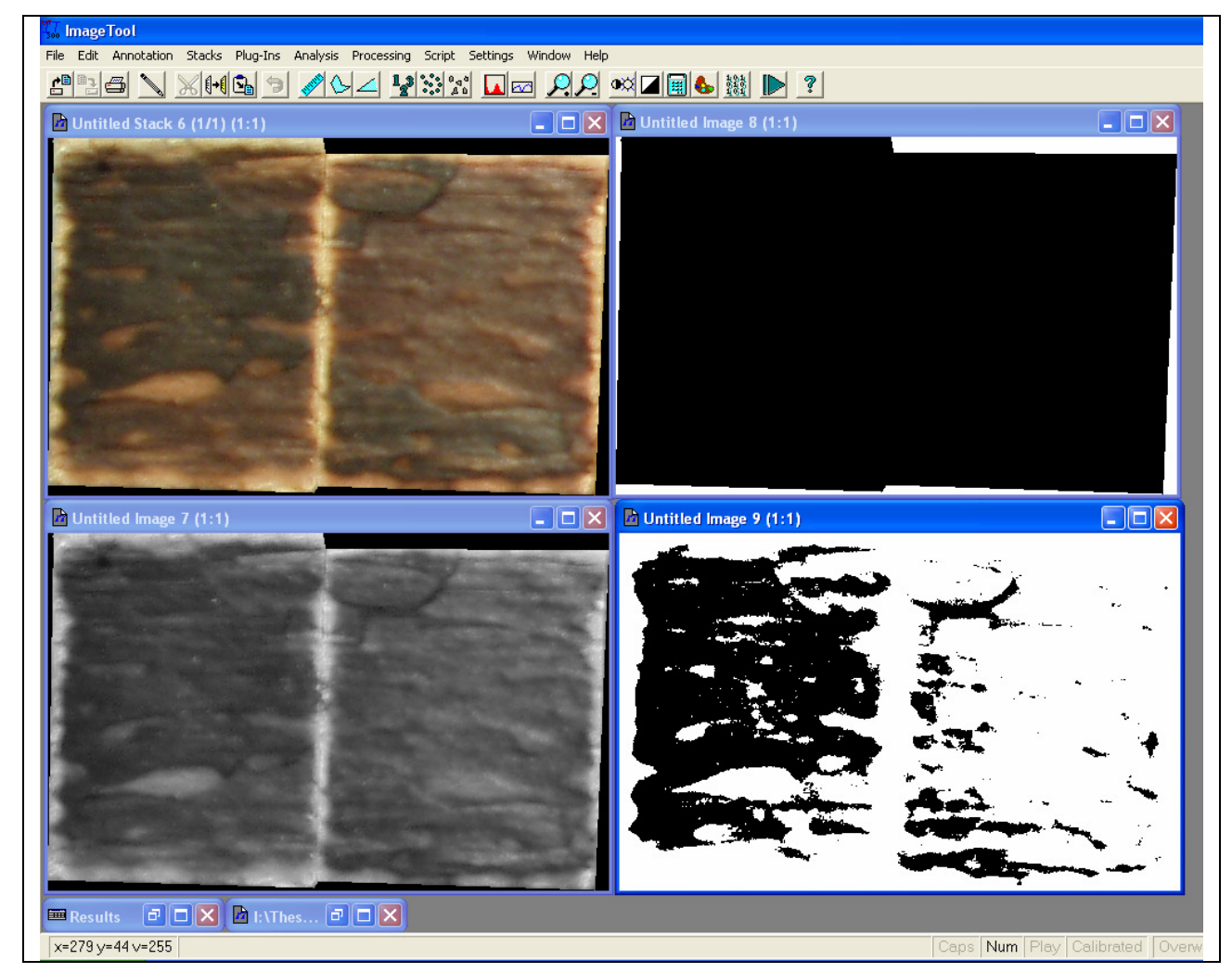

6. Pixel Counting

a. Select the calibration image and under the "Analysis" tab, select "Count Black/White Pixels". The black pixel count will be displayed in the "Results" panel of the screen.

b. Select the bonding image and under the "Analysis" tab, select "Count Black/White Pixels". The black pixel count will be displayed in the "Results" panel of the screen.

c. Take the number of black pixels found in the bonding image and divide by the number of black pixels found in the calibration image. The bonding ratio has now been calculated. 


\section{Appendix H: Experimental Bounding - Additional Material}

\section{H.1 Shielding Gas Side Effect - Potential Surface Hardening}

During the earliest trials with the welding machine, prior to the usage of sprockets, the frequency variance was attempted with the use of a Variac. The variable power source, Variac, was abandoned since its could not reliably alter the welding frequency. However, it has been mentioned because it usage revealed a potential alternative use for wood welding equipment during early exploratory experiments.

When early birch samples were processed using the Variac, with flowing nitrogen, no bonding between the pieces occurred. When the Variac was used the welding frequency was significantly reduced, although the exact value could not be determined. When a bond did not form between the samples, the surfaces of the blocks at the interface were markedly different. Each surface was noticeably smooth and appeared to have an almost polished finish. Also, the surface hardness appeared to have increased. While the use of sunflower oil has been attempted to increase hardness and water repellency [42], as mentioned in the supplementary literature review (Appendix B.2), the use of gas to accomplish such a goal has not been reported.

\section{H.2 Summary of Hardness Testing Methods}

Previous researchers have used a Brinell hardness scale for their experiments, but timber hardness values are normally reported using the Janka hardness scale. Both methods use a spherical indenter, typically steel, to apply a load to the test surface. The Brinell scale values are found using a formula based on the applied force $(\mathrm{Kg})$, indenter diameter $(\mathrm{mm})$, and impression diameter $(\mathrm{mm})$. A force is applied for a given time 
period and then removed. Measurements of the impressions are then made, usually under a microscope, and values can then be computed. This method is relatively simple but labor intensive.

The Janka method works opposite to the Brinell. Brinell applies a given load and measures material deformation where as Janka drives an intender to a preset displacement and records the requisite force. The Janka steel ball has a diameter of 0.444 " (11.28 $\mathrm{mm}$ ); the strange dimension was designed to leave a $100 \mathrm{~mm}^{2}$ impression in the wood during testing. When taking a measurement, the indenter is driven into the wood to a depth of half of its diameter, $0.222 "(5.64 \mathrm{~mm})$.

As with the Brinell method, the Janka hardness measurement did not seem appropriate for this experiment. While researchers have not mentioned to what depth the surface hardening effect penetrates the wood, it was likely to be rather shallow. Since the Janka process displaces a comparatively large amount of wood for each measurement, any difference in surface hardness would likely go unnoticed and overshadowed by the bulk properties.

A different approach was needed and a Rockwell hardness test appeared to be a good solution. Indenter tips come in different geometries (conical or spherical) and sizes, but the principle is the same. Minor and major loads are applied to the test surface and create a difference in penetration. When the major load is removed, the material partially recovers and the depth of penetration is decreased. Based on loads, indenter, and penetration, a hardness value is calculated. The advantage of the Rockwell system is speed. Many testing machines are automated once the user inputs the loads and readies the sample. Each test usually requires less than a minute, and the value is displayed at 
the end of the test cycle. Additionally, superficial Rockwell tests, those that use reduced loads, are available for studying surface level hardness. Many different load settings are available for a gambit of materials from steels to plastics, but none were found for timber. Because of this, an indenter and load set were needed. While an ASTM, or other standard may exist to use a Rockwell test in this manner, it was not necessary as long as the hardness testing was done in a reproducible fashion.

After some consideration it was believed that the largest readily available steel ball indenter should be used due to timber's microstructure. Timber is made of alternating annual rings of springwood and latewood. As the indenter gets smaller, the chances of testing a single ring region versus the other increases. Consistently testing one of the other regions would be difficult but necessary in order to determine if any change in hardness was the result of machine induced transformations or simply differences found between springwood and latewood. By using a large indenter, preferably wide enough to span several annual rings, the differences between the springwood and latewood hardness values would ideally be averaged out and better represent the timber sample as a whole.

\section{H.3 Experimental Set-up}

An Instron 1/2" steel ball indenter (Catalog \#: 900007204) was obtained for the testing purposes. The three lightest superficial Rockwell scales were chosen (HR15Y, HR30Y, HR45Y) with the hope that one of the settings would produce repeatable results without excessively crushing the wood samples. Each test was performed on an Instron Wilson Rockwell Series B2000 hardness testing machine with a 21/2" diameter anvil. 
Measurements were taken perpendicular to the grain and repeated multiple times for each sample.

\section{H.4 Exploratory Findings}

As mentioned previously, the accidental finding that arose from the first uses of nitrogen shielding gas was the possible creation of a surface hardened layer. While the birch samples were small, they still provided a large enough area for multiple measurements to be taken from one sample. Even though three load settings were attempted: HR15Y, HR30Y, and HR 45Y, each produced similar results. The data for each scale was not only widely scattered, but both positive and negative values were generated. Based on the data collected, it seemed obvious that using a Rockwell test on timber was unfeasible and likely unreliable. The hardness value of the surface layer could not be quantitative measured using the Rockwell method. However, the presence of a surface with potentially altered properties, generated with low welding frequencies and in the presence of nitrogen gas, was important and worth mentioning. 


\section{Appendix I: Machine Shop Basics}

\section{I.1 Safety, Tools, and Equipment}

There are a great number of potentially valuable tools and capabilities in a good machine shop, but before any work can be performed the user must be familiar with the equipment. Safely knowing how to operate and use the machinery and tools is essential before any work can be performed.

Once the user has been properly trained, tools found in a machine shop can be put to good use. Horizontal and vertical band saws are great for removing excess material and cutting stock down to more manageable sizes. Vertical milling machines can use a wide assortment of cutting tools: end mills, ball mills, center drills, face cutters, and a variety of drill bits. Although a vertical mill is often used for drilling operations, a drill press does prove useful in certain situations, most notably when reaming is required to widen a drill hole to a very specific diameter. Lastly, the lathe is the best tool available for any cylindrically based part.

While power tools such as band saws, vertical mills, drill presses, and lathes are essential for bulk material removal and finishing processes, the usefulness of hand tools cannot be understated. Calibers and scribes are necessary to accurately measure parts and transfer dimensions onto pieces of stock metal. Files, de-burring tools, and wire brushes give freshly milled parts their finished edges and appearance. Tap and die sets are quite valuable and are necessary if any component is to connect to either internal or external threaded parts. 


\section{I.2 Process Planning}

Machining is a subjective process where many different approaches and processing steps could lead to the final result, a component that looks like the drawing on the page and has the specified dimensions and conforms to the listed tolerances. Before any cuts are made or material removed, the first step in the fabrication of any part is mapping out the various process steps. What makes one approach superior to another is the number of re-mountings required. Once a raw piece of material has been clamped into a vise for milling or drilling, as much work as possible should be done on the exposed surfaces. Every time the work piece must be remounted, the machine's coordinate system must be re-calibrated and the likelihood of dimensional errors increase. As the complexity of the part increases, the number of processing steps required to achieve that part also increases. Simple parts can often be mapped out by merely thinking about them, while more complex ones can require the machinist to write them out to see how to combine the steps in a way that minimizes the number of re-mountings. A sample of such a procedure has been listed below (Appendix G: Sample Machining Procedure).

\section{I.3 Design-Fabrication Interaction}

Communication is paramount during any design-build process. The various individuals involved do not need to be experts in the other's field, but a little knowledge goes a long way. Designing and fabricating the welding machine and shear fixture for this research was made easier due to good communication.

Vertical mills, band saws, lathes, and CNC machinery are tools that can be utilized to create some astonishing pieces of work, but they have their limitations. 
Having a designer know this range of capabilities is critical. Uneducated designers could unwillingly envision a component that looks and functions great in SolidWorks, but in reality is impossible, prohibitively expensive, or too time intensive to fabricate.

Applying a basic understanding of general machining procedures to future design will not only save time and resources but will earn the designer confidence and credibility.

Before a designer can begin their work, they should have some basic knowledge about the machining process in general, and if possible, be familiar with the specific machine shop where the components will be manufactured. Often times in design, features can have arbitrary dimensions. Thinking about the values of these dimensions is important. Instead of making the length 3.907", 4.000" is a much easier number to work with provided it does not affect other features. If the diameter of a hole is a non-standard value, shrink or enlarge the diameter until the value makes sense. Whenever possible, use similar parts and dimensions. If two plates must be bolted together, do not use four different diameter and length bolts. Again, if a specific dimension is needed, it should be specified, otherwise changes should be made.

Be sure to check for material and tool availability. For example, if a design absolutely requires a specific aluminum alloy, notify the machinist as early as possible to allow for ordering and shipping time. Most machine shops should have a good selection of end mills, ball mills, reamers, drill bits, etc.; however, if the designer's component needs a specialized or unique tool, the machinist should be notified.

Prior to the final design submission, it can be helpful to show the machinist a preliminary version of the design. Not only will this allow the machinist to provide an approximate fabrication time estimation, he or she may be able to suggest alternative 
methods of production or design features that could save either material or fabrication costs. Once the final design is finished, provide the machinist with an educated set of shop drawings. Whenever possible, use dimension values off of a common origin. This makes the drawings clear and well organized. Also, be sure to indicate any special instructions regarding material or handling. 


\section{Appendix J: Sample Machining Procedure}

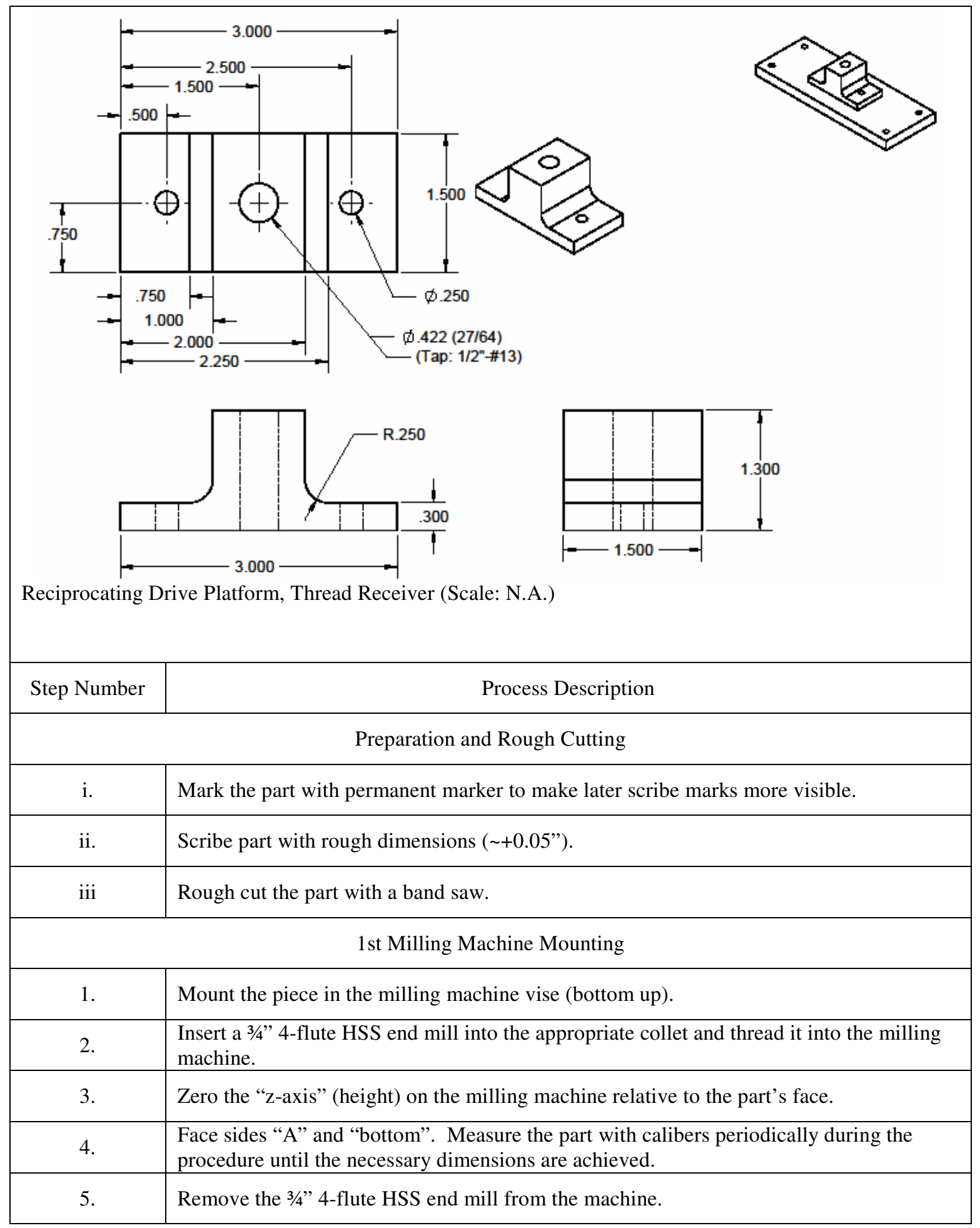




\begin{tabular}{|c|c|}
\hline \multicolumn{2}{|r|}{ 2nd Milling Machine Mounting } \\
\hline 6. & Re-mount the piece in milling machine vise (top up). \\
\hline 7. & $\begin{array}{l}\text { Insert an edge finder into an appropriate collet and thread it into the milling machine. } \\
\text { Establish a coordinate system and zero the machine relative to the part in the } \mathrm{x} \text { and } \mathrm{y} \\
\text { axes. }\end{array}$ \\
\hline 8. & Remove the edge finder from the machine. \\
\hline 9. & $\begin{array}{l}\text { Insert a } 3 / 4 " 4 \text {-flute HSS end mill into the appropriate collet and thread it into the } \\
\text { milling machine. }\end{array}$ \\
\hline 10. & Zero the "z-axis" (height) on the milling machine relative to the part's face. \\
\hline 11. & Face the "top" plane and edge "B". \\
\hline 12. & Remove the $3 / 4$ " 4-flute HSS end mill from the machine. \\
\hline 13. & $\begin{array}{l}\text { Insert a } 1 / 2 " 2 \text {-flute HSS ball end mill into the appropriate collet and thread into the } \\
\text { machine. }\end{array}$ \\
\hline 14. & Zero the "z-axis" (height) on the milling machine relative to the part's face. \\
\hline 15. & Cut fillet radii on appropriate edges. \\
\hline 16. & Remove the $1 / 2$ " 2-flute HSS ball end mill from the machine. \\
\hline 17. & Insert \#5 center drill bit into the applicable collet and thread into the machine. \\
\hline 18. & Pre drill all of the hole locations. \\
\hline 19. & Remove \#5 center drill bit from the machine. \\
\hline 20. & Insert a $1 / 4 "$ drill bit into the appropriate collet and thread into the machine. \\
\hline 21. & Drill all holes throughout the entire depth of material. \\
\hline 22. & Remove the $1 / 4$ " drill bit from the machine. \\
\hline 23. & Insert a $27 / 64$ " drill bit into a chuck head and thread it into the machine. \\
\hline 24. & Drill the existing 1/4" center hole throughout the entire depth of material. \\
\hline 25. & Remove the 27/64" drill bit from the machine. \\
\hline 26. & Remove the part from milling machine vise. \\
\hline \multicolumn{2}{|r|}{ Milling Complete } \\
\hline 28. & Tap to the main hole (center location) with $1 / 2$ "-\#13 tap. \\
\hline 29. & File and deburr all edges and clean the finished part. \\
\hline
\end{tabular}


Appendix K: ImageTool Sample Photographs

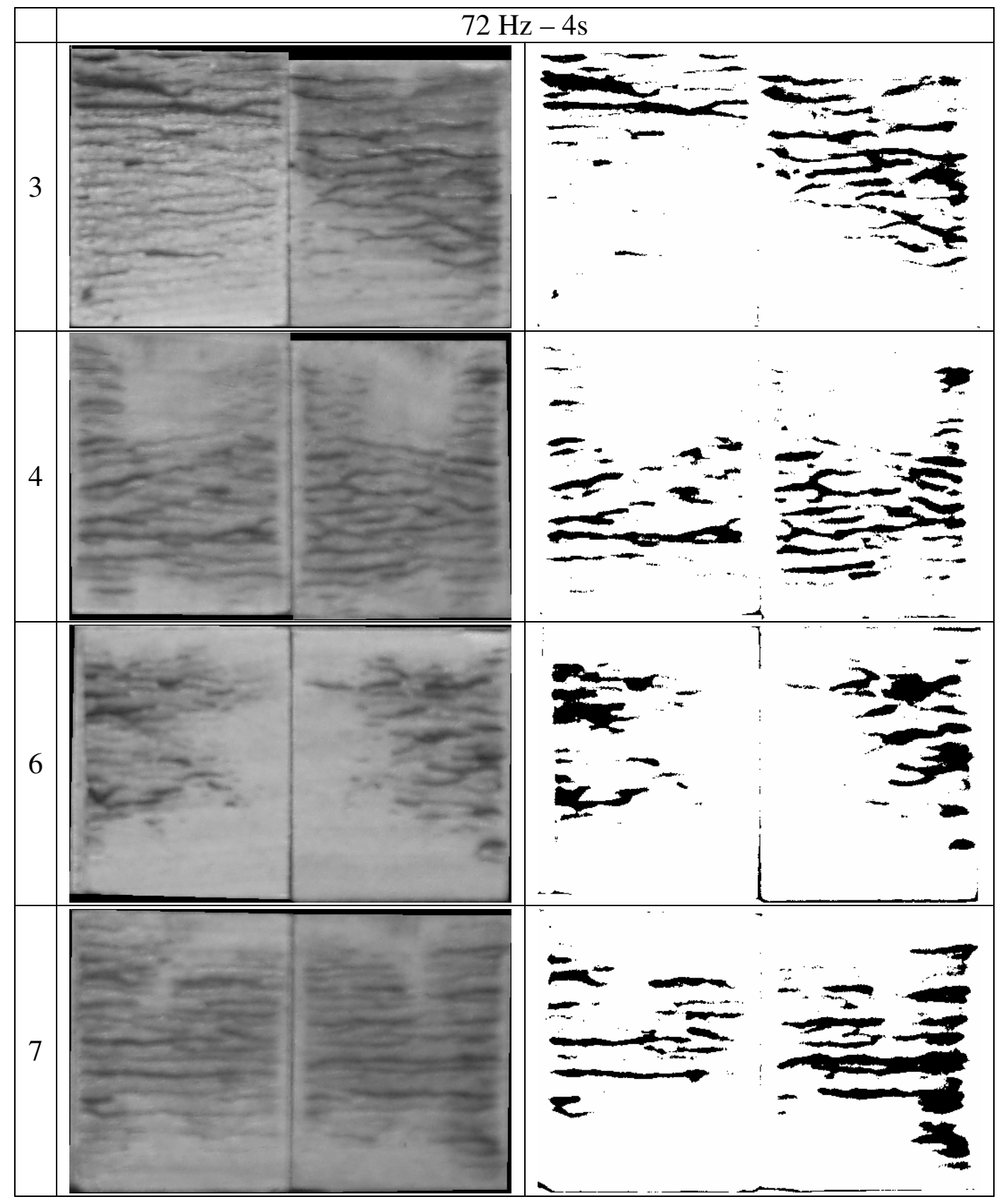




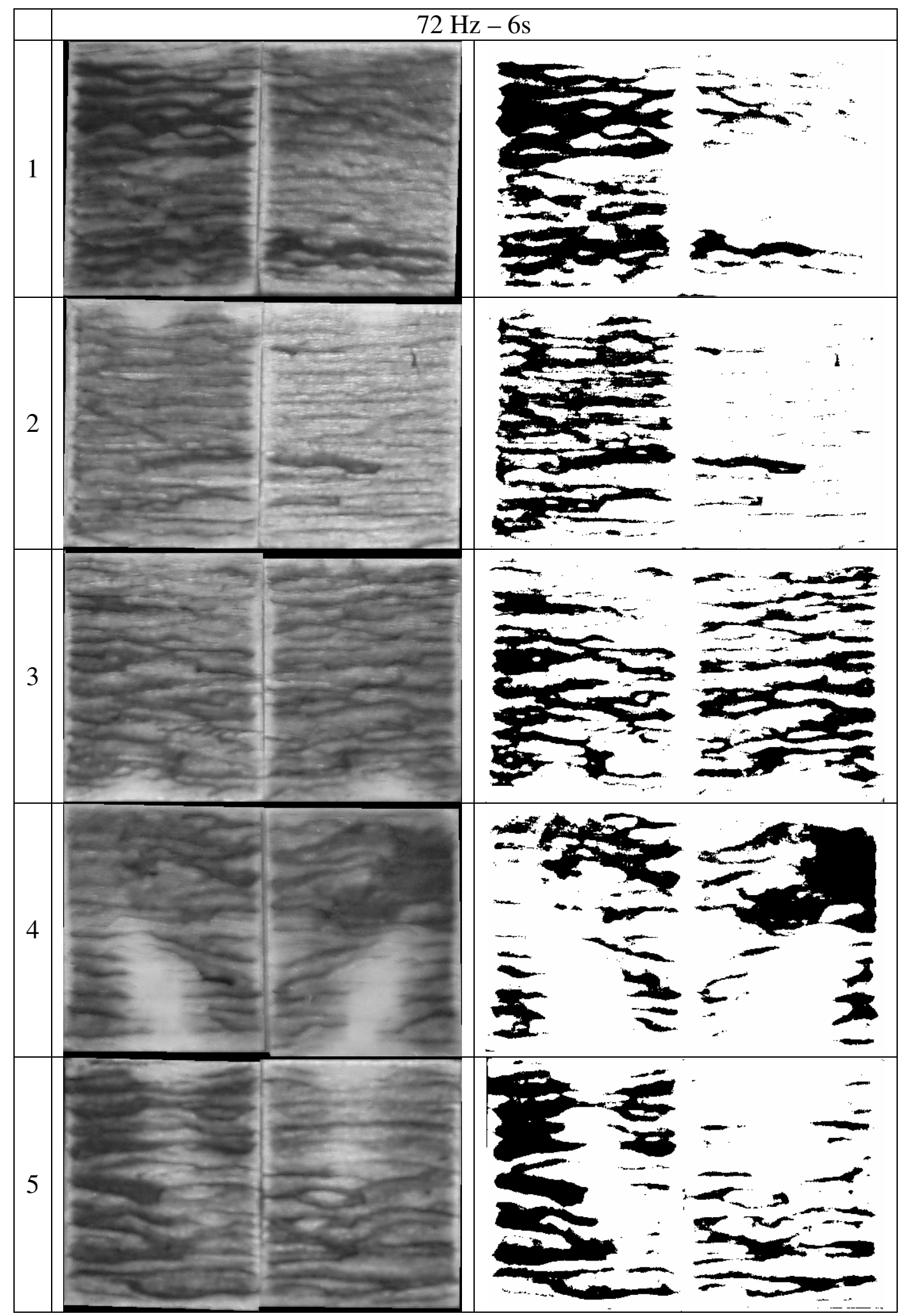



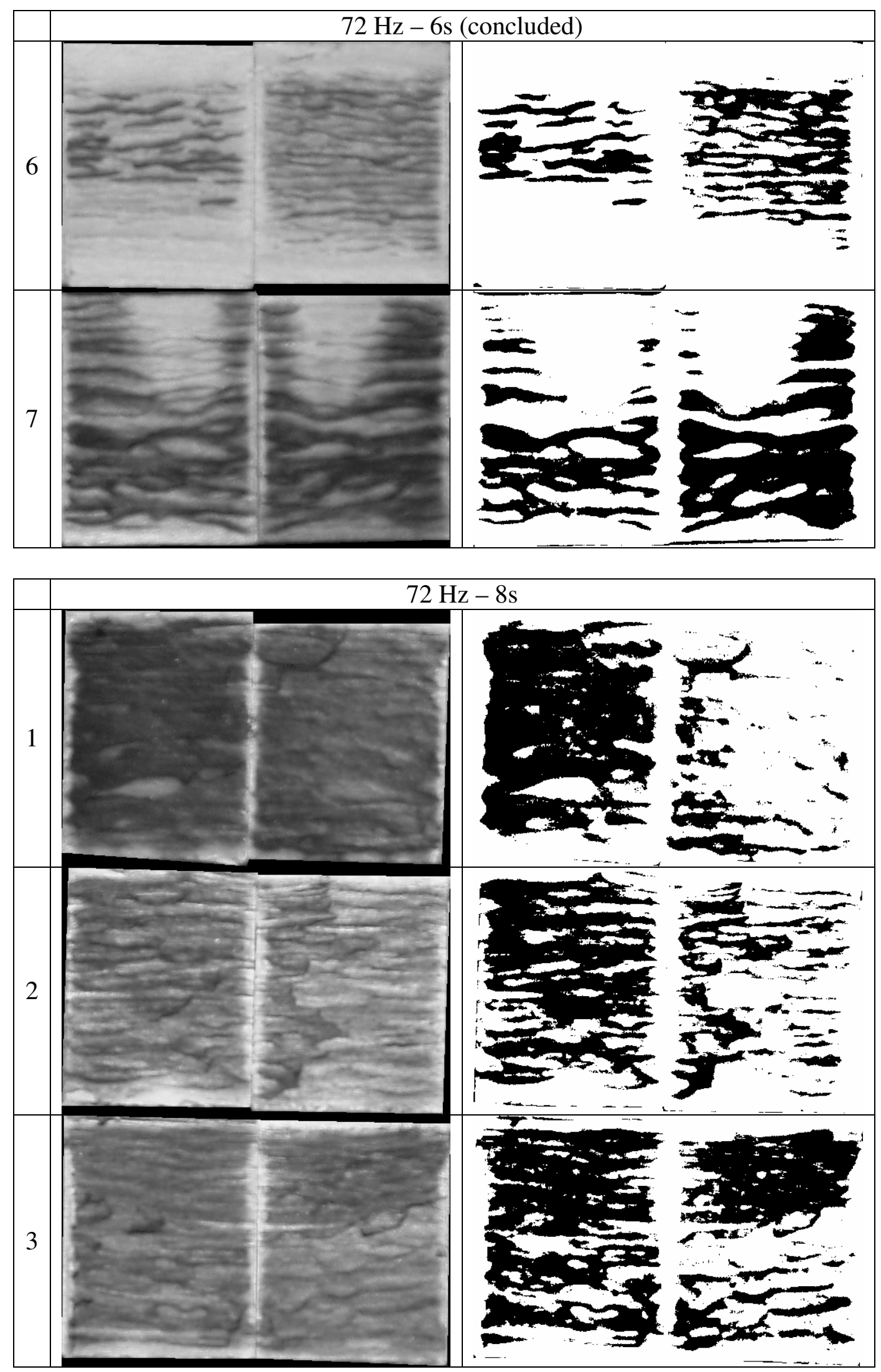


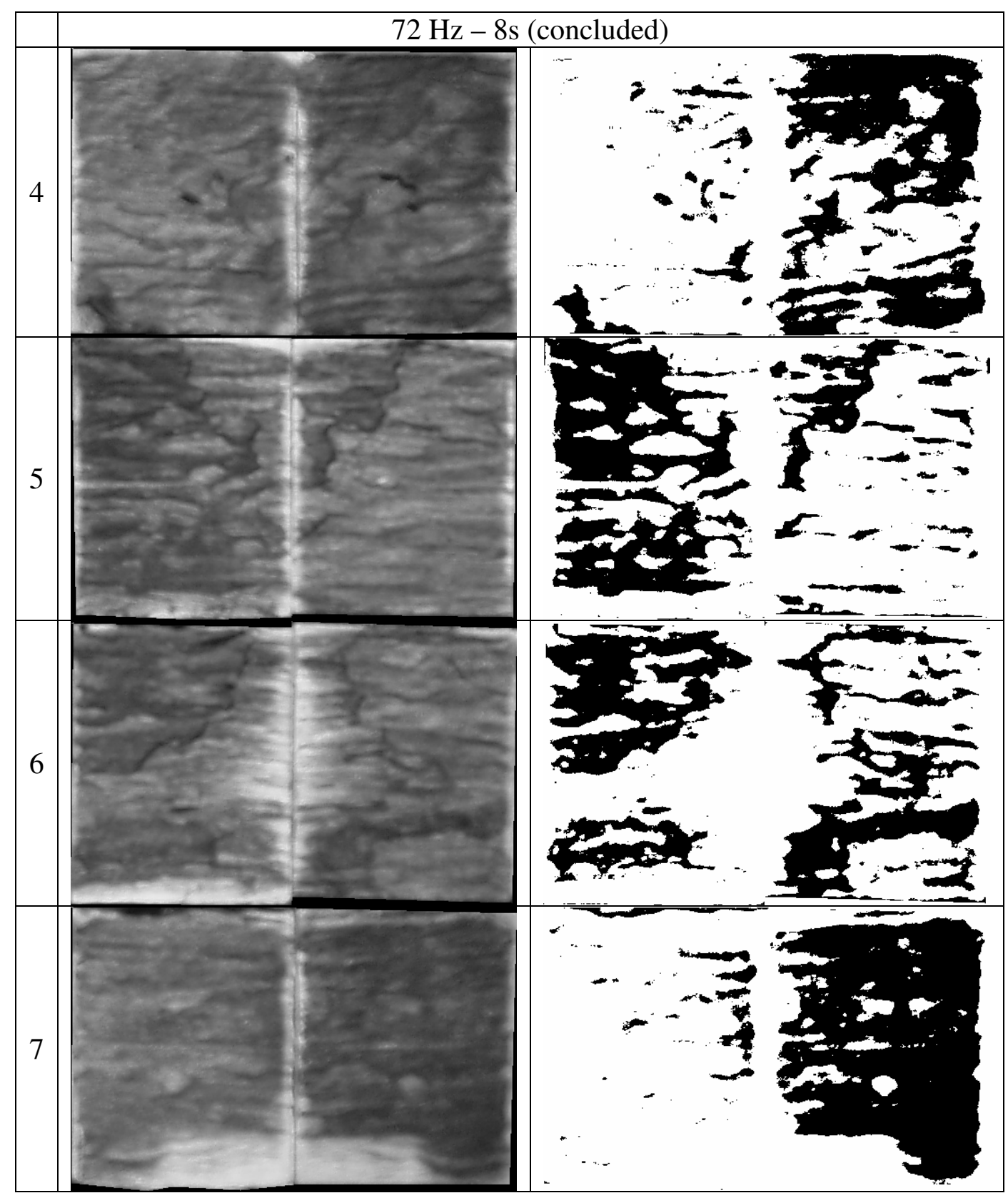




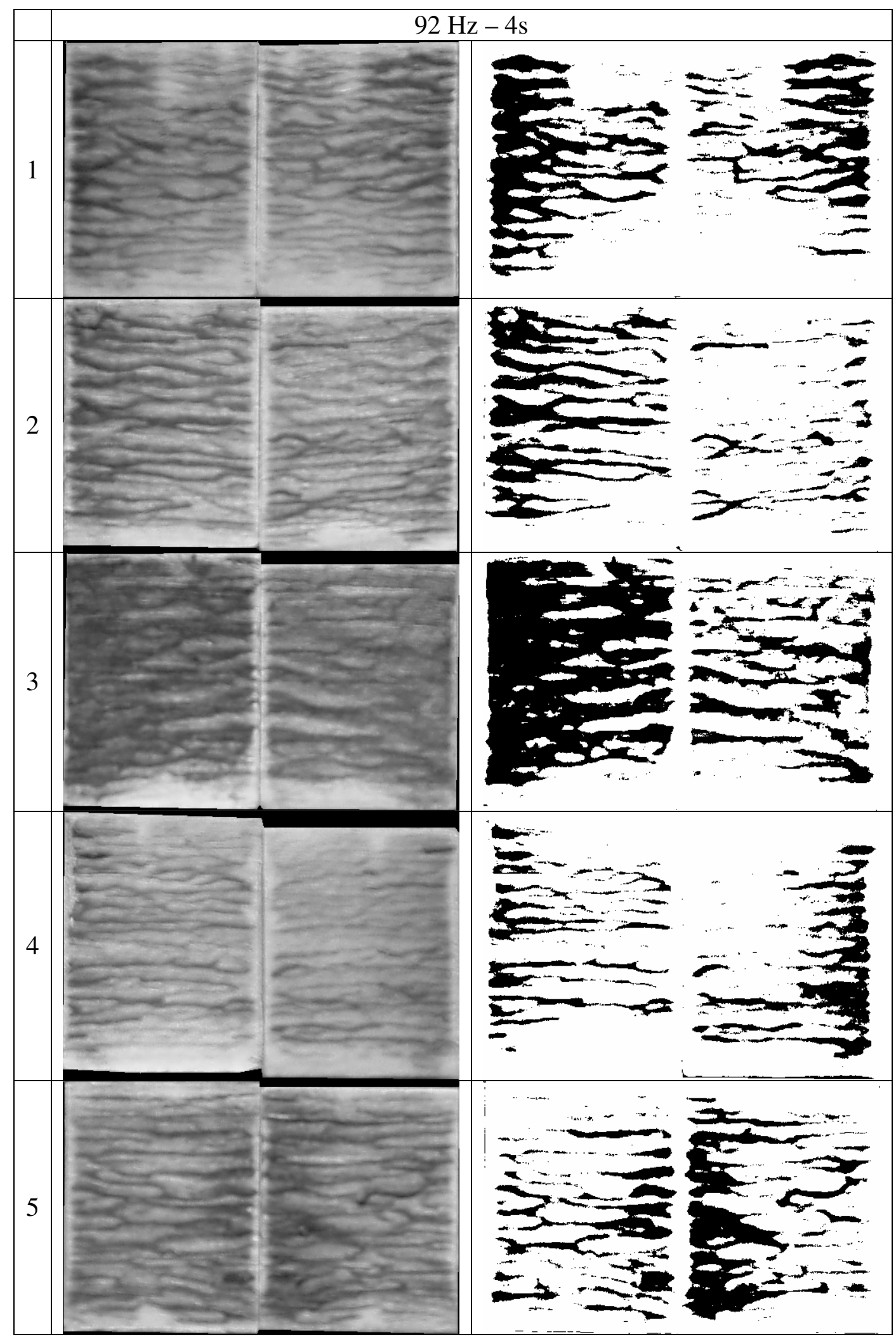



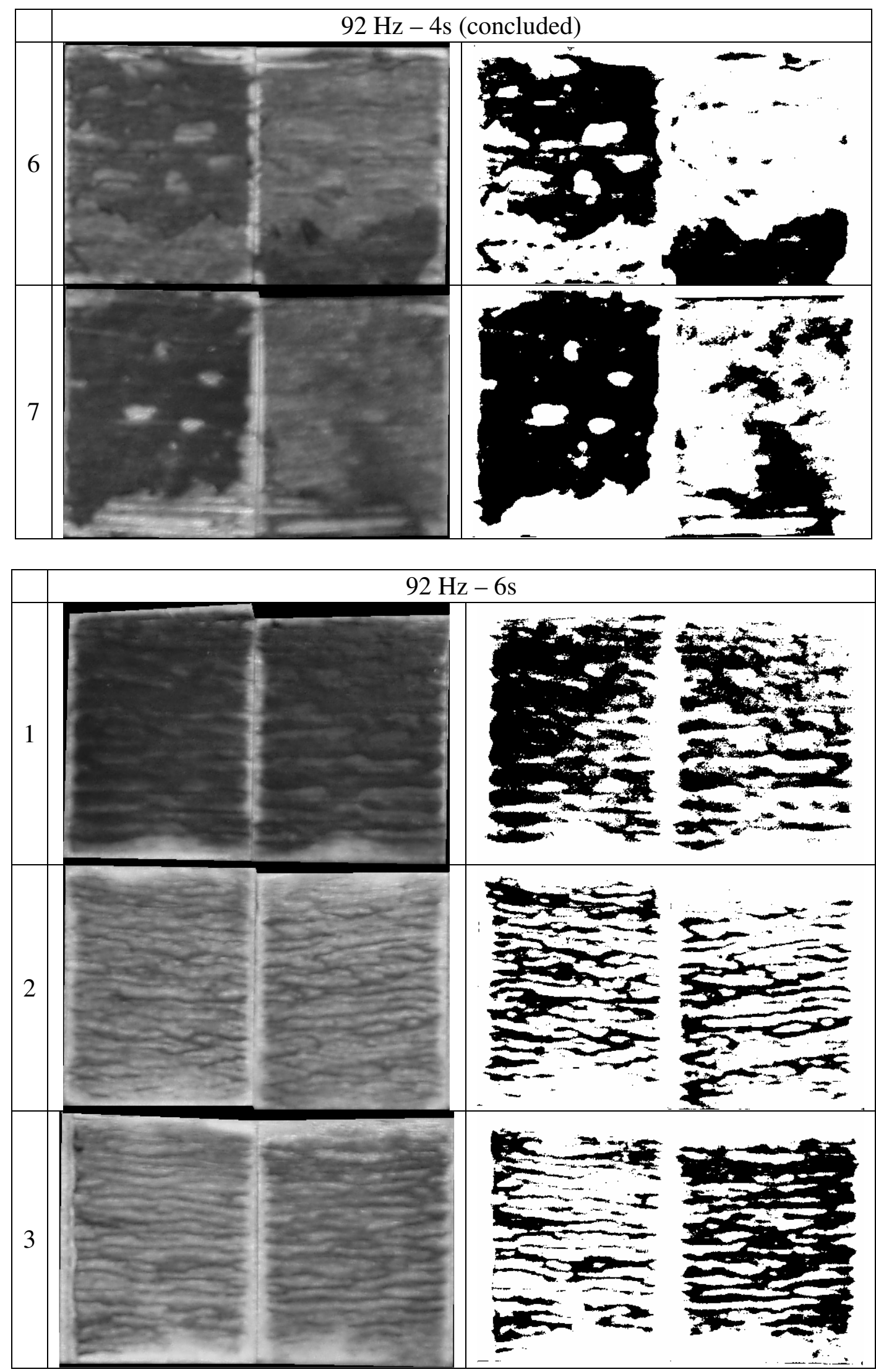


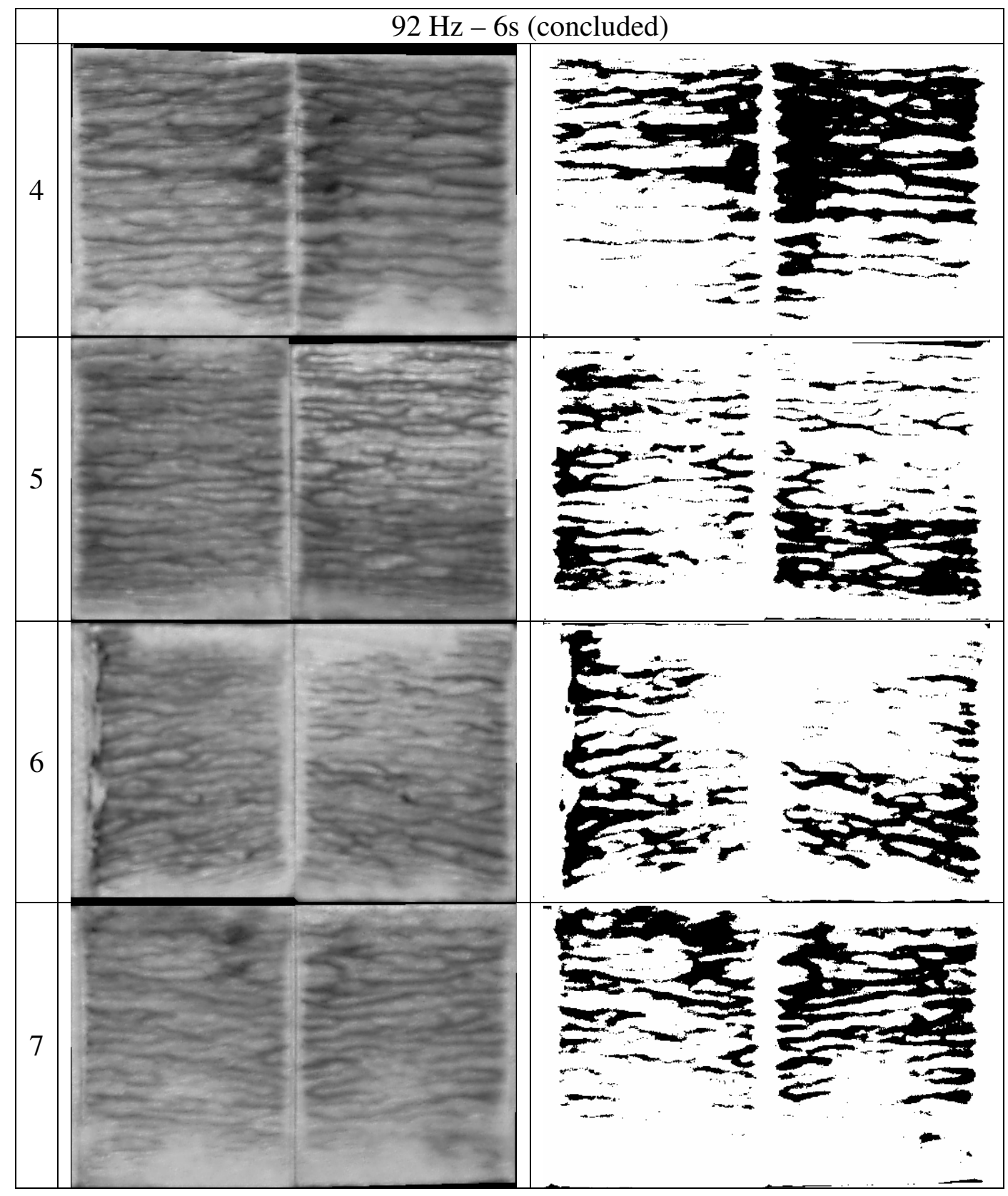




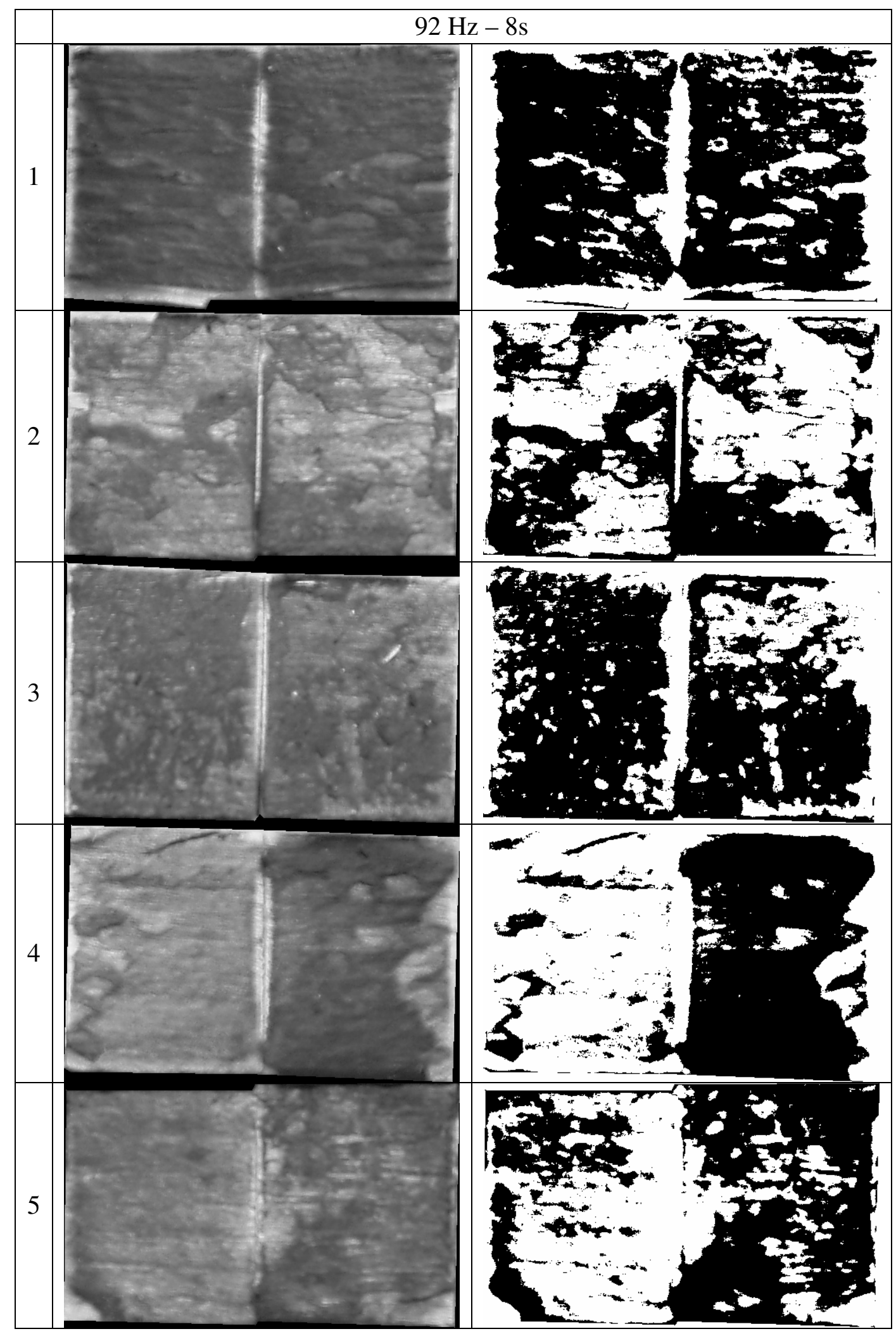



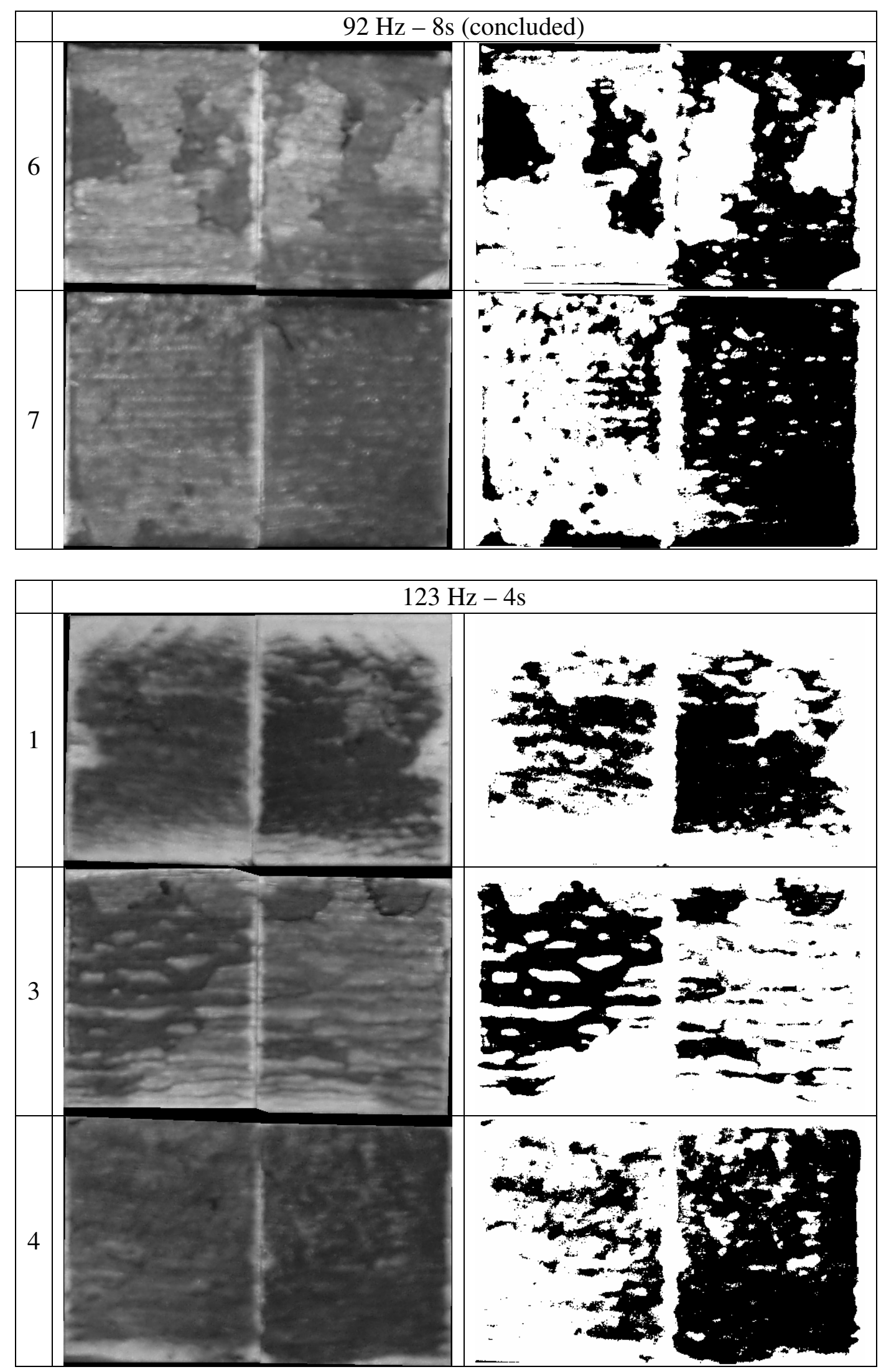

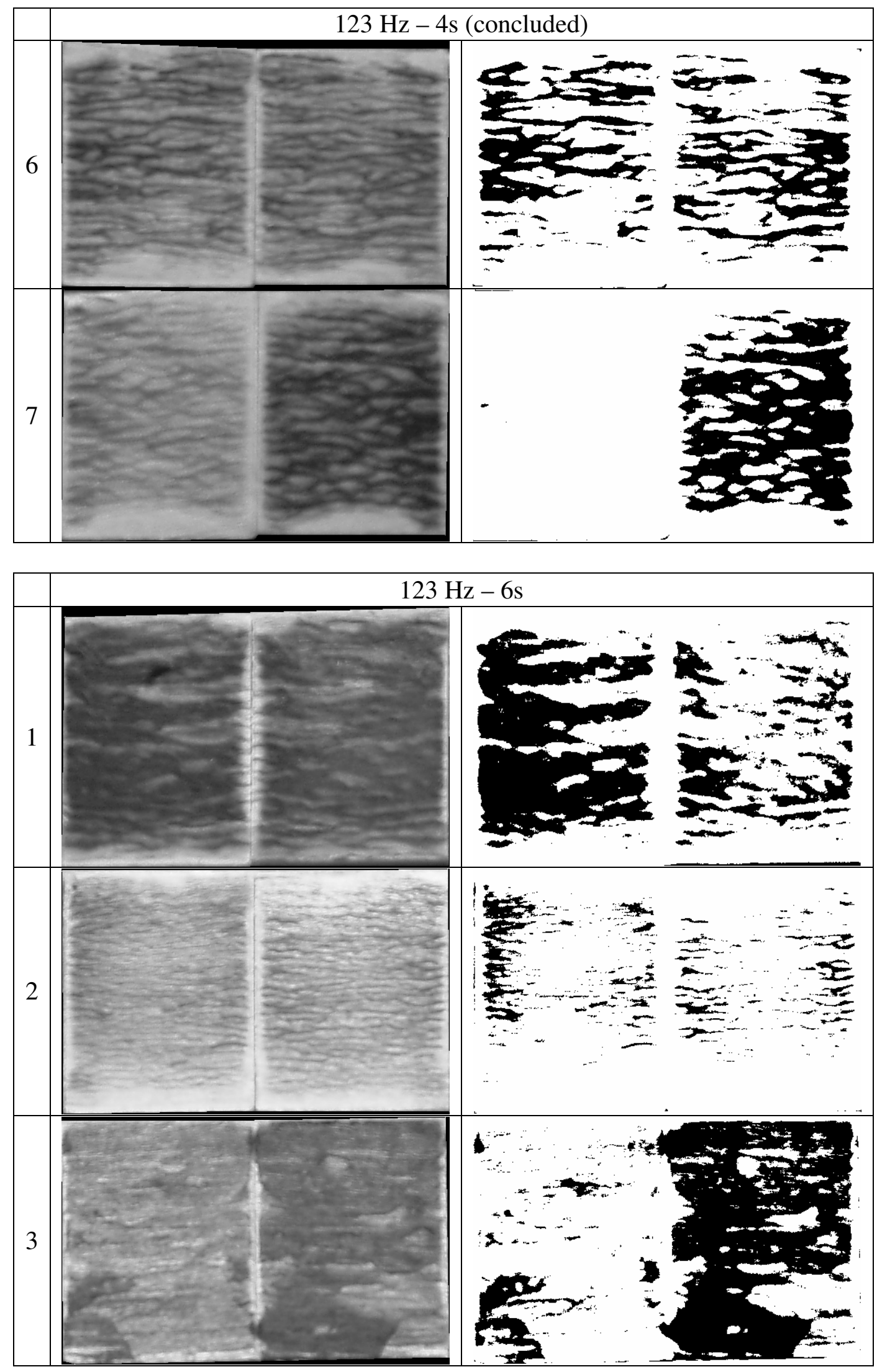


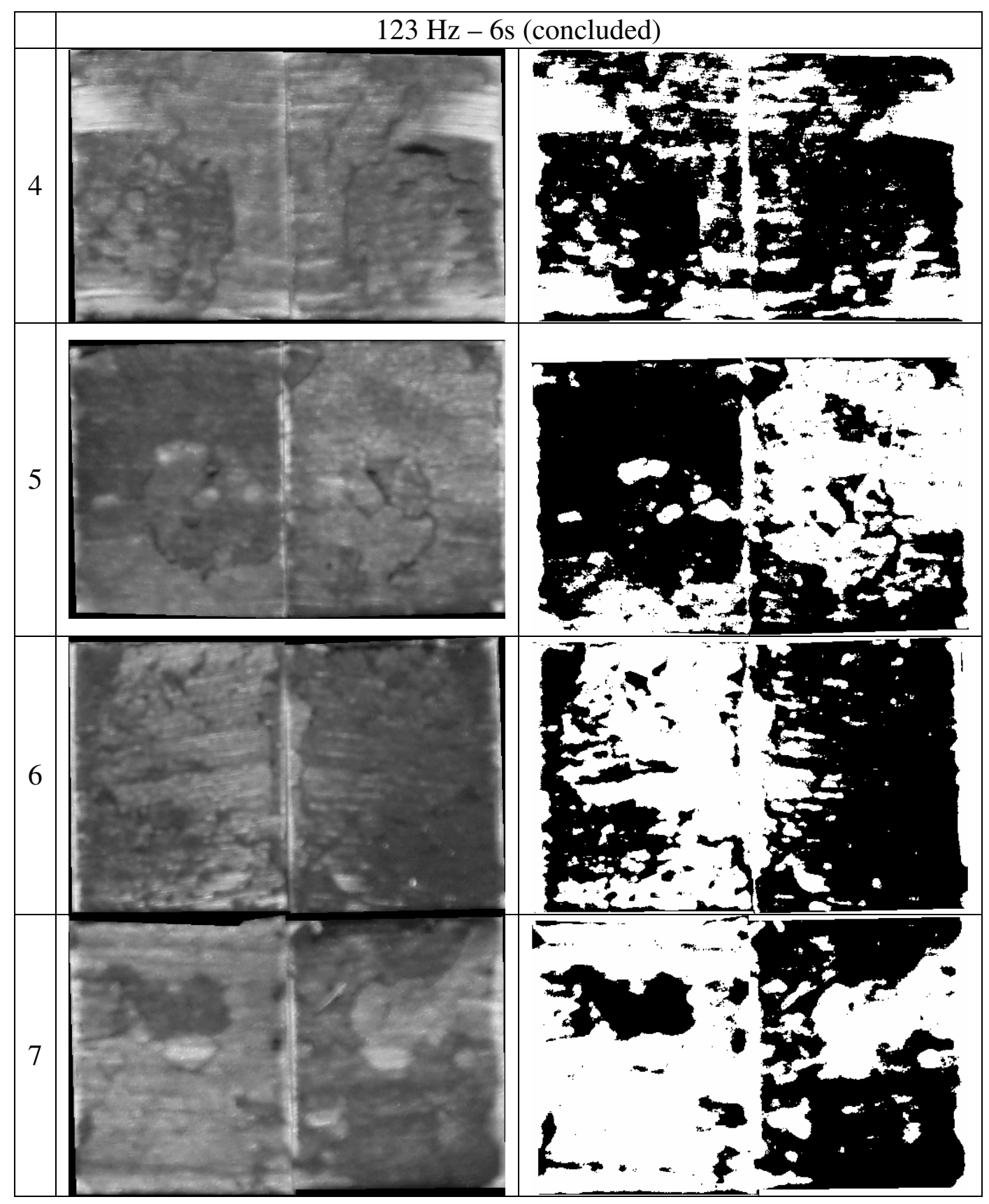




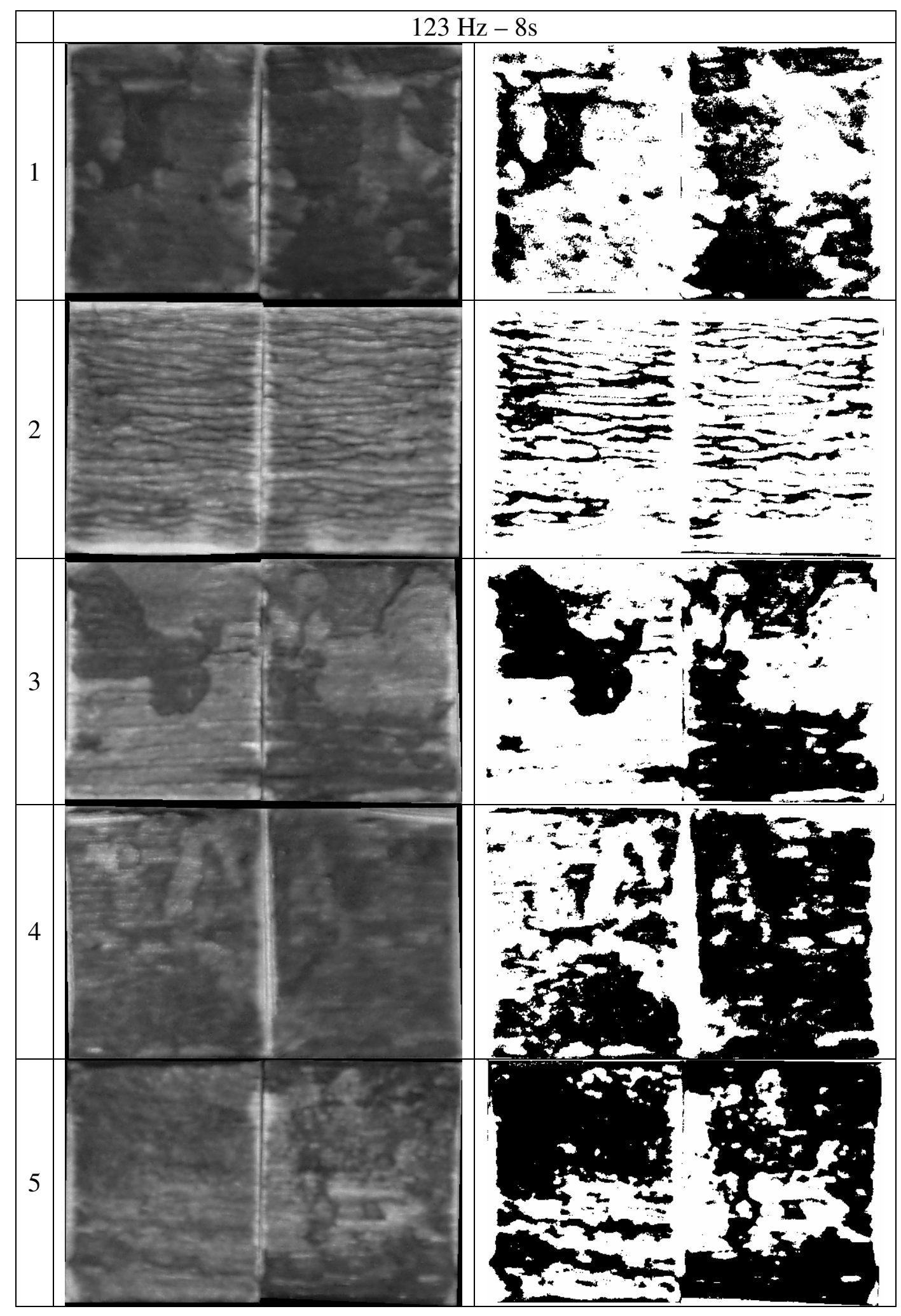



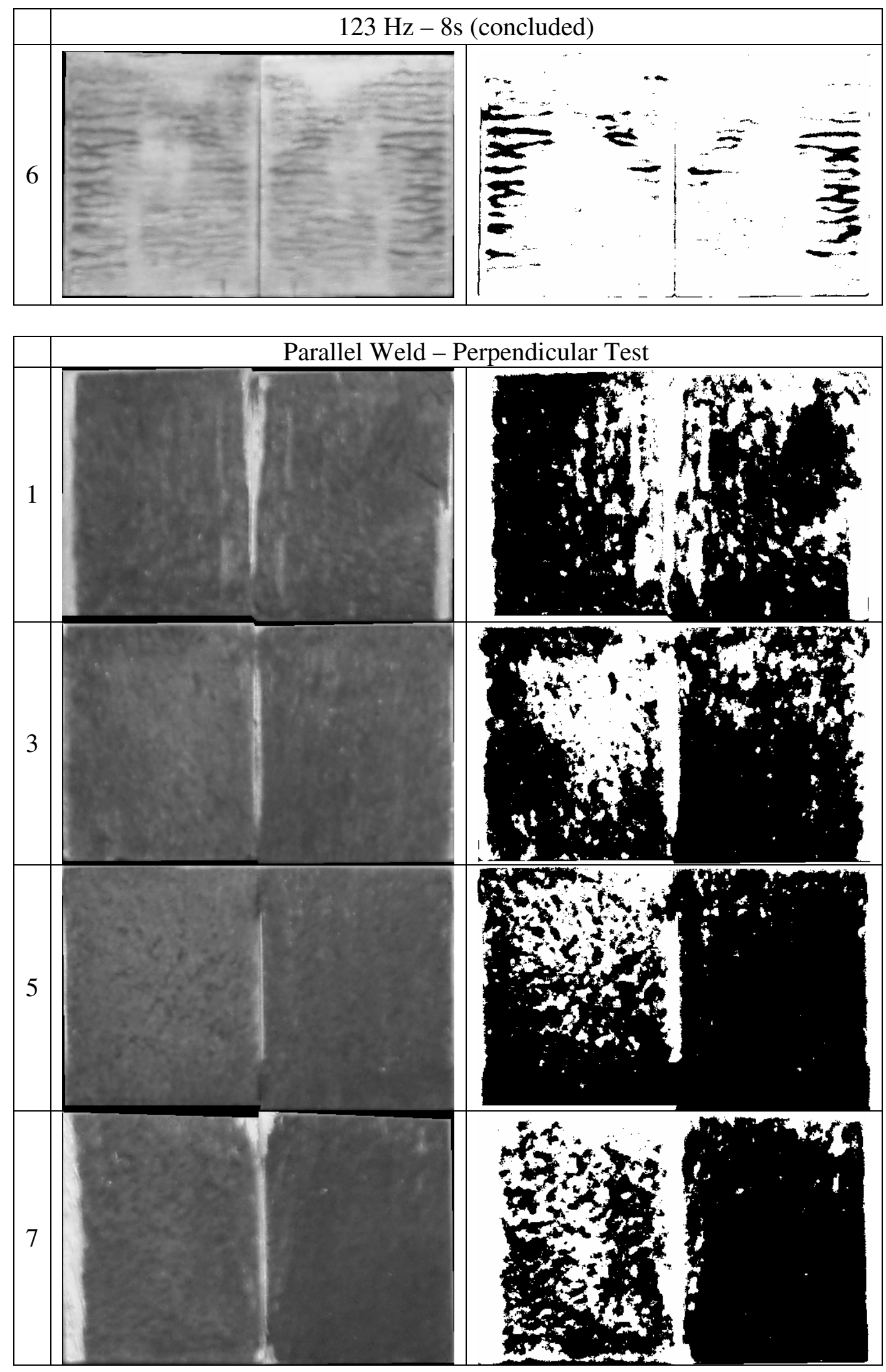


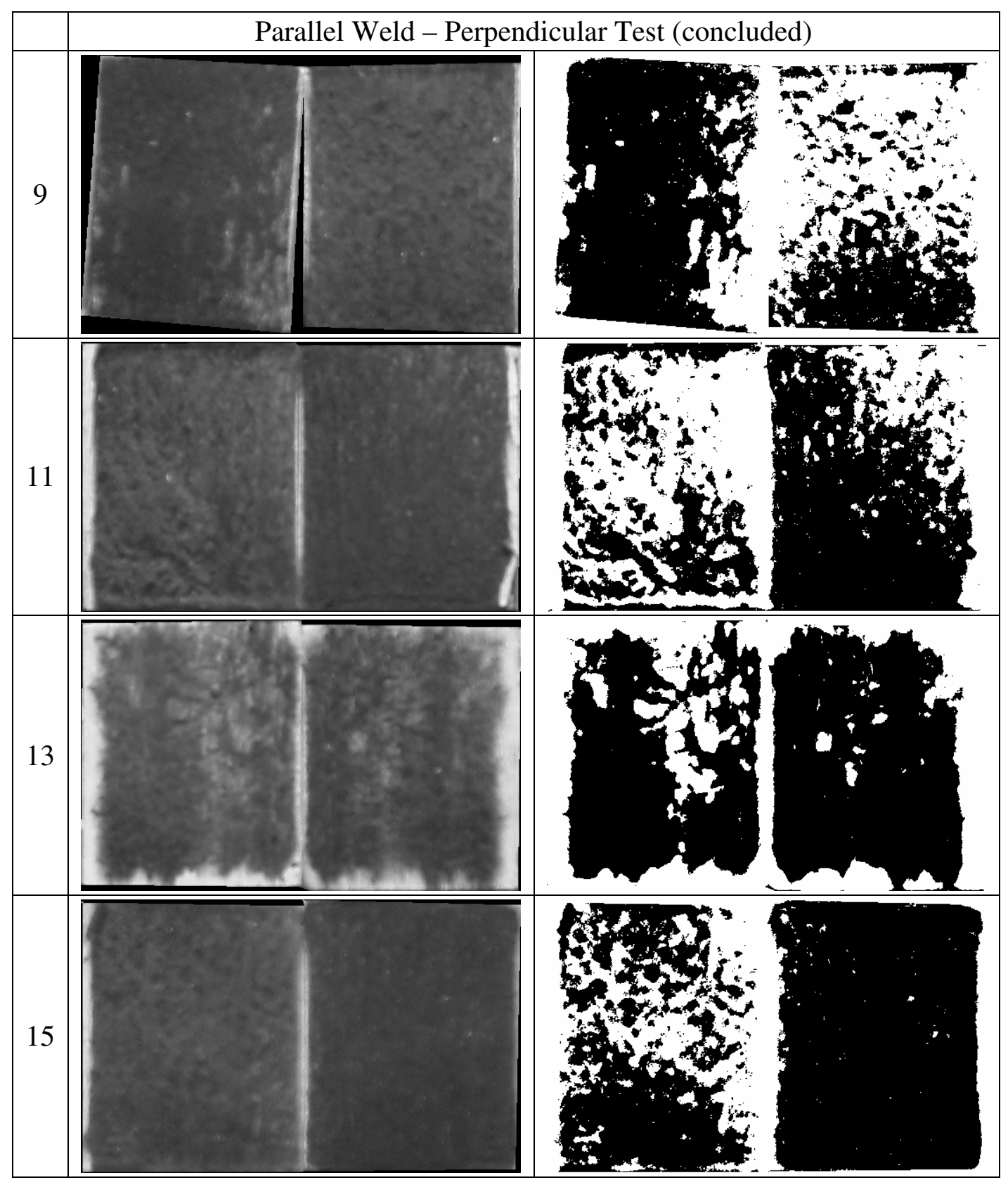




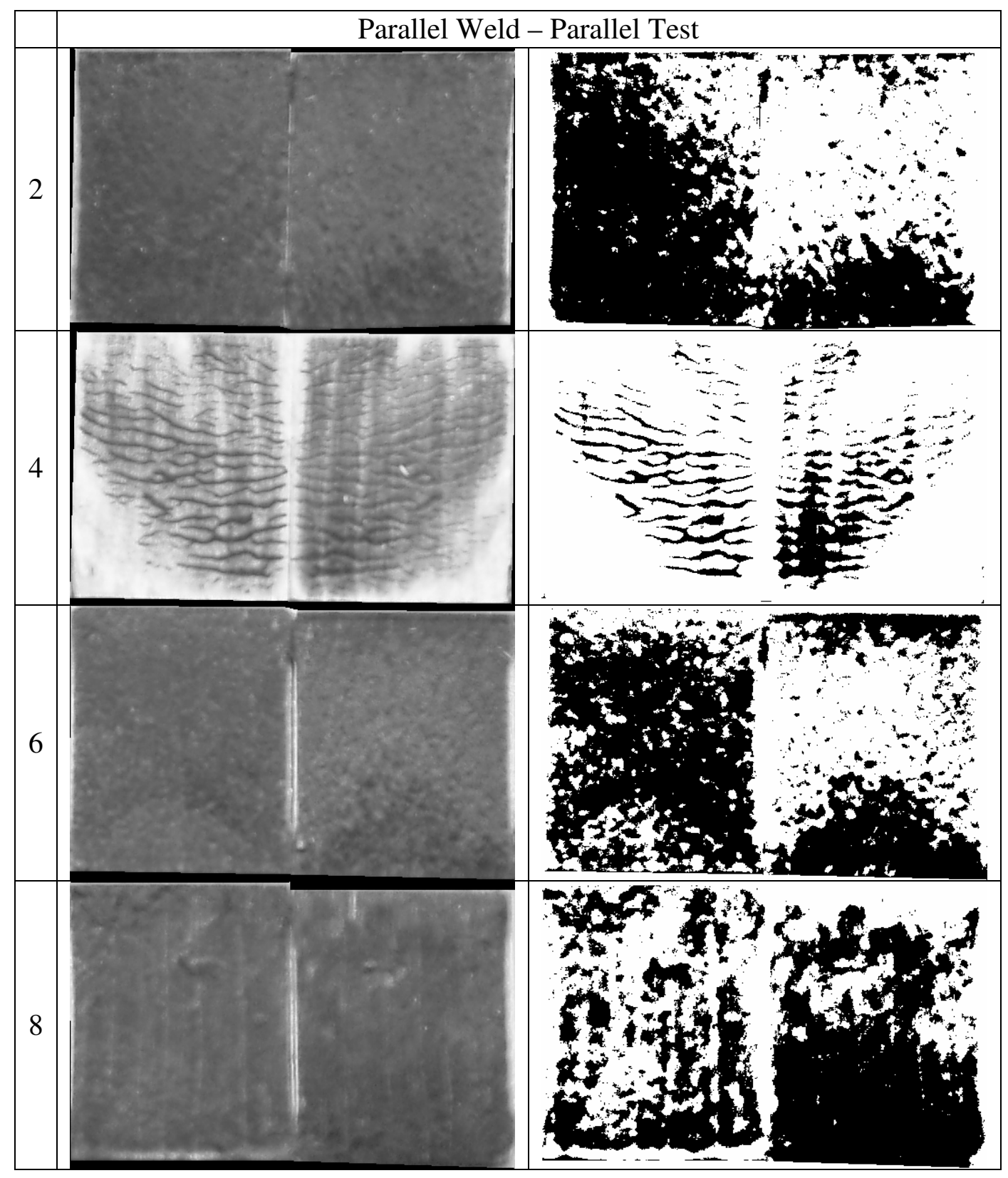




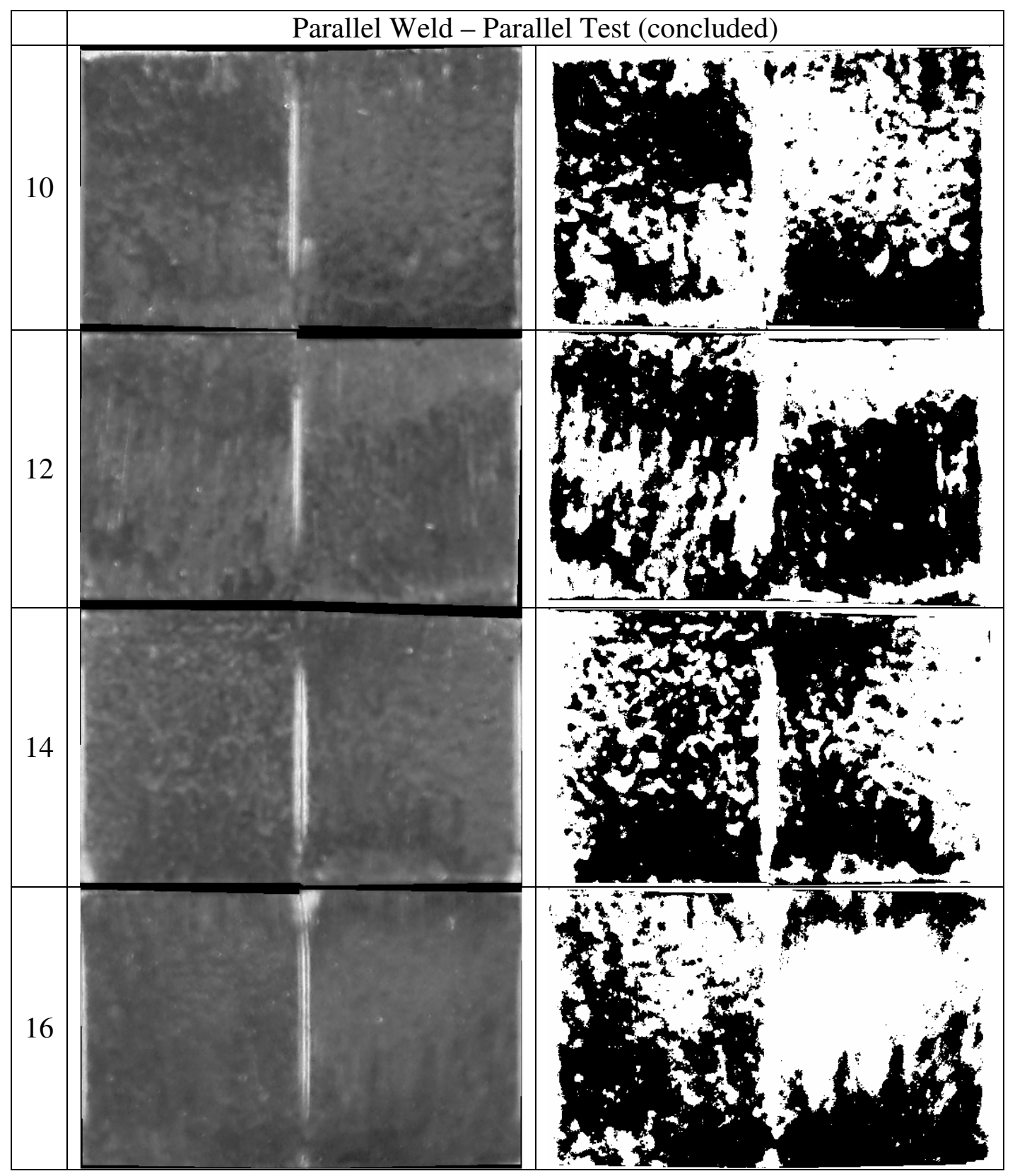




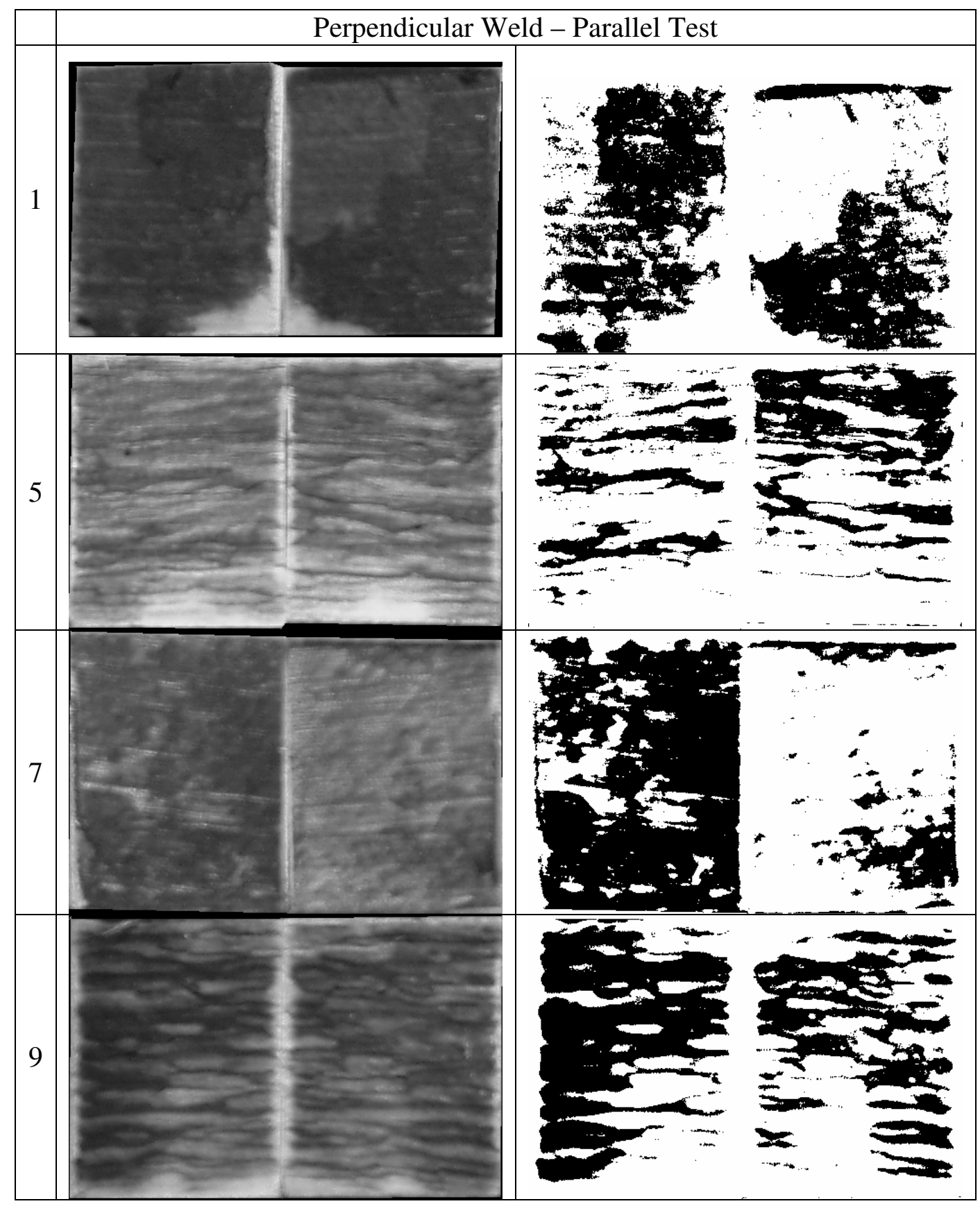




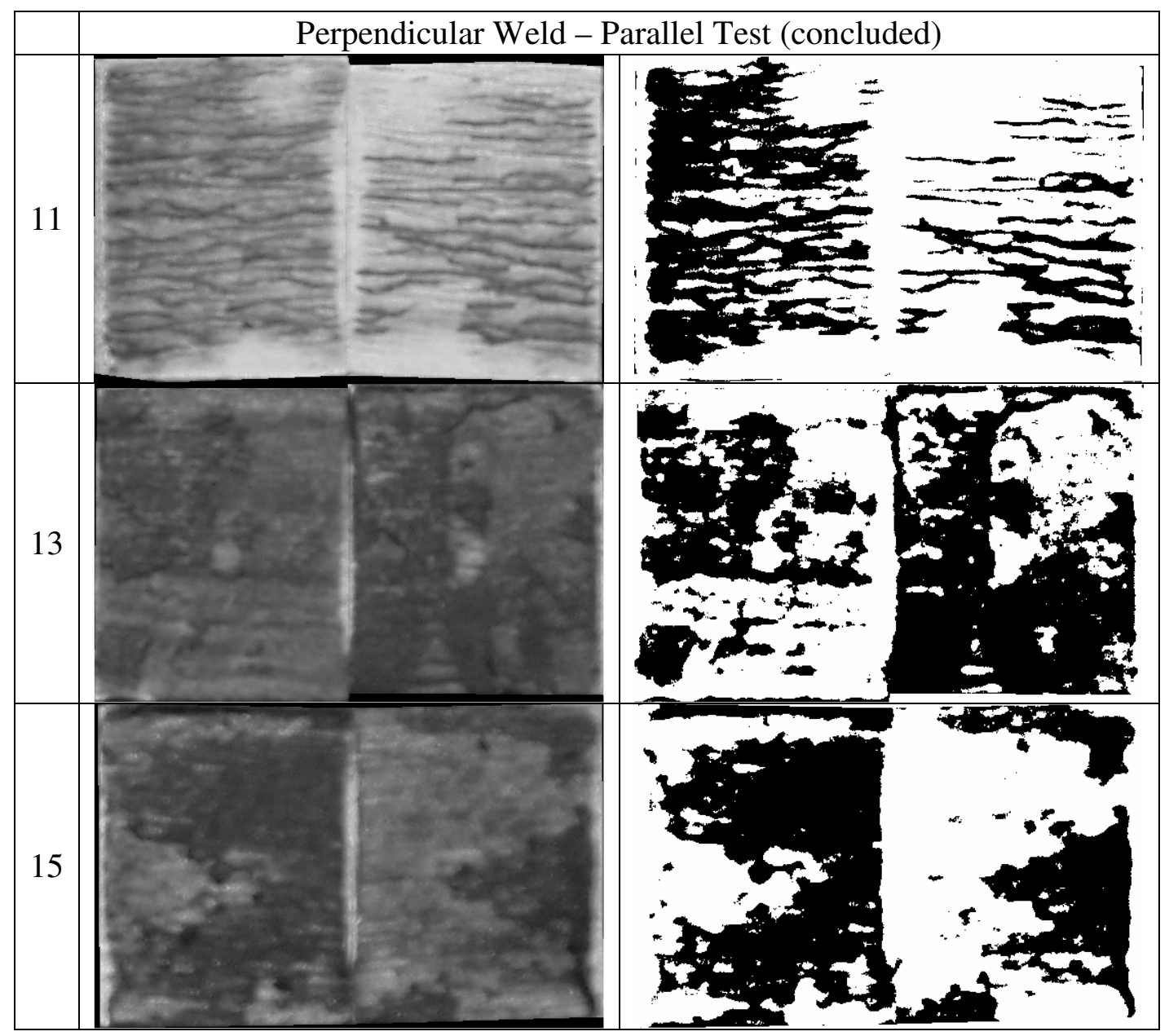




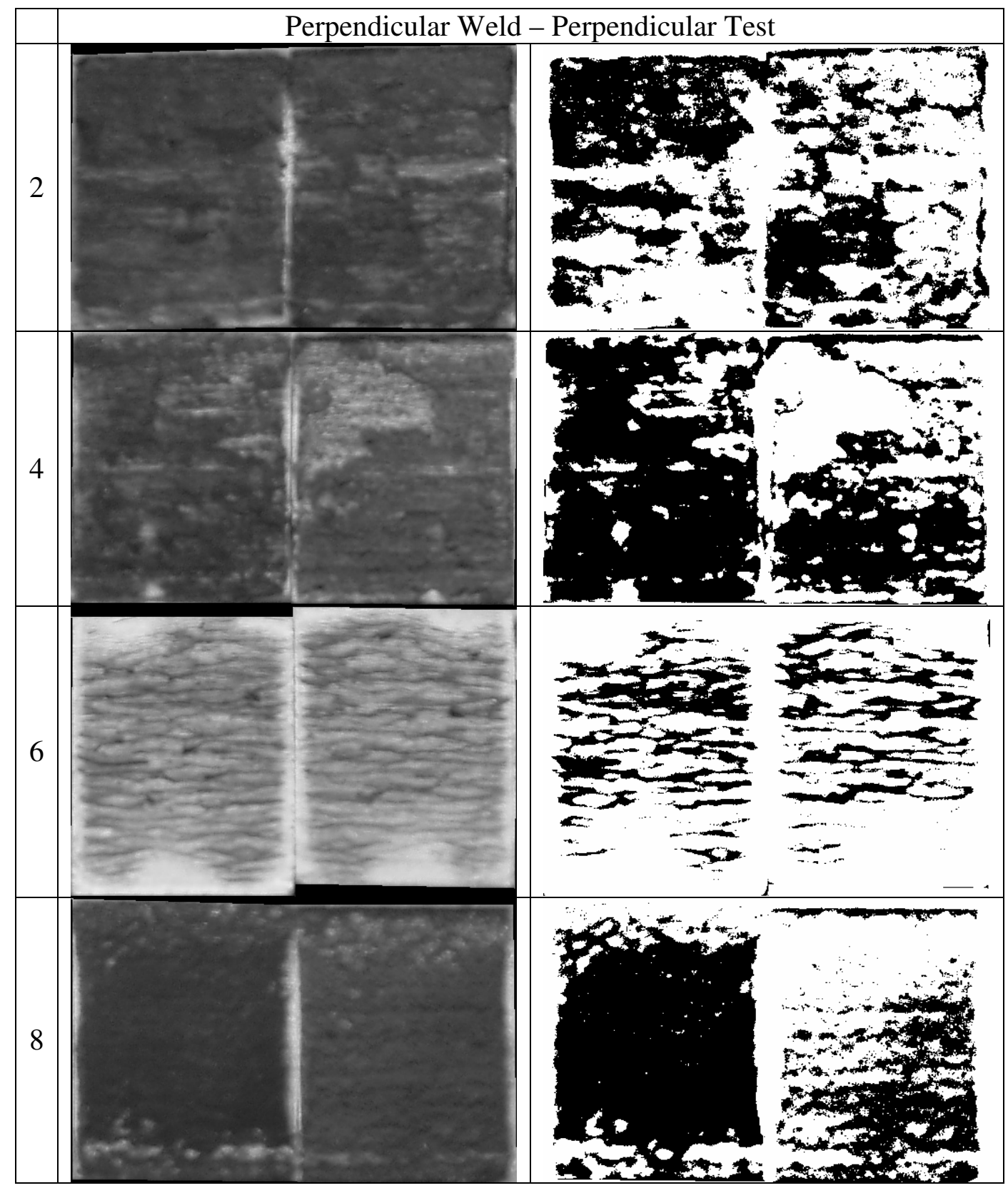




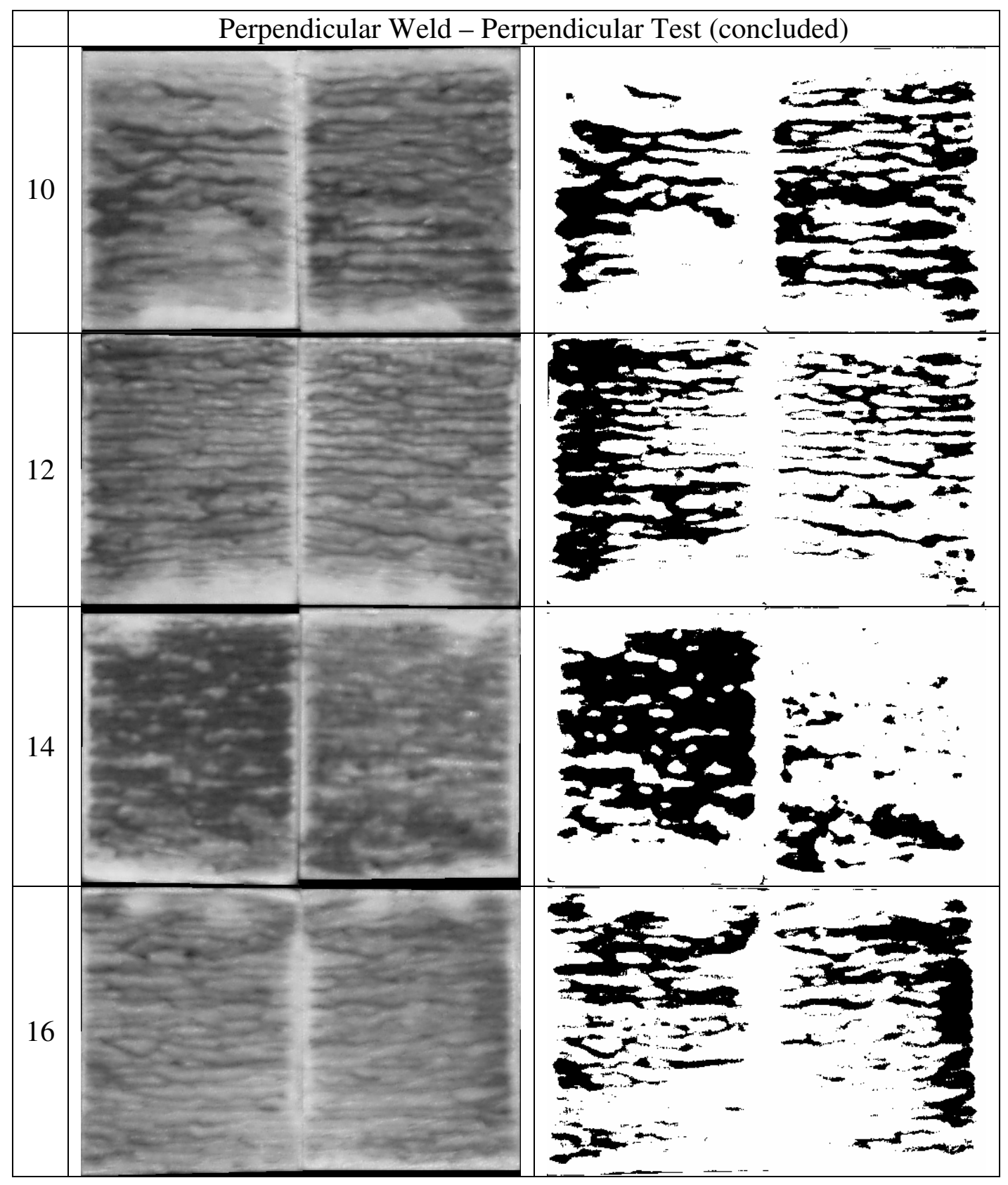




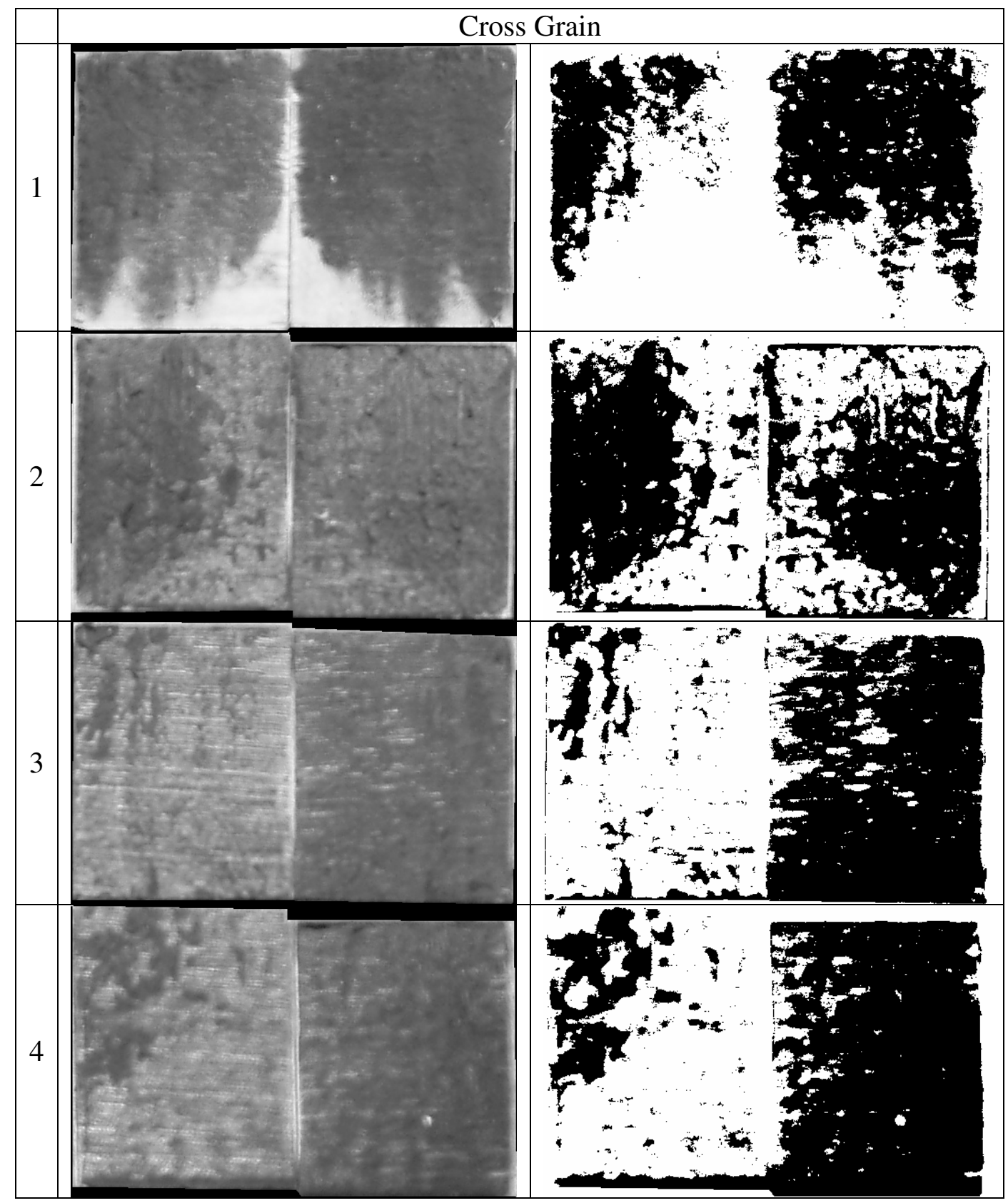




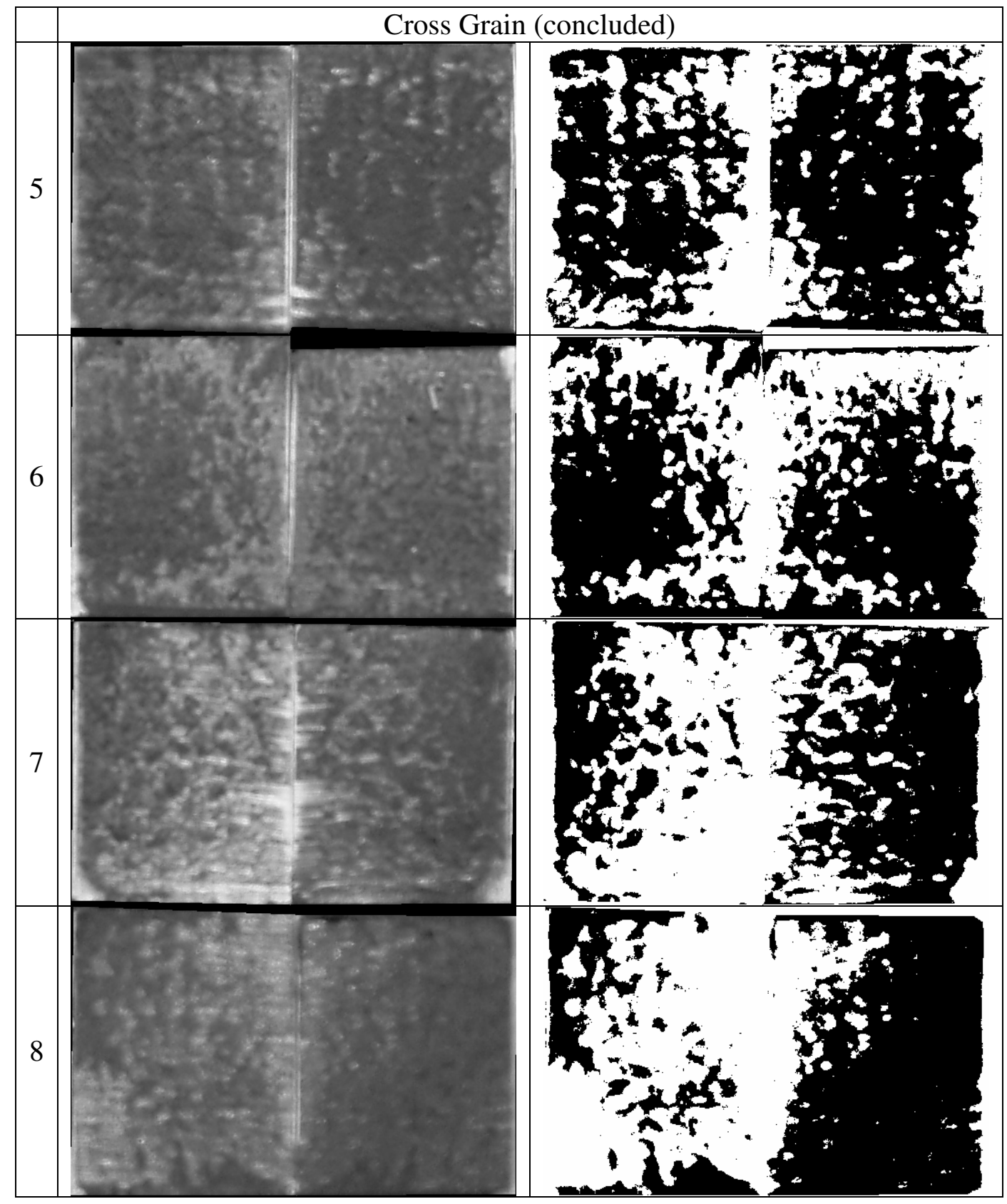




\section{Appendix L: FEA Analysis: Orthotropic Model Data}

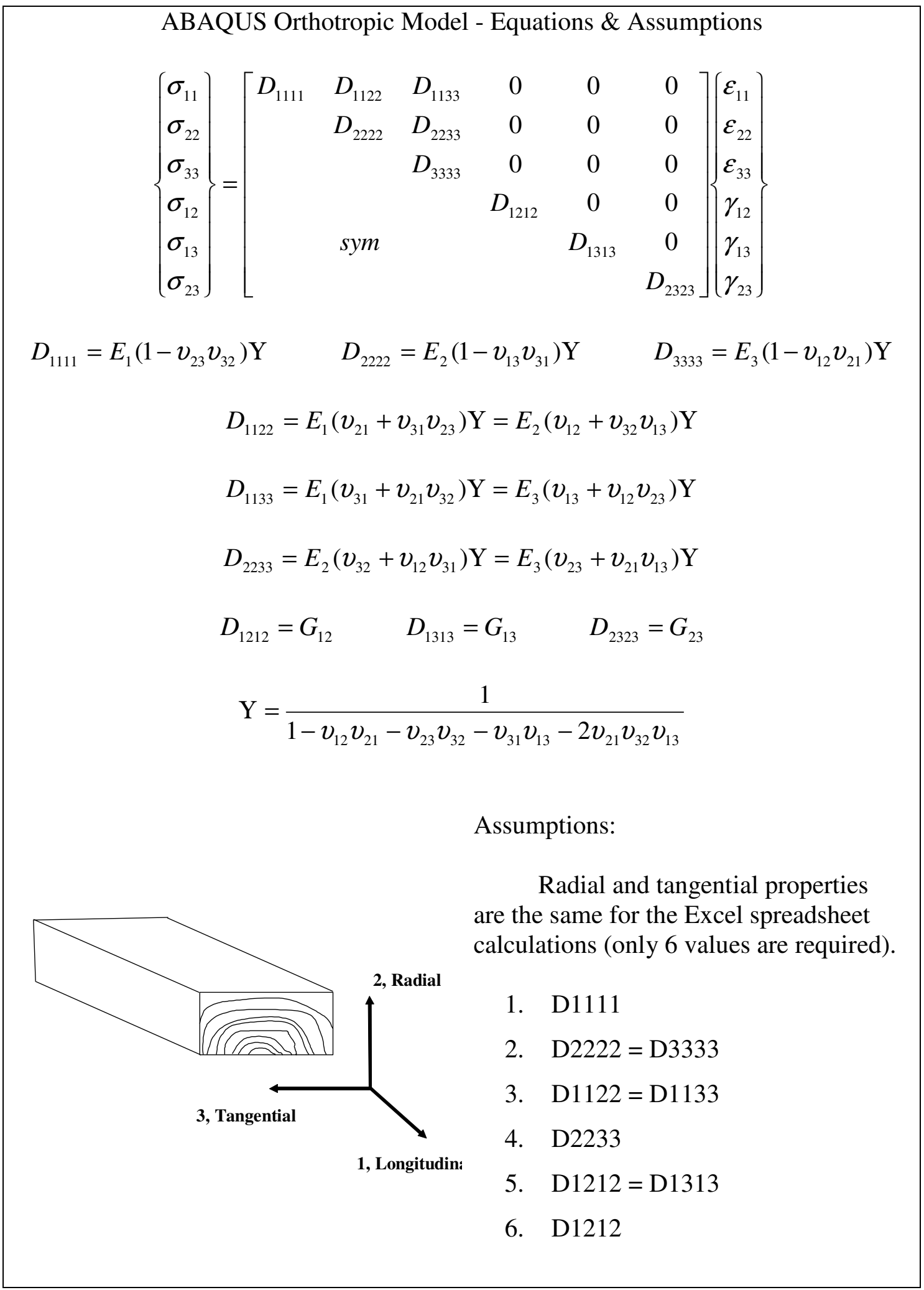




\section{ABAQUS Orthotropic Timber Properties}

TIMBER TYPE: Douglas Fir

GRADE: $\quad$ Select Structural

REFERENCE: $\quad$ NDS Supplement, 2005 ed. Pg 32

Wood Handbook (Chapter 4: Tables 4-1, 4-2)

ABAQUS On-line Handbook (Chapter 17, Defining Orthotropic Elasticity)

NOTE: Wood has been modeled as an orthotropic composit material where one direction is dominated by fiber properties and the other two, by matrix properties.

NOTE: Tangential and radial properties have been averaged. Average value was appiled to both directions

\begin{tabular}{|c|c|c|c|c|c|}
\hline \multirow{3}{*}{$\begin{array}{l}E(L) \\
E(T) / E(L) \\
E(T)\end{array}$} & \multirow{2}{*}{$\begin{array}{c}1,900,000 \mathrm{psi} \\
0.05\end{array}$} & \multicolumn{2}{|c|}{$\begin{array}{l}\text { Special Orthtropic Material } \\
\text { 1-Fiber Direct }\end{array}$} & \multicolumn{2}{|c|}{ Ortho Props (General) } \\
\hline & & \multicolumn{2}{|c|}{ 2-Matrix } & $\mathrm{E}(1)$ & $1,900,000$ \\
\hline & $95,000 \mathrm{psi}$ & \multirow{2}{*}{\multicolumn{2}{|c|}{ 3-Matrix }} & $\mathrm{E}(2)$ & 112,100 \\
\hline & & & & $\mathrm{E}(3)$ & 112,100 \\
\hline $\mathrm{E}(\mathrm{R}) / \mathrm{E}(\mathrm{L})$ & 0.068 & & & $\mathrm{G}(12)$ & 134,900 \\
\hline \multirow[t]{2}{*}{$\mathrm{E}(\mathrm{R})$} & $129,200 \mathrm{psi}$ & & & $\mathrm{G}(13)$ & 134,900 \\
\hline & & & & $\mathrm{G}(23)$ & 13,300 \\
\hline $\mathrm{G}(\mathrm{LR}) / \mathrm{E}(\mathrm{L})$ & 0.064 & & & $\mathrm{v}(12)$ & 0.3705 \\
\hline \multirow[t]{2}{*}{$\mathrm{G}(\mathrm{LR})$} & $121,600 \mathrm{psi}$ & & & $\mathrm{v}(13)$ & 0.3705 \\
\hline & & & & $\mathrm{v}(23)$ & 0.382 \\
\hline $\mathrm{G}(\mathrm{LT}) / \mathrm{E}(\mathrm{L})$ & 0.078 & & & $\mathrm{v}(32)$ & 0.382 \\
\hline \multirow[t]{2}{*}{$\mathrm{G}(\mathrm{LT})$} & $148,200 \mathrm{psi}$ & & & $\mathrm{v}(21)$ & 0.0325 \\
\hline & & & & $\mathrm{v}(31)$ & 0.0325 \\
\hline $\mathrm{G}(\mathrm{RT}) / \mathrm{E}(\mathrm{L})$ & 0.007 & & & & \\
\hline $\mathrm{G}(\mathrm{RT})$ & $13,300 \mathrm{psi}$ & & & Y (gamma & 1.2183325 \\
\hline $\mathrm{v}(\mathrm{LR})$ & 0.292 & & & & \\
\hline $\mathrm{v}(\mathrm{LT})$ & 0.449 & \multirow{2}{*}{\multicolumn{2}{|c|}{ Abaqus Props (D matrix) }} & \multirow{2}{*}{\multicolumn{2}{|c|}{ Abaqus Input }} \\
\hline $\mathrm{v}(\mathrm{RT})$ & 0.39 & & & & \\
\hline $\mathrm{v}(\mathrm{TR})$ & 0.374 & $\mathrm{D}(1111)$ & $1,977,042$ & $\mathrm{D}(1111)$ & $1,977,042$ \\
\hline $\mathrm{v}(\mathrm{RL})$ & 0.036 & $\mathrm{D}(2222)$ & 134,931 & $\mathrm{D}(1122)$ & 103,971 \\
\hline \multirow[t]{7}{*}{$\mathrm{v}(\mathrm{TL})$} & 0.029 & $\mathrm{D}(3333)$ & 134,931 & $\mathrm{D}(2222)$ & 134,931 \\
\hline & & $\mathrm{D}(1122)$ & 103,971 & $\mathrm{D}(1133)$ & 103,971 \\
\hline & & $\mathrm{D}(1133)$ & 103,971 & $\mathrm{D}(2233)$ & 53,816 \\
\hline & & $\mathrm{D}(2233)$ & 53,816 & $\mathrm{D}(3333)$ & 134,931 \\
\hline & & $\mathrm{D}(1212)$ & 134,900 & $\mathrm{D}(1212)$ & 134,900 \\
\hline & & $\mathrm{D}(1313)$ & 134,900 & $\mathrm{D}(1313)$ & 134,900 \\
\hline & & $\mathrm{D}(2323)$ & 13,300 & $\mathrm{D}(2323)$ & 13,300 \\
\hline
\end{tabular}




\section{Appendix M: Load versus Displacement Charts}

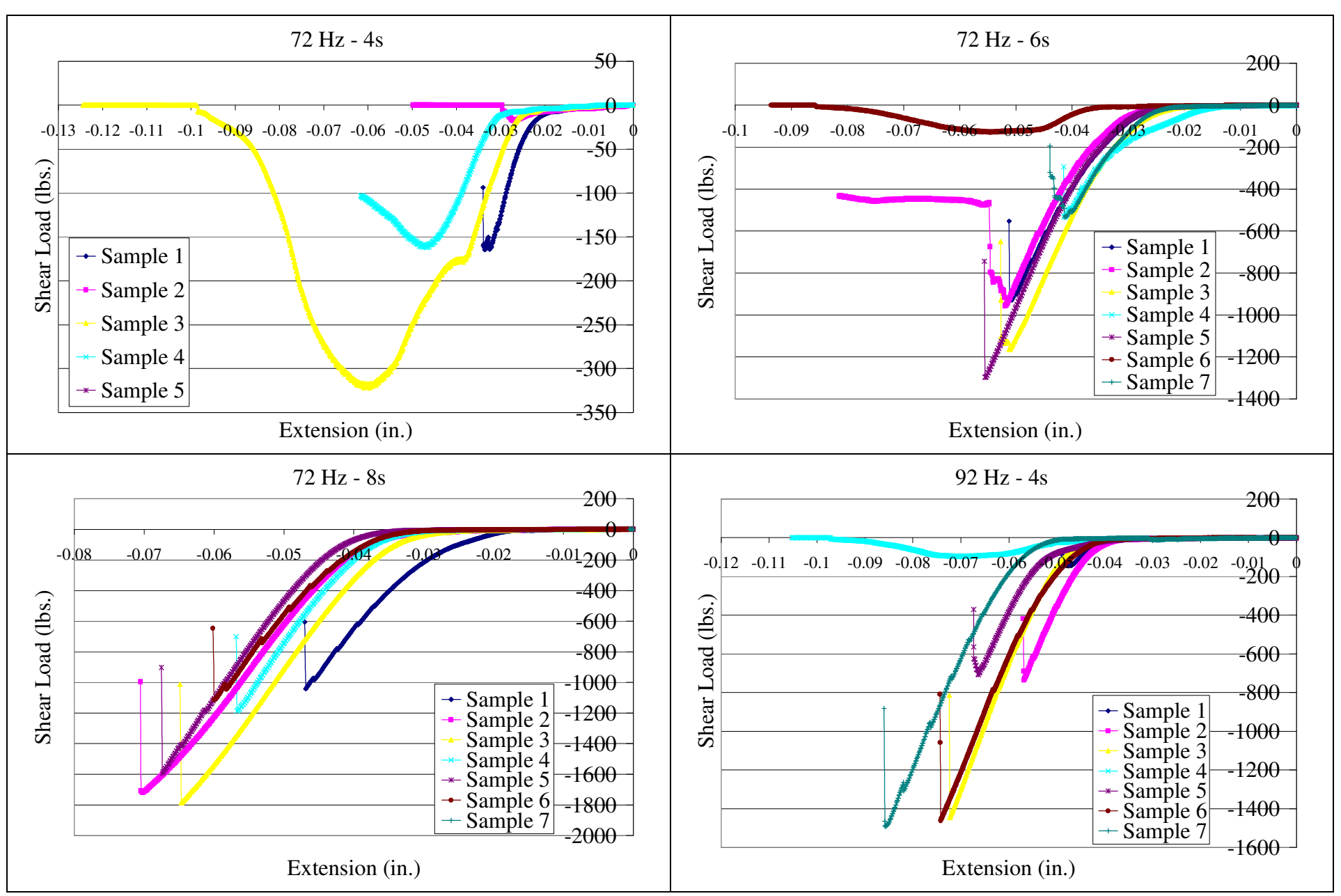




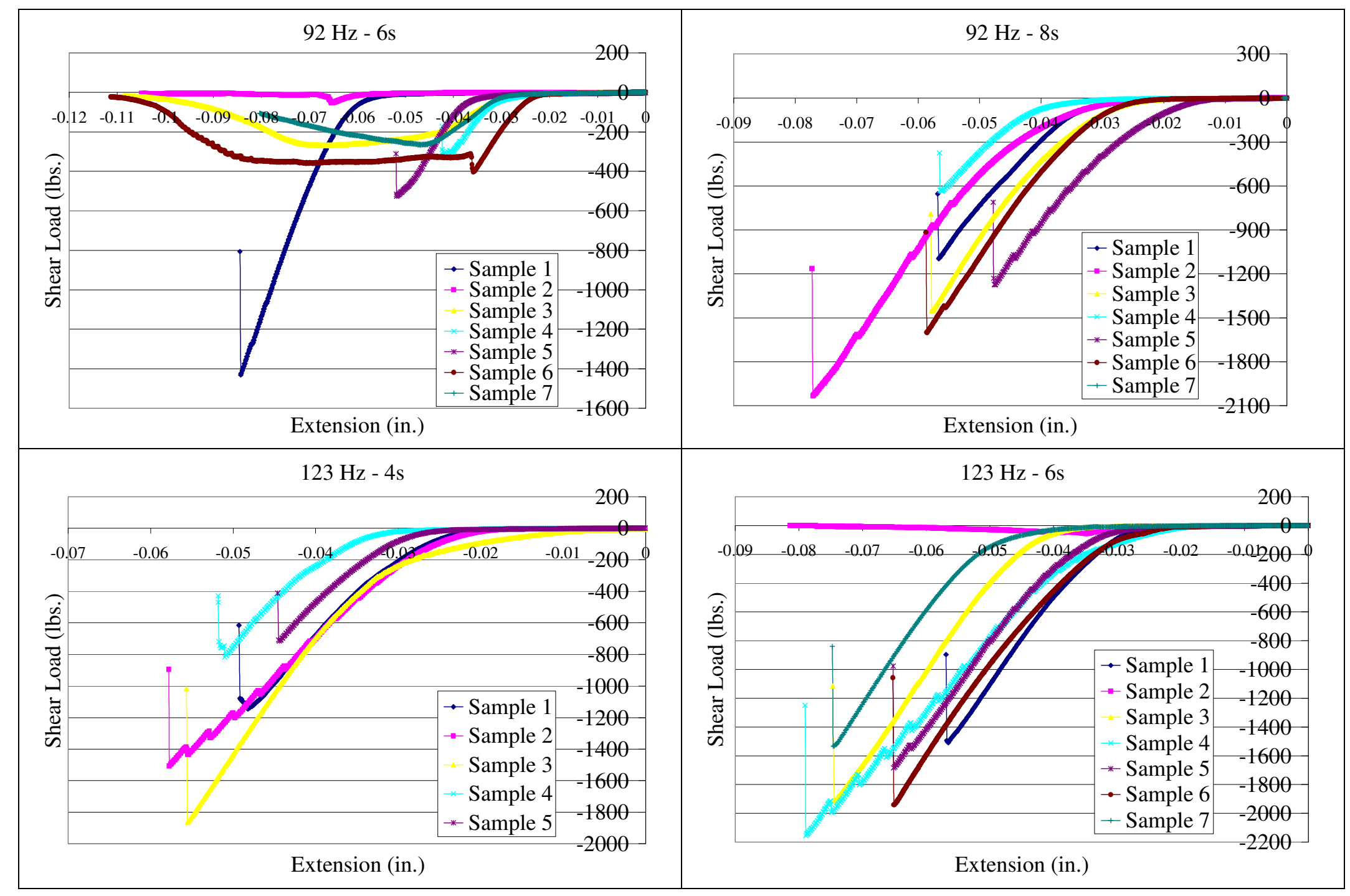




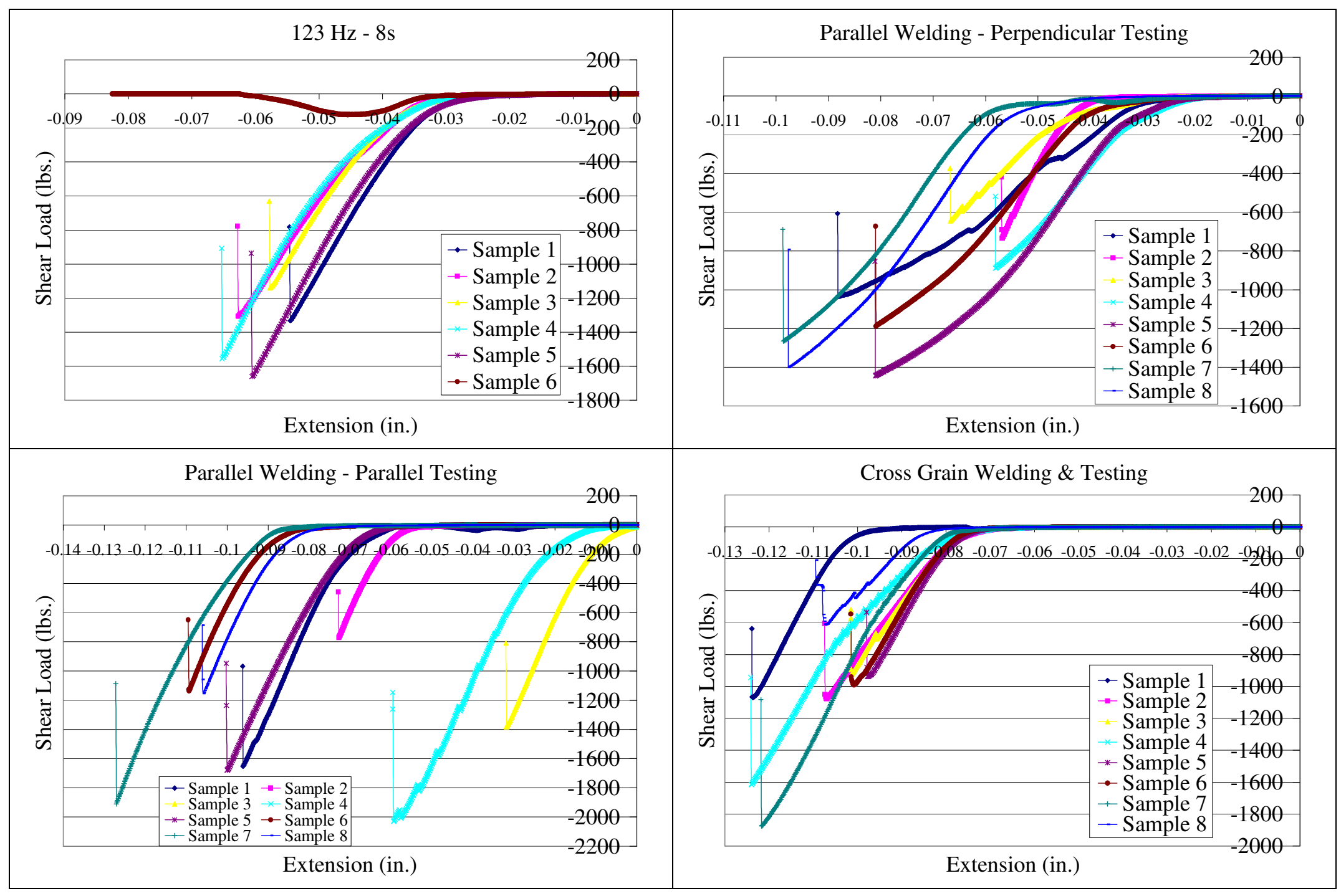




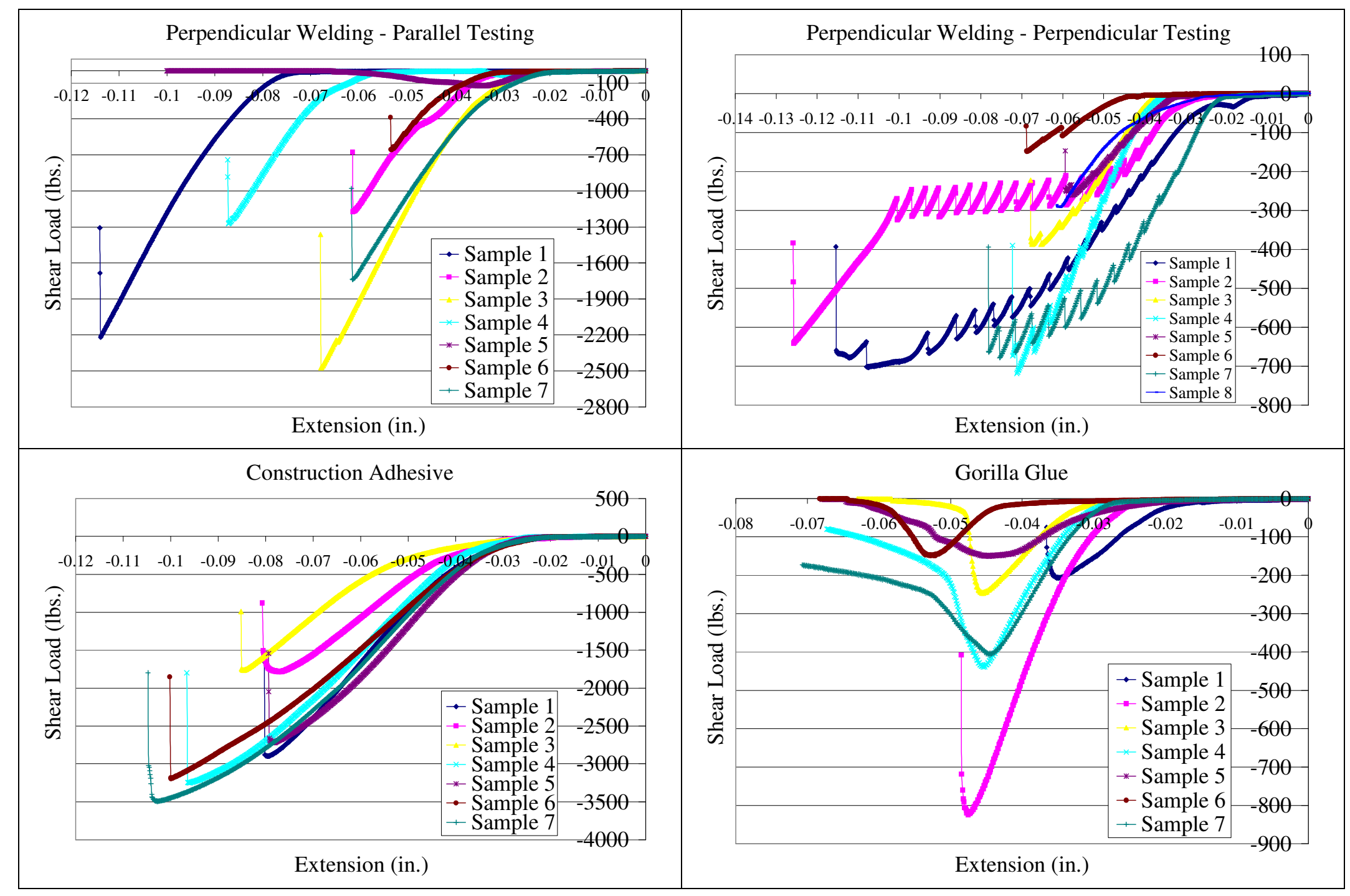




\section{Appendix N: Raw Testing Data}

\begin{tabular}{|c|c|c|c|c|c|c|c|c|c|c|c|c|c|c|c|}
\hline \multirow[b]{2}{*}{$\begin{array}{c}\text { Series } \\
\text { Info }\end{array}$} & \multirow[b]{2}{*}{ \# } & \multicolumn{3}{|c|}{ Welding Metrics } & \multicolumn{6}{|c|}{ Bonding Information } & \multicolumn{5}{|c|}{ Shear Information (lb \& psi) } \\
\hline & & Smoke & Goop & Pitch & $\begin{array}{l}\text { Black } \\
\text { Calib. }\end{array}$ & $\begin{array}{c}\text { Actual } \\
\text { Black }\end{array}$ & Ratio & Bond & Mean & $\begin{array}{l}\text { Std } \\
\text { Dev }\end{array}$ & $\begin{array}{c}\text { Fail } \\
\text { Load }\end{array}$ & $\begin{array}{c}\text { Area } \\
\left(\mathrm{in}^{\wedge} 2\right)\end{array}$ & Stress & Mean & $\begin{array}{l}\text { Std } \\
\text { Dev }\end{array}$ \\
\hline $72 \mathrm{~Hz}$ & - & $\mathrm{NO}$ & $\mathrm{NO}$ & $\mathrm{NO}$ & & & & 0.00 & 0.15 & 0.11 & & 0.00 & & 614 & 517 \\
\hline \multirow[t]{6}{*}{$4 \mathrm{sec}$} & - & NO & $\mathrm{NO}$ & NO & & & & 0.00 & & & & 0.00 & & & \\
\hline & 1 & YES & NO & NO & 158,515 & 17,570 & 0.11 & 0.22 & & & 165 & 0.28 & 594 & & \\
\hline & 2 & NO & NO & NO & 153,464 & 16,923 & 0.11 & 0.22 & & & 18 & 0.28 & 63 & & \\
\hline & - & $\mathrm{NO}$ & NO & $\mathrm{NO}$ & 156,477 & 13,466 & 0.09 & 0.17 & & & & 0.22 & & & \\
\hline & 3 & $\mathrm{NO}$ & $\mathrm{NO}$ & NO & 158,662 & 15,595 & 0.10 & 0.20 & & & 322 & 0.25 & 1310 & & \\
\hline & 4 & NO & $\mathrm{NO}$ & NO & 153,144 & 20,201 & 0.13 & 0.26 & & & 162 & 0.33 & 491 & & \\
\hline $72 \mathrm{~Hz}$ & 1 & YES & $\mathrm{NO}$ & YES & 147,590 & 35,153 & 0.24 & 0.48 & 0.49 & 0.11 & 929 & 0.60 & 1561 & 1323 & 725 \\
\hline \multirow[t]{6}{*}{$6 \mathrm{sec}$} & 2 & YES & $\mathrm{NO}$ & NO & 154,246 & 29,181 & 0.19 & 0.38 & & & 956 & 0.47 & 2022 & & \\
\hline & 3 & YES & $\mathrm{NO}$ & NO & 155,729 & 43,228 & 0.28 & 0.56 & & & 1164 & 0.69 & 1677 & & \\
\hline & 4 & YES & $\mathrm{NO}$ & YES & 151,521 & 34,643 & 0.23 & 0.46 & & & 533 & 0.57 & 933 & & \\
\hline & 5 & YES & $\mathrm{NO}$ & NO & 156,671 & 37,312 & 0.24 & 0.48 & & & 1297 & 0.60 & 2178 & & \\
\hline & 6 & NO & $\mathrm{NO}$ & $\mathrm{NO}$ & 155,387 & 29,273 & 0.19 & 0.38 & & & 130 & 0.47 & 276 & & \\
\hline & 7 & YES & $\mathrm{NO}$ & YES & 154,282 & 53,776 & 0.35 & 0.70 & & & 535 & 0.87 & 614 & & \\
\hline $72 \mathrm{~Hz}$ & 1 & YES & YES & YES & 147,501 & 54,320 & 0.37 & 0.74 & 0.70 & 0.12 & 1042 & 0.92 & 1132 & 1538 & 373 \\
\hline \multirow[t]{6}{*}{$8 \mathrm{sec}$} & 2 & YES & YES & NO & 154,086 & 56,741 & 0.37 & 0.74 & & & 1719 & 0.92 & 1867 & & \\
\hline & 3 & YES & YES & YES & 156,703 & 72,624 & 0.46 & 0.93 & & & 1784 & 1.16 & 1540 & & \\
\hline & 4 & YES & YES & YES & 150,959 & 41,718 & 0.28 & 0.55 & & & 1188 & 0.69 & 1719 & & \\
\hline & 5 & YES & YES & YES & 156,874 & 48,546 & 0.31 & 0.62 & & & 1595 & 0.77 & 2061 & & \\
\hline & 6 & YES & YES & YES & 159,612 & 51,152 & 0.32 & 0.64 & & & 1114 & 0.80 & 1391 & & \\
\hline & 7 & YES & YES & YES & 152,789 & 53,237 & 0.35 & 0.70 & & & 920 & 0.87 & 1056 & & \\
\hline $92 \mathrm{~Hz}$ & 1 & $\mathrm{NO}$ & $\mathrm{NO}$ & $\mathrm{NO}$ & 146,779 & 34,196 & 0.23 & 0.47 & 0.59 & 0.25 & 148 & 0.58 & 255 & 1088 & 588 \\
\hline \multirow[t]{6}{*}{$4 \mathrm{sec}$} & 2 & $\mathrm{NO}$ & $\mathrm{NO}$ & $\mathrm{NO}$ & 155,896 & 28,075 & 0.18 & 0.36 & & & 735 & 0.45 & 1632 & & \\
\hline & 3 & YES & YES & NO & 157,350 & 64,110 & 0.41 & 0.81 & & & 1447 & 1.02 & 1421 & & \\
\hline & 4 & $\mathrm{NO}$ & $\mathrm{NO}$ & $\mathrm{NO}$ & 154,348 & 23,691 & 0.15 & 0.31 & & & 98 & 0.38 & 255 & & \\
\hline & 5 & YES & NO & $\mathrm{NO}$ & 156,589 & 35,504 & 0.23 & 0.45 & & & 710 & 0.57 & 1252 & & \\
\hline & 6 & YES & YES & NO & 160,095 & 59,967 & 0.37 & 0.75 & & & 1462 & 0.94 & 1562 & & \\
\hline & 7 & YES & YES & NO & 151,873 & 73,002 & 0.48 & 0.96 & & & 1493 & 1.20 & 1243 & & \\
\hline
\end{tabular}




\begin{tabular}{|c|c|c|c|c|c|c|c|c|c|c|c|c|c|c|c|}
\hline $123 \mathrm{~Hz}$ & 1 & YES & YES & YES & 148,870 & 52,698 & 0.35 & 0.71 & 0.67 & 0.36 & 1333 & 0.88 & 1507 & 1543 & 936 \\
\hline \multirow[t]{6}{*}{$8 \mathrm{sec}$} & 2 & NO & $\mathrm{NO}$ & $\mathrm{NO}$ & 157,931 & 24,463 & 0.15 & 0.31 & & & 1307 & 0.39 & 3375 & & \\
\hline & 3 & YES & YES & YES & 158,361 & 66,789 & 0.42 & 0.84 & & & 1140 & 1.05 & 1081 & & \\
\hline & 4 & YES & YES & YES & 151,765 & 85,203 & 0.56 & 1.00 & & & 1557 & 1.25 & 1245 & & \\
\hline & 5 & YES & YES & YES & 154,970 & 98,573 & 0.64 & 1.00 & & & 1661 & 1.25 & 1329 & & \\
\hline & 6 & NO & $\mathrm{NO}$ & NO & 160,312 & 10,995 & 0.07 & 0.14 & & & 124 & 0.17 & 721 & & \\
\hline & - & NO & $\mathrm{NO}$ & NO & & & & & & & & 0.00 & & & \\
\hline Para Weld & 1 & YES & YES & $\mathrm{NO}$ & 142,727 & 91,581 & 0.64 & 1.00 & 0.99 & 0.03 & 1036 & 1.25 & 828 & 755 & 333 \\
\hline \multirow[t]{7}{*}{ Perp Test } & 2 & YES & YES & YES & 152,714 & 101,157 & 0.66 & 1.00 & 0.94 & 0.19 & 645 & 1.25 & 516 & & \\
\hline & 3 & YES & YES & YES & 155,027 & 122,276 & 0.79 & 1.00 & & & 889 & 1.25 & 711 & & \\
\hline & 4 & YES & YES & YES & 145,695 & 95,181 & 0.65 & 1.00 & & & 145 & 1.25 & 116 & & \\
\hline & 5 & YES & YES & YES & 146,080 & 81,312 & 0.56 & 1.00 & & & 1189 & 1.25 & 951 & & \\
\hline & 6 & YES & YES & YES & 158,059 & 72,172 & 0.46 & 0.91 & & & 1265 & 1.14 & 1108 & & \\
\hline & 7 & $\mathrm{NO}$ & YES & $\mathrm{NO}$ & 159,690 & 105,452 & 0.66 & 1.00 & & & 866 & 1.25 & 693 & & \\
\hline & 8 & YES & YES & YES & 150,738 & 108,354 & 0.72 & 1.00 & & & 1401 & 1.25 & 1121 & & \\
\hline Para Weld & 1 & YES & YES & YES & 143,914 & 71,386 & 0.50 & 0.99 & 0.89 & 0.27 & 1653 & 1.24 & 1333 & 1427 & 526 \\
\hline \multirow[t]{7}{*}{ Para Test } & 2 & $\mathrm{NO}$ & $\mathrm{NO}$ & $\mathrm{NO}$ & 155,504 & 18,655 & 0.12 & 0.24 & & & 771 & 0.30 & 2569 & & \\
\hline & 3 & YES & YES & YES & 155,411 & 78,845 & 0.51 & 1.00 & & & 1381 & 1.25 & 1105 & & \\
\hline & 4 & YES & YES & YES & 149,213 & 76,813 & 0.51 & 1.00 & & & 2030 & 1.25 & 1624 & & \\
\hline & 5 & YES & YES & YES & 146,360 & 72,145 & 0.49 & 0.99 & & & 1679 & 1.23 & 1363 & & \\
\hline & 6 & YES & YES & YES & 154,740 & 86,856 & 0.56 & 1.00 & & & 1138 & 1.25 & 910 & & \\
\hline & 7 & YES & YES & YES & 157,423 & 82,798 & 0.53 & 1.00 & & & 1910 & 1.25 & 1528 & & \\
\hline & 8 & YES & YES & YES & 150,529 & 70,748 & 0.47 & 0.94 & & & 1155 & 1.17 & 983 & & \\
\hline Perp Weld & 1 & YES & YES & YES & 141,274 & 56,362 & 0.40 & 0.80 & 0.79 & 0.16 & 2220 & 1.00 & 2226 & 1411 & 818 \\
\hline \multirow[t]{7}{*}{ Para Test } & - & $\mathrm{NO}$ & $\mathrm{NO}$ & $\mathrm{NO}$ & & & $\mathrm{n} / \mathrm{a}$ & $\mathrm{n} / \mathrm{a}$ & 0.73 & 0.20 & & $\mathrm{n} / \mathrm{a}$ & & & \\
\hline & 2 & YES & YES & NO & 157,724 & 39,722 & 0.25 & 0.50 & & & 1174 & 0.63 & 1864 & & \\
\hline & 3 & YES & YES & YES & 148,683 & 64,798 & 0.44 & 0.87 & & & 2473 & 1.09 & 2269 & & \\
\hline & 4 & YES & $\mathrm{NO}$ & $\mathrm{NO}$ & 145,739 & 56,502 & 0.39 & 0.78 & & & 1274 & 0.97 & 1314 & & \\
\hline & 5 & $\mathrm{NO}$ & $\mathrm{NO}$ & NO & 155,200 & 52,841 & 0.34 & 0.68 & & & 124 & 0.85 & 146 & & \\
\hline & 6 & YES & YES & YES & 158,485 & 80,708 & 0.51 & 1.00 & & & 657 & 1.25 & 526 & & \\
\hline & 7 & YES & YES & YES & 152,932 & 69,333 & 0.45 & 0.91 & & & 1740 & 1.13 & 1535 & & \\
\hline
\end{tabular}




\begin{tabular}{|c|c|c|c|c|c|c|c|c|c|c|c|c|c|c|c|}
\hline Perp Weld & 1 & YES & YES & YES & 142,451 & 60,017 & 0.42 & 0.84 & 0.68 & 0.23 & 703 & 1.05 & 668 & 552 & 203 \\
\hline \multirow[t]{7}{*}{ Perp Test } & 2 & YES & YES & YES & 152,577 & 89,997 & 0.59 & 1.00 & & & 641 & 1.25 & 513 & & \\
\hline & 3 & YES & YES & NO & 157,292 & 36,671 & 0.23 & 0.47 & & & 387 & 0.58 & 664 & & \\
\hline & 4 & YES & YES & YES & 151,167 & 77,615 & 0.51 & 1.00 & & & 719 & 1.25 & 575 & & \\
\hline & 5 & $\mathrm{NO}$ & NO & NO & 146,068 & 38,397 & 0.26 & 0.53 & & & 261 & 0.66 & 397 & & \\
\hline & 6 & NO & NO & NO & 157,512 & 44,450 & 0.28 & 0.56 & & & 147 & 0.71 & 208 & & \\
\hline & 7 & YES & NO & NO & 155,189 & 47,242 & 0.30 & 0.61 & & & 678 & 0.76 & 891 & & \\
\hline & 8 & $\mathrm{NO}$ & NO & NO & 149,243 & 34,687 & 0.23 & 0.46 & & & 292 & 0.58 & 502 & & \\
\hline \multirow[t]{8}{*}{ Cross Weld } & 1 & $\mathrm{NO}$ & NO & $\mathrm{NO}$ & 141,718 & 55,623 & 0.39 & 0.78 & 0.96 & 0.07 & 1071 & 0.98 & 1091 & 953 & 346 \\
\hline & 2 & YES & YES & NO & 154,065 & 85,082 & 0.55 & 1.00 & 0.96 & 0.07 & 1078 & 1.25 & 862 & & \\
\hline & 3 & YES & YES & YES & 155,009 & 73,523 & 0.47 & 0.95 & & & 920 & 1.19 & 776 & & \\
\hline & 4 & YES & YES & YES & 146,777 & 79,071 & 0.54 & 1.00 & & & 1617 & 1.25 & 1293 & & \\
\hline & 5 & YES & YES & YES & 148,412 & 91,846 & 0.62 & 1.00 & & & 937 & 1.25 & 750 & & \\
\hline & 6 & YES & YES & YES & 155,649 & 88,096 & 0.57 & 1.00 & & & 992 & 1.25 & 793 & & \\
\hline & 7 & YES & YES & YES & 157,055 & 74,988 & 0.48 & 0.95 & & & 1874 & 1.19 & 1570 & & \\
\hline & 8 & YES & YES & YES & 150,774 & 76,303 & 0.51 & 1.00 & & & 613 & 1.25 & 490 & & \\
\hline \multirow[t]{7}{*}{ Const. Glue } & 1 & & & & & & & 1.00 & & & 2901 & 1.25 & 2321 & 2182 & 556 \\
\hline & 2 & & & & & & & 1.00 & & & 1788 & 1.25 & 1431 & & \\
\hline & 3 & & & & & & & 1.00 & & & 1764 & 1.25 & 1412 & & \\
\hline & 4 & & & & & & & 1.00 & & & 3224 & 1.25 & 2579 & & \\
\hline & 5 & & & & & & & 1.00 & & & 2722 & 1.25 & 2177 & & \\
\hline & 6 & & & & & & & 1.00 & & & 3197 & 1.25 & 2557 & & \\
\hline & 7 & & & & & & & 1.00 & & & 3498 & 1.25 & 2798 & & \\
\hline \multirow[t]{7}{*}{ Gorilla Glue } & 1 & & & & & & & 1.00 & & & 208 & 1.25 & 166 & 278 & 193 \\
\hline & 2 & & & & & & & 1.00 & & & 825 & 1.25 & 660 & & \\
\hline & 3 & & & & & & & 1.00 & & & 247 & 1.25 & 197 & & \\
\hline & 4 & & & & & & & 1.00 & & & 440 & 1.25 & 352 & & \\
\hline & 5 & & & & & & & 1.00 & & & 151 & 1.25 & 121 & & \\
\hline & 6 & & & & & & & 1.00 & & & 149 & 1.25 & 119 & & \\
\hline & 7 & & & & & & & 1.00 & & & 409 & 1.25 & 327 & & \\
\hline
\end{tabular}




\begin{tabular}{|c|c|c|c|c|c|c|c|c|c|c|c|}
\hline \multirow{4}{*}{ 60-min } & 1 & \multirow{4}{*}{ YES } & 174,269 & 53,850 & 0.31 & 0.62 & 1297 & 0.77 & 1678 & 1623 & 611 \\
\hline & 2 & & 177,366 & 62,900 & 0.35 & 0.71 & 1583 & 0.89 & 1785 & & \\
\hline & 3 & & 174,741 & 77,651 & 0.44 & 0.89 & 2494 & 1.11 & 2245 & & \\
\hline & 4 & & 163,049 & 52,401 & 0.32 & 0.64 & 631 & 0.80 & 785 & & \\
\hline \multirow[t]{4}{*}{ 100-min } & 1 & & 174,675 & 40,420 & 0.23 & 0.46 & 564 & 0.58 & 975 & 1102 & 523 \\
\hline & 2 & & 179,610 & 65,102 & 0.36 & 0.72 & 1689 & 0.91 & 1864 & & \\
\hline & 3 & & 175,315 & 73,190 & 0.42 & 0.83 & 709 & 1.04 & 679 & & \\
\hline & 4 & & 166,795 & 33,824 & 0.20 & 0.41 & 452 & 0.51 & 891 & & \\
\hline \multirow[t]{3}{*}{ 750-min } & $\begin{array}{l}1 \\
-\end{array}$ & & 176,637 & 39,688 & $\begin{array}{r}0.22 \\
\mathrm{n} / \mathrm{a}\end{array}$ & $\begin{array}{r}0.45 \\
\mathrm{n} / \mathrm{a}\end{array}$ & 830 & $\begin{array}{r}0.56 \\
\mathrm{n} / \mathrm{a}\end{array}$ & 1477 & 1374 & 245 \\
\hline & 2 & & 174,980 & 41,955 & 0.24 & 0.48 & 656 & 0.60 & 1094 & & \\
\hline & 3 & & 166,351 & 35,174 & 0.21 & 0.42 & 820 & 0.53 & 1550 & & \\
\hline \multirow[t]{4}{*}{$1200-\min$} & 1 & & 173,802 & 26,599 & 0.15 & 0.31 & 470 & 0.38 & 1229 & 1278 & 174 \\
\hline & 2 & & 178,228 & 82,694 & 0.46 & 0.93 & 1741 & 1.16 & 1501 & & \\
\hline & 3 & YES & 175,787 & 72,460 & 0.41 & 0.82 & 1339 & 1.03 & 1300 & & \\
\hline & 4 & & 167,913 & 32,715 & 0.19 & 0.39 & 527 & 0.49 & 1082 & & \\
\hline \multirow[t]{4}{*}{ 2040-min } & 1 & & 174,612 & 61,115 & 0.35 & 0.70 & 428 & 0.88 & 489 & 1120 & 868 \\
\hline & 2 & YES & 180,532 & 92,523 & 0.51 & 1.00 & 1748 & 1.25 & 1398 & & \\
\hline & 3 & & 175,544 & 50,813 & 0.29 & 0.58 & 266 & 0.72 & 367 & & \\
\hline & 4 & & 165,006 & 51,569 & 0.31 & 0.63 & 1738 & 0.78 & 2224 & & \\
\hline \multirow[t]{4}{*}{ 3000-min } & 1 & & 142,035 & 60,562 & 0.43 & 0.85 & 1307 & 1.07 & 1226 & 1392 & 591 \\
\hline & 2 & YES & 146,171 & 88,730 & 0.61 & 1.00 & 2541 & 1.25 & 2033 & & \\
\hline & 3 & & 140,084 & 34,388 & 0.25 & 0.49 & 402 & 0.61 & 656 & & \\
\hline & 4 & & 131,921 & 61,435 & 0.47 & 0.93 & 1924 & 1.16 & 1653 & & \\
\hline \multirow[t]{4}{*}{ 4500-min } & 1 & & 99,036 & 27,828 & 0.28 & 0.56 & 332 & 0.70 & 473 & 594 & 454 \\
\hline & 2 & & 101,823 & 52,946 & 0.52 & 1.00 & 913 & 1.25 & 731 & & \\
\hline & 3 & YES & 98,821 & 44,290 & 0.45 & 0.90 & 1264 & 1.12 & 1128 & & \\
\hline & 4 & & 96,803 & 14,214 & 0.15 & 0.29 & 17 & 0.37 & 46 & & \\
\hline \multirow[t]{2}{*}{ 6000-min } & $\begin{array}{l}1 \\
-\end{array}$ & $\mathrm{NO}$ & 98,859 & 48,796 & $\begin{array}{r}0.49 \\
\mathrm{n} / \mathrm{a}\end{array}$ & $\begin{array}{r}0.99 \\
\mathrm{n} / \mathrm{a}\end{array}$ & 1281 & $\begin{array}{r}1.23 \\
\mathrm{n} / \mathrm{a}\end{array}$ & 1038 & 979 & 83 \\
\hline & $\begin{array}{l}2 \\
-\end{array}$ & YES & 101,887 & 44,855 & $\begin{array}{r}0.44 \\
\mathrm{n} / \mathrm{a}\end{array}$ & $\begin{array}{r}0.88 \\
\mathrm{n} / \mathrm{a}\end{array}$ & 1013 & $\begin{array}{r}1.10 \\
\mathrm{n} / \mathrm{a}\end{array}$ & 920 & & \\
\hline
\end{tabular}




\section{Appendix O: Testing Statistics}

\begin{tabular}{|c|c|c|c|c|c|c|c|c|c|c|c|c|}
\hline \multirow[b]{3}{*}{ Series } & \multirow[b]{3}{*}{ Sub-set } & \multicolumn{6}{|c|}{ Standard Data } & \multicolumn{5}{|c|}{ Smoke Generation } \\
\hline & & \multicolumn{4}{|c|}{ Shear Strength (psi) } & \multicolumn{2}{|c|}{ Bonding } & \multicolumn{3}{|c|}{ Shear Strength (psi) } & \multicolumn{2}{|c|}{ Bonding } \\
\hline & & Control \% & Mean & SD & $\mathrm{CV}$ & Mean & SD & Mean & SD & $\mathrm{CV}$ & Mean & SD \\
\hline $72 \mathrm{~Hz}$ & $4 \mathrm{sec}$ & $28 \%$ & 614 & 517 & $84 \%$ & $15 \%$ & $11 \%$ & 594 & $\mathrm{n} / \mathrm{a}$ & $\mathrm{n} / \mathrm{a}$ & $22 \%$ & $\mathrm{n} / \mathrm{a}$ \\
\hline $72 \mathrm{~Hz}$ & $6 \mathrm{sec}$ & $61 \%$ & 1,323 & 725 & $55 \%$ & $49 \%$ & $11 \%$ & 1,497 & 612 & $41 \%$ & $51 \%$ & $11 \%$ \\
\hline $72 \mathrm{~Hz}$ & $8 \mathrm{sec}$ & $70 \%$ & 1,538 & 373 & $24 \%$ & $70 \%$ & $12 \%$ & 1,538 & 373 & $24 \%$ & $70 \%$ & $12 \%$ \\
\hline $92 \mathrm{~Hz}$ & $4 \mathrm{sec}$ & $50 \%$ & 1,088 & 588 & $54 \%$ & $59 \%$ & $25 \%$ & 1,369 & 152 & $11 \%$ & $74 \%$ & $21 \%$ \\
\hline $92 \mathrm{~Hz}$ & $6 \mathrm{sec}$ & $29 \%$ & 633 & 439 & $69 \%$ & $56 \%$ & $15 \%$ & 1,372 & $\mathrm{n} / \mathrm{a}$ & $\mathrm{n} / \mathrm{a}$ & $83 \%$ & $\mathrm{n} / \mathrm{a}$ \\
\hline $92 \mathrm{~Hz}$ & $8 \mathrm{sec}$ & $53 \%$ & 1,161 & 425 & $37 \%$ & $95 \%$ & $7 \%$ & 1,161 & 425 & $37 \%$ & $95 \%$ & $7 \%$ \\
\hline $123 \mathrm{~Hz}$ & $4 \mathrm{sec}$ & $70 \%$ & 1,527 & 258 & $17 \%$ & $62 \%$ & $20 \%$ & 1,615 & 312 & $19 \%$ & $67 \%$ & $26 \%$ \\
\hline $123 \mathrm{~Hz}$ & $6 \mathrm{sec}$ & $67 \%$ & 1,453 & 539 & $37 \%$ & $77 \%$ & $31 \%$ & 1,642 & 222 & $14 \%$ & $88 \%$ & $14 \%$ \\
\hline $123 \mathrm{~Hz}$ & $8 \mathrm{sec}$ & $71 \%$ & 1,543 & 936 & $61 \%$ & $67 \%$ & $36 \%$ & 1,290 & 177 & $14 \%$ & $89 \%$ & $14 \%$ \\
\hline
\end{tabular}




\begin{tabular}{|c|c|c|c|c|c|c|c|c|c|c|c|}
\hline \multicolumn{2}{|c}{} & \multicolumn{6}{|c|}{ Goop Formation } & \multicolumn{5}{c|}{ Audible Pitch Change } \\
\cline { 2 - 13 } & \multicolumn{2}{|c|}{ Shear Strength (psi) } & \multicolumn{2}{c|}{ Bonding } & \multicolumn{2}{c|}{ Shear Strength (psi) } & Bonding \\
\hline Series & Sub-set & Mean & SD & CV & Mean & SD & Mean & SD & CV & Mean & SD \\
\hline $72 \mathrm{~Hz}$ & $4 \mathrm{sec}$ & $\mathrm{n} / \mathrm{a}$ & $\mathrm{n} / \mathrm{a}$ & $\mathrm{n} / \mathrm{a}$ & $\mathrm{n} / \mathrm{a}$ & $\mathrm{n} / \mathrm{a}$ & $\mathrm{n} / \mathrm{a}$ & $\mathrm{n} / \mathrm{a}$ & $\mathrm{n} / \mathrm{a}$ & $\mathrm{n} / \mathrm{a}$ & $\mathrm{n} / \mathrm{a}$ \\
\hline $72 \mathrm{~Hz}$ & $6 \mathrm{sec}$ & $\mathrm{n} / \mathrm{a}$ & $\mathrm{n} / \mathrm{a}$ & $\mathrm{n} / \mathrm{a}$ & $\mathrm{n} / \mathrm{a}$ & $\mathrm{n} / \mathrm{a}$ & 1,036 & 482 & $47 \%$ & $54 \%$ & $13 \%$ \\
\hline $72 \mathrm{~Hz}$ & $8 \mathrm{sec}$ & 1,538 & 373 & $24 \%$ & $70 \%$ & $12 \%$ & 1,483 & 376 & $25 \%$ & $70 \%$ & $13 \%$ \\
\hline $92 \mathrm{~Hz}$ & $4 \mathrm{sec}$ & 1,408 & 160 & $11 \%$ & $84 \%$ & $11 \%$ & $\mathrm{n} / \mathrm{a}$ & $\mathrm{n} / \mathrm{a}$ & $\mathrm{n} / \mathrm{a}$ & $\mathrm{n} / \mathrm{a}$ & $\mathrm{n} / \mathrm{a}$ \\
\hline $92 \mathrm{~Hz}$ & $6 \mathrm{sec}$ & 1,372 & $\mathrm{n} / \mathrm{a}$ & $\mathrm{n} / \mathrm{a}$ & $83 \%$ & $\mathrm{n} / \mathrm{a}$ & 1,372 & $\mathrm{n} / \mathrm{a}$ & $\mathrm{n} / \mathrm{a}$ & $83 \%$ & $\mathrm{n} / \mathrm{a}$ \\
\hline $92 \mathrm{~Hz}$ & $8 \mathrm{sec}$ & 1,161 & 425 & $37 \%$ & $95 \%$ & $7 \%$ & 1,161 & 425 & $37 \%$ & $95 \%$ & $7 \%$ \\
\hline $123 \mathrm{~Hz}$ & $4 \mathrm{sec}$ & 1,573 & $\mathrm{n} / \mathrm{a}$ & $\mathrm{n} / \mathrm{a}$ & $95 \%$ & $\mathrm{n} / \mathrm{a}$ & $\mathrm{n} / \mathrm{a}$ & $\mathrm{n} / \mathrm{a}$ & $\mathrm{n} / \mathrm{a}$ & $\mathrm{n} / \mathrm{a}$ & $\mathrm{n} / \mathrm{a}$ \\
\hline $123 \mathrm{~Hz}$ & $6 \mathrm{sec}$ & 1,617 & 239 & $15 \%$ & $92 \%$ & $11 \%$ & 1,590 & 267 & $17 \%$ & $90 \%$ & $12 \%$ \\
\hline $123 \mathrm{~Hz}$ & $8 \mathrm{sec}$ & 1,290 & 177 & $14 \%$ & $89 \%$ & $14 \%$ & 1,290 & 177 & $14 \%$ & $89 \%$ & $14 \%$ \\
\hline
\end{tabular}




\begin{tabular}{|c|c|c|c|c|c|c|c|c|c|c|c|c|}
\hline \multirow[b]{3}{*}{ Series } & \multirow[b]{3}{*}{ Sub-set } & \multicolumn{6}{|c|}{ Standard Data } & \multicolumn{5}{|c|}{ Smoke Generation } \\
\hline & & \multicolumn{4}{|c|}{ Shear Strength (psi) } & \multicolumn{2}{|c|}{ Bonding } & \multicolumn{3}{|c|}{ Shear Strength (psi) } & \multicolumn{2}{|c|}{ Bonding } \\
\hline & & Control \% & Mean & SD & $\mathrm{CV}$ & Mean & SD & Mean & SD & $\mathrm{CV}$ & Mean & SD \\
\hline Para Weld & Perp Test & $35 \%$ & 755 & 333 & $44 \%$ & \multirow{2}{*}{$94 \%$} & \multirow{2}{*}{$19 \%$} & 764 & 358 & $47 \%$ & \multirow{2}{*}{$99 \%$} & \multirow{2}{*}{$3 \%$} \\
\hline Para Weld & Para Test & $65 \%$ & 1427 & 526 & $37 \%$ & & & 1,264 & 272 & $22 \%$ & & \\
\hline Perp Weld & Para Test & $65 \%$ & 1411 & 818 & $58 \%$ & \multirow{2}{*}{$73 \%$} & \multirow{2}{*}{$20 \%$} & 1,622 & 655 & $40 \%$ & \multirow{2}{*}{$80 \%$} & \multirow{2}{*}{$19 \%$} \\
\hline Perp Weld & Perp Test & $25 \%$ & 552 & 203 & $37 \%$ & & & 662 & 144 & $22 \%$ & & \\
\hline Cross Weld & Cross & $44 \%$ & 953 & 346 & $36 \%$ & $96 \%$ & $7 \%$ & 934 & 368 & $39 \%$ & $99 \%$ & $2 \%$ \\
\hline
\end{tabular}

\begin{tabular}{|c|c|c|c|c|c|c|c|c|c|c|c|}
\hline \multirow[b]{3}{*}{ Series } & \multirow[b]{3}{*}{ Sub-set } & \multicolumn{5}{|c|}{ Goop Formation } & \multicolumn{5}{|c|}{ Audible Pitch Change } \\
\hline & & \multicolumn{3}{|c|}{ Shear Strength (psi) } & \multicolumn{2}{|c|}{ Bonding } & \multicolumn{3}{|c|}{ Shear Strength (psi) } & \multicolumn{2}{|c|}{ Bonding } \\
\hline & & Mean & SD & $\mathrm{CV}$ & Mean & SD & Mean & SD & $\mathrm{CV}$ & Mean &. $\mathrm{D}$ \\
\hline Para Weld & Perp Test & 755 & 333 & $44 \%$ & \multirow{2}{*}{$99 \%$} & \multirow{2}{*}{$3 \%$} & 754 & 391 & $52 \%$ & \multirow{2}{*}{$99 \%$} & \multirow{2}{*}{$3 \%$} \\
\hline Para Weld & Para Test & 1264 & 272 & $22 \%$ & & & 1264 & 272 & $22 \%$ & & \\
\hline Perp Weld & Para Test & 1684 & 713 & $42 \%$ & \multirow{2}{*}{$82 \%$} & \multirow{2}{*}{$20 \%$} & 1639 & 815 & $50 \%$ & \multirow{2}{*}{$92 \%$} & \multirow{2}{*}{$8 \%$} \\
\hline Perp Weld & Perp Test & 605 & 75 & $12 \%$ & & & 585 & 78 & $13 \%$ & & \\
\hline Cross Weld & Cross & 934 & 368 & $39 \%$ & $99 \%$ & $2 \%$ & 945 & 402 & $43 \%$ & $98 \%$ & $2 \%$ \\
\hline
\end{tabular}




\begin{tabular}{|r|r|r|r|r|r|}
\hline \multicolumn{2}{|c|}{} & \multicolumn{5}{|c|}{ Shear Strength (psi) } \\
\hline Series & \multicolumn{1}{|c|}{ Sub-set } & Control \% & Mean & \multicolumn{1}{c|}{ SD } & \multicolumn{1}{c|}{ CV } \\
\hline Cure Time & $60-$ min & $74 \%$ & 1,623 & 611 & $38 \%$ \\
\hline Cure Time & $100-$ min & $51 \%$ & 1,102 & 523 & $47 \%$ \\
\hline Cure Time & $750-$ min & $63 \%$ & 1,374 & 245 & $18 \%$ \\
\hline Cure Time & $1200-$ min & $59 \%$ & 1,278 & 174 & $14 \%$ \\
\hline Cure Time & $2040-$ min & $51 \%$ & 1,120 & 868 & $78 \%$ \\
\hline Cure Time & $3000-$ min & $64 \%$ & 1,392 & 591 & $42 \%$ \\
\hline Cure Time & $4500-$ min & $27 \%$ & 594 & 454 & $76 \%$ \\
\hline Cure Time & $6000-$ min & $45 \%$ & 979 & 83 & $9 \%$ \\
\hline Control & Const. Glue & $100 \%$ & 2,182 & 556 & $25 \%$ \\
\hline Control & Gorilla Glue & $13 \%$ & 278 & 193 & $69 \%$ \\
\hline
\end{tabular}




\section{Appendix P: Testing Statistics with SI Units}

\begin{tabular}{|c|c|c|c|c|c|c|c|c|c|c|c|c|}
\hline \multirow[b]{3}{*}{ Series } & \multirow[b]{3}{*}{ Sub-set } & \multicolumn{6}{|c|}{ Standard Data } & \multicolumn{5}{|c|}{ Smoke Generation } \\
\hline & & \multicolumn{4}{|c|}{ Shear Strength (MPa) } & \multicolumn{2}{|c|}{ Bonding } & \multicolumn{3}{|c|}{ Shear Strength (MPa) } & \multicolumn{2}{|c|}{ Bonding } \\
\hline & & Control \% & Mean & SD & $\mathrm{CV}$ & Mean & SD & Mean & SD & $\mathrm{CV}$ & Mean & SD \\
\hline $72 \mathrm{~Hz}$ & $4 \mathrm{sec}$ & $28 \%$ & 4.24 & 3.57 & $84 \%$ & $15 \%$ & $11 \%$ & 4.09 & $\mathrm{n} / \mathrm{a}$ & $\mathrm{n} / \mathrm{a}$ & $22 \%$ & $\mathrm{n} / \mathrm{a}$ \\
\hline $72 \mathrm{~Hz}$ & $6 \mathrm{sec}$ & $61 \%$ & 9.12 & 5.00 & $55 \%$ & $49 \%$ & $11 \%$ & 10.32 & 4.22 & $41 \%$ & $51 \%$ & $11 \%$ \\
\hline $72 \mathrm{~Hz}$ & $8 \mathrm{sec}$ & $70 \%$ & 10.60 & 2.57 & $24 \%$ & $70 \%$ & $12 \%$ & 10.60 & 2.57 & $24 \%$ & $70 \%$ & $12 \%$ \\
\hline $92 \mathrm{~Hz}$ & $4 \mathrm{sec}$ & $50 \%$ & 7.50 & 4.05 & $54 \%$ & $59 \%$ & $25 \%$ & 9.44 & 1.05 & $11 \%$ & $74 \%$ & $21 \%$ \\
\hline $92 \mathrm{~Hz}$ & $6 \mathrm{sec}$ & $29 \%$ & 4.37 & 3.02 & $69 \%$ & $56 \%$ & $15 \%$ & 9.46 & $\mathrm{n} / \mathrm{a}$ & $\mathrm{n} / \mathrm{a}$ & $83 \%$ & $\mathrm{n} / \mathrm{a}$ \\
\hline $92 \mathrm{~Hz}$ & $8 \mathrm{sec}$ & $53 \%$ & 8.01 & 2.93 & $37 \%$ & $95 \%$ & $7 \%$ & 8.01 & 2.93 & $37 \%$ & $95 \%$ & $7 \%$ \\
\hline $123 \mathrm{~Hz}$ & $4 \mathrm{sec}$ & $70 \%$ & 10.53 & 1.78 & $17 \%$ & $62 \%$ & $20 \%$ & 11.14 & 2.15 & $19 \%$ & $67 \%$ & $26 \%$ \\
\hline $123 \mathrm{~Hz}$ & $6 \mathrm{sec}$ & $67 \%$ & 10.02 & 3.72 & $37 \%$ & $77 \%$ & $31 \%$ & 11.32 & 1.53 & $14 \%$ & $88 \%$ & $14 \%$ \\
\hline $123 \mathrm{~Hz}$ & $8 \mathrm{sec}$ & $71 \%$ & 10.64 & 6.45 & $61 \%$ & $67 \%$ & $36 \%$ & 8.90 & 1.22 & $14 \%$ & $89 \%$ & $14 \%$ \\
\hline
\end{tabular}




\begin{tabular}{|c|c|c|c|c|c|c|c|c|c|c|c|}
\hline \multirow[b]{3}{*}{ Series } & \multirow[b]{3}{*}{ Sub-set } & \multicolumn{5}{|c|}{ Goop Formation } & \multicolumn{5}{|c|}{ Audible Pitch Change } \\
\hline & & \multicolumn{3}{|c|}{ Shear Strength (MPa) } & \multicolumn{2}{|c|}{ Bonding } & \multicolumn{3}{|c|}{ Shear Strength (MPa) } & \multicolumn{2}{|c|}{ Bonding } \\
\hline & & Mean & $\mathrm{SD}$ & $\mathrm{CV}$ & Mean & $\mathrm{SD}$ & Mean & SD & $\mathrm{CV}$ & Mean & SD \\
\hline $72 \mathrm{~Hz}$ & $4 \mathrm{sec}$ & $\mathrm{n} / \mathrm{a}$ & $\mathrm{n} / \mathrm{a}$ & $\mathrm{n} / \mathrm{a}$ & $\mathrm{n} / \mathrm{a}$ & $\mathrm{n} / \mathrm{a}$ & $\mathrm{n} / \mathrm{a}$ & $\mathrm{n} / \mathrm{a}$ & $\mathrm{n} / \mathrm{a}$ & $\mathrm{n} / \mathrm{a}$ & $\mathrm{n} / \mathrm{a}$ \\
\hline $72 \mathrm{~Hz}$ & $6 \mathrm{sec}$ & $\mathrm{n} / \mathrm{a}$ & $\mathrm{n} / \mathrm{a}$ & $\mathrm{n} / \mathrm{a}$ & $\mathrm{n} / \mathrm{a}$ & $\mathrm{n} / \mathrm{a}$ & 7.14 & 3.32 & $47 \%$ & $54 \%$ & $13 \%$ \\
\hline $72 \mathrm{~Hz}$ & $8 \mathrm{sec}$ & 10.60 & 2.57 & $24 \%$ & $70 \%$ & $12 \%$ & 10.22 & 2.59 & $25 \%$ & $70 \%$ & $13 \%$ \\
\hline $92 \mathrm{~Hz}$ & $4 \mathrm{sec}$ & 9.71 & 1.10 & $11 \%$ & $84 \%$ & $11 \%$ & $\mathrm{n} / \mathrm{a}$ & $\mathrm{n} / \mathrm{a}$ & $\mathrm{n} / \mathrm{a}$ & $\mathrm{n} / \mathrm{a}$ & $\mathrm{n} / \mathrm{a}$ \\
\hline $92 \mathrm{~Hz}$ & $6 \mathrm{sec}$ & 9.46 & $\mathrm{n} / \mathrm{a}$ & $\mathrm{n} / \mathrm{a}$ & $83 \%$ & $\mathrm{n} / \mathrm{a}$ & 9.46 & $\mathrm{n} / \mathrm{a}$ & $\mathrm{n} / \mathrm{a}$ & $83 \%$ & $\mathrm{n} / \mathrm{a}$ \\
\hline $92 \mathrm{~Hz}$ & $8 \mathrm{sec}$ & 8.01 & 2.93 & $37 \%$ & $95 \%$ & $7 \%$ & 8.01 & 2.93 & $37 \%$ & $95 \%$ & $7 \%$ \\
\hline $123 \mathrm{~Hz}$ & $4 \mathrm{sec}$ & 10.85 & $\mathrm{n} / \mathrm{a}$ & $\mathrm{n} / \mathrm{a}$ & $95 \%$ & $\mathrm{n} / \mathrm{a}$ & $\mathrm{n} / \mathrm{a}$ & $\mathrm{n} / \mathrm{a}$ & $\mathrm{n} / \mathrm{a}$ & $\mathrm{n} / \mathrm{a}$ & $\mathrm{n} / \mathrm{a}$ \\
\hline $123 \mathrm{~Hz}$ & $6 \mathrm{sec}$ & 11.15 & 1.65 & $15 \%$ & $92 \%$ & $11 \%$ & 10.96 & 1.84 & $17 \%$ & $90 \%$ & $12 \%$ \\
\hline $123 \mathrm{~Hz}$ & $8 \mathrm{sec}$ & 8.90 & 1.22 & $14 \%$ & $89 \%$ & $14 \%$ & 8.90 & 1.22 & $14 \%$ & $89 \%$ & $14 \%$ \\
\hline
\end{tabular}




\begin{tabular}{|c|c|c|c|c|c|c|c|c|c|c|c|c|}
\hline \multirow[b]{3}{*}{ Series } & \multirow[b]{3}{*}{ Sub-set } & \multicolumn{6}{|c|}{ Standard Data } & \multicolumn{5}{|c|}{ Smoke Generation } \\
\hline & & \multicolumn{4}{|c|}{ Shear Strength (MPa) } & \multicolumn{2}{|c|}{ Bonding } & \multicolumn{3}{|c|}{ Shear Strength $(\mathrm{MPa})$} & \multicolumn{2}{|c|}{ Bonding } \\
\hline & & Control \% & Mean & SD & $\mathrm{CV}$ & Mean & SD & Mean & SD & $\mathrm{CV}$ & Mean & SD \\
\hline Para Weld & Perp Test & $35 \%$ & 5.21 & 2.29 & $44 \%$ & \multirow{2}{*}{$94 \%$} & \multirow{2}{*}{$19 \%$} & 5.27 & 2.47 & $47 \%$ & \multirow{2}{*}{$99 \%$} & \multirow{2}{*}{$3 \%$} \\
\hline Para Weld & Para Test & $65 \%$ & 9.84 & 3.63 & $37 \%$ & & & 8.71 & 1.87 & $22 \%$ & & \\
\hline Perp Weld & Para Test & $65 \%$ & 9.73 & 5.64 & $58 \%$ & \multirow{2}{*}{$73 \%$} & \multirow{2}{*}{$20 \%$} & 11.19 & 4.52 & $40 \%$ & \multirow{2}{*}{$80 \%$} & \multirow{2}{*}{$19 \%$} \\
\hline Perp Weld & Perp Test & $25 \%$ & 3.81 & 1.40 & $37 \%$ & & & 4.57 & 0.99 & $22 \%$ & & \\
\hline Cross Weld & Cross & $44 \%$ & 6.57 & 2.38 & $36 \%$ & $96 \%$ & $7 \%$ & 6.44 & 2.54 & $39 \%$ & $99 \%$ & $2 \%$ \\
\hline
\end{tabular}

\begin{tabular}{|c|c|c|c|c|c|c|c|c|c|c|c|}
\hline \multirow[b]{3}{*}{ Series } & \multirow[b]{3}{*}{ Sub-set } & \multicolumn{5}{|c|}{ Goop Formation } & \multicolumn{5}{|c|}{ Audible Pitch Change } \\
\hline & & \multicolumn{3}{|c|}{ Shear Strength (MPa) } & \multicolumn{2}{|c|}{ Bonding } & \multicolumn{3}{|c|}{ Shear Strength $(\mathrm{MPa})$} & \multicolumn{2}{|c|}{ Bonding } \\
\hline & & Mean & SD & $\mathrm{CV}$ & Mean & SD & Mean & $\mathrm{SD}$ & $\mathrm{CV}$ & Mean & SD \\
\hline Para Weld & Perp Test & 5.21 & 2.29 & $44 \%$ & \multirow{2}{*}{$99 \%$} & \multirow{2}{*}{$3 \%$} & 5.20 & 2.70 & $52 \%$ & \multirow{2}{*}{$99 \%$} & \multirow{2}{*}{$3 \%$} \\
\hline Para Weld & Para Test & 8.71 & 1.87 & $22 \%$ & & & 8.71 & 1.87 & $22 \%$ & & \\
\hline Perp Weld & Para Test & 11.61 & 4.91 & $42 \%$ & \multirow{2}{*}{$82 \%$} & \multirow{2}{*}{$20 \%$} & 11.30 & 5.62 & $50 \%$ & \multirow{2}{*}{$92 \%$} & \multirow{2}{*}{$8 \%$} \\
\hline Perp Weld & Perp Test & 4.17 & 0.52 & $12 \%$ & & & 4.04 & 0.54 & $13 \%$ & & \\
\hline Cross Weld & Cross & 6.44 & 2.54 & $39 \%$ & $99 \%$ & $2 \%$ & 6.52 & 2.77 & $43 \%$ & $98 \%$ & $2 \%$ \\
\hline
\end{tabular}




\begin{tabular}{|r|r|r|r|r|r|}
\hline \multicolumn{2}{|c|}{} & \multicolumn{4}{|c|}{ Shear Strength (MPa) } \\
\hline Series & \multicolumn{1}{|c|}{ Sub-set } & Control \% & Mean & \multicolumn{1}{c|}{ SD } & \multicolumn{1}{c|}{ CV } \\
\hline Cure Time & $60-$ min & $74 \%$ & 11.19 & 4.21 & $38 \%$ \\
\hline Cure Time & $100-$ min & $51 \%$ & 7.60 & 3.60 & $47 \%$ \\
\hline Cure Time & $750-$ min & $63 \%$ & 9.47 & 1.69 & $18 \%$ \\
\hline Cure Time & $1200-$ min & $59 \%$ & 8.81 & 1.20 & $14 \%$ \\
\hline Cure Time & $2040-$ min & $51 \%$ & 7.72 & 5.99 & $78 \%$ \\
\hline Cure Time & $3000-$ min & $64 \%$ & 9.60 & 4.08 & $42 \%$ \\
\hline Cure Time & $4500-$ min & $27 \%$ & 4.10 & 3.13 & $76 \%$ \\
\hline Cure Time & $6000-$ min & $45 \%$ & 6.75 & 0.58 & $9 \%$ \\
\hline Control & Const. Glue & $100 \%$ & $100 \%$ & 15.05 & $25 \%$ \\
\hline Control & Gorilla Glue & $13 \%$ & $13 \%$ & 1.91 & $69 \%$ \\
\hline
\end{tabular}

